\title{
MEKKANISCHE SPRICHWÖRTER UND REDENSARTEN
}

\author{
GESAMMELT UND ERKLART VON \\ Dr. C. SNOUCK HURGRONJE.
}

Es wäre überflüssig nach den bekannten Arbeiten Burckhardts, Wallins, Wetzsteins, Socins, Spittas und Landbergs (von anderen $\mathrm{zu}$ schweigen) noch beweisen $\mathrm{zu}$ wollen, dass das Studium der neuarabischen Dialecte von höchster Wichtigkeit ist für die Linguistik und für die Ethnographie; auch braucht nicht mehr hervorgehoben zu werden, welch hervorragende Rolle innerhalb der arabischen Sprache die Sprichwörter und Redensarten spielen. Als ich mich vor etwas mehr als zwei Jahren auf ein Jahr nach Arabien begab, beabsichtigte ich weniger die Förderung jener sprachlichen Studien als die Beobachtung des vom Islām beherrschten häuslichen und gesellschaftlichen Lebens an einem Punkte, wo die muslimische Cultur von europäischen Einflüssen am wenigsten berührt ist und gar nicht von Europa controllirt wird. Zugleich wollte ich mit eignen Augen sehen, welche Wirkungen der Islām von jenem Centrum aus auf die Länder ausübt, woher jährlich Pilger dahin zusammenströmen, namentlich in Bezug auf die ostindische Inselwelt. Es versteht sich aber von selbst, dass sprachliche Studien, dass die Bekanntschaft mit den Sprichwörtern und Redensarten der Mekkaner zu den unentbehrlichen Mitteln zur Erreichung meines Zweckes gehörten. Von den Ergebnissen meiner Beobachtung lege ich hiermit den Orientalisten und Allen, die sich für die moderne arabische Gesellschaft interressiren, einige Proben vor. Dr. Landberg hat mit Recht nachdrücklich betont, dass die blosse Mittheilung eines neuarabischen Sprichworts ohne Commentar in den meisten Fällen wie ein Räthsel ist, das man seinen Lesern zu errathen gibt; ich habe mich desshalb bestrebt, bei jedem Sprichworte soviel sprachliche und ethnographische Anmerkungen zu geben, als zum richtigen. Verständnisse desselben erforderlich waren; oft bin ich 
sogar ziemlich weit über diese Schranken hinausgegangen, um das fragmentarische Bild, welches die Sprichwörter an und für sich von der Sprache und den Sitten der Mekkaner geben, nach dieser und jener Seite hin ein wenig zu vervollständigen.

Die Beschreibung der mekkanischen Gesellschaft gedenke ich demnächst in einem grösseren Werke zu geben; hier sei nur soviel erwähnt, als zur Rechtfertigung der von mir gemachten Auswahl nöthig ist. Die Einwohner Mekkahs sind nur zum geringsten Theile Abkömmlinge der vorislamischen Mekkaner; Ḥadhramr's, Aegypter, Syrer, Inder, sogar Türken, Malaien und andere Völkerschaften haben alle ihren Beitrag zur Zusammensetzung der heutigen Bevölkerung der heiligen Stadt geliefert. Es leben immer in Mekkah Leute aus den bezeichneten Ländern, welche hauptsächlich mit ihren eignen Landsleuten verkehrend, ihre Sprache (resp. ihren Dialect) und manches von ihren Sitten beibehalten. Die Mehrzahl derjenigen meğāwirin aber, welche Mekkah zu ihrem zweiten Vaterlande wählen, gehen bald gänzlich in der mekkanischen Gesellschaft auf, und ihre Söhne zeigen weder in ihrer Sprache, noch in ihren Sitten eine Spur von der Nationalität ihrer Väter. Obgleich nämlich das mekkanische Leben von allen jenen Seiten stark beeinflusst worden ist und noch wird, so hat doch die Gesellschaft Mekkahs ein selbständiges Dasein, ist sie nicht nur ein Conglomerat verschiedener ausländischer Civilisationen. Den Kern dieser Gesellschaft bilden die in ganz Westarabien äusserst zahlreichen alidischen Scherife '), echte Quraischiten also, welche vom ersten Jahrhunderte des Islāms an immer grösseren Einfluss in diesen Gegenden gewonnen haben. Die Beduinen Westarabiens gehorchen, sofern bei ihnen von Gehorsam die Rede sein kann, nur den Scherifen von Mek$\mathrm{kah}$, die Städter empörten sich gegen die Omajjaden wiederholentlich unter Anführung der Aliden, und die Abbasiden und spätere muhammedanische Dynastien konnten ihre Souveränität über den Hiğgāa nur durch die Vermittelung der Scherife behaupten.

Diese Aliden haben dem westarabischen Leben und Treiben im Sturme der Einwanderung fremder Elemente seinen eigenen Charakter gerettet; ausserdem waren sie immer die Verbindungs-

1) Die spärlichen Reste des Hauses der Beñ Schêbah sowie ein paar andere Familien, welche behaupten, ihre quraischitische Genealogie nachweisen zu können, kommen hier nicht in Betracht. 
glieder zwischen den Städtern und den Beduinen Westarabiens. Beide letztere sind schon durch die Verhältnisse ihres Landes genöthigt, viel mit einander zu verkehren; unter der Leitung der Scherife nahm dieser Verkehr festere Formen an und übte natürlich auf die Erhaltung des localen Typus der mekkanischen Sprache bedeutenden Einfluss. Es lebt also heute noch eine mekkanische Sprache, abgeschliffen wie jeder vulgärarabische Dialect, durch den internationalen Verkehr mit einer Unzahl von Fremdwörtern bereichert, aber dennoch einen eigenen, stark ausgeprägten Charakter zeigend.

Die Frage: »où parle-t-on, dans le Levant, le mieux l'arabe?" (Landberg, Proverbes et Dictons, I, Introduction, S. XLII) ist, soweit sie überhaupt berechtigt ist, vielleicht als etwas verfrüht anzusehen. In so manchen Lande, wo es eine von der Umgangssprache verschiedene Schriftsprache gibt, behaupten die Ungebildeten jeder Provinz, dass man bei ihnen am besten spricht, und die höher Gebildeten sprechen nahezu überall gleich gat, obschon der Dialect ihres Landes seine Wirkung auch auf sie ausübt. Der Kreis unserer Beobachtung ist noch zu enge, um hier ein allgemeines Resultat feststellen zu können. Sicher ist, dass der in Europa nur dürftig bekannte moderne Dialect des Hiğāz sich in mancher Beziehung vortheilhaft von dem ägyptischen sowie von dem syrischen unterscheidet: das ewige ش ( شي (resp) hinter den Verbalformen ärgert z. B. den Hiğāzī und jeden, dêr an den Hiğāzi-Dialect gewöhnt ist, wenn er mit Aegyptern und Syrern spricht; ebenfalls das in Mekkah nur äusserst selten ') dem Imperfectum vorgesetzte bi. Ohne mehr Werth auf solche Urtheile zu legen, als sie verdienen, will ich doch erwähnen, dass die syrischen Dialecte in Mekkah als besonders schlecht verrufen sind.

In einer modernen Sprache, welche der Berölkerung einer Stadt als Mittel zum Gedankenaustausche dient, gibt es mehr zu unterscheiden, als in den Dialecten des Landes. Wer den Dialect der Beduinen eines kleinen Gebietes, der Bauern eines syrischen Dorfes,

1) Die Mekkaner gebrauchen es fast nur in dem Ausdrucke br'addin $=$ "man ruft eben den a ̣̦ān aus", als Antwort auf die Frage: "wie spät ist es?" Wenn der von Spitta, Grammatik, S. 203, angegebene Unterschied zwischem dem einfachen Imperf. und dem mit vorgesetztem bi von den Syrern und Aegyptern wirklich innegehalten wurde, so wäre der Gebrauch von bi als ein Vortheil zu betrachten. Sie thun das aber nicht, und die Sprache hat in den Participia und dem Worte a m m a l Mittel genug, die unvollendete Handlung zu bezeichnen. 
der fèllā ḥin einer Gegend Aegyptens studirt, wird im grossen Ganzen fast nur individuelle Unterschiede innerhalb desselben beobachten. In einer Stadt wie Mekkah dagegen gibt es Leute, denen viel, Andere, denen wenig, Andere denen gar nichts an der feinen Handhabung ihrer Muttersprache liegt, und geben die in den verschiedenen Kreisen der Gesellschaft besprochenen Gegenstände zu Verschiedenheiten im Sprachgebrauche Anlass. Ganz abgesehen von den beiden Extremen: den pedantischen Gelehrten, welche eine lächerlich affectirte Sprache ${ }^{1}$ ) reden, und dem aus freigelassenen Sklaven und verkommenen Freien zusammengesetzten Gesindel, welches aus allem Vorhandenen einen Mischmasch macht, ganz abgesehen von diesen beiden, hört man ähnlich wie in europäischen Städten die Gebildeten sorgfältig , die Handwerker dagegen nachlässig sprechen. Beide gebrauchen aber eine von der Schriftsprache sehr abweichende, wirkliche Umgangssprache und wer den mekkanischen Dialect kennen lernen will, hat beide in gleicher Weise zu berücksichtigen. Der scharfe Gegensatz, welchen Landberg (vgl. vorzüglich Introduction, S. X-XI) für den syrischen Dialect zwischen der Umgangssprache der Gebildeten und der der Ungebildeten behauptet, lässt sich weniger auf die Sprache der Städter, gar nicht auf den Dialect der Mekkaner anwenden. Beide sind ja auch ihrem Gebiete nach gar nicht getrennt, sie leben und entwickeln sich neben einander, die eine empfindet die Einwirkung der andern, geht langsam in die andere über. Diese Bemerkung gilt von den gebräuchlichen Sprachformen, aber auch von den gebräuchlichen Redensarten und Sprichwörtern. Es gibt Abstufungen und Uebergänge zu constatiren, nicht aber etwa zwei Klassen von Sprichwörtern, deren eine zur Volkssprache, deren andere zur affectirten Rede der grammatisch Gebildeten gehört. Dass die altarabischen Schriftsteller vielen vorhandenen Sprichwörtern eine gekünstelte Form aufgedrängt haben, dass vielfach derselbe Gedanke in sehr verschiedener Weise formulirt worden ist und dass die Ungebildeten daraus das am leichtesten Verständliche auswählen, lässt sich natürlich nicht bestreiten. Ueberall und immer hat die Litteratur auf den Sprachgebrauch der Gebildeten mehr eingewirkt als auf den der unteren

1) Die litterarische, oder nach der litterarischen affectirte Sprache, nennt man in Mekkah nahw I, die Umgangssprache einfach ' $a \mathrm{rab}_{\mathrm{I}}$; f a ç I $\underline{\underline{h}}$ heisst derjenige, welcher die letztere geläufig spricht. ' $\mathrm{a} \mathrm{m} \mathrm{m} \times \mathrm{l}$ j it $\mathrm{a}$ çç $\mathrm{a}$ h (von Fremden und Sklaven gesagt) = "er fingt an, geläufig Arabisch zu sprechen." 
Klassen; immer haben sich aber auch Letztere, in der Sprache wie in anderen Sachen, beflissen, den höheren Ständen, mit denen sie zusammen leben, nachzuahmen. Manche von den kurzgefassten Sprüchen, welche die altarabischen Sammler in ihre Bücher aufgenommen haben oder welche man auch in den ersten Jahrhunderten der Higyrah dem Propheten in den Mund gelegt hat, haben sich als wirkliche Bestandtheile der Umgangssprache aller Klassen der mekkanischen Gesellschaft bis jetzt erhalten. Man lässt den $i^{c} r a \bar{b}$ fort oder bringt ihn auch manchmal in gesetzwidriger Weise an - denn auch der gemeine Mann weiss, dass der $i^{c} r \bar{a} b$ zur feierlichen Rede gehört und betrachtet die Sprichwörter als fertig Gegebenes; die kubārijeh ${ }^{1}$ ) sprechen sie etwas anders aus als die awlād ès-sūq, aber alle kennen und gebrauchen dieselben. Das von Landberg als ausschliesslich classisch angeführte Sprichwort: خير الامور أَّنسَطها gebraucht die ganze Bevölkerung Mekkahs sehr häufig, und sie betrachtet dasselbe als dem hadith entnommen. Ich habe es bisher in keiner hadith-sammlung angetroffen, aber es würde darin mit ebensoviel Recht seine Stelle einnehmen, wie z.B. die im èl-ğā mic غ̀ ê -çaghīr angefübrten prophetischen Aussprüche: خير العبادة خير الصهات أيََّرهر ,اخفّها Sprichwörter betrachte.

Diese Bemerkungen, welche weiter auszuführen mir an diesem Orte nicht gestattet ist, rechtfertigen es wohl, dass ich dem Leser nur eine kleine Anzahl specifisch mekkanischer Sprichwörter mittheile. Die Sprichwörter, welche in die Litteratur gedrungen sind, findet man in den Büchern erklärt; in Bezug auf Mekkah ist dabei nur zu beachten, dass die gekünstelten und weitläufigen selten ausserhalb der Gelehrtenkreise gebraucht werden; die kürzeren Sätze gehören in sehr grosser Anzahl zur lebenden Sprache Mekkahs, welcher sie nur durch das Aufgeben grammatischer Endungen und durch Erleichterung der Aussprache angepasst worden sind. Von den nicht in die feine Litteratur aufgenommenen Sprichwörtern, welche schon von europäischen Gelehrteu gesammelt worden sind, habe ich wohl etwa die Hälfte in mehr oder weniger modificirter Form in Mekkah gehört; dies versteht sich

1) Mit dieser von dem Plural كُبَّ (كَبار gemachten Nisbahbildung bezeichnet der. Mekkaner die höheren Stände. 
eigentlich von selbst in der internationalen Versammlung, welche schon seit Jahrhunderten unaufhaltsam ihre țawāfs um die mekkanische Gesellschaft herum verrichtet. Manche von diesen Redens. arten haben sich auch wirklich in Mekkah oder in einigen von dessen Stadtvierteln eingebürgert; darunter sogar solche, welehe, wie das bei $\mathrm{N}^{0}$. 55 angeführte ( $\mathrm{m} \overline{\mathrm{a}}$ ḥa walēn èç-Ç $\mathrm{a}^{c} \bar{a} \mathrm{j} d \mathrm{ah}$ etc.), ganz deutlich ihren localen Ursprung verrathen. Unter diesen Umständen wird es bei sehr vielen Sprichwörtern schwer, genau festzustellen, ob sie wirklich das Bürgerrecht erlangt haben, oder ob sie immer noch zu den meğāwirin gehören. Desshalb habe ich den mir gewährten Raum dazu verwendet, alle mir bekannten nicht-litterarischen Sprichwörter und Redensarten aufzufübren, welche eine locale mekkanische Farbe zeigen, ferner solche, deren volles Bürgerrecht ich constatiren konnte und welche entweder in keiner mir bekannten Sammlung vorkommen, oder für die Mekkaner eine ganz besondere Bedeutung haben und zu Ausführungen über deren Sitten und Sprache Anlass geben.

In Bezug auf die Schreibung, bez. Transcription des Arabischen wird man es mir hoffentlich verzeihen, das ich, wie jeder Andere, meinen eigenen Weg gegangen bin, auch wenn ich diesen gar nicht als den einzig richtigen betrachte. Die Sprichwörter selbst habe ich desshalb nicht transcribirt, weil ich dazu jedesmal willkürlich eine von den in der Sprache der Mekkaner vorhandenen Schattirungen den anderen hätte vorziehen müssen; meine Angaben über die Aussprache werden genügen, um ein ungefähr richtiges Bild von der Durchschnittsaussprache zu bekommen. Wo ich in den Bemerkungen Mekkaner redend einführte, durfte ich etwas freier verfahren, da ich dann eigentlich die Worte eines Individuums oder doch verschiedener Leute einer Klasse wiederzugeben hatte. Man würde vergeblich versuchen, alle phonetischen Erscheinungen (abgesehen noch von zahlreichen individuellen, durch die Sprachorgane und persönliche Gewohnheit bedingten Abweichungen) in der Schrift genau zu reproduciren. Ich habe mir gedacht, auch hier wäre خير الامور أوسَسطها لخها, will aber nicht behaupten, dass es mir gelungen ist, diesen Grundsatz immer richtig anzuwenden.

Hamzah habe ich im Anlaute gar nicht reproducirt, im Inlaute durch ' und wo die Aussprache (zwischen den Vocalen $\bar{a}$ und $i$ ) zwischen $j$ und hamzah schwankt (wie țāir $N^{\circ}$. 7, ḥawāiğ $\mathrm{N}^{\circ} .26$ u. s. w.) wieder gar nicht. $\varphi=b . \quad=t$. 
$\dot{ث}$ ist meistens zu die heutige Aussprache der Mekkaner handelte, ist es durch th wiedergegeben worden.

$\boldsymbol{\gtrless}=\check{g}$, wie englisches $j$ in John zu sprechen.

$\boldsymbol{\Sigma}=\mathrm{h}$, (resp. $\underline{\mathrm{h}}$ ) $\dot{\boldsymbol{C}}=c h, \mathrm{o}=d$ spreche man regelrecht aus.

$\dot{j}$ wird bald zu $z(j)$, bald zu $d(\mathcal{})$; wo es regelrecht gesprochen wird, wie von gebildeten Leuten beim Gebrauche religiöser Formeln, habe ich ḍ (resp. $\underline{\text { d}}$ ) geschrieben (z. B. $a^{c} \bar{u} d \underline{u}$, vulg. $a^{c} \bar{u} z u$, dikr, vulg. dikr und dikir). $-,=r, ;=z, \omega=s, ~ ش=s$

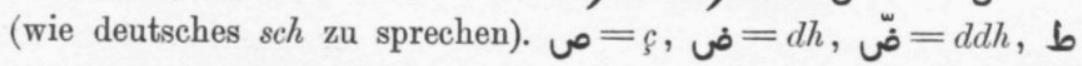
$=t$ werden alle regelrecht ausgesprochen. $b$ wird in vielen Fällen $ض$, ist aber sonst von dem $z$ nur durch stärkere Pressung der Zunge gegen den Gaumen unterschieden; im letzteren Falle habe is es z (resp. $\underline{\mathrm{z}}$ ) geschrieben.

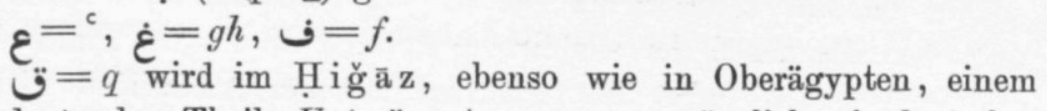
bedeutenden Theile Unterägyptens u.s.w., gänzlich wie deutsches $g$ gesprochen, namentlich am Anfang der Silbe. Schliesst es die Silbe, so wird es hie und da etwas härter und kommt der beim Qurānrecitiren gebotenen Aussprache näher. Und viele gebildete Mekkaner sprechen ohne jegliche Affectirung das ت immer in der letzteren Weise.

$$
\text { J }=k, \mathrm{~J}=l, \mathrm{p}=m, \mathrm{\cup}=n,,=w, \mathrm{~s}=j \text {. }
$$

Das fathah habe ich mit $a$ und, wo es immer mit imalah gesprochen wird mit $\grave{e}$ wiedergegeben; den langen Vocal immer mit $\bar{a}$, weil ich in Mekkah keine regelmässige imālah darin beobachtet habe. $\mathrm{kasrah}=i$, langes $=\bar{\imath} ; \mathrm{dhammah}=u$, langes $=\bar{u}$. Der $u$-vocal wird von echten Mekkanern in der überwiegenden Mehrzahl der Fälle rein gesprochen; meine Beobachtungen gestatten mir nicht, die allerdings vielmals von mir gehörte Aussprache $\ddot{u}$ oder $\ddot{o}$ in der Transcription wiederzugeben. Die Diphthonge ai und au spreche man immer, wenn nicht anders angegeben ist, $\bar{e}$ und $\bar{o}$. Einfaches $e$ bezeichnet den unbestimmten Vocal (hebr. šewa).

Namentlich in Bezug auf die Vocale ist jede Transcription etwas willkürlich. Zwei offene Silben mit unbestimmtem Vocale werden. wirklich hinter einander von vielen Mekkanern gesprochen, z. B. wefelān ( $N^{\circ}$. 9); viele sagen aber wiflān, andere wuflān oder waflān. Hinter einer offenen Silbe mit langem $\bar{a}$ fällt der 
unbestimmte Vocal öfters fort: z. B. hạahāa $\mathbf{r}^{2} \mathrm{mah}\left(N^{\circ} .7\right)$ qājmīn $\left.\left(N^{\circ} .9\right)^{1}\right)$; ob nun aber des $\bar{a}$ dabei zu $a$ verkürzt wird, hängt vielfach von individueller Gewohnheit oder von der Schnelligkeit des Sprechens ab. Die Conjunction, wird mit dem Artikel bald wèl, bald wil oder wul ausgesprochen; in der Redensart (»und damit aus") hört man wekān, wukān, ukān. Auch gibt es unter den von mir als bestimmt angegebenen Vocalen manche, welche in der schnellen Rede oder im Munde der unteren Klassen häufig ihre Farbe einbüssen. Verschiedene Verbalformen des IIten Stammes verlieren im Volksmunde dann und wann die Verdoppelung des $2^{\text {ten }}$ Radicals und zu gleicher Zeit den darauf folgenden Vocal; man hört meqèjjilın, meqèjjelın und meqèj’lin (مقيّليبن). In diesen und ähnlichen Fällen wird man hoffentlich nicht allzustrenge urtheilen ${ }^{2}$ ).

Dass ich das $h$ des Suffix der IIIten Person masc. im Auslaute und ebenfalls das $h$ der weiblichen Endung $a h$ in der Transcription beibehalten habe, hat natürlich mit der Aussprache nichts zu thun. Es schien mir bequemer für die Leser zu sein; übrigens sind wir alle in der Rechtschreibung an Rudimente ohne phonetische Bedeutung gewöhnt, und dieses Rudiment wird zu keinerlei Verwirrung Anlass geben.

1) Neben lā tehin ( $\left.N^{\circ}, 10\right)$ sagt man lā t'hin und la t’hin, neben meb ã širin hört man me băšr In und mebašrin, neben la jek an ("es ist doch wohl nicht... P) auch $l \bar{a} j \mathrm{k} \mathrm{a} n$ und $l \bar{e}$ 'k $\mathrm{n} n$. Wo $\mathrm{ma}$ einem Impf. IIten oder IIIten Stammes vorangeht, sind fast immer die drei Formen mājefa"il, ma jfa" mè 'f a"til möglich.

2) $\hat{3}$ habe ich immer mit kurzem $i$ transcribiert; es wird sogar häufig zu fe: fi-IdI fe-IdI und fIdI = "in meiner Hand." 
1.

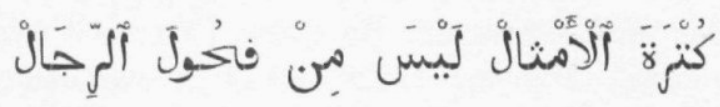

Vielheit von Sprichwörtern kommt nicht von den treffichsten Männern.

Dieses dem Anscheine nach etwas gelehrte Sprichwort wird von ungebildeten gleichwie von gebildeten Leuten gebraucht. Es klingt seltsam in einer Gesellschaft, wo vielleicht ein Viertel alles Gesprochenen aus amthāl (man spricht dieses th bald $t$, bald $s$ ) besteht. Es richtet sich aber nur gegen eine specielle Art der Uebertreibung, gegen Leute, mit denen gar kein vernünftiges Wort zu reden ist, da sie jede Einwendung mit einer nichtssagenden allgemeinen Redensart erwidern. Charakteristisch ist es, dass man als Waffe gegen den excessiven Gebrauch von Sprichwörtern ein Sprichwort gebraucht.

\section{2.}

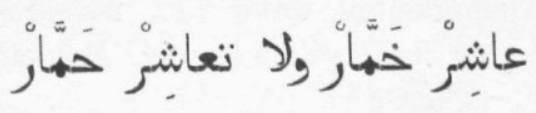

Verkehre lieber mit einem Weinwirthe als mit einem Eseltreiber.

Weinhäuser gibt es in Mekkah ebenso wenig als karachā$\mathrm{n} \overline{\mathrm{a}} \mathrm{t}$, obwohl im geheimen wohl (aus indischen Rosinen gemachter) Wein getrunken und auch der Venus vulgivaga geopfert wird. Man darf aber sagen, dass bei Weitem die meisten geborenen Mekkaner niemals Wein zu Gesicht bekommen. Der Weinwirth ist aber, vielleicht gerade weil er nicht da ist, ein Gegenstand allgemeiner Verachtung. Eseltreiber gibt es die Fülle; die Mekkaner lieben es nicht, spazieren zu gehen; sie legen oft kleine Entfernungen innerhalb der Stadt zu Esel zurück, reiten nach den Gärtẹn in der Umgegend, wo sie Picknicks veranstalten, und 
begeben sich meistens auf Eseln nach $\operatorname{Tan}^{\mathrm{c}} \mathrm{Im}$, dem Orte auf der Ḥaramgrenze, wo sie den iḥrām für eine ${ }^{c} u \mathrm{mrab}$ anzulegen pflegen. Die Pilger gebrauchen auch vielfach Esel zu ihren zijārah's nach dem Máclā (dem grossen Friedhofe) und anderen heiligen Stätten. Die ' $\mathrm{umrah}$ ist in keinem Monate so verdienstlich als im Ramadhān, woher denn auch die meisten Mekkaner wenigstens eine ' u m rah im Fastenmonate, viele Mekkaner und früh nach Mekkah gekommene Pilger täglich eine machen. Kein Wunder also, dass am Ende der Fastenzeit alle Miethesel abgemagert sind. Mancher borgt sich kurz vor dem Ramadhān das Geld zum Kaufe eines Esels, miethet einen Eseltreiber dazu, wenn er selbst für dieses Geschäft zu vornehm oder zu faul ist, lässt den Esel 3-4 mal täglich »zur 'umrah gehen" und verkauft das erschöpfte Thier, wenn es ihm 30 Tage seine Dienste geleistet hat. Ausser den im Dienste von Eseleigenthümern stehenden $\operatorname{ç}_{\mathrm{u}} \mathrm{j}_{\bar{a}} \mathrm{n}^{1}$ ) gibt es auch solche ḥammārin, deren eigenes Kapital in ihren einem oder zwei Eseln steckt; sie stehen alle im Rufe der razālah (مروّة . mal in Fetzen gehüllt, fast immer ohne Hosen, verbringen sie ihre Mussezeit in den qaháwi, bald auf den Bänken (kerāsi) liegend und schlafend, bald zankend und sich infolge des geringsten Anlasses schlagend. Wegen einer $\mathrm{chamsah}( \pm 2$ Pfennige) verflucht Einer von ihnen nicht nur den Andern und dessen ganzes Geschlecht, sondern spaltet ihm nöthigenfalls mit seinem n abbūt den Schädel. Ueberhaupt sind heftige Zänkereien wegen solcher Kleinigkeiten unter den $\mathrm{ahl}$ è s-s ūq in Mekkah an der Tagesordnung und gilt von den Mekkanern unserer Zeit gar nicht, was Burckhardt zu ihrem Lobe sagt, dass sie nämlich selten Schimpfworte gebrauchen. Ich glaube eigentlich, dass letztere Aussage nie richtig gewesen ist; der treffliche Beobachter, welcher von der Topographie Mekkah's und von dem Leben der Pilger und Händler daselbst in kurzer Zeit fast alles Bemerkenswerthe aufzeichnete, hat, wie aus seinem ganzen Werke ersichtlich, das gesellige Leben der Mekkaner selbst nur oberflächlich kennen gelernt. Kinder von 6 Jahren an wechseln bei dem geringsten Aerger Ausdrücke wie: jā nājik abūk (Antwort: jā nājik ummak), dajjūs (ديّوث), mecarras, qawwād usw.

1) Plural von çá bi = freier Lohndiener. 
Einen sonderbaren Eindruck macht es, wenn man (wie dies häufig vorkommt) eine Mutter zu ihrem Töchterchen die Worte sagen hört, mit welchen man eine zudringlich um etwas anhaltende Person abfertigt: kuss ummik, jā bint! wenn eine Frau ihren Gatten qawwād schimpft oder wenn, wie ich dies einmal hörte, ein Vater seine Tochter: $\mathrm{j}$ ā bint èl-kèlb, jā bint èl-kāfir, jā bint èl-inglizi nennt. Man ersieht aus alledem, dass diese feinen Worte beim häufigen Gebrauche ibr Leben eingebüsst haben, aber zugleich, dass Burckhardt die Sitten der Mekkaner in dieser Beziehung zu milde geschildert hat ${ }^{1}$ ).

Vor den scheusslichen Sitten der Eseltreiber schaudern aber sogar die meisten ahl ès $-\mathrm{s} u \bar{q}$ zurück. Einmal sah ich einige hammarin vor dem qahwah, welchem gegenüber•ich wohnte, um zwei zankende Collegen herumstehen; einer von diesen lag auf einer Bank (kursi), der andere stand daneben. Es handelte sich wie gewöhnlich um ein paar Pfennige. Als nun der stehende seinem »Bruder" weitläufig vorrechnete, er schulde ihm dieselben, da gerieth jener in die Stimmung, welche bei einem Europäer etwa ein "geh' zum Teufel!" und bei einem Durchschnittsmekkaner ein kussummak! hervorrufen würde. Die razālah der Eseltreiber verleugnete sich aber nicht: der Angeredete erhob ein Bein, fasste vor der ganzen Gesellschaft seinen penis mit der Linken und warf denselben gleichsam seinem Gegner ins Gesicht.

3.

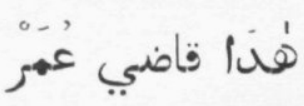

Dies ist der quadh̄ ${ }^{\mathrm{C}}$ Umar!

Dieser Ausruf, über dessen wirklichen oder vermeintlichen Ursprung ich nichts erfahren konnte, dient zum Ausdrucke der Freude über das Finden einer längst vergebens gesuchten Sache, auch über die Erwähnung eines Namens, dessen man sich nicht

1) Man könnte fragen, ob vielleicht im Anfange dieses Jahrhunderts die Sitten der Mekkaner sich unter der strengen Herrsehaft der Wahbabiten etwas verbessert batten; dem widerspricht aber wieder Burckhardt's Mittkeilung, dass Nachts in der Moschee bly begangen wurde. Auch diese Aussage klingt dem, der das heutige Mekkah kennt, fast unmöglich; jetzt wären jedenfalls solche Ausschreitungen undenkbar. 
444 DR. C. SNOUCK HURGRONJE, MEKKANISCHE SPRICH Ẅ̈TER.

entsinnen konnte. Wenn das Gedächtniss eines Mekkaners in solchen Fällen versagt, so sagt er meistens: allāhumma ȩallı 'ala sèjjidaña Meḥammèd! z. B.: $A$. fi dik ès-sèneh ğánā fi 'l-ḥağğ ēš ismuh dāk (oder: dāka) ${ }^{1}$ ) .... allāhumma çallı cala sèjjidanā Meḥammèd!..... ma

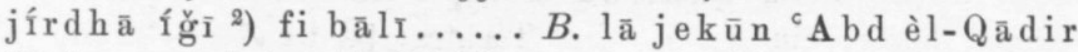
Hakım. A. jebārik frk! hấdā qādhI ${ }^{c} U \mathrm{mar}$ ! d. h. $A$. »in »jenem Jahre ist zur Zeit des Pilgerfestes zu uns (in Mekkah) gekom»men ..... wie heisst er doch?..... O Allah, segne unsern „Herrn Muhammed.... . es will mir nicht einfallen......"

$B$. »es ist wohl nicht Abd el-Qādir Ḥakīm (den du meinst)?".

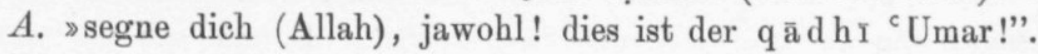

Dieser Ausruf wird auch in Aegypten gebraucht, wie ich aus den Collectaneen des gelehrten 'Abd er-Rahịm Efendi Ahmed ersehe.

4.

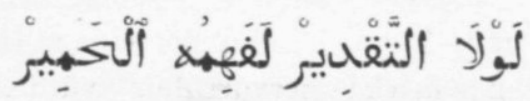

Wenn nicht die göttliche Fügung (es anders gewollt hätte), so verstünden dies sogar die Esel."

Diese für den Angeredeten nicht gerade schmeichelhaften Worte hört man nur in den derūs (Vorlesungen), also in der Moschee. Der Lehrer, der sich vergeblich anstrengt einem seiner Zuhörer eine sehr einfache Sache verständlich zu machen und endlich die Geduld verliert, vergleicht diesen darin mit dem Vierfüssler, dessen Namen man in Arabien in anständiger Gesellschaft nur » mit Erlaubniss" ${ }^{3}$ ) nennt und den man vor vornehmen Ohren nur als

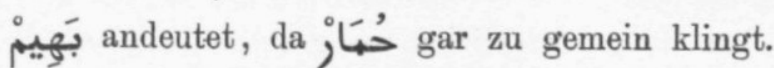

1) $\bar{e} \mathrm{~g}$ is $\mathrm{m} \mathrm{uh} \mathrm{d} \bar{a}, \mathrm{~d} \overline{\mathrm{a}} \mathrm{k}, \mathrm{d} \overline{\mathrm{a}} \mathrm{k}$ a ist ein überaus hänfig gebrauchtes Flickwort, welches dem deutschen "Dings” für Personen und Sachen entspricht; öfters wird es š is mu h ausgesprochen.

2) Das $j$ der IIIten Person Imperf. löst sich in der vulgären Aussprache vielfach

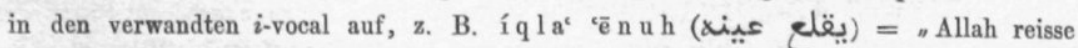
ihm das Auge aus!" Da aber diese Aussprache nicht allgemein ist, habe ich in solchen Fällen jif a l transcribiert; Íğ I sagt aber jeder Mekkaner.

3) $\mathrm{Vgl}$, unten $\mathrm{N}^{\circ} .67$. 


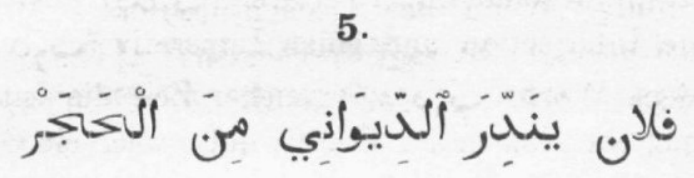

N. N. bringt den Dīwān $\left(\right.$ d. h. den Para $=\frac{1}{4^{\frac{1}{0}}}$ Piaster) aus dem Steine hervor.

Hyperbolische Beschreibung einer Person, welche immer und überall Gelegenheit findet, Geld zu verdienen. Man berechnet die Preise nach faddhah's = dīwānì's, obgleich Geldstücke zu weniger als fünf $d \bar{I} w \bar{a} n I^{\prime} s$ nicht vorhanden sind. Hier steht èddi wānī für èl-felūs d. h. Geld überhaupt. Vgl. No. 68.

nadar, jindur tritt in Mekkah durchweg an die Stelle von charağ; dieses wird selten als Verbum gebraucht: andur (undur), Imperat. = »hinaus!"; naddiruh oder naddiruh barra $=$ ssetze oder jage ihn hinaus!" Oppos.: dachchiluh ğuwwa. - sidak fih = sist dein Herr da?" - Antwort: nadar min zamān = »er ist schon längst ausgegangen." - aw wal challī 'l-ḥakĩm jenaddir èr-ruẹāȩ èl-qēh ba ba dēn jindur benafsub $=$ »lass zuerst den Arzt die Kugel (aus der Wunde) herausnehmen, nachher wird der Eiter von selbst herauskommen." dūbuh nadar = »er ist eben ausgegangen."

Anstatt d ūbuh hört man auch dōbuh; bisweilen wird das $d$ hart, fast wie $t$ gesprochen. In einem von Wallin mitgetheilten neuarabischen Gedichte kommt der folgende Halbvers vor (ZDMG. VI: 207, Vers 20): barkin baidin dawbi arà kheiālah = »ein in der Ferne leuchtender Blitz, von dem ich kaum den »Schimmer wahrnehme." In den Anmerkungen (a. a. 0., S. 217) sagt Wallin: "دوبي, Infinitivform mit Suffix, und يل، kommen »sehr oft als adverbiale Ausdrücke in allen neuern Dialekten des "Arabischen vor in der Bedeutung von kaum, ungefähr, mit Mühe. »....... Diese Formen sind wahrscheinlich vom alten " حأب hergenommen, obgleich ich sie nirgends unter den jetzigen »Arabern mit Hamz gehört." Die Herleitung von oأب erklärt Spitta (Grammatik, S. 178-179) für richtig; er erwähnt aber nur die Form $j \bar{a} d \bar{u} b$, welche vom ihm als Imperativ aufgefasst wird: » $0_{0}$ streng dich an!" d.h. » mit Anstrengung, mit Mühe, à peine, kaum" ". Die Verbindung von d ūb (d ōb, daub) mit Suffixen scheint von ihm nicht beobachtet worden zu sein, und 
446 Dr. c. SNOUCK hURgRonJe, MEKKANISCHE SPRICHWÖRTER.

das was Wallin für eine Imperfectform (يل،,وب) hielt, wird von Spitta in eine Interjection und einen Imperativ (يا دوب) zerlegt. Dass aber dem Worte vorangeht und ein Nomen im Genitiv (also auch ein Genitivsuffix) folgen kann, bestätigt uns für Aegypten Hèzz èl-quhūf (ed. Būlāq, 1274), S. $140-141$ der folgende Halbvers aus der qaçıdah des Abū Šādūf:

\section{ويا دوب عبري فى الخـراج وهّبّ}

Der Commentar gibt einige اشتقاقات فشرويّة d des Wortes d ū b; die einzige, welche er selbst ernsthaft zu nehmen scheint, ist die مر. Hier wäre es also, falls die Ableitung richtig ist, zunächst als Infinitiv zu betrachten.

Der ägyptische Gelehrte 'Abd er-Raḥim Efendi Aḥmed sagte mir, dass die Aegypter häufig $\mathrm{j} \bar{a} \mathrm{~d} \bar{u} \mathrm{bi}, \mathrm{j} \bar{a} \mathrm{~d} \overline{\mathrm{u}} \mathrm{buh}$ für: genau, gerade, eben gebrauchen. Dass er $\mathrm{d} \overline{\mathrm{u}} \mathrm{b}$ als Nomen auffaste, erhellt ausserdem aus der Probe einer Erklärung, welche er mir mittheilte: $d \bar{u} b$, welches man auch $t \bar{u} b$ ausspricht, wäre ursprünglich tōb (ثوب); der Ausruf: jā tōbi , jā tōbuh hätte ursprünglich den Schnitt eines neuen Gewandes als »ganz passend" bezeichnet und wäre daher auf alles genau Passende, gut Gerathene übertragen worden. Dass $d \bar{u} b \bar{r}, d \bar{u} b u h$ in Aegypten auch wohl ohne die Interjection gebraucht werde, schien mir mein ägyptischer Freund nur aus der abstracten Möglichkeit zu erschliessen, nicht aber aus wirklicher Beobachtung zu entnehmen. Zieht man nun aber den mekkanischen Sprachgebrauch in Betracht, so befriedigt keine der angeführten Erklärungen gänzlich. ja $d \bar{u} b$ habe ich in Mekkah niemals, jā dūbi u. s. w. nur selten gehört; ganz gewöhnlich ist aber der Gebrauch von $d \bar{u} b$ mit allen Pronominalsuffixen, namentlich den Suffixen der Iten und IIIten Person, in der Bedeutung: »eben, soeben", z. B. dūbi ğ It, dūbanā ğinā, dūbahum rāhū dūbahum kānù hine, dūbuh katab èl-ğ aw $\bar{a} b=$ »Soeben bin ich, sind wir gekommen, sind „sie gegangen, waren sie hier, hat er den Brief geschrieben." Der Gedanke der Anstrengung, Mühe u. s. w." liegt diesem Gebrauche fern, und in der Bedeutung »kaum" kommt das Wort schwerlich je vor. Nur dies liesse sich für Wallins Erklärung anführen, dass $\mathbf{d} \overline{\mathbf{u}} \mathbf{b}$ mit seinen Suffixen in Mekkah weitaus am 
häufigsten mit Verben verbunden wird, welche den Begriff des Kommens und des Gehens ausdrücken; der Gebrauch in anderen Verbindungen könnte also eine secundäre Erscheinung sein, welche durch den überhandnehmenden Gebrauch von $d \bar{u} b \bar{i}$ etc. in der Bedeutung: soeben veranlasst wäre. Die bedeutende Schwankung in der Aussprache legt aber die Voraussetzung eines complicirteren Ursprunges dieser Redensart nahe. Ungeachtet des Subjectes des folgenden Verbums kann man dem Worte $d \bar{u} b$ immer das Suffixum sing. masc. der IIIten Person anhängen, also : dūbuh ğit, ruḥn ā, rāḥ̄i in diesem Falle wird $d \bar{u} b$ fast als eine Präposition mit der Bedeutung: » ein wenig vor" (etwa قُبَيْنِ) betrachtet und das Suffix auf den »gegenwärtigen Augenblick" bezogen. In gleicher Bedeutung, aber seltener und nur mit dem Suffixum sing. masc. der IIIten Person wird das Wort تَّ gebraucht: ta w$\mathrm{wuh}$ ğ $\bar{a}=$ »er ist soeben gekommen". Viel häufiger ist die Verbindung von taww mit dem Suffix der IIten Person als Antreibung zur Eile: tawwak = »eile, mache fertig!" hört man vorzüglich die ğammālin einander zurufen, wenn sie mit Aufladen beschäftigt sind ( $\mathrm{j}$ šúd $\mathrm{d} \overline{\mathrm{u}}$ ).

Die Gelehrten Mekkahs fertigen dūbuh als eine kilmeh içtilāhịjah batțālah ab und ziehen es vor (wenn sie الآن zu pedantisch finden) dā 'l-ḥin oder qarib dā 'l-ḥin zu sagen; sie sündigen aber selbst sehr oft gegen diese puristische Regel. Ueber den Ursprung des verwerflichen Wortes behaupten sie nicht etwas zu wissen.

6.

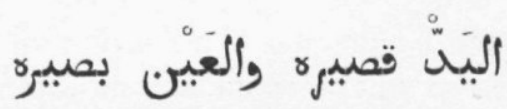

Die Hand ist (zu) kurz, während das Auge (begierig) schaut.

Mit diesen Worten wird der Zustand eines Menschen beschrieben, der sich eine Sache äusserst gern erwerben möchte, dessen Mittel aber nicht ausreichen. Iduh țawilah=»er ist diebisch"; dem steht kein Id uh qaçirah gegenüber, sondern huwa a mĩn; lisānuh țawil = er ist unverschämt in der Rede gegen seine Vorgesetzten". i d und jè d d werden beide gebraucht; Dual je dēn und Idēn, mit Snffixen: jedēni, jedēnuh, jedēnanā, jedēnahum u. s. w. Plural ajádı, (ajādíhum, -kum, -nā). 
7.

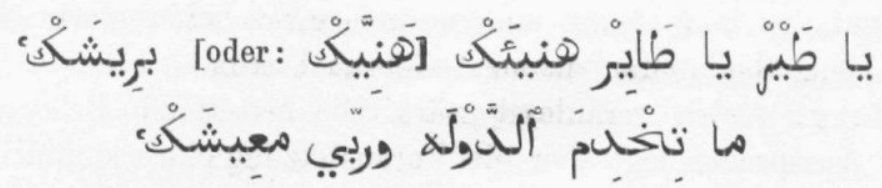

O Vogel, o Fliegender! Glück dir mit deinem Gefieder! Du dienst der Regierung nicht, und mein Herr (Gott) gewährt dir Lebensunterhalt.

Dieses Sprichwort soll von einem Beduinen herstammen. Die ${ }^{c} \mathrm{urb} \overline{\mathrm{a}} \mathrm{n}$ halten sich bekanntlich jeder dōlah möglichst fern; nur solche, welche in der Nähe von Städten wohnen, sich an dem Karavanenverkehre betheiligen u.s.w., sehen sich genöthigt, jeden Augenblick ihre Wünsche denen der Regierungsbeamten unterzuordnen. Wer von ihnen der Regierung Dienste erzeigt, sieht seine Mühe nur selten belohnt; ist er ein tüchtiger Kerl, so entzieht man ihn wohl seiner gewohnten Beschäftigung und Lebensweise, um ihn fortwährend zu benutzen. Schon mancher Ḥiğāzì wurde wider seinen Willen der Leibwache des Grossscherifs, dem Corps

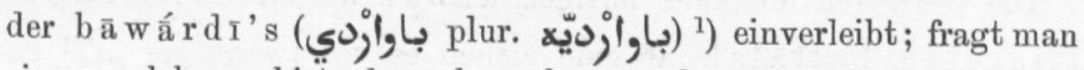
einen solchen: bist du schon bāwārdi geworden? so fasst er zur Antwort seine Nase mit dem Zeigefinger seiner rechten Hand und dreht sich die Nasenspitze gleichsam um - eine sehr übliche Geberde, welche man durch: ghaçban 'ánni=»wider meinen Willen, mit Zwang” übersetzen kann. Ein in ähnlicher Weise zur $\mathrm{chidmet}$ èd $-\mathrm{d} \overline{\mathrm{l}} \mathrm{l} \mathrm{ah}$ gezwungener Beduine soll seinen Kummer in den angegebenen Worten einem Vogel mitgetheilt haben. Die Mekkaner fanden den Ausdruck zwar sehr naïv, aber in manchen Fällen so gut anwendbar auf ihre eigenen Verhältnisse, dass sie denselben als mathal beibehielten. Die Worte werden natürlich nie auf türkische Beamte bezogen, sondern auf

1) Ueber den Ursprung dieses Namens weiss ich nichts mitzatheilen. Da von jeher

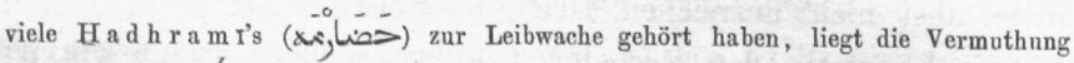
nahe das bā wá $\mathbf{r d i}$ (auch bāwárdi gesprochen) hadhramitischen Ursprungs sei. Die Geschlechtsnamen der $\mathrm{Hadh} \mathrm{ram}$ r’s fangen meistens mit ب̣ an, welches (abgesehen

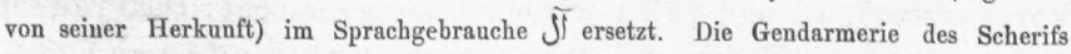
hat ihren Namen yon einem Stamme, welcher die meisten Polizisten zu liefern pflegte: die Bršeh. 
Leute von den $a \mathrm{hl}$ èl-bèlè $\mathrm{d}$, welche zu ihrem eignen Schaden genöthigt oder gewillt sind, der dōla h irgendwie in der Verwaltung behülflich zu sein. Diese machen sich ihren Mitbürgern verhasst und ernten von ihren Herren meistens Undank.

8.

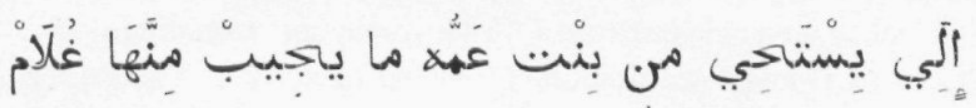

Wer sich vor seiner bint ${ }^{\mathrm{c}}$ a $m \mathrm{~m}$ schämt, der bekommt von ihr keinen Knaben.

Die bint ${ }^{c}$ a mm, die Tochter des Oheims väterlicherseits, wurde und wird noch bei vielen Beduinenstämmen vorzugsweise ihrem Vetter zur Ehe gegeben ${ }^{1}$ ). Daraus hat sich die auch jetzt noch sogar in den Städten herrschende Gewohnheit entwickelt, dass der Mann seine erste Gattin mit diesem Namen bezeichnet, wenngleich sie ihm gar nicht verwandt ist. In diesem allgemeinen Sinne steht das Wort auch hier.

Wer einen guten Freund oder Gönner hat, ohne dessen Hülfe er seinen Plan nicht ausführen, seinen Zweck nicht erreichen kann, der lasse sich nicht durch unbegründete Furcht oder falsche Verschämtheit davon abhalten, sich die nöthige Unterstützung zu erbitten. Wenn Einer in solchen Fällen unschlüssig ist, so hält man ihm halb spottend, halb ermunternd unser Sprichwort entgegen.

Ueber die Verdoppelung des $n$ in minnahā vgl. No. 19 und über das $a \mathrm{~N}^{0} .20$.

9.

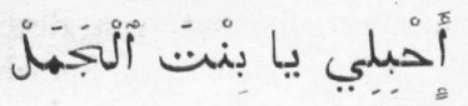

Empfange, du Tochter des Kameels.

Der Imperativ des Verbums حبل = empfangen, schwanger werden" ist selbstverständlich äusserst selten; die schwankende

1) Ueber die ethnographische Bedeutung dieser Sitte vergl. G. A. Wilken, das Ma: triarehat bei den alten Arabern (Leipzig, 1884), S. $59 \mathrm{ff}$.

5e Volgr. I. 
Vocalisirung hat ihren Grund in der Beliebtheit des $a$ als Vorschlagsvocal ${ }^{1}$ ). Der Sinn ist: empfange doch ohne Furcht, du bist ja eine Tochter des Kameels, du hast also von Natur die Fähigkeit schwanger zu werden. Mit diesen Worten ermuntert man einen Freund, welcher in schwierigen Umständen vor einer Handlung zurückschaudert, weil ihm das erforderliche Selbstvertrauen abgeht. Namentlich wo es eine Sache gilt, welche allem Anscheine nach nur durch einen richterlichen Ausspruch $\mathrm{zu}$ beendigen ist, da bedürfen die meisten Mekkaner der wiederholten Aufnunterung. Wer nicht von Jugend an mit den Leuten der hạ kümah zu thun gehabt hat, fürchet sich vor dem ersten Gange in den diwān wie vor dem Tode; wer schon mehr Erfahrung in diesen Dingen hat, der weiss, dass man $d a^{c} \bar{a} w \bar{i}$ (Prozesse) nur mittels grosses nefūs (vergl. No. 10) oder vieler felūs glücklich zu Ende führen kann. Vielleicht hat die andere Partei mächtigere Freunde, mehr Geld, und dann hat man von der ḥukūmah nur zulm zu erwarten. lā, èl-ḥāl māu kède, jā šêch; èl-ḥaqq māu candak? wefelān wefelān māhum qājmīn macāk? a ḥbili jā bint èl-ğèmèl a twakkal 'alá $\left.{ }^{2} l l a ̄ h{ }^{2}\right)$, sagen ihm die Freunde, d. h. > Nein, so steht die Sache nicht, o Schēch! »hast denn du nicht das Recht auf deiner Seite, und stehen nicht »A. und B. dir bei? Empfange, du Tochter eines Kameels, setze »dein Vertrauen auf Allah!"

Das Wort haqq hat in Mekkah ausser seinen abstracten (vgl. den eben angeführten Satz) und sonstigen bekannten Bedeutungen (wie der des Preises einer Sache, oder des für eine zu kaufende Sache bestimmten Geldes: haqq èl-qahwah euphemistisch für das Geschenk zur Bestechung eines Regierungsbeamten u. dgl. m.) noch die eigenthümliche Function des anderswo gebräuchlichen bet $\left.\bar{a}^{c}\left(\mathrm{met} \bar{a}^{c}\right)^{3}\right)$. حقّي صقّه , حقّ etc. bezeichnet im Altarabischen : das, was mir, dir u.s. w. zukommt, von Rechts wegen zugehört. Daran schliesst sich in der modernen Sprache aufs Engste der

1) Vgl. $\mathrm{N}^{\circ} .25,33$.

2) Dieser Ausdruck der Ermunterung wird jeden Augenblick beim Anfangen grosser und kleiner Arbeiten aller Art Einem zugernfen. Zum ha m māl, dem man das Gepäck auf den Rücken hebt, ebenso wie zu einem auf lange Zeit abreisenden Freunde oder zu Einem der den Entschluss fasst, eine neue Bude zu eröffnen, sagt man: at wakkal'ala H lah!

3) Vergl. Spitta, Grammatik, S. 262 f. 
substantivische Gebrauch von حق = thatsächliches Eigenthum an: hád ā ḥaqqi=dies gehört mir;" lā tāehud di 'l-chašabah ḩaqq èn-nās hIja=»nimm dieses Stück Holz nicht, es gehört den (= andern) Leuten." Hieraus hat sich nun, ebenso wie bei bet $\bar{a}^{c}$, der adjectivische Gebrauch entwickelt und infolge dessen das Streben der Sprache, das Adjectiv ha aq in Geschlecht und Zahl mit seinem Substantiv übereinstinmen zu lassen. Also èl-bēt ḥaqqī=»mein Haus", èl-marah haqqat $\left.{ }^{1}\right)=»$ meine Frau". Den weiblichen Plural habe ich nie gehört, statt dessen inmer den männl. oder den weibl. Singular oder auch den männl. Plural: èl-ḥarim ${ }^{2}$ ) ḥaqquh oder hạqqatuh, èl-benāt, èl-ğawār ${ }^{3}$ ) haqquh oder haqqatuh; in diesen Fällen wird prädicativ fast nur haqq gebraucht und gibt es also keine verschiedene Ausdrücke für: »mein Eigenthum" und »die Meinigen": èl-benāt hadōi haqqub=»diese Mädchen sind die seinigen (seine Töchter)." Höchst merkwürdig ist nun aber die Erscheinung dass für den männlichen Plural die Form ḥaqqūn in Gebrauch ist, die einzige Pluralform auf بُ-, welche ich in der lebenden Sprache Mekkahs beobachtet habe. èr-riğāl ḥaqqūnahum = »ihre Männer"; èl-chaddāmin ḥaqqūn èššerif $=»$ die Diener des Scherifs". Wie gesagt, ist dieser Plural auch für das Femin. üblich: èl-ḥarīmāt $t^{4}$ ḥaqqūn èl-ğā$\left.\mathrm{wah}^{5}\right)=\triangleright$ die Weiber der Malaien." Statt des männlichen Plurals gebraucht man auch den Singular: èl-chaddāmin hạq èš -šerĩf; die adjectivische Auffassung des Wortes haqq hat überhaupt ihre volle Wirkung noch nicht ausgeübt.

1) Die Accentuirung is meistens háqqat $\mathrm{T}$, bisweilen, vorzüglieb wenn das Wort prädicativ gebraneht wird, haqqát I; hãd I 'l-marah haqqátI = "diese Frau ist die meinige;" haqqáti hrja = "sie gehört mir."

2) Plural von $\underline{h} \mathbf{u} \mathbf{r m h}=$ Weib; seine Frau (sing.) kann nur mit marat uh, nicht mit h u rmat $\mathrm{n} h$ übersetzt werden.

3) Plural von ğa $\mathrm{rijeh}=$ Sklavin.

4) Diese Pluralform wird vielfach gebrancht, wenn von Weibern überhaupt, nicht wenn von den Weibern einer Familie die Rede ist.

5) Alle Bewohner der ostindischen Inseln, Malakkas, und Siams heissen in

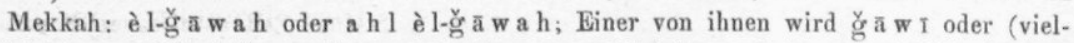

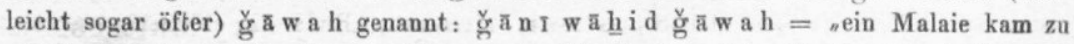

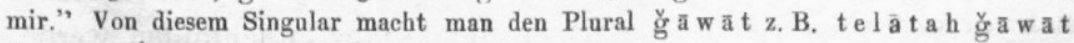
ğ $\bar{a} \mathrm{u}=$ "d̀rei Malaien sind gekommen." 
10.

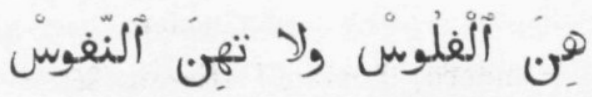

Schätze lieber das Geld gering als das Ansehen.

hin ist Imperativ von أهاب = Hier sind zwei von den drei Triebfedern erwähnt, welche nach der populären Lebensanschauung der Mekkaner, das Leben der menschlichen Gesellschaft beherrschen: fel $\bar{u} s, n$ ef $\bar{u} s, n \bar{a} m \bar{u} s$ heisst die Trias. Die erstere ist am leichtesten $\mathrm{zu}$ definiren, vielleicht aber am schwersten zu erwerben; die meisten Mekkaner sind darüber einig dass die klingende Münze die wirksamste von den dreien ist und dass man, zu ihrem Besitze gelangt, nefūs und nāmūs entweder ohne Mühe bekommen oder doch entbehren kann. Man gibt zwar den

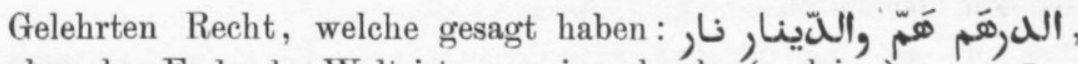
aber das Ende der Welt ist nun einmal nahe (āehir èz-zamān, jā še ch!), und da ändern sich bekanntlich die Ansichten über das, was dem Leben Werth verleiht. nefūs, eigentlich Plural von نَفْس , كَ, also: Seelen, hat im mekkanischen Sprachgebrauche auch die Bedeutung des persönlichen Einflusses, gleichsam der „Seelen", über welche man verfügt, bekommen, und ist dann ein abstractes Wort, welches als Singular construiert wird. Wer von vielen geachtet oder gefürchtet wird, der hat nefūs. Mit einem blutarmen Menschen ist dies wohl selten der Fall, aber man braucht dazu nicht gerade reich zu sein. Die Zuneigung hochgestellter Beamten, specielle Kenutnisse und damit zusammenhängende Unentbehrlichkeit, grosse Gelehrsamkeit, ein einzelnes Mal auch wohl ein besonders solider Charakter können Einem auch ohne felūs zum nefūs verhelfen. Es gibt also sehr verschiedene Sorten von nefūs; solche populäre Wörter für abstracte Begriffe haben überhaupt eine etwas vage Bedeutung, weil die Begriffe selbst unbestimmten Umfanges sind. Ein unbemittelter Gelehrter, dessen Unterricht sehr gesucht ist, dessen Gutachten von vielen eingeholt wird und welchen die Regierungsbeamten um keinen Preis ärgern möchten, hat nef $\overline{\mathrm{u} s}$; der Zunftmeister einer grossen Zunft, dessen Hülfe die Regierung öfters braucht, um die Zunftgenossen auszubeuten, dessen Gunst aber jeder Zunftgenosse sich zu erwerben strebt, damit er nicht ganz geschunden werde, 
hat gleichfalls $n$ ef $\overline{\mathrm{u}} \mathrm{s}^{1}$ ). Man sieht aber, dass im ersten Falle alles von persönlichen Qualitäten abhängt, während im zweiten Falle öfters äussere Umstände alles entscheiden. Es gibt ein moralisches und ein rein äusserliches nefūs. Es versteht sich, dass nur von ersterem in dem Sprichworte die Rede sein kann. Der $n \bar{a} m \bar{u} s$ ist der makellose, ehrliche Name, den man unter den Menschen hat; ihm steht ${ }^{c_{\bar{a}}{ }^{2}}{ }^{2}$ ), Schande entgegen. Auch dieser Begriff ist selbstverständlich ein relativer: manche Leute erachten ihren $n \bar{a} \mathrm{~m} u \bar{s}$ für unversehrt, so lange sie sich keine grossen Sünden (Unzucht, Weintrinken, Diebstahl) zu Schulden kommen lassen; andere betrachten den $\mathrm{n} \overline{\mathrm{a}} \mathrm{m} \overline{\mathrm{u}} \mathrm{s}$ als gemeinsames Eigenthum der Mitglieder einer Familie, sodass die Frevelthat Eines von ihnen auch den andern ibren $n \bar{a} m \bar{u} s$ wegnimmt (jedhajjic $n a \bar{m}$ ú$^{-}$ sahum). Dem, der nicht in Armuth erzogen wurde, erscheint

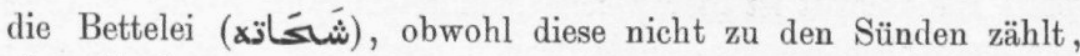
als mit dem $n \bar{a} m \bar{u} s$ unvereinbar. Jedenfalls ist der $n \bar{a} m \bar{u} s$ an und für sích gänzlich unabhängig von felūs und nefūs, und verträgt er sich mit jeder gesellschaftlichen Stellung. Wer einem Ehrenmanne öffentlich gemeine Schimpfworte zufügt, jekassir $n \bar{a} m \bar{u} s u h \gg$ zerbricht seinen nām $\mathrm{u} s$ ", ist also zur Genugthuung verpflichtet, aber er kann ihm denselben nicht nehmen (mā jiqdar jedhajjic nāmūsuh).

Dem Armen gereicht es zum Troste, das Keiner ihm seinen $\mathrm{n}$ ām $\mathrm{u} \mathrm{s}$ nehmen kann; das leichtsinnige Weltkind hält ihm aber das virtus post nummos entgegen. Wenn Einer über felūs verfügt, so sagt dieser: wer wird es wagen, an seinem $n \bar{a} m \bar{u} s$ zu rütteln? und wenn der Reiche des Armen $n \bar{a} m \bar{u}$ s in tausend Stücke zerbricht, wer hilft ihm? Das Verhältniss und der relative Werth dieser drei Factoren des Lebens werden unter Mekkanern sehr oft besprochen; das Weltkind hat aber nicht ganz Unrecht.

Wie schon bemerkt, wird in unserem Sprichworte ein solches $\mathrm{n}$ efūs gemeint, von dem der $\mathrm{n} \overline{\mathrm{a}} \mathrm{m} \bar{u}_{\mathrm{s}}$ unzertrennlich ist.

1) Wer nefas irgendwelcher Sorte besitzt, von dem gilt; kalàmuh masmac $=$,man achtet auf seine Worte," er gehört zu den mútabarın, den muhtašimin, luh hēbeh 'anda kull èn-năs willa canda bacdhahum, ,ihm wird Ehre erwiesen, sei es von allen oder nur von einigen Menschen," jeh habbi s èn-nas

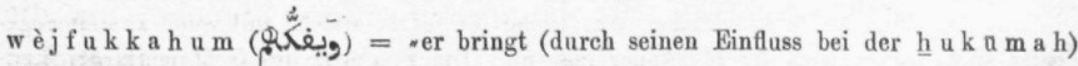
die Leute ins Gefängniss und befreit sie daraus" u. s. w.

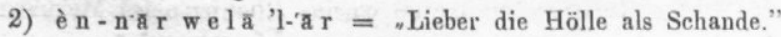




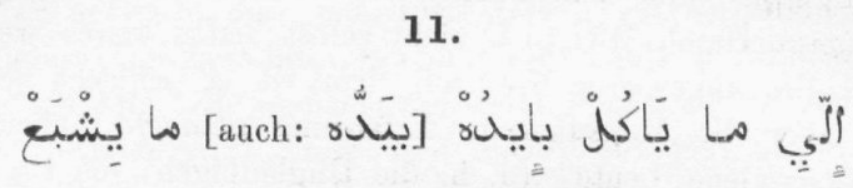

Wer nicht mit seiner Hand isst, wird nicht gesättigt.

Man spricht biduh, be-Iduh und bejèdduh ${ }^{1}$ ). Neben أكل gibt es vielleicht nur noch ein einziges Verbum, dessen Imperf. passivi von allen Mekkanern gebraucht wird: jūkal »es ist essbar", jū ğ ad »es ist vorhanden, es gibt". Fast jeder, der Lesen und Schreiben gelernt hat, wird Einen, der sich wegen seiner schlechten Handschrift entschuldigt, beruhigen mit den Worten:

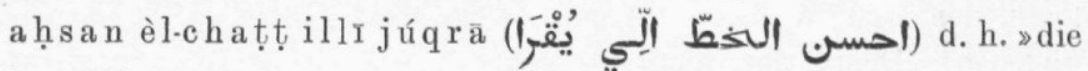
beste Handschrift ist die, welche man lesen kann"; oder wenn er sich vergeblich bemüht, einen Brief zu entziffern, wird er sagen: hád $\bar{a}$ mā juqra $=$ »dies ist unleserlich". Ziemlich allgemeinen Gebrauches ist auch der Ausdruck mā juqrā ${ }^{c} \mathrm{a} l e \bar{h} \mathrm{~h}$ ès-salām oder salām èl-musliminn z. B. X. hatte längere Zeit als Gast im Hause des N.N. gewohnt und schliesslich das Geld zur Heimreise von ihm geborgt unter feierlichem Versprechen, dass er ihm dies gleich nach seiner Heimkehe zurücksenden werde; als nun das Geld Tage lang ausblieb, da sagte der gänzlich ungebildete N.N.: in kān má jerudd èl-felūs ḥaqqátr ${ }^{2}$ ) dā'l-ḥ̂neh ${ }^{3}$ ) mā juqrā alēh salām èl-muslimın $=$ »wenn er mir jetzt mein »Geld nicht zurückgibt, so hat er das Recht verwirkt, mit dem »Grusse der Muslime begrüsst zu werden". Uebrigens treten auch hier die reflexiven Formen an die Stelle der passiven.

Dieses Sprichwort wird in zweierlei Sinn gebrancht. Die ursprüngliche Bedeutung wird im deutschen Sprichworte: »selber essen macht fett" am besten wiedergegeben; der Nachdruck fällt

1) Vgl. $N^{\circ} \cdot 6$.

2) Vgl. $\mathrm{N}^{\circ} \cdot 9$.

3) Der Missbrauch der Endung $\gamma_{-}$- gehört za den Eigenthümlichkeiten der Vulgärsprache; in Medinah soll dieselbe noch viel häufiger vorkommen als in Mekkah, aber auch hier sagen die ungebildeten Leute z. B. $1 \mathrm{a} \mathrm{h} \mathrm{m}$ a h für Fleisch überhaupt. Die Ge-

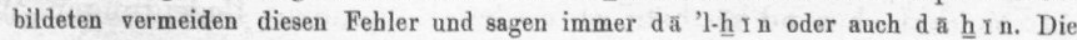
in anderen Ländern gebräuchlichen Ausdrücke für jetzt, welche mit vaqt zusammenge. setzt sind, gebrauchen die Mekkaner fast nie. Die Frequenz des Gebrauches der Endung ${ }_{-}-$ist eins von den besten Kriterien für die allgemeine Bildung eines Mekkāwr. 
dann auf seiner und man könnte biduh übersetzen durch: mit seiner eignen Hand. Wer sich nicht selbst helfen kann, wer auf fremde Hülfe angewiesen ist, mit dem ist es schlecht bestellt. Seitdem aber die Mekkaner in Erfahrung gebracht haben dass hàdolak=»jene Leute" (d. h. die Ungläubigen, die Franken) beim Essen anstatt der traditionellen chamsah (»fünf" d. h. die Hand) sich verschiedener šokah und ma laqah genannter Instrumente bedienen, seitdem sie bemerkt haben, dass diese Unsitte sogar unter Türken und vornehmen Malaien und Indern Anhänger findet, gebrauchen sie unser Sprichwort, um ihren Unwillen über diesen Rückschritt der Civilisation Ausdruck zu geben. »Wer nicht mit seiner Hand (sondern mit šokah mōkah, mit »Gabel und weiss ich was) isst, wird nicht satt", sagen sie mit voller Ueberzeugung. Die Gelehrten tadeln den Gebrauch jener

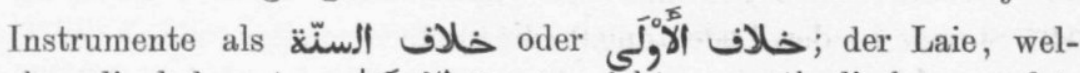
cher die bekannten خicht so methodisch anwendet, verdammt denselben als حرم الم und gestattet sich und Andern nur beim Essen von ganz flüssigen Speisen den Gebrauch eines hölzernen Lrffels. Es wird aber wohl eine Zeit kommen, wo diese Neuerung wie so manche andere vorhin (man denke nur an den Gebrauch der sèğğă $\mathrm{deh}$ ) in die Reihe der بufgenommen wird.

12.

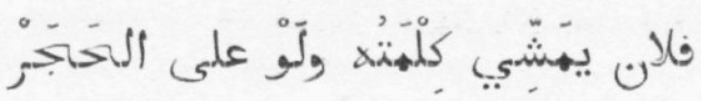

N.N. weiss sein Wort zur Ausführung zu bringen, sogar wenn es Stein betrifft.

Gewöhnlich gesagt von Einem, der einmal gefasste Pläne nicht aufgibt und einmal gegebene Befehle nicht widerruft, also von einem energischen Geiste; seltener von Einem, der es versteht durch gewandtes Reden immer seine Wünsche zu erreichen, sei es auch durch Schmeichelei oder Betrug. Der Stein bezeichnet in beiden Fällen zähen Widerstand; vgl. $\mathrm{N}^{0} .5$ und $\mathrm{N}^{0} .40$.

in Mekkah besonders häufig in den folgenden Bedeutungen ${ }^{1}$ )

1) Mit dem Subject: bat $\mathbf{n}$ bezeichnet das Verbum bekanntlich -Durchfall haben"; 
gebraucht: a) "gangbar sein" von Münzen. z. B. dā's-sittın

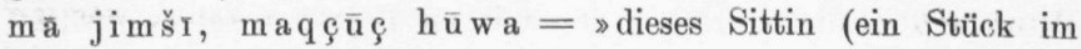
Werthe von $1 \frac{1}{2}$ Piaster) ist nicht gangbar, es ist beschnitten". Der IIte Stamm heisst dann sherausgeben, gangbar machen", z. B. hāda māu mamsūh, a díni hūwa hatta (a)maššr ${ }^{2}$ ) $=$ diese (Münze) ist gar nicht abgeschliffen; gib sie mir her, »ich will sie herausgeben". b) verbunden mit حال in Ausdrücken wie māšı ḥāluh, jimši ḥ̄aluh = »so ziemlich", »mässig", ses geht schon". Hast du ein schönes Haus? - Antw. jim šı hâluh d. h. »es lässt sich darin wohnen". Statt ḥ̂aluh sagt

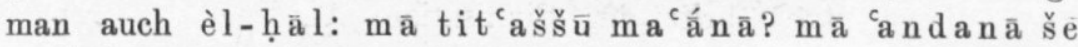
$m u^{c}$ tábar, māšj- (auch gesprochen: mašj) èl-ḥ̄al wekān d. h. »wollt ihr nicht mit uns speisen? wir haben freilich nichts „Besonderes, einen gewöhnlichen Tisch, weiter nichts". Daher der IIte Stamm in der Bedeutung: »die Sachen nehmen, wie sie gerade sind", »sich mit dem Vorhandenen begnügen", »keine Complimente machen". Atfaddhalū ḥatta nemašši ḥālanā sagt der Gastgeber zu seinen Gästen, d. h. »Seid so freundlich (euch 》zu Tische zu setzen), damit wir das (einfache) Vorhandene ge»niessen". ma šši ḥa alak = »keine Umstände, bitte". Wenn ein kleiner Bube sich, unbekümmert um die Anwesenden, hinsetzt und mit ungetheilter Aufmerksamkeit Früchte oder Süssigkeiten isst, da sagt wohl Einer ironisch: jemašš hāluh d. h. »Er genirt sich nicht, er nimmt mit dem Finfachen vorlieb". - Ueber welau (welo) vgl. $\mathrm{N}^{0} .54$.

13.

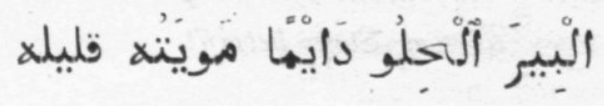

Der süsse Brunnen hat immer wenig Wasser.

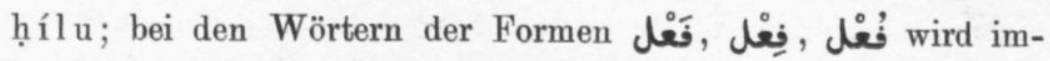
mer der dritte Radical, wenn dieser $w$ oder $j$ ist, in den ver-

jim\&̌YbatnI = ich leide am Durchfall", Oppos. batn I masik, jimsík oder mađaje qa bdh ( Arzneimittel wirkt abführend."

2) Der Vocal des Praefix der Ien Person imperf. des IIten und IIIten Stammes ist gewöhnlich entweder $a$ oder unbestimmt oder er wird (wie im oben angeführten Satze) gar nicht gehört. 
wandten Vocal aufgelöst. - Man sagt mōjetuh und moj'tuh. Wenn ein Hülfsbedürftiger von reichen Leuten meistens zurückgewiesen wird und grade bei solchen Unterstützung findet, welche nur etwas weniger bedürftig sind als er, so gibt er in diesem Sprichworte zu gleicher Zeit dem Lobe seiner armen Wohlthäter und dem Tadel der geizigen Reichen Ausdruck.

13.

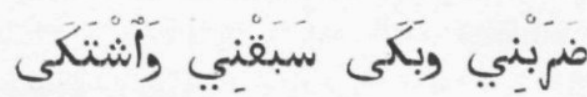

Er hat mich geprügelt und dann selbst geweint; er hat über mich den Vortheil davongetragen und mich desshalb angeklagt.

Das Subject dieser beiden Sätze hat also in beiden Fällen grade das Umgekehrte gethan von dem was man erwarten sollte. Er thut dem Andern Leid, resp. besiegt ihn und führt sich nachher auf, als wäre ihm Leid widerfahren und als wäre er von dem Andern besiegt worden. Die Redensart wird gebraucht von Leuten, welche durch ihre Stellung verpflichtet sind, immer nach den Befehlen ihrer Vorgesetzten zu handeln. Mancher Chef gibt seinen Untergebenen die Schuld von allen Fehlern, welche sie auf seinen Befehl begangen haben; haben dieselben aber auf eigene Faust etwas Gutes zu Stande gebracht, so nimmt Jener das Verdienst davon für sich in Anspruch, weil es unter seinen Auspicien geschehen ist. Ueber derartige Chefs beschweren sich die ma ${ }^{3}$ mürin in dem citirten hyperbolischen Ausdrucke.

15.

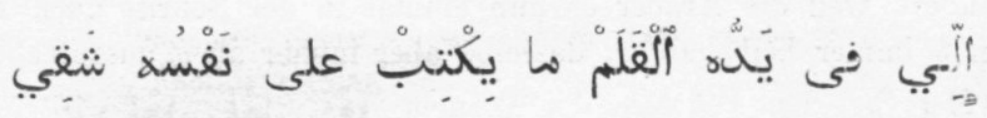

Wer die Feder in seiner Hand hat, trägt sich selbst nicht als Unglückseligen (Verdammten) ein.

Die Feder, von welcher hier die Rede ist, ist die himmlische, mit welcher Allah die Namen der Menschen zur Verdammung und zur Seligkeit aufschreibt. Gesetzt einmal, die Verfügung über diese Feder wäre einem Sterblichen anheimgegeben, so würde der nicht seinen eigenen Namen unter die Verdammten (šáq I, Oppos. 
said) aufnehmen. In diesen Worten äussert sich das populäre Urtheil über das Benehmen von Leuten, welchen Autorität, Macht oder Einfluss gegeben ist, wenn sie diese zu ihrem eigenen Vortheile ausbeuten. Am häufigsten sagt man es von Regierungsbeamten, Zunftmeistern und ähnlichen Leuten, welche dann und wann die Vertheilung gewisser Einkünfte zu verwalten haben. Kein Wunder, dass er das Beste für sich behalten hat; » wer die Feder u. s. w."

Anstatt fi jèdduh sagt man auch fi-Iduh, fe-Iduh und fiduh; vgl. $\mathrm{N}^{0} .6$.

16.

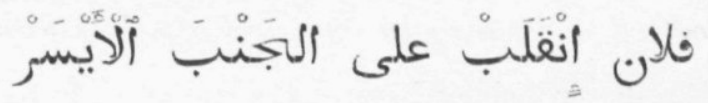

N. N. hat sich nach links umgewendet.

Diese Redensart gebraucht man im eigentlichen Sinne gewöhnlich von schlafenden, oder doch liegenden Leuten. Bekanntlich ist auch bei den Arabern die rechte Seite boni ominis, und in den Handbüchern der Pflichtenlehre (فِقِّen wird den Gläubigen anempfohlen, sich immer auf die rechte Seite schlafen zu legen. inqálab wird im reflexiven und im passiven Sinne gebraucht; es kann also auch vom unbewussten Umwenden im Schlafe gesagt werden. Im bildlichen Sinne bezeichnet man damit eine Person, welche augenscheinlich besonders schlecht aufgelegt ist, genau so wie man in solchen Fällen sagt: »er ist mit dem linken Beine (zuerst) aus dem Bette gestiegen."

Das $n$ in الحََنْب habe ich nicht unnöthiger Weise in $m$ umgeändert weil die Araber es nun einmal in der Schrift auch vor dem $b$ immer beibehalten, dasselbe aber immer als $m$ aussprechen.

17.

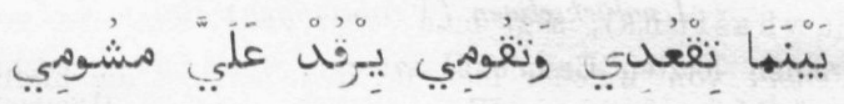

Indem du dich setzest und wieder aufstehst, schläft mir mein Unglückskind ein.

Ein Mann, so wird uns erzählt, verlangte einmal von seiner 
Frau, was Männer von ihren Weibern zu verlangen pflegen. Die Frau wollte zwar ihrer ehelichen Pflicht genügen, hatte aber vorher noch allerhand Sachen zu besorgen. Bald setzte sie sich, um ihre Toilette noch etwas zu berichtigen, bald stand sie auf, um einen Schrank zuzuschliessen, und wenn der Mann sie zur Eile antrieb, war ihre Antwort jedesmal: challı awwal aqūm asaww I ${ }^{1}$ ) hád $\bar{a}$, aqud asaww ${ }^{1}{ }^{1}$ ) háda $=$ »lass mich zuerst »noch aufstehen, damit ich dies.., mich niedersetzen damit, ich »jenes besorge". Der Mann verlor über alledem die Geduld, und sein Verlangen nahm ab, ohne gestillt zu sein; dann redete er seine Frau mit den angegebenen Worten an. مَشْبُم = مشوم ist einer von den zahlreichen Zunamen des ذَّك (vgl. Mrḥā'il Șabbāğ's Grammatik, ed. H. Thorbecke, Strassburg, 1886 i. v.) wird in Mekkah viel gebraucht.

Wenn man von Einem etwas verlangt hat (z. B. einen Becher Wasser, eine šı š eh) und dieser sich durch nichtige Beschäftigungen von der schnellen Erledigung der gewünschten Sache abhalten lässt, so tadelt man ihn mit diesen Worten.

18.

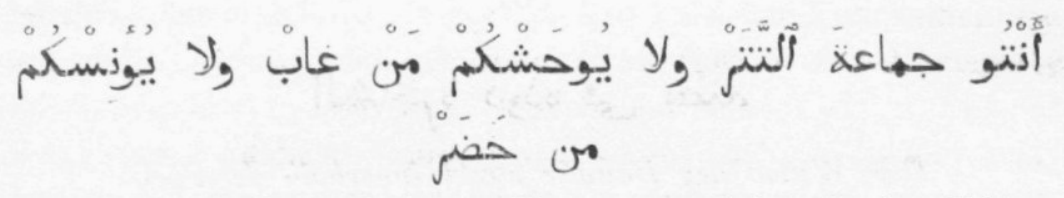

Ihr seid die Gesellschaft der Tataren; euch betrübt das Fehlen der Abwesenden ebenso wenig, wie euch das Dasein der Anwesenden erfreut.

awhaštúnā, ānastúnā, šarraftúnā sind die gewöhnlichsten höflichen Redensarten, mit denen man einen Besucher bewillkommt nachdem man die Begrüssungsformeln ausgetauscht und sich gesetzt hat; man lässt das Suffix nā auch wohl fort. Ihr habt uns (durch eure lange Abwesenheit) wie vereinsamt gemacht (awhaštūnā), sagt man sogar zu Einem, der vor zwei Tagen seinen letzten Besuch abstattete; wenn der Besucher sich entfernt, gibt man seinen Wunsch nach baldiger Wiederholung seines Besuches durch die Worte: la tūhašúnã zu erkennen,

1) Ueber den Vocal des Präfixes der Iten Person vgl. $N^{\circ} .12$. 
d. h.: 》 lasst uns nicht (durch eure lange Abwesenheit) vereinsamt". Der $a$-vocal ist hier im Imperf. des IV ten Stammes an die Stelle des $i$ getreten. Der IVte Stamm ist übrigens meistens von dem IIten verdrängt worden; vgl. Spitta, Grammatik. S. 196. Von in sind die beiden Stämme gebräuchlich; der IIte in der Bedeutung: »unterhalten” (mit Gesprächen, Erzählungen, Spiel oder sonst) z. B. harğatuh ${ }^{1}$ ) ḥilweh walláhi je'annis (auch jewannis) kull èn-nās = seine Rede ist, bei Allah, »angenehm; er unterhält alle Leute"; der IVte Stamm bedeutet: »durch seine Anwesenheit erfreuen", wobei also als Subject eine geliebte, verehrte oder angesehene Person stehen kann, auch wenn sie gar nicht unterhaltend ist. wálāa ${ }^{2}$ ) jūnisnā wálā jūhašnā heisst: »er ist uns völlig gleichgültig", » wir legen auf seine Gesinnung gegen uns nicht den geringsten Werth".

Der erste Theil unserer Redensart steht wohl nur des Reimes wegen; wenn er je für sich einen Sinn gehabt hat, so hat er denselben völlig verloren. Das Ganze bezeichnet die Angeredeten als schreckliche Egoisten, welche sich um keinen Menschen ausser sich selbst kümmern.

19.

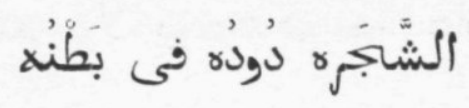

Der Wurm des Baumes steckt innerhalb desselben.

fi bațn ist die gewöhnliche Präposition: »in .... drin", »im Inneren von....," entstanden aus fi bätin. Die Form $f \bar{a}^{c} i l$ wird, wenn bei der Hinzufügung von Suffixen oder Endungen der zweite Vocal sich öffnet, bald $f \bar{a}^{c} l$, bald $f a^{c} l$ ausgesprochen ${ }^{3}$ ), z. B. $F \bar{a} t^{2} \mathrm{mah}$ neben $F a t^{2} \mathrm{mah}$, èl-qā $b^{3} l e h$ neben

1) Vgi. $N^{\circ}, 46$, Anm.

2) Wála hat zum ersten Vocal das accentuierte $a: 1^{\circ}$ in dem Ausdruck: wálā.... wál a $=$ "weder .... noch" (vgl. Spitta, Grammatik, S. 181); $2^{\circ}$ in der Bedeutung : " sogar nicht, nicht einmal", z. B. ma att I k wála $\mathrm{chamsah}=$, ich gebe dir (nichts), nicht einmal ein Fünf-para-stück."

3) Diese Erscheinung, dass nämlich ein unbestimmt gewordener Vocal in offener Silbe hinter einer offnen Silbe mit langem $\bar{d}$ ausfällt, findet man auch in Pluralformen wie ha a d hã r'ma h, mag hã r'b a h, t a kā r'n a h und nach der Ansicht vieler Mekkaner in $b$ a wardr (aus ba waridr); ferner wo einer Verbalform ein Adverb oder eine Conjnnction vorangeht, welche damit enge verbunden ist, wie z. B. ma a, lă, la mma: 
èl-qableh (das nächste Jahr), ${ }^{{ }^{\bar{a}} j^{3} \mathrm{~d} \mathrm{rn}}$ (Zurückkehrende) ${ }^{1}$ ), fā $j^{2} z i n$ (Beglückte, Selige) ${ }^{1}$ ), chā $\mathbf{r}^{2}$ ğah neben charğah (Terrasse, flaches Dach, auf welches sich eine Thüre in einem höheren Stockwerke öffnet und wo man auch am Tage im Schatten der umgebenden Mauern die frische Luft einathmen kann), rāj ${ }^{3}$ hah neben rēḥh (Geruch, und auch: »gehend", femin.), q aflah (Karavane). Wo beide Formen neben einander bestehen, wird die kürzere beim schnellen Sprechen und also vorzüglich von ungebildeten Leuten gebraucht; bei vielen Wörtern (wie beim obengenannten bațn, welches ohne Suffix nicht vorkommt) ist die kurze Form zur Regel geworden.

Die Redensart bezeichnet ein Uebel, welches eine Person trifft, als von ihr selbst verursacht; oder ein Uebel, welches eine Gesammtheit (Zunft, Familie) trifft, als innerhalb derselben entstanden und nicht von aussen her gekommen (ǧat mínnahum²) èl-fitneh oder èl-bèlwe, māu še barrāñ d. h. »die Unordnung" oder »das Unglück ${ }^{3}$ ) ist von ihwen selbst verursacht »worden, es ist keine von aussen her gekommene Sache”). Im Anfang des Monates Šawwāl 1302 wurde eine Gesellschaft aus Tạif nach Mekkah zurückkehrender Leute in der Nähe von Zëmah von Bedünen angegriffen und geplündert. Die Räuber wurden von Scherifen angeführt, welche zu den nächsten Verwandten des regierenden Grosscherifs gehörten. Diese hatten sich geweigert,

ñā 'jqu l (neben mājequl); dies wird sogar manchmal majq al und mēqul ausgesprochen, und diese drei (resp. vier) Formen sind immer alle möglich, wo $\mathrm{m} \bar{a}$ einem Imperfect, welches mit $j$ e anfängt, vorangeht. La tehin wird auch $1 \bar{a}$ thin ge-

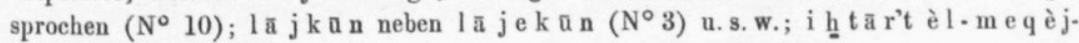
jin a h $\left(N^{\circ} 32\right)$, 'i m ām'ti.

1) Beide Wörter gehören zur mekkanischen Gratulationsformel bei den religiösen

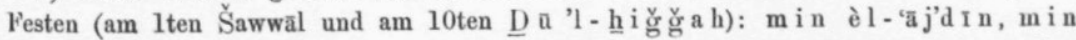
è $\mathrm{l}-\mathrm{f} a \mathrm{j}$ 'zin, $\mathrm{k}$ ulla sèneh wèn $\mathrm{t} \mathbf{a} \mathrm{tajjibin} \mathrm{d.} \mathrm{h.} \mathrm{"(möget} \mathrm{ihr)} \mathrm{zu} \mathrm{den}$ "Wiederkehrenden (für welche das Fest wiederkehrt), zu den Seligen (gehören), jedes "Jahr, indem ihr each wohl befindet!"

2) Die Verdoppelung des $n$ in ${ }^{s}$ findet in Mekkah vor allen Suftixen statt, aber sonst nicht überall (gegen Landberg, Proverbes et Dictons I: 1-2); vor dem Artikel z. B. ist sie ganz bestimmt höchst selten.

3) Der attributive Gebrauch von Substantiven, von welchem Spitta, Grammatik, S. 279 Beispiele gibt (š $\overline{\mathrm{e}} \mathrm{hal}$ a k u.s.w), ist auch in Mekkah häufig: š ê quwwah,

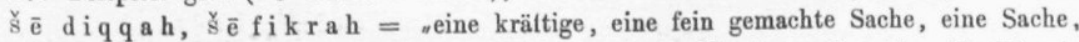
welche Nachdenken erfordert". Von b è l w e und $\mathrm{d}$ a h'j e h werden aber die Plurale ebenso wohl prädicativ als attributiv gebraucht: $\mathrm{r} \overline{\mathrm{a}} \mathrm{g} \mathrm{il} \mathrm{d}$ a wa $\mathrm{h} \mathrm{I}=$ "ein verschmitzer, schlauer Kerl"; è n t e ba la w $\mathrm{I}=$ „du bist ein Unglü $\mathrm{ck}$ ". Beide Ausdrücke werden sehr oft, auch in scherzendem Sinne gebraucht. 
sich dem Ausspruche des Stellvertreters ( $q$ āi m maq ām) des Grossscherifs in einem zwischen ihnen und einer Scherifah geführten Prozesse zu unterwerfen, weil der Sultan balçah (in anderen Ländern unter den Namen bèrțil bekannt) darauf den grössten Einfluss ausgeübt hatte. Als nun der Qāimmaqām Gewaltmassregeln gegen sie ergriff, drohten sie ihm um die Mitte des Ramadhān, sie würden den Weg zwischen Mekkah und Ṭaif unsicher machen, bis man ihnen zu ihrem Rechte verhelfe. Der Qāimmaqām betrachtete diese Drohung als kalām fārigh (leere Worte); sobald aber der Fastenmonat vorbei war, führten die Unzufriedenen ihr Vorhaben aus. Dieses Ereigniss versetzte den Grossscherif, dessen Autorität gerade in den letzten Jahren schon so manchen Schlag erlitten hat, in eine äusserst schwierige Lage. Es macht der Bevölkerung immer einen schlechten Eindruck, wenn die ašrāf mit einander kämpfen; ausserdem hat der regierende Scherif so viele Feinde und verfügten die Unzufriedenen über so viele Anhänger, dass der Erfolg eines Kampfes gar nicht sicher gewesen wäre. Die friedliche Beilegung des Streites dagegen konnte nach der stattgefundenen Plünderung nur als ein Zeugniss von der Schwäche des Emirs betrachtet werden. In den ersten Tagen wurde in Mekkah kaum von etwas Anderem geredet. Da hörte man nun oftmals, wenn die Leute bei der Discussion dem Verhalten der Beduinen oder der Gesinnung der Städter hohe Bedeutung beilegten, unser Sprichwort von einem Sachverständigen anführen: $h \bar{a} \mathrm{~d}_{\overline{1}}{ }^{1}$ ) ' $\mathrm{l}-\mathrm{h} \operatorname{arakah}{ }^{2}$ ) min èl-bèdu hija? ismac mínnī jā šēch! èš-šağarah etc. $=$ »st denn diese "Bewegung von den Beduinen verursacht worden? Höre, was »ich dir sage, o Schëch! der Wurm des Baumes" u. s. w.

1) Das gewöhnliche Demonstrativum für den naheliegenden Gegenstand lantet: $\left.\begin{array}{ll}\text { männlich } \mathrm{d}_{\overline{\mathrm{a}}}, & \mathrm{h} \overline{\mathrm{a}} \mathrm{d} \bar{a} \\ \text { weiblich } \mathrm{d}_{\mathrm{I}}, \mathrm{h} \overline{\mathrm{a}} \mathrm{d} \mathrm{I}\end{array}\right\}$ Plural d $\mathrm{l}, \mathrm{h} \overline{\mathrm{a}} \mathrm{d} \overline{\mathrm{o}} \mathrm{l}$

und für den entfernt liegenden Gegenstand:

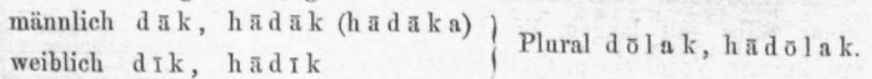

Wenn es adjectivisch gebraucht wird, geht es seinem Substantive bald voran, bald wird es demselben nachgesetzt. Das Substantiv wird dabei immer durch den Artikel bestimmt, ausser in $\mathrm{d} \overline{\mathrm{a}}$ hin (neben $\mathrm{d} \overline{\mathrm{a}} \mathrm{\jmath} \mathrm{l} \cdot \mathrm{h} \mathrm{I} \mathrm{n})=$ jetzt.

2) Ueber harakah vgl. $N^{\circ} 63$. 
DR. C. SNOUCK HURGRONJE, MEKKANISCHE SPRICHWÖRTER. 463

20.

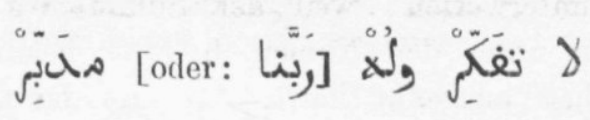

Sei nicht bekümmert; die Sache hat ihren Lenker (unser Herr lenkt).

فكّى wird häufig synonym mit تفكّ gebraucht; aber auch in der causativen Bedeutung: erinnern, eingedenk machen. Der Vokal $a$ ist als Bindevokal im mekkanischen Dialekte äusserst beliebt ${ }^{1}$ ).

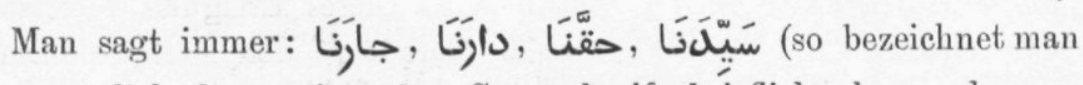
vorzüglich den regierenden Grossscherif, brieflich aber auch namhafte Gelehrte, letztere gewöhnlich mit Hinzufügung von:ومولنا; scherzhaft sagt man öfters zu Kindern: jā sèjjídana oder jā sidana), سيََنَ (so redet Einer denjenigen an, dem er sich unterwürfig, gleíchsam als seinen Sklaven bezeichnen will; der Sklave sagt nur سيلئische Gastgeber sagt zu seinén Gästen: èl-bët bêtakum wèl-mehill mehillakum d. h. das (mein) Haus ist euer Haus, und die (meine) Wohnung ist eure Wohnung. Wo der Ien Person des Perfects zur Erleichterung der Aussprache ein Vokal hinzugefügt

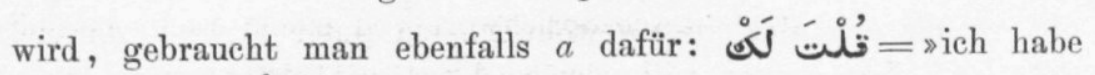

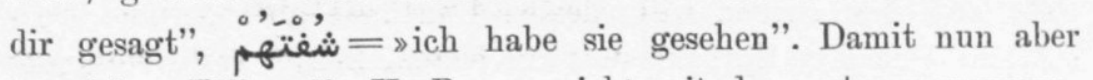
in solchen Fällen die $\Pi$ e Person nicht mit der ersten zusammenfalle, gebraucht man unter gleichen Umständen die vulgärarab. Mehrzahl der II'n Person, also تلتو لي = du hast mir gesagt",

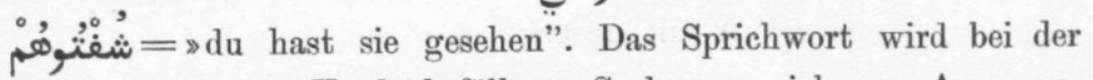
Erwähnung von Unglücksfällen, Sachen unsicheren Ausgangs u. s. w. zur Tröstung bekümmerter Seelen (لتسلية النفس) gebraucht.

1) Dieser Bindevocal tritt namentlich auf, wo sonst eine durch einen Consonanten geschlossene Silbe mit langem Vocal oder eine durch zwei Consonanten geschlossene Silbe mit kurzem Vocal einem Consonanten vorangehen würde, vgl. dabana etc. $\left(\mathrm{N}^{\circ}\right.$. 5); jedēnanā $\left(N^{\circ} .6\right)$; minnana $\left(N^{\circ}\right.$. 8) und minnahum $\left(N^{\circ} .19\right)$; haqq a-

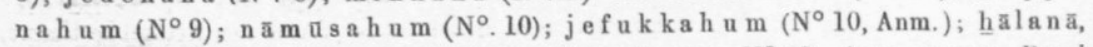
'andana ( $\left.N^{\circ} 12\right)$, g hēranā ( $\left.N^{\circ} 34\right)$; vgl. auch unten $N^{\circ} 58$, Anm. u. 8. w. Der $i$ in $s$ èjjídañ wird auch fast wie langes $\bar{\imath}$ gesproehen. 
464 DR. C. SNOUCK HURGRONJE, MEKKANISCHE SPRICHWÖRTER.

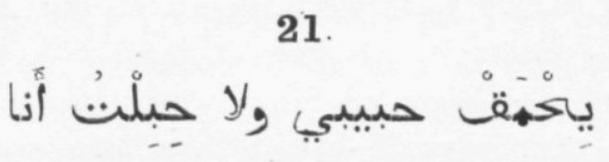

Es ist besser dass mein Schatz zürnt, als dass ich schwanger werde.

صهق wird immer vom Zorne gebraucht. Der ha a b b einer Frau oder eines Mädchens ist der Gegenstand verbotener Liebe; die Frau könnte ihren Gatten ebenso wenig mit jā ḥa bi als die Sklavin ihren Herrn. Ein Mann kann den anderen habí $\mathbf{~ I ~ n e n n e n , ~ d i e s ~ g e s c h i e h t ~ j e d o c h ~ n u r ~ h a l b - i r o n i s c h , ~ z u n a ̈ c h s t ~}$ wenn man ihm widerspricht: »aber, mein lieber Freund!" Zu Kindern sagt man es dagegen häufig. حبلت steht als oratio directa; verschwiegen ist dabei etwa: dass ich sagen müsste: (ich bin schwanger geworden)". Die Form des zweiten Theiles dieses Sprichwortes steht ausserhalb des vulgären Sprachgebrauchs; sonst wäre auch das dhammah in حبلت (welches man dabei immer ausspricht) unmöglich $\left.{ }^{1}\right)$. Man würde sagen: صرّتَ حُبْلَى bildete Männer gebrauchen anstatt des nachdrücklichen أن meistens: الفقير oder, Weiber umschreiben die Ite Person nur selten.

Die Situation, in welche das Sprichwort uns versetzt, ist die einer Frau, deren Liebhaber höchst ärgerlich darüber ist, dass sie ihm die höchste weibliche Gunst weigert. Der bildliche hạ abrb ist für den Mekkaner gewöhnlich ein guter Freund, der viel Geld von ihm borgen will, dessen Umstände aber geringe Aussicht auf jemalige Zurückerstattung bieten. Leistet er die verlangte Hülfe nicht, so ist es öfters auf einmal aus mit der innigsten Freundschaft, welche vielleicht auch nur zum Zwecke der spätern Ausbeutung gesucht worden war. Er tröstet sich dann über die verlorene Freundschaft mit unserem mathal.

22.

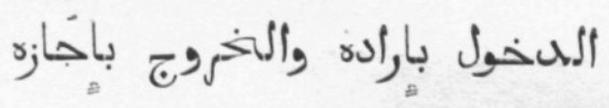

Das Hereinkommen geschieht nach (eignem) Willen, aber das Hinausgehen geschieht (nur) mit Erlaubniss (des Gastherrn).

Diesen Ausdruck gebraucht man natürlich nur in der feineren

1) Vgi. $N^{\circ} 20$. 
(wenngleich gar nicht gelehrten oder litterarisch gebildeten) Gesellschaft. Man stattet in Mekkah zu jeder beliebigen Tageszeit Besuche ab, nur die Zeit unmittelbar nach den fünf a ḍāns ausgenommen. Die üblichsten Besuchsstunden sind ungefähr von 811 Morgens, von $\left.3\right|_{2} ^{1}-6$ Nachmittags und nach dem íša, weil es sonst den meisten Leuten zu heiss ist zum Ausgehen. Später als $9 \mathrm{Uhr}$ Abends besucht man nur intime Bekannte oder Leute von denen man weiss, dass sie spät Abends Besuche empfangen

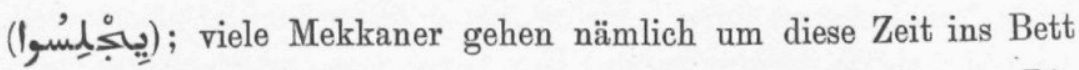
oder sitzen mit ihren ḥarìm auf den Dächern ihrer Häuser. Die Einwohner der heiligen Stadt haben während des grössten Theiles des Jahres (ausser der Zeit, wo die meisten Pilger kommen und gehen) keine eilende Geschäfte und verbringen ganze Tage in Gesellschaft ihrer Freunde. Das Erste, was man einem Besucher zu jeder Zeit vorsetzt, ist ein finğ àn Kaffee und, wenn der Gast keine besondere Eile zeigt, eine šišeh (Wasserpfeife); man präsentirt nur selten mehrere Tassen Kaffee hinter einander. Nach dieser Einleitung dauert es gewöhnlich nicht lange, bis der Was-

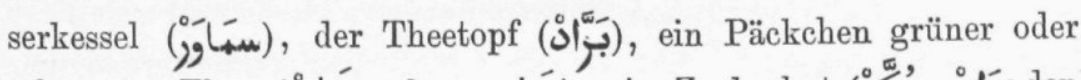

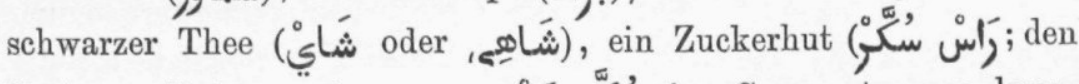

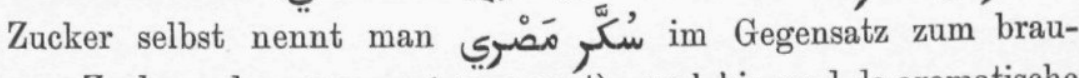
nen Zucker, den man oن nennt), und hie und da aromatische Kräuter, welche man d̈em Thee hinzufügt ${ }^{1}$ ), von einem Diener hereingeschafft werden. Der Hausherr, sein Sohn oder wer immer den Anwesenden aufwartet (jebāšir) ${ }^{2}$ ) macht den Thee, kostet ihn unzählige Male vor, und giesst endlich die fanāğın (fa$n \bar{a}$ ğil) ein. Jeder trinkt wenigstens drei Gläser: $q \bar{a} n \bar{u} n$ kède $=$ so will es die Sitte. Weiss die Zudringlichkeit des Gastherrn ihn zu bereden, dass er ein viertes trinkt, so muss auch das fünfte folgen, denn die Gesammtzahl muss, der sunnah gemäss, ungerade (witr) sein. Das Theetrinken wechselt dann und wann mit dem Trinken gekochter Schaafsmilch ab, welcher man

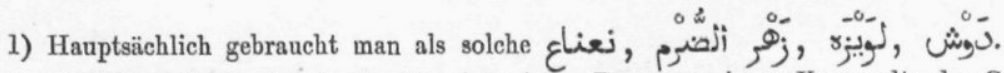

2) Bei jedem Feste oder Gastmahle sind einige Personen, junge Verwandte des Gastherrn oder Fremde, denen man für ihre Bemühung ein ba cȟ̌ı̌ gibt, mit dieser

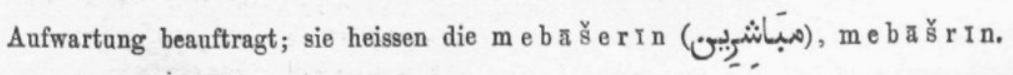


viel Zucker und vielfach auch aromatische Kräuter hinzufügt: oder man füllt jedes Glas zur Hälfte mit Thee, zur Hälfte mit dieser heissen Milch. Wer einen Besucher ehren will, vorzüglich wenn es ein neuer Bekannter ist, der zum ersten Male zu ihm kommt, lässt ihn nicht gehen, bis er auch seinen Thee genossen hat. ēš qaddám lak? fragen nachher Andere in solchen Fällen den Besucher; » was hat er dir vorgesetzt?" Je nachdem die Antwort qahwah oder šă $\mathbf{c}$ lautet, denkt man sich das ganze Verhalten des Hausherrn weniger odẹ mehr entgegenkommend. Ist die Stunde der Mahlzeit nahe, so lässt der wohlerzogene Mekkaner seine Besucher nicht gehen, bis sie mit ihm gegessen haben, und wenn die Umstände es ihm gestatten, verfrüht oder verspätet er die Mahlzeit gern seinen Gästen zu Liebe. Es versteht sich dass auf diese Weise ein Besuch sich sehr in die Länge ziehen kann: es ist gar keine Seltenheit, dass man um 8 Uhr Morgens zu einem Freunde geht und erst um 3 oder 4 Uhr mit schwerer Noth davonkommt. Wer sich empfehlen will, braucht dazu, der Sitte (q $\bar{a} n \bar{u} n)$ gemäss, die Erlaubniss des Hausherrn: nista'dínkum (نستأْنكم) muss er sagen, indem er sich erhebt und mit der rechten Hand die Stirn berührend eine Verbeugung macht. Hat der Hausherr selbst Geschäften nachzugehen, oder ist der Besucher ein alter Bekannter, von dem er weiss, dass er anderswohin gehen muss, so wird das lā, jā šēch, lissā! ${ }^{1}$ ) oder eine ähnliche verneinende Antwort nur aus Gewohnheit gegegeben; das walláhi 'andi šughūl ${ }^{2}$ ) des Besuchers wird dann ohne Weiteres mit einfachem marḥabā! als Entschuldigung seiner Eile angenommen, und noch etwa ein ānastúnā! šarraftúnā! la tūhašúnā! 3) u.s. w. hinzugesetzt, damit er wisse, wie hoch sein Besuch geschätzt wird. Dem fi a mān illāh wehafdhuh (فى أَماب اللع وحفظه) des Gehenden folgt nun ein wiederholtes: ahlan wesahlan jā marhaba $\left.\bar{a}^{4}\right)$ ! von Seiten der Bewohner des Hauses und damit sind wenigstens die unumgänglichen Formalitäten zu Ende. In vielen Fällen bleibt aber

1) Nein, o Schëch! noch nicht!

2) "Bei Allah, ich habe Geschäfte zu besorgen."

3) Vgl. $\mathrm{N}^{\circ}$. 18 .

4) Mit dieser, laut gesprochenen, Formel empfangt man zwar auch hie und da die Ankommenden (man leschränkt sich dann aber meistens anf ahlan! oder ah lan wesahlan!), sie wird aber immer als Abschiedsgruss dem heimkehrenden Gaste nachgerufen. 
der Hausherr auf seiner Weigerung der Erlaubniss bestehen und findet bei jedem Abschnitte des Besuches (also nach dem Kaffee, nach dem $3^{\text {ten }}$ und nach dem $5^{\text {ten }}$ Glas Thee und auch nach der Mahlzeit, denn dieser folgt wieder wenigstens eine Tasse Kaffee mit einer šǐ̌eh und öfters abermals einige Gläser Thee) ein neuer Streit zwischen ihm und seinem Gaste statt. Sind des Besuchers Einwendungen dem Hausherrn zu weitläufig, so beendigt er die Sache mit: hạalaft jemı̃n, jā šêch, mā terūh d. h. »ich habe einen Eid geschworen, o Schēch, du sollst nicht gehen". Ist es dem Besucher mit seinem Wunsche zu gehen wirklich Ernst, so schwört er seinerseits theure Eide, dass er nicht länger bleiben kann, und dann wäre es unhöflich von Seiten seines Freundes, wenn er mit dem Rechte, welches das qan̄̄n ihm seinem Besucher gegenüber gewährt, Missbrauch triebe. Es liesse sich von diesen Gesprächen eine hochkomische Beschreibung geben, aber man müsste die begleitenden Geberden dazu abbilden. Unser Sprichwort; welches gleichsam das Recht des Hausherrn für solche Fälle codificirt, wird dabei jeden Augenblick von ihm, seinen Söhnen und sonstigen Hausgenossen zur Erhärtung seiner Weigerung angeführt.

23.

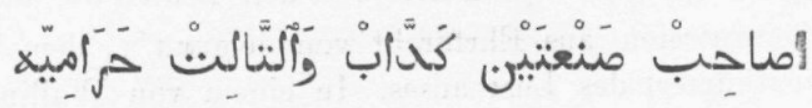

Wer zwei Gewerbe treibt ist ein Lügner, der dritte (= wer ein drittes G. hinzunimmt) ist ein Dieb (wörtl.: sind Diebe).

Dieses Sprw., welehes nichts weniger als مصلَّم (nach grammatischen Regeln verbessert) ist, wird niemals in seiner eigentlichen Bedeutung angewendet. Es gibt vielmehr in Mekkah unzählige Leute, welche drei und mehr Gewerbe sehr gescheidt nach den dortigen Bedürfnissen ausüben. Man sagt es zu oder von Einem, der viel mehr verspricht, als er voraussichtlich leisten kann, welchem aber die billigen Zusagen augenscheinlich nur dazu dienen, die Sache einstweilen zu verschieben. Je mehr Einer verspricht, um so weniger glauben wir ihm.

çāhib wird in der modernen Sprache fast nur in der Bedeutung: "Geselle, Bekannter" gebraucht; wo es sich darum handelt, 
ganz allgemein eine Beziehung auszudrücken, sagt man jetzt mehr: illi luh, illī a anduh und dgl., oder man ersetzt das altarab. çāhib durch abu , welches bekanntlich in der Umgangssprache viel häufiger in übertragenem Sinne gebraucht wird als in der Schriftsprache. Die Mekkaner bezeichnen aber ausserdem mit dem Worte $r \bar{a}^{c} \bar{I}$ sehr häufig gewisse Beziehungen einer Person zu einer Sache, wie die des Eigenthümers, des Verkäufers, des Verfertigers und dgl. z. B. rudd dI 'l-ḥabḥabah cand èr$\mathrm{ra}^{\mathrm{c}} \overline{\mathrm{i}}$ (mit oder ohne Hinzusetzung von: ḥaqqaha $\left.{ }^{1}\right)$ ) di zèjj è $\mathrm{d}-\mathrm{dubbah}=\gg$ gib diese Wassermelone dem (ihrem) Verkäufer »urück, die ist (so unschmackhaft) wie ein Kürbiss"; ruḥt ler $\bar{a}^{c} \bar{i}$ 'l-fānūs ${ }^{2}$ ) lissā mā çalláḥhā = »ich bin zum »Maune (Ausbesserer) der Laterne gegangen; er hat dieselbe noch »nicht ausgebessert". abū 'l-ğ ubbah èl-bédhā heisst: »der »Mann mit der weissen ğubbah, der dieselbe anhat"; $r \bar{a}^{c} \bar{i}$ 'l-ğubbah èl-bédhā = der Mann der weissen ğ ubbah, »bei dem sie gekauft, von dem sie entliehen wurde, der sie ge»näht oder ausgebessert hat". Aehnlich finde ich das Wort r $\bar{a}^{c} \bar{I}$ gebraucht von Quțb èd-din, in den Chroniken der Stadt Mekka, ed. Wüstenfeld III : pqv; dieser besuchte in Qairo ein vom Sultan

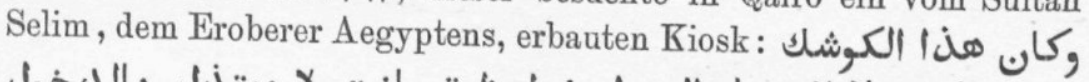

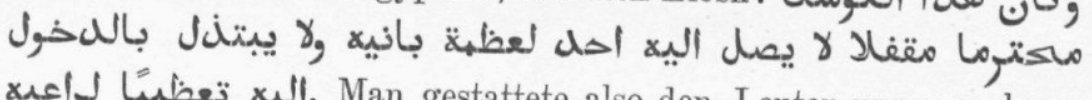
. Man gestattete also den Leuten nur ausnahmsweise hineinzutreten aus Ehrfurcht von dem $\mathbf{r a}^{\mathrm{c}}{ }^{\mathrm{I}} \mathrm{I}$, dem Erbauer (und Eigenthümer) des Lusthauses. In einem von Wallin mitgetheilten neuarabischen Gedichte liest man (ZDMG. VI: 207, Vers 21, vgl. die Uebersetzung S. 208): ja $\mathrm{r}^{\mathrm{a}}{ }^{\mathrm{c}} \mathrm{i}-\mathrm{ls} \mathrm{skh} \overline{\mathrm{a}} \mathrm{wa}-$ lgelālah=»du Mann der Freigebigkeit und Erhabenheit"; hier ist also ebenfalls

Elliptisch sagt man auch oftmals: ḥ aqq èl-ḥabha a, hạqq èl-n $\left.\mathrm{a}^{\mathrm{c}} \overline{\mathrm{a}} \mathrm{l}^{3}\right)=\gg \operatorname{der}($ Verkäufer) der Wassermelonen", »der (Ver-
käufer, Verfertiger oder Ausbesserer) der Sandalen", wo ha aq

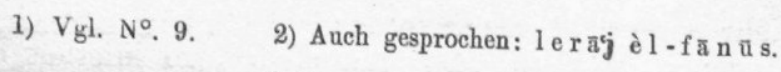

3) Sandalen heissen نَّعَ (collectiv; eine einzige Sandale: fard n acal, ein Paar:

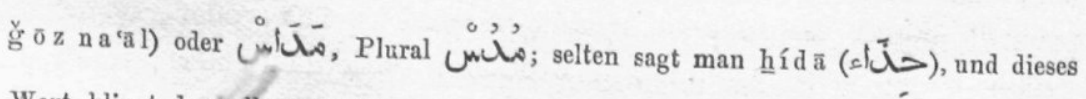
Wort klingt desshalb anständiger. 
eigentlich, wie beta $\bar{a}^{c}(m e t \bar{a})$ in andern Dialecten, ein Genitivverhältniss ausdrückt: ḥabasu haqqūn èl-ḥabhab kulla-

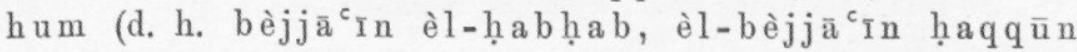
èl-ḥabḥab) = »man hat alle (Verkäufer) von Wassermelonen verhaftet".

\section{4.}

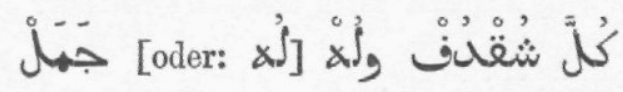

Jedes $̌$ uqduf hat sein (für dasselbe geeignetes) Kameel.

Das šuqduf findet man ziemlich genau beschrieben Burton, Pilgrimage, $3^{\mathrm{d}}$ ed. (London and Belfast, 1879), S. 163-4. Der allgemeine Name für die Saüften in welchen auf beiden Seiten eines Kameels eine Person Platz nehmen kann, ist maḥmil oder mihmal; in der Vulgärsprache sagt man mahmal, und gebraucht man dies Wort jetzt ausschliesslich von dem ägyptischen und dem syrischen mahmal, welche jährlich von Qaïro und Damaseus die Pilgerfahrt nach Mekkah machen.

Die syrischen Pilger reisen vielfach im hōdağ (plur. haw a diğ), die Aegypter im saḥlā oder saḥleh (plur. saḥālī), beides modificirte Formen des im Ḥi ğāz nur als Bettgestell gebräuchlichen serir, mit oder ohne eine als Sonnenschirm dienende Ueberdachung. Jedes $\mathrm{h} \bar{o} d a \mathrm{~g}$ und jedes saḥleh bilden also ein Ganzes; sie werden auf den Rücken der Kameele festgemacht und gewähren einer oder mehreren Personen Raum, wenn nur das Gleichgewicht erhalten bleibt. Das šuqduf besteht dagegen aus einem Paare (جَ) gleichförmiger Gestelle (فَرْنَ شُقْفُفْ), welche über dem Packsattel mittels Stricke mit einander verbunden werden. Burton übertreibt wenn er sagt, dieses Reisemittel werde hauptsächlich von Weibern, Kindern und weichlichen Männern gebraucht. Bei Weitem die meisten Städter im Hiğ̄àz und fast alle Fremde (Pilger u.s. w.) reisen im šuqduf, weil sie nur so ihr Gepäck bei sich behalten können. Geht Einer auf ein paar Tage von Ǧiddah nach Mekkah oder umgekehrt, so miethet er sich einen Esel, auf welchem er sich's wenigstens ebenso bequem machen kann als in dem schaukelnden šuqduf, oder, wenn er solche selber besitzt oder von Freunden entlehnen kann, reitet er auf einem Pferde (خصان; der Zelter heisst رَخْوران) oder einem 


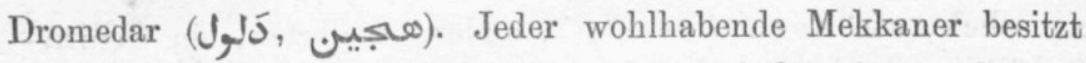
ein oder mehrere šaqādif; die andern miethen jedesmal eins, wenn sie auf Reisen gehen.

Das Sprichwort wird gebraucht, wenn von der Fähigkeit einer Person, eine bestimmte Aufgabe zu erfüllen, die Rede ist; z. B. challi nafsak fi bádā ’š-šughl lammā-tšūf tiçlụ̣ willā lā; in kān jeçir, ạ̣san mā jkūn - mā-jȩirr,

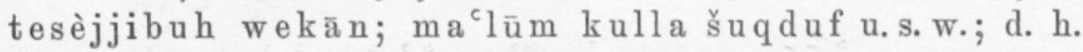
»Bleibe bei diesem Geschäft (dieser Arbeit), bis du gesehen hast, $\gg$ ob du dazu fähig bist (taugst) oder nicht; geht es - ausge»eichnet! geht es nicht, so gibst du es auf, und damit aus; na»türlich: jedes šuqduf u. s. w."

wekān (وكاب) wird hinter einem Satze angefügt und heisst: »damit aus", oder: »damit is alles gesagt". $k \bar{a} n$ wird für sich gebraucht als Antwort auf die Mittheilung mehr oder weniger bedauernswerther Sachen: »es ist nun einmal so! es lässt sich da nichts ändern!"

25.

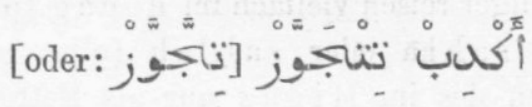

Lüge, so gelangst du zur Ehe.

Der Imperativ wird zwar in Mekkah auch nach den von Spitta, Grammatik S. 208-9 angegebenen Regeln gebildet, sehr gewöhnlich ist aber $a$ als Vorschlagsvokal ${ }^{1}$ ): askut, açbur, adhrab, a mši (aber häufiger: imši), ațbuch, asma $a^{c}$, a ğri (aber häufiger: iğri), aqțu (d. h. binde die Kameele der Karavane derart an einander, dass sie genöthigt sind, hinter einander zu gehen), a ç̧ ḥa (d. h. Achtung! gewöhnlicher Ruf der Packträger und Eselreiter auf dem Markte), a q ${ }^{c} u d$ (aber ebenfalls: u q $\left.{ }^{c} u d\right), a c h l u c ̧$ (mache fertig), aqdhi u. s. w. sind die gebräuchlichsten Formen.

Die V und VI Stämme des Verbums werden (vgl. Spitta, S. 197) durch Vorsatz von at (et; imperf. jit) oder ta (te) von den II und III gebildet; so immer: atfaddhal z. B. in der stehenden Formel der Einladung zu einer Mahlzeit in Mekkah: jesallim álēk sidí felān salām ketĩr, jeqūl bukrah

1) Vgl. No. 9 . 
DR. C. SNOUCK HURGRONJE, MEKKANISCHE SPRICHWÖRTER, 471

$b a^{c} d$ èd-dhuhr atfaddhal finğān qahwah d. h. »Mein »Herr (der Redende ist ein Sklave) N. N. lässt dich vielmals "grüssen und sagt: morgen Nachmittag sei so freundlich eine »Tasse Kaffee (trinken zu kommen)." Die Assimilation des $*$ in تحبّ وِّز

Der Sinn ist: wenn du dich verheirathen willst, so binde den Verwandten der von dir gewünschten Frau möglichst viel von deinem Reichthume, deiner hohen Stellung und ähnlichem auf, denn sonst gelingt es dir nicht. Wer eine Tochter oder Schwester verheirathen soll, will gewöhnlich ein wenig getäuscht werden.

26.

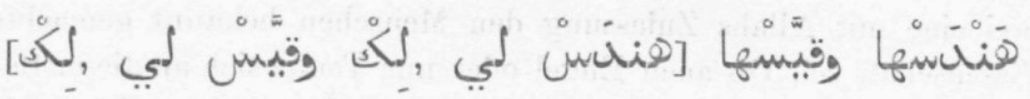

Er hat ihr (mir, dir) angemessen und das Maass qenommen!

Dies wird von einem Manne (gewöhnlich - wenn die Frau selbst redet, immer - zu seinem Lobe) gesagt, welcher alles aufbietet, um seiner Gattin oder Sklavin das Leben angenehm zu machen. Die muhammedanischen Weiber legen bekanntlich auf Nichts mehr Werth als auf den Schmuck ihrer Körper, und sie beurtheilen die Lièbe ihrer Gatten, resp. Herren, nach deren Liberalität in dieser Beziehung. NB. Wenn man in dieser Redensart von der Frau in dritter Person spricht, ist dieselbe immer grammatisch directes, in den beiden andern Fällen immer indirectes Object ${ }^{1}$ ).

Das allgemeine Wort für Kleider (in Aegypten pdo, in Syrien أواعي, vgl. Landberg, Proverbes et Dictons I: 4) ist im Ḥiğāz حوايجج, plur. von حاجَه nahezu in allen Fällen, wo die Schriftsprache شي شي li) ḥa ăg ah oder šughl (mit oder ohne"Hinzusetzung von buh vor ḥa ğah oder šughl)=»das geht ihn (dich, mich) nichts an". Von einer Sache gebraucht, heisst mā luh ḥāgah oder šughl auch: »das brauchen wir nicht, das nützt uns nicht"; etwas anders: $\mathrm{m} \bar{a} \mathrm{luh}$ lez $\mathrm{u} \mathrm{m}$ d. h. „das brauchen wir nicht, das können wir entbehren". Einestehende Formel im Briefwechsel zwischen

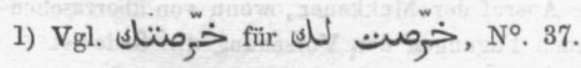


Giddah und Mekkah, welche fast immer dem Schluss-salām vorangeht, lautet folgendermaassen: وان كان حاجه خِ فِ عَّفونا d. h. sund wenn es (hier) irgendwelchen (euch zu erweisenden) „Dienst gibt, so meldet es uns."

\section{7.}

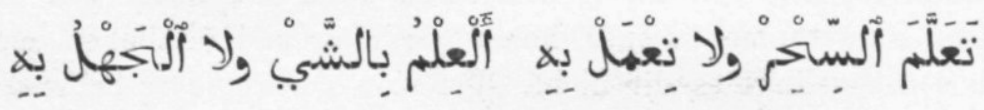

Lerne die Zauberkunst, ohne dieselbe anzuwenden; es ist besser, eine Sache zu verstehen, als mit derselben unbekannt zu sein.

Der Islām lehrt im Anschluss an Qorān II : 96 dass die Zauberei eine mit Allahs Zulassung den Menschen bekannt gemachte Wissenschaft sei. $\mathrm{Ob}$ auch Engel oder nur Teufel sich an dieser Belehrung des menschlichen Geschlechts betheiligt haben, ist zweifelhaft; dagegen steht fest, dass man die Zauberkunst nicht ohne die Hülfe Satans ausüben kann. Daher ist das ausüben des siḥ̣r (العهل بm Gesetze strengstens untersagt; das Erlernen dieser verbotenen Kunst nennen die doctores zwar erlaubt, aber sie erachten es für besser (أولى (آَ), sich nicht damit zu befassen. Die populäre Weisheit überschreitet hier also ein wenig die vom Gesetze gezogenen Grenzen. Es ist aber der Spruch natürlich nicht im eigentlichen Sinne, sondern als Hyperbel zu verstehen. Ungeachtet seiner etwas gelehrten, grammatischen Form wird derselbe von Mekkanern aller Stände hänfig gebraucht und zwar immer-mit der angegebenen Vocalisation; nur wird siḥr oft siḥir gespro-

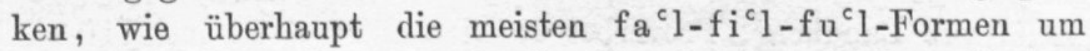
einen Vocal bereichert werden ${ }^{1}$ ). So oft ich in kleinen Kreisen intimer Bekannten in Mekkah die Resultate meiner photographischen Thätigkeit zeigte, wurden mir von irgend einer Seite diese Worte zugerufen. Als z. B. die wenig im Sehen flacher Bilder geübten Augen eines Mekkaners endlich deutlich die Züge des regierenden Grossscherifs auf dem Papier erkannt hatten, da hörte man etwa: ēwállāh, çạ̣ị̣, sèjjídanābe ${ }^{c} \bar{e} n u h$ bezātuh, allāh jețawwil cumruh; wallāhi ḥikam²), jā šēch!

1) Vgl. $N^{\circ} .64$.

2) Dies ist der immer wiederkehrende Ausruf der Mekkaner, wenn von überraschenden, neuen Erfindungen oder von seltsamen Fügungen der Vorsehung die Rede ist.

$(40)$ 
$\mathrm{ma}^{\mathrm{c}} \mathrm{lu} \mathrm{m}: \mathrm{ta}^{\mathrm{c} a l l a m}$ u. s. w. d. h.: \$ Wahrhaftig, ja richtig, das »ist unser Herr (der Grossscherif) selbst in eigener Person (Allah »verlängere sein Leben); bei Allah! (dies sind) Proben geheim»nissvoller Weisheit, o Schēch! ja wohl, es heisst nicht umsonst: „lerne die Zauberkunst u. s. w." Es ist vielleicht nicht überflüssig hinzuzufügen, dass von einer Vergleichung der Photographie mit der Zauberei als einer verbotenen Kunst dabei nicht im Geringsten die Rede war, denn die so sprachen, waren in der Beziehung alle völlig vorurtheilsfrei. Eine Kunst, welche für Mekkah höhere praktische Bedeutung hat als die Photographie, ist das Winden der Turbane ('amāim). Die verschiedenen Nationalitäten und Stände unterscheiden sich von einander durch einzelne Eigenthümlichkeiten in der Windung (laff); innerhalb dieser Gruppen hat aber wieder jedes Individuum seine eigene, dem Anscheine nach mit seinem Aeusseren und mit seinem ganzen Wesen eng zusammenhängende Form der ${ }^{c} \mathrm{im} \overline{\mathrm{a}} \mathrm{mah}$. Letzteres lässt sich vergleichen mit dem Zeugniss, das in Europa die Art, den Hut zu tragen, vom Charakter des Trägers ablegt. Die Weise, wie die vorzüglichsten in Mekkah vorhandenen Standesunterschiede in der Windung der Turbane Ausdruck gefunden haben, kann mann jetzt im leidener ethnographischen Museum studiren, welches der Güte des Herrn P. N. van der Chijs, unseres Vice-consuls in Ğiddah, eine schöne Sammlung fertig gewundener mekkanischer Turbane verdankt. Es ist aber nicht Jedermanns Sache, der ${ }^{\mathrm{c}} \mathrm{i} m \mathrm{a} \mathrm{m}$ ah die verlangte Form zu geben; verhältnissmässig wenige Mekkaner besitzen die erforderte Geschicklichkeit, in dieser Beziehung ihren eigenen Geschmack einigermassen zu befriedigen. Es gibt also für diese Arbeit Specialitäten, von denen jede Fanilie durchschnittlich nur eine besitzt. Wer sich einer gewissen Fertigkeit in dieser Kunst erfreut, läuft Gefahr, jeden Freitagabend (d. h. nach europäischer Rechnung: Donnerstagabend) eine Unzahl von k ūfrjeh's s') und šāš-tüchern von seinen Nachbarn und Freunden ins Haus geschickt zu bekommen mit der Bitte, jedem von ihnen seine 'im āmah zu winden, wie er sie gewöhnlich trägt. Ein Gelehrter,

1) Das Kopftuch, welches Dozy, Supplément i. v. كوفيّة beschreibt, heisst im Hi-

ğa z صماده = çemadeh oder çumādeh und wird mit dem عَقَال auf den Kopf befestigt. Die k afijje h ist dagegen die cylinderförmige, aus indischem Rohr geflochtene, mit vielfarbiger Seide oder Kattun durchstickte Mütze, um welche die ci mă$\mathrm{m}$ a h herumgewunden wird: 
den ich einmal in einer Mussestunde mit Uebungen in der Windungskunst beschäftigt fand, antwortete auf meine Frage, wozu er sich auf solche Sachen einlasse, mit unserem Sprichworte.

28.

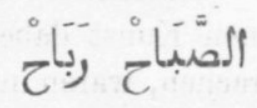

\section{Die Morgenzeit ist Gewinn.}

Die meisten wohlhabenden Mekkaner besitzen Uhren; somit ist die Eintheilung des Tages in Stunden (Sonnenuntergang $=12$ Uhr) allgemein bekannt. Dieselbe hat aber wenig praktische Bedeutung; wo man die Zeit eines Besuches, einer Zusammenkunft u. s. w. bestimmt, rechnet man nach wie vor nach den aw qāt èç-çalawāt, deren Anfang durch den aḍa ān bekannt wird. fi ${ }^{’}$ $\mathrm{d}-\mathrm{d} \mathrm{h}$ uhr kann ebensowohl heissen: innerhalb der Zeit des Mittagsgottesdienstes" (also zwischen 12 und $3 \mathrm{Uhr}$ ungefähr) als >zur Zeit des Mittag-a ḍanns"; will man die erstere, allgemeine Bestimmung unzweideutig ausdrücken, so sagt man: $b a^{c} d$ eddhuhr oder fijd-dhuhrijeh. Aehnlich ist es mit allen aw qāt, nur dass man von 'išā keine Nisbah-bildung macht. Die Zeit des 'íša dauert bekanntlich bis weit in die Nacht; sind $2-3$ Stunden nach dem aḍān verflossen, so spricht man aber nur von lēleh. Die "Nacht" zerfällt in Unterabtheilungen, deren Grenzen das nuçç èl-lēleh und das tarḥım (die mehr als eine Stunde vor dem Morgen-a ḍān von den menāreh's ausgerufene Formel) bilden; man sagt: ich bin aufgewacht, ausgegangen u. s. w. qabl, fi, bacd nuçç èl-lēleh, resp. èt-tarḥım. Eine weitere Zeitbestimmung machen die Mekkaner nach den Concerten(!), welche die Musikanten des Grossscherifs täglich zweimal vor dessen Palaste geben; von Alters her ist das Recht, die "Bande" (nōbah) vor seiner Thüre spielen zu lassen, als die Prärogative der regierenden Fürsten angesehen worden $\left.{ }^{1}\right)$. Die nōbah's (so nennt der Mekkaner auch die Concerte) finden täglich statt: $1^{0}$ eine Stunde vor dem $\mathrm{maghrib}, 2^{0}$ eine Stunde nach dem iša $^{2}$, und sie dauern jedesmal eine halbe Stunde. Die

1) Vergl. die Bedentung der طبلخحانات in Aegypten unter der Tscherkessendynastie, Chroniken/d. St. Mekka, ed. Wüstenfeld, III: In . 


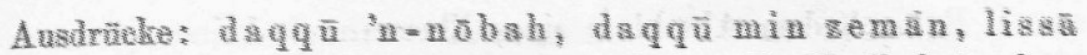

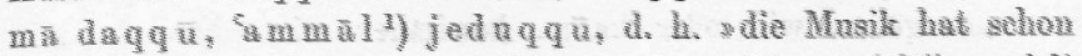
gespielt", shat linggst gespielt", snoeh nicht grespielt", wspielt eben", geben also Nachmittags und Abends die Zeit an. Das

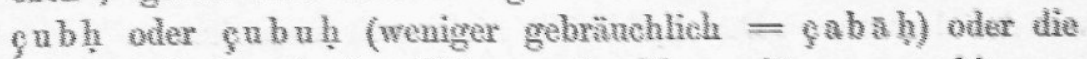
gub hrjeh dauert eigentlich von der Morgendummernng bis zum Mittag: die Zeit von ungefahr eine Stunde nach Sonnenaulgang bis gegen Mittag wird aber noeh als $d \mathrm{~h}$ a ba ( Der weitere Umfang des Begriffes des c ub hedgt sich darin, dass die stehende Grussformel (nach dem $s a l a m$ ) bis Mittag lauteb: kef a pa htum? = wie befindet ihr ench heute Morgen ?" und die Antwort: sallah jecabbihkum (gabbák kum allah) bil-chēr (oder: bil-chêr wèl-çfjeh oder bil-ehēr wèlkerāmeh") d. h. "Allah gewähre euch heute Morgen Gutes" (oder: "Gutes und Heil" oder "Gutes und Gnade"). Nachmittags wird in diesen Formeln açbahtum, ję̧abbihkum ( durch amsetum, jemassikum (massákum) ersetzt.

Ziemlich allgemein ist unter den Muslimen der Volksglaube verbreitet, der Morgen sei eine schwere", wichtige Zeit. Sachen, auf welche man sonst nicht achtet, gelten Morgens als ominös; hat der Händler Morgens nichts verkauft, so verzweifelt er an seinem Glück während des ganzen Tages, und Mancher verkauft im Morgen etwas zu bedeutend ermässigtem Preise, damit er nur nicht leer ausgehe, zum Fröffnen der Thüre (lefath èl-bāb); böse und gute Handlungen zäblen Morgens doppelt. Daher treibt man oft die Lente an, ein Geschäft oder eine Arbeit noch während des çabāh zu vollenden, damit ihnen dieser Segen nicht entgehe; oder aber man schlägt am Abend oder in der Nacht vor, eine Sache bis frühmorgens aufzuschieben, weil die Zeit günstiger ist. In beiden Fällen gründet man sich auf unser Sprichwort.

29.

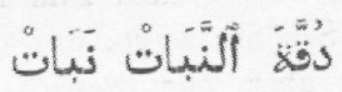

Kandispulver ist auch Kandis.

Der Kandiszucker ist bei den Mekkaniern ausserordentlich beliebt;

1) Jü vgl Dozy, Supplément, i. v. 
476 DR. C. SNOUCK HURGRONJE, MEKKANISCHE SPRICHWÖRTER.

wer z. B. nach dem Abschluss eines Ehecontracts keinen grossen Schmaus geben will oder kann, bewirthet seine Freunde mit Kaffee und nabāt.

Das Sprichwort wird genau in derselben Bedeutung gebraucht wie das deutsche: „Der Apfel fällt nicht weit vom Stamm."

30.

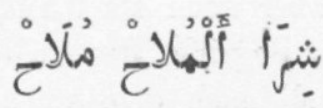

Der Kauf (= das Gekaufte) von schönen Leuten sind schöne (Sachen).

Die Vokale $u$ und $i$ wechseln im mekkanischen wie in andern vulgärarabischen Dialecten; in Pluralen von der Form فِ ist das $i$ fast regelmässig zu $u$ geworden (ğ umāl, țuwāl, quẹār u. s. w. vgl. ḥuğàr plur. von ḥağar, No. 40), und überhaupt ist $u$ mehr beliebt als $i$. Das gewöhnliche Wort für »schön" ist melị̣ $\left.{ }^{1}\right)$; ğemil klingt etwas vornehm, und hasan wird nur im Comparativ (resp. Superlativ) gebraucht in der Bedeutung s besser, nützlicher". Mit dem Accente auf der Paenultima (mèlīḥ) heisst das Wort: »schön!", »nun gut!", »wohlan!", » weiter!" und dgl., und wird es nach Belieben im Anfang oder zu Ende eines Satzes angebracht, z. B. mèlị̣ ès qual lak $=» N u n$ gut (weiter), was hat er dir gesagt?"; mèlị ẹ ěs nesawwi oder nesawwi ěs mèlı̣ $=$ »Schön, was sollten wir (anders) machen? (als wie wir es gemacht haben)"; mèlịh harríğnì oder harríğnI mèlīḥ zèjj èn-nās $=\gg N u n$ aber rede zu mir, wie es sich geziemt (wie die Menschen)", gesagt zu Einem der z. B. durch Geberden zu erkennen gibt, was er wünscht. Für den Accent von Worten wie šírā (شر) beachte man, was Spitta, Grammatik, S. 94 bemerkt; sehr viel von; dem daselbst, S. 60 Gesagten, gilt auch vom Accente in dem mekkanischen Dialecte.

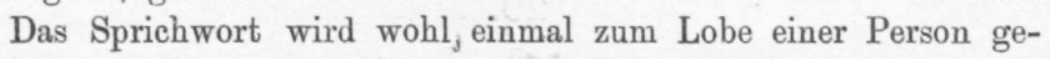
braucht, welche etwas Schönes zeigt, das sie ${ }_{3}$ selber gekauft hat; meistens sagt man es aber nur ironisch und "also tadelnd zu Dienern und Kindern, welche im Auftrage ihrer Herren oder Eltern etwas gekauft haben, das unbrauchbar oder viel zu theuer ist.

Die letzten Worte spricht man auch: èl-mulāḥ umlāḥ.

1) Ueber hil $\mathrm{u}$ und $\mathrm{kew}$ ajjis vgl. $\mathrm{N}^{\circ} .48$. 


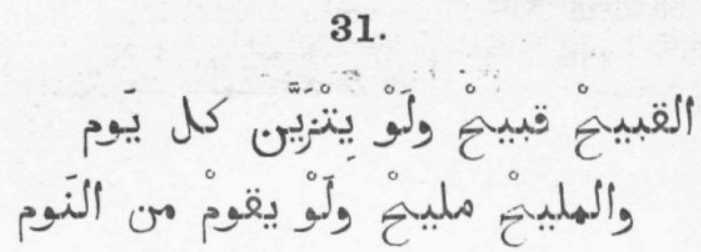

Der Hässliche ist hässlich, wenngleich er jeden Tag seine Toilette macht - der Schöne ist schön, wenngleich er eben vom Schlafe aufwacht.

Ueber den Accent und die Bedeutungen des Wortes melíḥ (mèlīḥ) vgl. No. 30. a tzèjjèn (أتزيّن) heisst zwar überhaupt: »sich schmücken", aber gewöhnlich »sich rasiren und die überflüssigen Haare und Nägel (von Händen und Füssen) abschneiden lassen". Der Barbier übernimmt alle diese Verrichtungen und heisst daher mezèjjin; bekanntlich ist er ausserdem vielfach Wundarzt, und versteht er sich wenigstens auf Aderlassen und Schröpfköpfesetzen.

Die Frau, welche die sehr weitläufige Toilette der Braut (عَروسَّ) besorgt, heisst wohl einmal mezèjjin a ${ }^{1}$ ), wird aber viel häufiger meqèjjinah ${ }^{1}$ ) (مقَيَّenant.

nãm, jeñam heisst schlafen, aber auch »liegen" (von Menschen und Thieren); so sagt der Arzt zu Einem, an dem er eine Operation verrichten soll: $\mathrm{n} \overline{\mathrm{a}} \mathrm{m}$ fi-l-ardh $=$ »lege dich auf den Boden"; daher der IIe Stamm nawwam oder nèjjèm z. B. $\mathrm{n}$ è j jèm $\mathrm{uh}=$ »er hat ihn auf den Boden gelegt, ausgestreckt". Das übliche Wort für »schlafen" ist raqad; eine sehr gewöhnliche Antwort von einem mekkanischen Sklaven, den man fragt, ob sein Herr zu Hause ist, lautet: rāqid = »er schläft". Jeder Mekkāwi kennt irgend eine Version der heiligen Ueberlieferung, الرواقل فيعا كالعابل في غيرها : الريا d. h. »Wer in Mekkah schläft steht (an Verdienst) dem gleich, »der anderswo religiöse Uebungen hält". Solche Traditionen finden thätigen Glauben !

Das Sprichwort wird vorzüglich gebraucht, wenn eine hässliche Person ihre Mängel unter einer prachtvollen Toilette zu verhüllen sich bestrebt, dadurch aber gerade in doppeltem Maasse die allgemeine Aufmerksamheit auf ihre Hässlichkeit lenkt.

1) Anch mèzèj'na h, me q èj’n a h vgl. $N^{\circ} .32$. 
32.

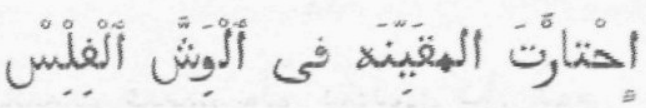

Die Kammerjungfer (Putzerin) geräth in Verlegenheit beim grässlichen Gesichte.

حار VIII = V vgl. Dozy, Supplément, i. v. Die meqèjjinah (auch: meq èj'nah) ist die Frau, welche die Toiletle einer jungen Dame, vorzïglich einer Braut, herstellt; vgl. $N^{0} .31$.

Neben den Formen wašs, wišš kommt (vgl. N ${ }^{0} .58$ ) auch wèğh vor. fils, welches man auch fílis spricht (vgl. No. 64) heisst eigentlich "Arseh" (Landberg, Proverbes et Dictons I, Glossaire i. v.) und wird als Apposition gebraucht, um den höchsten Grad des qabrh, des Hässlichen zu bezeichnen.

Man gebraucht diese Redensart von Einem, welchem Erziehung, Ermahnungen, guter Rath und Bestrafung nichts nützen, illr $\mathrm{m} \bar{a}$ jis $\mathrm{ma}^{\mathrm{c}} \mathrm{kalā} \mathrm{m}$ èbèdèn. Ein Sohn, der seinen Vater einen untauglichen Sklaven immer wieder ermahnen hört, sagt etwa: sèjjibuh èl-walad èl-mal cun dā challīnenazziluh èd-dèkkeh ') aḥsan; iḥtār't èl-meqèjjinah etc. $=$ lass ihn gehen, diesen verfluchten Kerl, wir wollen ihn auf »den Sklavenmarkt bringen (verkaufen), das ist besser; »die » Kammerjungfer u. s. w." "

33.

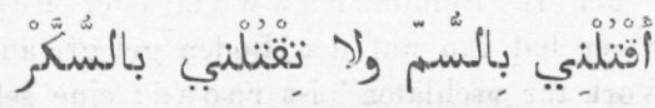

Tödte mich lieber mit Gift als mit Zucker.

Ueber die Beliebtheit des $a$ als Vorschlagsvocal im Imperativ vgl. $\mathrm{N}^{\circ} .9$ und $\mathrm{N}^{0} .25$.

Der Mörder hat diesen Rath im entgegengesetzten Sinne aufzufassen und anzuwenden. Tödte mich mit Gift, so bittet ihn sein Gegner, denn das kann ich zur Noth ortragen, der Wirkung des Zuckers bin ich aber nicht gewachsen; wenn du also deinen Zweek erreichen willst, so wende das süsse Mittel an. Einer gelinden Behandlung vermag ich keinen Widerstand zu leisten; der Rohheit und Grobheit dagegen gebe ich nicht nach. Ein Bekannter

1) Ueber dè k keh (auch dik keh) vgl. $N^{\circ} 75$. 
eines Kaufmannes kann z. B. eine Sache nicht sogleich unter den von ihm gewünschten Bedingungen erlangen; er wird zornig darüber, und sie gehen in übler Stimmung aus einander. Später erfährt der Kauflustige, dass ein Andrer das von ihm Verlangte um einen geringeren Preis von demselben Kaufmanne erhalten hat. Er macht diesem desswegen Vorwürfe; der Kaufmann aber erwidert ihm: wallāhi añā maghlūb, jā šēch; kān māu be é wešírā ${ }^{1}$ ) hádā lākin kalāmak fën wekalāmuh fēn; $\mathrm{ma}^{c} l \bar{u} \mathrm{~m}$ aqtulni etc. $=$ »Bei Allah, ich bin (in der Sache) »unterlegen, o Schēch, das war kein rechtes Geschäft mehr (ich »habe nichts dabei verdient); aber seine (des Käufers) Rede war » mit der deinigen gar nicht zu vergleichen; natürlich: »tödte » mich lieber u. s. w." "

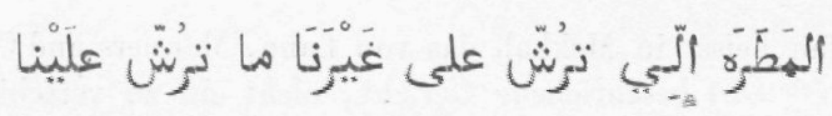

Der Regen, welcher Andere benetzt, benetzt uns nicht.

Ueber die Beliebtheit der Endung $\gamma_{z}=$, auch wo kein nomen unitatis gemeint ist, vgl. $\mathrm{N}^{0} .11$; hier könnte man dieselbe zur Noth als nomen unitatis interpretiren, weil ein Regen, ein Regenguss ${ }^{2}$ ) gemeint ist. (ش) sbespritzen, begiessen" wird oftmals mit doppeltem Aceusativ construiert: ruššu èd-dihliz mojo $=$ segiesst die Vorhalle mit Wasser". Für ssicb mit Wasser begiessen,

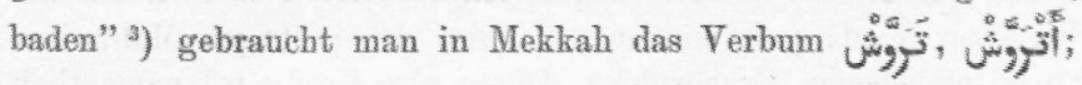

1) slu, يu ist der gewöbnliche Ausdruck für "Handel", "das Abschliessen eines Geschâfts". Wenn einer sich weitlänfig nach dem Preise einer Sache erkundigt, sagt

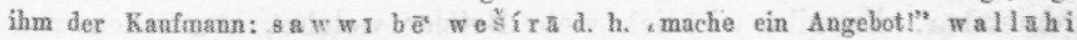

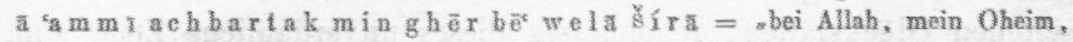
ich habe dir (den Preis) mitgetheilt ohne Kauf und Verkauf" d. h. ans Freundschaft verlange ich nar von dir, was es mich selbst gekostet hat.

2) Es ist nicht unwahrecheinlich, dass mit matarah in Sprichworte ursprünglich "Schlanch" gemeint wurde, vgl. Dozy, Supplément i. v. und Fraenkel, Aramüische Fremdwörter (Leiden, 1886), S. 209. Das Wort ist aber in dieser Bedentung in Mekkah unbekannt, folglich denkt man dabei nur an .Regen".

3) Die gewöhnliche Weise zu baden besteht bekanntlich in Arabien darin, dass man ans einem Wassergefässe ( $(j ;)$ mit einer (gewöbnlich blechernen) Wasserschanfel Wasser sehöpft und dasselbe jedesmal über den nackten Körper ansgiesst. Alles dies geschieht im unten $\left(N^{\circ} 65\right)$ beschriebenen b ēt è $1-\mathrm{m} a \overline{\text { }}$. 
in der Umgangssprache hat dieses Wort die Wörter ghusl, ightisāl u.s. w. auch für das rituelle Bad völlig verdrängt.

Wenn einem Hause etwas Gutes (ein Geschenk, ein ausserordentlicher Gewinn oder dgl.) zu Theil wird, so herrscht in der muslimischen Welt die fast zum Gesetze gewordene Sitte, dass man seinen Freunden, vorzüglich seinen Nachbarn etwas davon mittheilt. Behält Einer in diesen und ähnlichen Fällen alles für sich, so zucken die Nachbarn die Achseln und citiren unter einander unser Sprichwort.

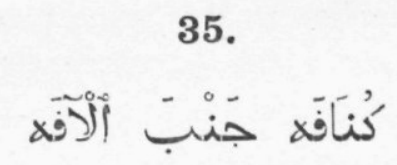

Kunāfah neben der Viper.

Kunāfah heisst in Mekkah das von Lane, Manners and Customs I : 185 (5th ed.) beschriebene Gericht, nicht ein zu verschiedenen Backwerken verwandter Teig (Landberg, p. $123{ }^{1}$ )); man isst dies während des ganzen Jahres, vorzüglich aber als Dessert beim fațū $\mathbf{r}$ im Monate Ramadhān. Die mekkanischen Weiber frühstücken immer gern mit Kunāfah. Wir wollen hier in Kürze die gebräuchlichsten Speisen der Mekkaner aufzählen. Die allerärmsten Einwohner Ǧiddah's und Mekkah's gehen von frühmorgens so lange bettelnd herum, bis ihre blechernen Töpfe mit altem Brode gefüllt sind. Die Brotverkäufer geben ihnen die nicht verkauften Brode (اقر,اص) des vorigen Tages, Andere, sofern sie nicht frisches Brot zur çadaqah kaufen, die von den gestrigen Mahlzeiten übrig gebliebenen Bruchstücke. Dieses alte Brot wird namentlich in der heisstrocknen Luft Mekkahs in einer Nacht steinhart; es wird nur mittels weitläufiger Einweichung in Wasser einigermässen geniessbar. Es gibt wirklich viele Bettler welche, abgesehen von seltenen Glücksfällen, regelmässig dieses unverdauliche Zeug zum Frühstück, zu Mittag und zu Abend essen. Man sieht täglich die nämlichen Leute mit hungrigen Gesichtern ihren Gang durch die heilige Stadt antreten, und die Gierigkeit, mit welcher sie das Ungeniessbare wie Leckerbissen verschlingen, ist der beste Zeuge für

1) Das von Landberg a. a. O. erwähnte شعريّي bedentet in Mekkah immer die Vermicelli selbst, niemals die "passoire". 
ihre ungeheuchelte Armuth. Unvergesslich ist es mir, wie ich während mehrerer Wochen zwei in Fetzen gehüllte', unverschleierte Weiber (Mutter und Tochter) jeden Morgen stundenlang niedergehockt neben einander sitzen sah an der Ecke der Steingasse

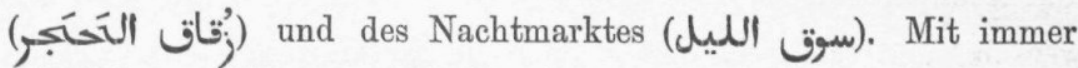
schwächerer Stimme rief die Alte ununterbrochen: »Ich bitte »Allah, die Güte Allahs um einen Bissen Brod; es ist nicht »viel für Dich, o Herr!" (ațlub min alláh, min chēr alláh luqmèt 'ēś, māu ketir 'alēk jā rabb!). Obgleich die beiden Unglücklichen einer Brodbude gegenüber zu sitzen pflegten, dauerte es öfters zwei Stunden, bis die ersten luqam in ihren Topf hereinfielen. Viel besser als die Bettler (مَكَّاتينْن (مَلَّاحينْ sind schon solche bestellt, welche jeden Tag Brod und Salz, oder Brod und »Pulver” (כَّ) zum Frühstück essen. Die symbolische Bedeutung von Brod und Salz, auch ausserhalb Arabiens, ist bekannt genug; bēnanā 'éš wemíliḥ ') bezeichnet in Mekkah ein Verhältniss, wobei Trug und Falschheit ausgeschlossen sein sollen, thatsächlich aber nur gewisse Formen der Betrügerei als besonders schändlich angesehen werden. Das einfachste duqqah besteht aus Pfeffer und Salz; gewöhnlich kommen andere Gewürze hinzu; alles wird zusammen feingestossen, und jeder taucht seinen Bissen in das Pulver ein. Ein besonders geschätztes duqqah wird von den Mekkanern aus Medinah mitgebracht, wenn sie zum Grabe Muhammeds gepilgert sind; dasselbe ist grün und hat einen pikanten Geschmack. Die Pilger aus Mekkah gehen gewöhnlich im Rèğèb auf die Reise und bringen für alle ihre Freunde einige Datteln, etwas medinensisches duqqah und vielfach auch ein paar aus Palmenblättern geflochtene Fächer heim. Die Ǧiddāw̄̄s und Mekkāwĩ's, welche sich mit anstrengender Arbeit zu beschäftigen haben: die Packträger (حَسَّالين), Bauleute

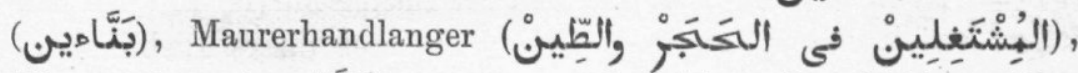
Wasserträger (سَفَّاصئى) u. s. w., auch solche, die viel hin und her

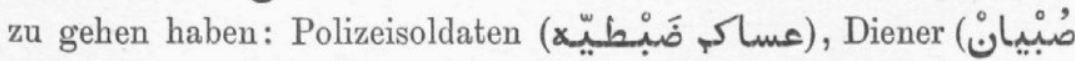
plur. von çábi) von Kaufleuten und dgl. nehmen als Frühstück

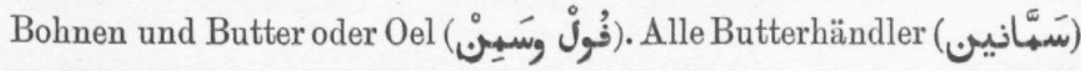

1) Wörtlich: "zwischen uns ist Brot und Salz"; im jetzigen Sprachgebrauche aber; "wir haben schon zusammen zu Tisch gesessen."

5e Volgr. I. 
verkaufen frühmorgens in Wasser gekochte Bohnen; mit einem hölzernen Löffel nehmen sie aus dem grossen Kessel (تِِِ) soviele Portionen heraus, als ihnen $\mathrm{chamsah}$ s oder ${ }^{c}$ a šarah's (Fünfund Zehnparastücke, resp. ungefähr $=2$ und 4 Pfennige) gereicht werden, und schütteln dieselben in die dargereichte Schale (زبْديّ) aus. Dieser Unterlage wird je nach dem Wohlstande der Käufér

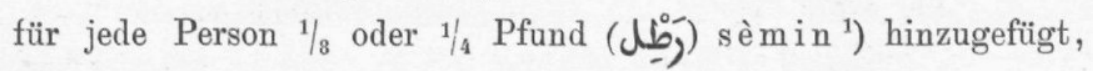
und als Zugabe etwas Salz und grobgestossener Pfeffer daraufgestreut. Leute von besonders feinem Geschmack neutralisiren das Fett ein wenig, indem sie den Saft einer Limone darin auspressen. Die zibdijeh wird in der Mitte der Anwesenden auf das Tischtuch hingestellt; öfters steht aber auf diesem Tischtuch (سُفْرِ) ein hölzerner, vier- oder mehreckiger kursi, welcher dann mit oder ohne Vermittelung eines grossen metallenen Tellers (țibsi) die Schale trägt. Jeder Essende hat ein Brod vor sich und zwar gewöhnlich 'ēš bèlèdi, welches viele Frauen oder Sklavinnen zu Hause bereiten um es in irgend einem Ofen (فُ ) نُن) backen zu lassen; man kann es aber auch auf dem Markte zu festen Preisen haben. Dem 'êěs bèlèdi steht das hauptsächlich für die türkischen Soldaten aus ungebeuteltem Mehle gebackene ${ }^{c} \bar{e} \mathrm{~s}$ sāmūli oder einfach : sāmūli (استهبولي = سامولي) gegenüber: letzteres hat die Form unserer runden Brode, ersteres wird in platten, runden Scheiben gebacken. Wenn dieses hie und da mit einer Kruste bedeckt is, nennt man es m eq a mmar (مقتَّ); so hat man es gern. Jeder Bissen wird in das sèmin eingetaucht und ein paar Bohnen werden dabei mitgenommen. Die meisten vornehmeren Mekkaner, welche verschiedene Gerichte (أشْكَالْ) frühstücken, verschmähen jedoch auch das fūl we sèmin nicht und geniessen es wohl jeden zweiten Tag. Zur Zeit der Dattelreife (im Juli und den folgenden Monaten) ersetzen viele Mekkaner dieses Lieblingsgericht durch einige ráțil Datteln; die Söhne Ḥadhramōt's verzehren unglaubliche Quantitäten $r u t a^{2}{ }^{2}$ ). Frische Datteln ,werden als nahrhaft geschätzt, aber als Speise von »heisser" Natur von vielen Mekkanern gefürchtet, umsomehr, da die Dattelreife grade

1) Die Butter ist natürlich immer flüssig wie Wasser.

2) Eine frische Dattel heisst $\mathbf{r} \mathbf{u} \underline{\mathrm{t}} \mathrm{b}$ a h. 
in die heisse Jahreszeit fällt. Solche neutralisiren die »Hitze" der

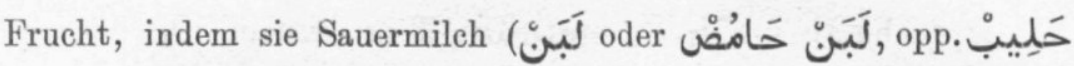
oder süsse Milch) hinzunehmen oder die Datteln jedesmal" eintauchen. Neben dem $f \bar{u} l$ wesèmin oder anstatt desselben werden aber verschiedene andere Sachen zum Frühstück (فَ فَطور) oder, wenn nicht vom Ramadhān die Rede ist, häufiger: فكوكَ آلرّيقت = das Eröffnen des Speichels) genommen.

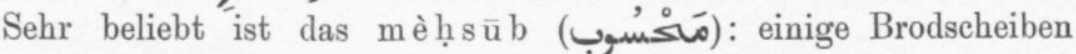
werden dazu in ganz kleine Stückchen zerhackt und in einem hölzernen Napfe mit viel heisser Butter und Honig durcheinander gestampft. Dieses sehr »heisse" ') Gemengsel wird mit hölzernen Löffeln gegessen; wie das vorhergehende wird dasselbe vom Butterverkäufer zubereitet, und von manchen Leuten in dessen Bude gegessen. Drei weitere Gerichte besorgt eine andere Spezialität. Die ersten zwei: luqēmāt (لقيبات, eig. »Bisschen”) und lanqáṭah (لَنْعَاطع; es wird mitunter لنكاطع geschrieben, ich habe es aber immer mit 3 aussprechen gehört; eine Pluralform scheint es nicht zu geben) sind nur der Form nach verschieden. Sie schmecken ungefähr wie die auf den holländischen Kirmessen gebräuchlichen Oelkuchen, nur ist der Teig ungemein zähe und wird ungeheuer viel sèmin dazu gebraucht. Die luq ēmāt sind kleine kugelförmige Kuchen, die lanqáțah sind grösser, platt und haben gewöhnlich ein Loch in der Mitte. Wer sich eine Schüssel (صَكْنْ mit diesen Kuchen füllen lässt, kauft immer ein Glas oder eine

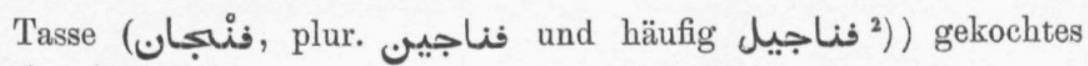
Zuckerwasser (شَيَرك) hinzu; darin taucht man beim Essen die einzelnen Kuchen ein.

1) Nicht nur die arab. Mediziner, sondern auch die Laien legen der "heissen" oder "kalten" und der "feuchten” oder "trocknen" Natur der Speisen hohe Bedeutung bei. Jedermann hat eine seiner Constitution angemessene Diät $(\stackrel{-0}{(x+0)})$; dieser enthält sich der Speisen und Getränke, welche حآر يبابس sind, jener darí das بارن يابس oler das بارن رَّب nicht geniessen, u.s.w.

2) Die Verwechselung des $J$ und $ن$ kommt auch im entgegengesetzten Sinne vor,

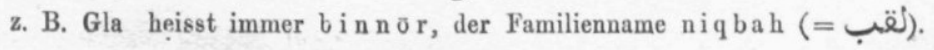


Feiner als diese Oelkuchen ist ein anderes Backwerk, welches man mețabbaq (مطبَّقى) nennt. Der Teig wird in sehr dünnen viereckigen Lagen auf einander gehäuft und zwischen die einzelnen Lagen viel Butter gegossen. Man bestellt sich die Füllung nach Belieben; gewöhnlich werden Eier oder (weicher) Käse mit Zucker gewählt. Diese Füllung wird in die Mitte des Vierecks gelegt, sodann die vier Ecken aufgenommen und auf den Mittelpunkt zusammengebracht, sodass die Füllung ganz vom Teige eingeschlossen ist. Das Ganze backt man, ohne dabei den sèm in zu schonen, im Ofen. Das mețabbaq gibt als vorzüglich, sodass man zum Lobe eines Ehemannes sagt: jefațțírhā kull jōm cala mețabbaq (das Suffix $h \bar{a}=$ maratuh) $=$ »er gibt ihr »(seiner Frau) täglich mețabbaq zum Frühstück." Der Verkäufer

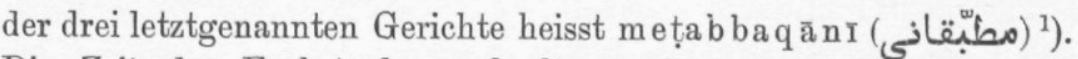
Die Zeit des Frühstücks wechselt von Sonnenaufgang bis gegen Mittag; es gibt Mekkaner, welche öfters bis zum Mittage nichts essen. Andere, welche nicht so lange mit leeren Magen (على الريق) aushalten können, nehmen wohl frühmorgens eine Kleinigkeit zu

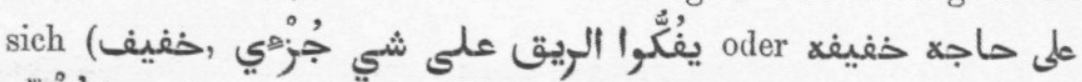

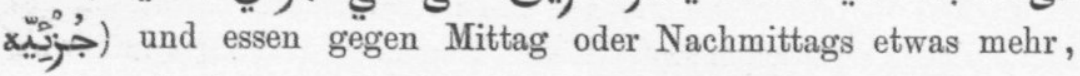
welches sie dann, weil sie »den Speichel schon eröffnet haben",

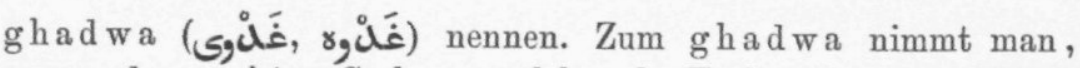
ausser den meisten Sachen, welche als Frühstück dienen, auch solche Speisen, welche erst gegen Mittag auf den Markte zubereitet und verkauft werden, z. B. Schafskopf (رَاسَ مَنْبِى) mit ungekochtem Meerrettig (فِيْلِ) oder Gurken (خِيَّار); - in kleine Stückchen zerschnittenes geröstetes Schafsfleisch ohne Knochen $(\tilde{\omega})$ mit Brod; - mit Fleisch ausgefüllte dreieckige Pas-

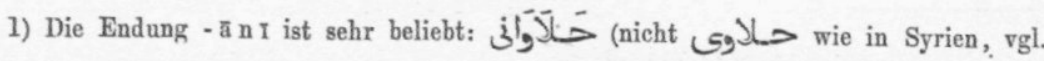

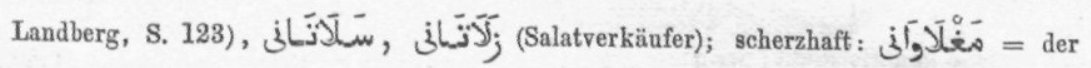

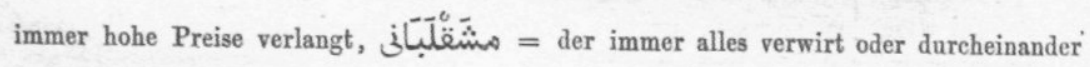

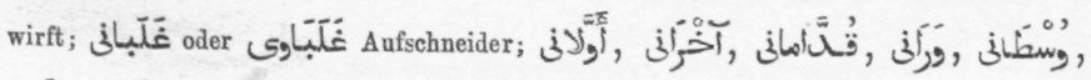

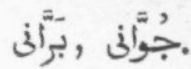


tetchen (سَنْبُوسَكَكْ) ; - kleine, runde Fleischpastetchen mit gehacktem kurrāt (كُرَّانَ, Porree), welche man in eine Essigsauce eintaucht und wozu man rohes kurrāt isst; diese Pastetchen heissen maqlijeh (مَقْليّيّ) ; manchmal gehen am Vormittag Leute umher, welche maqlijeh mit Zubehör verkaufen '). Die meisteu dieser als ghadwa gebrauchten Speisen werden auch manchmal als Leckerbissen zwischen den regelmässigen Mahlzeiten genossen. Zum gleichen Zwecke dienen auch die vielen » Süssigkeiten" (حَ) ḥalāwah țeḥinijeh, ḥ. simsimijeh, ha. sukkarrjeh, hạ. lōzijeh, u.s. w. geröstete und auf andere Weise zubereitete Erbsen $\left.(\text { h u m m uȩ })^{2}\right)$ und ähnliches.

Für die Hauptmahlzeit (عَشَ) gibt es keine allgemein angenommene Zeit; diese hängt gänzlich von den Beschäftigungen des Hauptes der Familie und von der Zeit ab, wo man frühstückt. Solche, welche ihre Tage regelmässig in gleicher Weise eintheilen können, nehmen das ćš à täglich entweder nach dem dhuhr, oder nach dem 'caçr (gewöhnlich ${ }^{c}$ açur gesprochen) oder nach dem maghrib; andere essen (يتْعَشُّوا) bald zu dieser, bald zu jener Zeit. Das Hauptgericht der Hauptmahlzeit is gewöhnlich Reis; die Abwechslung liegt in der Zubereitung und in der Zukost. Die ärmeren Mekkaner essen ihren Reis mit Salz oder mit sauren Gurken, Rüben und anderen Früchten, welche man theilweise mit einem dem Türkischen entnommenden Namen țurše und țuršr, theilweise mit dem indischen Worte atschar bezeichnet; man bekommt für wenige Pfennige eine kleine zibdijeh mit diesen Sachen gefüllt. Den Essig, den man hinzubekommt, benutzt man vielfach als Sauce zum Reis. Die mittleren und höheren Klassen geniessen meistens 》 Reis und Fleisch" ( letzteres natürlich Hammelfleisch ${ }^{3}$ ) oder Ziegenfleisch. Nachdem

1) Meqarmi šjāmaqlijah! jáăllăh ala bābak! bachti annèbi! élh $\bar{a}$ r r liddeh jā walád! waren die Ausrufe eines Verkäufers von maqlijeh in Ğiddah: "knusperig o maqlijeh! o Allah, vor deiner Thüre (stehen wir)! meine Hoff"nung (auf Glück im Verkaufe) ist auf den ('a nn è̀ b I = 'a l a 'n n è b I) Profeten! "Heiss schmeckt es fein, o Jüngling!"

2) Hā rrah ja belilah hummúç! = "heisse, o in Wasser gekochte, Erbsen!” war der Ausruf eines Mannes, der dies Lieblingsgericht vieler Weiber verkaufte.

3) Schaafe heissen ضأن, ein Hammel 
486 DR. C. SNOUCK HÜRGRONJE, MEKKANISCHE SPRICHWÖRTER.

das Fleisch gar gekocht ist, kocht man den Reis in der Brühe; den Geschmack dieser Brühe verbessert man öfters durch Hinzufügung von getrockneten aromatischen Kräutern. Zum Reis wird, wenn er nahezu gar ist, ein bedeutendes Quantum Butter hinzugegossen. Man trägt den $\mathrm{ruzz}_{\mathrm{z}}$ el a ḥm in einer Schüssel oder auf einem metallenen Teller auf: der Reis wird in Kegelform aufgehäuft, das Fleisch in der Mitte daraufgelegt. Wenn es Zuspeisen gibt, setzt man dieselben um die Hauptschüssel herum in kleinen Schüsseln oder Tellern; so z. B. Gurkensalat mit Sauermilch, riğleh (eine Art Portulack), melūchrjeh, mit Reis und gehacktem Fleisch gefüllte Tomaten (bādinğān a hạmar), gefüllte bādinğān's (b. aswad), gefüllte dubbah's (eine Art Kürbiss) und andere Gemüse; - verschiedenes Zuckerwerk und andere Süssigkeiten, wie $f \bar{a} l \bar{u} d a h$ (mit diesem Namen bezeichnet man allerlei aus Fischleim, Stärke oder dem ostindischen ag a r-ag a r zubereitete süsse Mehlspeisen), me hạ llabrjeh, kunāfah u. a.; bei festlichen Mahlzeiten fehlt nur selten ein eigenthümliches Backwerk, das mešabbak, welches aus netzförmig ${ }^{1}$ ) zusammengelegten, mit Honig gefüllten Teigröhren besteht und mit viel Butter gebacken wird; - Früchte, wie die herrlichen Trauben aus Tāif und Umgegend, Datteln, Feigen ( صهاط genannt), Aepfel, Birnen, Pfirsiche, Aprikosen , welche alle nach einander ungefähr von Juli an reifen, Melonen (chirbiz) und Wassermelonen (ḥabhab), welche es während des grösstes Theiles des Jahres gibt u. s. w. Es wird bekanntlich bei den Mahlzeiten der Araber keine Reihenfolge innegehalten, sondern jedermann nimmt zuerst, was ihm eben gefällt.

Ein anderes in Mekkah besonders beliebtes Gericht wird meistens ohne Zuspeisen oder nur mit Früchten genossen: Reis mit Linsen (ruzz we ${ }^{c}$ a das), mit viel Butter zusammengekocht. In der heissen Jahreszeit finden manche diese Speise zu warm $(ح)$; sie ersetzen dann die Linsen durch eine Art indisches Getreide, k u šša $\operatorname{ri}^{2}$ ), welches als »kalt" (بارن) betrachtet wird.

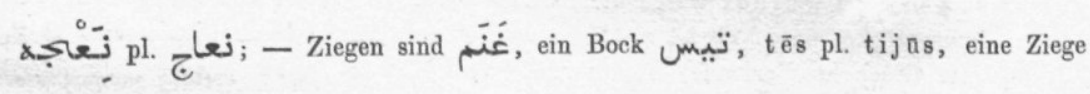
غَنَ.

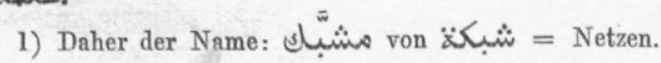

2) Die Geschjehte dieses Wortes (man spricht auch kušar , gewöhnlich wird aber das ( $\mathrm{A}$ verdoppelt) ist mir durch die gütigen Mittheilungen Prof. Kern's aufgeklärt 
Nichts geht aber dem Mekkaner über das mabšūr (مَْْشرور); vorzüglich bei den sehr häufig vorkommenden Picknicks und andern geselligen Partien und Schmausereien isst man dasselbe. Das Fleisch schabt man mit einem langen, scharfen Messer zu ganz dïnnen Blättchen $a b$; diese knetet man mit Pfeffer und andern Gewürzen und macht daraus Klösschen, von welchen man je 20 bis 40 auf ein Stück Eisendraht reiht. Das Ganze taucht man in Butter ein und brät die Klösschen auf dem Kohlenfeuer. Das in dieser Weise zubereitete Fleisch heisst mabšûr, ein einzelnes Klösschen ist ḥabbèt mab̌̌ūr (حبّة مبنشور). Der Reis wird ohne Weiteres mit der unentbehrlichen Butter gekocht; die Klösschen legt man auf den Reiskegel in 6-12 Reihen, welche von der Spitze nach der Grundfläche hinuntergehen. Gewöhnlich verschwinden die Klösschen sehr viel schneller als der Reiskegel, den sie schmücken; es steht dann immer ein Diener bereit, der, wenn dieselben zu Ende gehen, neues, frisch vom Feuer geholtes $\mathrm{m} a \mathrm{~b}$ šu $\mathrm{r}$ hinzulegt.

Es versteht sich von selbst, dass wir mit dem oben Bemerkten den Reichthum der mekkanischen Küche durchaus nicht erschöpft haben; es wären noch mancherlei Fleischgerichte (wie z. B. das la ha m meqèl qèl, im Butter geschmortes Fleisch) mit ihren verschiedenen Saucen (maraq), auch viele andere Zuspeisen zu erwähnen '). Für eine übersichtliche Darstellung des materiellen Lebens der Mekkaner genügt unsere Aufzählung aber vollständig. Man

worden. Aus dem Sanskrit: k r ça rā, k r s a rā (= Reisskörner, vermischt mit dāl, Salz, Ingwer und Asa foetida, mit Wasser zubereitet) ist im Hindı: $\mathrm{k} \mathrm{h} \mathrm{i} \mathrm{ch} \mathrm{a} \mathrm{r} \mathrm{I} \mathrm{als}$ Benennung eines aus Reis, Butter und $\mathrm{d} \overline{\mathrm{a}} \mathrm{l}$ zusammengesetzten Gerichtes entstanden.

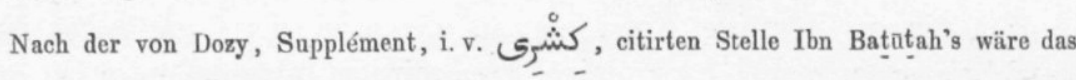
diesem bekannte $\mathrm{khi}$ h hār $\mathrm{I}$ ans Reis, Buttér and Phaseolus mungo (Hindī: $\mathrm{m}$ u $\dot{\mathrm{n}} \mathrm{g}$ ) zusammengesetzt gewesen; dies ist sehr wohl möglich, da dāl (Sanskr. dāli) alle gespalteten Feldfrüchte bezeichnen kann. In Arabien gebraucht man aber nicht diese Sorte des $d \bar{a} l$, sondern ein indisches Getreide von geringem Werthe zum khichări. Der Name ist in Westarabien $\mathrm{zu} \mathrm{ku} \breve{s}(\mathrm{~s})$ a r $\mathrm{r}$ geworden und wird dort $\mathrm{n} \mathrm{u} \mathrm{r}$ für das erwähnte Getreide gebraucht; eine Form كَشَّى gibt es nicht. Das ganze Gericht heisst im $\mathrm{Hi}$ ğa z immer: $\mathrm{ruzz}$ wekuš š a r $\mathrm{T}$; darnach ist Dozy’s Artikel zu verbessern.

1) Viele von den fremden Ansässigen (Buchărt’s, Hindr’s, Gāwi’s) behalten, sofern sie nicht in die mekkanische Gesellschaft anfgehen, ihre heimatliche Küche bei, und die Mekkaner verschmähen es nicht, dann und wann ihren Tisch mit einzelnen Ergebnissen-der ausländischen culinären Wissenschaft $\mathrm{zn}$ bereichern. 
ersieht daraus, dass in den Speisen der mittleren und höh eren Klassen zwar eine ziemliche Abwechselung, aber kein bedeutender durch die Standesverhältnisse bedingter Unterschied herrscht. Der Speisetisch des Reichen und Vornehmen unterscheidet sich von dem des weniger Begünstigten oft gar nicht, oder nur dadurch dass Jene häufiger viele Zuspeisen geniessen und ihre Sachen etwas feiner (resp. fetter) zubereitet bekommen. Dies erleichtert bedeutend den Verkehr der Mekkaner unter einander. Es braucht sich fast keiner zu schämen, irgend einen seiner Mitbürger zu Tisch einzuladen, und keiner fühlt sich solcher Einladung halber genirt. Der Herr des Hauses setzt sich mit seinen Freunden und Bekannten zu Tische; selbstverständlich isst der Maurer, der Zimmermann oder wer sonst grade in seinem Hause arbeitet, mit; sogar den saqqā (Wasserträger), der zufällig mit seiner qirbah (Wasserschlauch) hereintritt, lässt man nicht davon gehen, ohne dass er wenigstens lu qmah, luqmatēn (ein paar Bissen) mit genossen hätte - man würde sich sonst schämen, und viele würden sich vor dessen (bösem) Auge fürchten.

In unserem Sprichworte ist von kunāfah, einem sehr feinen Gerichte, welches infolge einer daneben befindlichen Viper ungeniessbar wird, die Rede. Dies liesse sich also auf jede erwünschte Sache anwenden, mit welcher irgend etwas Schlimmes unlöslich verknüpft ist. Es bezeichnet aber in dieser Redensart die Viper immer die Schwiegermutter, die Mutter der Frau, ein in der muslimischen Gesellschaft gründlich verhasstes Geschöpf. Die Schwiegermutter (gewöhnlich: ${ }^{c} \mathrm{mmah}$ ) verlegt sich der populären Ansicht nach mit allen Kräften darauf, bei ihrer Tochter Unzufriedenheit gegen ihren Gatten zu erwecken, wenn auch ihr eheliches Glück an und für sich ein ideales wäre. »Dein Mann »gibt dir so dürftige Kleidung, so elende Speisen, gestattet dir »nicht, auszugehen oder deine Freundinnen einzuladen u. s. w. »und du bist nach wie vor seine gehorsame Sklavin? Vergleiche s doch einmal dein Schicksal mit dem deiner verheiratheten Schwesఎter oder Cousine; die würden sich auch solches nicht gefallen »lassen!" Mit ähnlichen Reden zerstört die cammah den häuslichen Frieden; die Mekkaner bewillkommen denn auch ihren Besuch gewöhnlich mit einem kaum leise ausgesprochenen: » a ${ }^{\mathrm{c}} \overline{\mathrm{u}} \mathrm{d} \mathrm{u}$ billāh!", einer Formel, welche übrigens vorzüglich dazu dient, den Teufel fern zu halten, und sie bezeichnen die Schwiegermutter unter einander mit dem Spottnamen èl-ghāb'rah oder 
èl-ghabrah (غابرة) mit boshafter Anspielung auf den tadelnden Ausdruck, weleben der Qurān ') siebenmal auf die ungläubige Frau Loths anwendet. Es gereicht der ledigen Frau bei einem heirathslustigen Mekkaner zur wesentlichen Empfehlung, wenn mitgetheilt werden kann, ihre Mutter sei schon todt oder wohne an einem andern Orte. Ganz anders werden die männlichen Verwandten der Frau von ihrem Gatten geschätzt. Der Schwiegervater und der Schwager wissen ja aus Erfahrung, wie häufig die Rechte des Ehemannes von Seiten der Frauen verkannt werden; die schlechten Eigenschaften, durch welche sich nach muslimischer Anschauung das ganze weibliche Geschlecht auszeichnet, machen ihnen selbst täglich zu schaffen. Ist des Mannes Geduld durch die immer neuen Launen seiner Gattin erschöpft, so wendet er sich zu seinem raḥim ${ }^{2}$ ) um Hülfe, und diese wird ihm gewöhnlich gewährt. Der r a ḥı ertheilt seiner Tochter, resp. Schwester die nöthige Belehrung (jerabbíh $\bar{a}=$ er erzieht, belehrt sie); die unteren Klassen machen dieselbe sogar öfters durch Hinzufügung von Schlägen (kefūf, lațs, calqah) etwas empfindlicher. Der Ehemann, dessen häuslicher Friede durch die böse ghabrah öfters gestört würde, wenn nicht sein raḥīm dann und wann mit rettender Hand eingriffe, vergleicht seinen Zustand mit dem des im šuqd uf Reisenden, welcher sich nur so lange seiner bequemen Lage erfreut, als sich in dem auf der andern Seite des Kameels aufgehängten šuqduf ein Mitreisender befindet, der ihm das Gleichgewicht hält. Er bezeichnet seinen raḥım mit demselben Namen, den der šuqduf-reisende in Arabien seinem mit ihm ein Kameel theilenden Gefährten beilegt und nennt ihn also seinen cadil (d. h. der das Gleichgewicht hält). Stirbt in solchen Fällen der raḥim, und bleibt dem Ehemanne neben der Frau nur die ${ }^{c} \mathrm{ammah}$, so ist er tiefbetrübt; meine Ruhe ist hin,

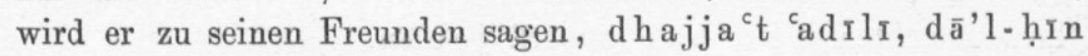

1) Qur. VII: $81, \mathrm{XV}: 60, \mathrm{XXVI}: 171$ u.s w.

2) Mit diesem Namen bezeichnen die Mekkaner in erster Linie den Schwiegervater, dann aber auch die andern männlichen Verwandten der Frau. In der Umgangssprache wird umgekehrt das Verhältniss des Ehemannes zu seinem Schwiegervater, resp. Schwager u.s.w. nur ausnahmsweise mit dem Namen rahim bezeichnet; man sagt von ihm: felān ăchid oder wāchid (i) bint resp. ucht felān d. h. "N. N. hat die Tochter, resp. Schwester des N. N. zur Frau”. anā wãchid bintuh d. h. "er ist mein Schwiegẹrvater"; ku nt āchid bintuh d. h. "er war mein Schwiegervater" (seine Tochter ist aber jetzt todt, oder ich habe sie verstossen). 


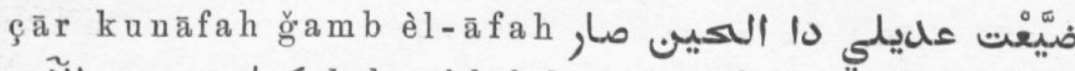
d. h. »ich habe meinen "adil verloren; jetzt »ist es geworden: kunāfah neben der Viper."

36.

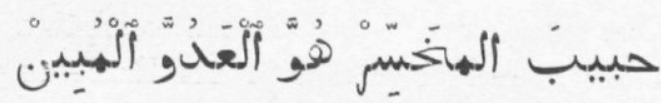

Der Freund, welcher Nachtheil verursacht, ist der rechte Feind.

ḥabíb èl-mechassir vulg, für èl-ḥabib, vgl. Landberg, Proverbes et Dictons I:5. - chasar, jichsar, chasārah wird häufig für Verluste jeder Art gebraucht; $j \bar{a}$ chasārah! sagt man immer, wenn etwas zerbricht, verdirbt, misslingt und dgl. Die mekkanischen Weiber schreien in solchen Fällen: $j \bar{a} d a h-$ watr! Oppos. von خساره ist فايله èš èlfājdah? ist die immer wiederkehrende Frage, nach deren Beantwortung der Mekkaner sein Handeln einrichtet; auch beim Freundschaftschliessen gibt diese Erwägung in der Regel den Ausschlag. Man nimmt sich Einen zum çāḥib, rafīq, hạbíb, weil man sich von diesem Verhältniss, sei es in dieser oder (aber seltener) in jener Welt Vortheil verspricht. Mitunter schlagen natürlich die Berechnungen fehl, und tritt die chas ārah an die Stelle der erhofften fājdah. Dann löst man unverzüglich die unnützen Bande und beruft sich dafür auf das citirte Sprichwort. Auffallend gross ist die Zahl der arabischen Sprichwörter, welche die verschiedenen Situationen schildern, in welche der Mensch durch das Verhalten seiner aç $h \bar{a} b$ versetzt wird.

mubin wird nur in Redensarten gebraucht (vgl. Qurān II : 163, 204 u.s. w.); gewöhnlich sagt man bājin; deutlicb sein, hervorleuchten heisst $b \bar{a} n$ imperf. jebān.

37.

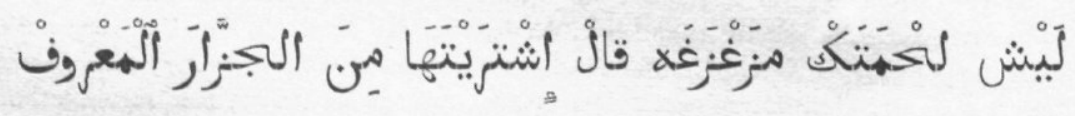

Wesshalb ist dein Stückchen Fleisch so karg? - Er sagte: weil ich "es von dem mir bekannten Fleischer gekauft habe.

Ueber, das $a$ als Bindevocal in išterētahā vgl. No. 5 . 
Wer sich von einem ihm befreundeten Kaufmann getäuscht findet, führt diesen Dialog an; aber auch Leute, welche bei irgend einer Verhandlung den Kürzeren gezogen haben, weil sie ihren Freunden gegenüber bescheiden, diese ihrerseits aber schamlos verfaluren sind, wenden denselben auf sich an.

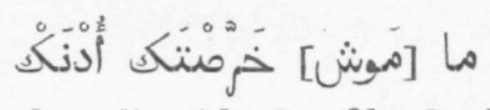

\section{Habe ich denn dir nicht das Ohr durchbohrt ${ }^{1}$ ).}

Man sagt dies zu Einem, der einen Auftrag gar nicht oder nicht richtig ausgeführt hat; habe ich es dir denn nicht tausendmal gesagt? Das Pronomen mā kommt ausser in Redensarten, nur in dem Ausdrucke mā l... (vgl. Landberg, Proverbes et Dictons, I : 22) vor; sehr häufig ist dagegen das negative (und auch prohibitive) mā. Ueber dessen Verbindung mit Personalpronn. im Dialecte Syriens hat Landberg (vgl. die im Gloss. i. v. Lo aufgezählten Stellen) ausführlich gesprochen. In Mekkah wird nı ǒ gleichfalls als Negation für alle Geschlechter und Zahlen gebraucht; die Mekkaner gebrauchen das $=0$ شي bei der Negation ausser in diesem Falle nur noch in $\mathrm{ma}$ fI šs $=$ es gibt nicht ${ }^{2}$ ). Die Aegypter und Syrer werden in Mekkah wegen ihres den Verben bei der Negation angehängten ش شي نder viel verspottet. Man zieht auch dem mōš den Gebrauch von "mā mit den verschiedenen Pronomina vor und sagt dann (vgl. Landberg, I: 91):

I. Pers. sing. māna oder ana māna plur. mèhṇa oder i ḥna mè̀ña.

II. 》 》 masc. mèn te oder ente mènte

》 》 $\quad$ fem. mènti oder èn $t i \mathrm{~m}$ èn $t I$.

plur. $m$ èn $t \bar{u}$ oder è $n t \bar{u}$ mèn $t \bar{u}$.

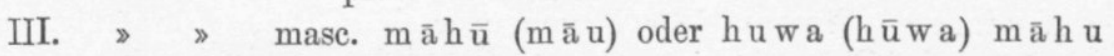
$(\mathrm{m} \overline{\mathrm{a}} \mathrm{u})$.

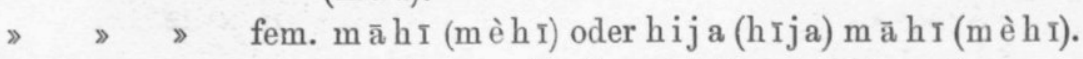

» \ plur. māhum oder huma (humma) māhum.

In steht das Objectssuffix für das indirecte Object (لكرصتك)),

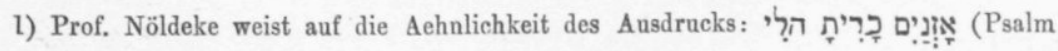
XL : 7) hin.

2) $\mathrm{M} \overline{\mathbf{a}} \mathrm{al}^{\mathrm{l}} \overline{\mathrm{e}} \mathrm{h} \breve{\mathrm{s}}=$ "es thut nichts" wird auch gebraucht; hier hat aber das $\hat{\omega}$ (oder $v^{\prime}$ ) noch seine eigne Bedentung. 


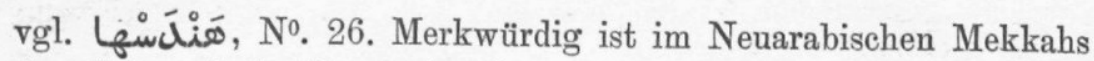
der Gebrauch der Pronomina h $\bar{u}$ wa und hīja, wo die alte Sprache die entsprechenden Suffixe hat, z. B. awarrik $\left.{ }^{1}\right)$ hūwa, a ğı lak hrja, nāwilni hūwa und dgl. d. h. »ich werde es dir zeigen", »ich werde es dir bringen", »lange es mir zu". Dagegen tritt das Suffix an die Stelle des Pronomen z. B. in fènak, $\mathrm{fē} \mathrm{nuh}=$ » wo bist du, wo ist er?"

39.

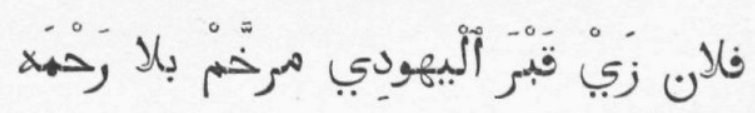

\section{N. N. ist wie das Grab eines Juden, mit Marmor (oder Stuk) belegt ohne Gnade.}

Das Wortspiel wäre vollkommen, wenn man anstatt $\mathrm{rahmah}$ das gleichbedeutende $\mathrm{rachmah}$ gebrauchte; dieses Wort ist aber in der lebenden Sprache nicht vorhanden und wird auch in diesem Gleichnisse nie gebraucht. ruchām heisst eigentlich Marmor; man nennt aber auch eine Art marmorähnlichen Stuk mit diesem Namen, und eine Mauer, ein Grab, welche damit übertüncht sind, heissen merachcham. Die Gnade, welche dem schön übertünchten Grabe des Juden fehlt, ist die Seligkeit im Jenseits; an die thätige Barmherzigkeit des Menschen ist dabei nicht zu denken. Es liesse sich dieser Spruch also auf die Heuchler ${ }^{2}$ ) anwenden, »die gleich sind wie die übertünchten Gräber" (Matth. XXIIl : 27), und zweifellos würde jeder Mekkaner das verstehen. Das tertium comparationis liegt aber bei jeder Anwendung dieses Gleichnisses n u r im Gegensatze des äusseren Scheines und des inneren Wesens einer Person oder einer Sache. Am häufigsten

1) Ueber den Vocal $a$ zur Bezeichnung der Isten Person vgl. No 12 Anm.

2) Es gibt in Mekkah selbstverständlich Viele, welche die Frömmigkeit als sehr einträglich erkannt haben und sich desshalb frömmer zeigen als sie sind. Skeptiker, welche die wahre muslimische Frömmigkeit nicht von Herzen bewundern, sind kaum da, auf jeden Fall sehr selten. Mit dem qurānischen Namen munãfiq bezeichnet der Mekkaner solche, welche (auch ohne eine Spur von Heuchelei) sich mit allen Kräften ihren weltlichen Interessen hingeben ohne sich dabei durch Gewissenszweifel stören zu lassen. Es ist wesentlich gleichbedentend mit kāfir; nur gebraucht der Gebildete dieses Wort

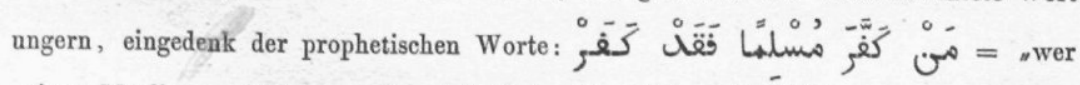
• einen Muslim ungläubig nennt, wird (dadurch) selbst unglänbig”". 
wird es gesagt von Einem, der sich aufführt, als wäre er sehr reich, vornehm oder einflussreich, der aber thatsächlich weder felūs noch nefūs ${ }^{1}$ ) besitzt; auch von solchen, welche ihre gründliche Unwissenheit unter der Kleidung, den Manieren und Redensarten der 'ulamā verhüllen.

ي) wird vor Consonanten meistens zēe, vor Vocalen öfters zèjj gesprochen.

40.

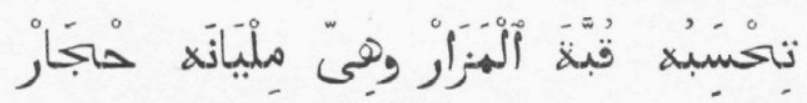

Du siehst ihn für eine Wallfahrtskuppel an, sie ist aber mit Steinen gefüllt.

حسب heisst »dafürhalten"; in der Vorstellung des Subjectes ist es ein bestimmtes Wissen. تَيَّ dagegen heisst »vermuthen", wobei auch das Subject selbst nur an Wahrscheinlichkeit denkt ${ }^{2}$ ). Die $q u b b a h$ ist bekanntlich das kuppelförmige Gebäude, welches man auf dem Grabe eines wáli's oder sonst einer wegen ihrer Frömmigkeit hochangesehenen Person errichtet; manches altheidnische Heiligthum ist in dieser Form in den Islām aufgenommen worden. Man erbaut diese Kuppeln auch wohl zu Ehren von Leuten, deren Grab sich in weiter Entfernung befindet. Solche q u b bah's werden dann gleichsam als Abbildungen des eigentlichen Grabes betrachtet, und die ${ }^{c} \mathrm{aw} \overline{\mathrm{a}} \mathrm{mm}$ unterscheiden dieselben nicht von den Originalen. Die orthodoxe Anschauung von dem Besuchen der Gräber überhaupt zieht zwar die heilsamen Eindrücke der Besucher von der Vergänglichkeit der Welt in Betracht, legt aber das höchste Gewicht auf die frommen Werke, welche man verrichtet, um den Lohn derselben den theuern Todten zu schenken. Man recitirt etwa wöchentlich einige chatmah's oder lässt sie auf seine Kosten recitiren, man vertheilt zu bestimmten Zeiten Brod oder Geld an die Armen bei dem Grabe eines verstorbenen Verwandten, und man formulirt dabei die Absicht (nijjah), dass dieser für den Ertrag dieser frommen Werke im himmlischen Buche creditirt werde. Die ausserwählten Freunde

1) Vgl. $\mathrm{N}^{\circ} 10$.

2) Vgl. $\mathrm{N}^{\circ} 49$. 
Gottes (Profeten, w á lI's) bedürfen dieser nachträglichen Geschenke nicht; sie bekommen davon jedoch mehr als alle Andere zusammen. Allah liebt nämlich, wer seine Günstlinge liebt und ehrt; um ihretwillen mildert er das Urtheil über Leute, welche an und für sich nicht viel Gutes verdient haben. Daher ist es viel vortheilhafter, den Lohn eines frommen Werkes einem Freunde Allahs zu schenken und sich dadurch dessen Fürsprache zu erkaufen, als auf eigene Faust sich um Allahs Gnaden zu bewerben. Ausser durch die Abtretung verdienstlicher opera kann man sich die Gunst der Vermittler noch durch Beiträge zur Erhaltung und Verschönerung ihrer Grabhäuser erwerben oder indem man ihnen zu Ehren etwas Weihrauch verbrennt oder ein Kerzchen anzündet. Schliesslich, wenn das gewünschte engere Verhältniss zwischen dem Heilbegierigen und dem Heiligen hergestellt ist, betet jener auf dem Grabe des Letzteren unter Anrufung seines Namens. Bei der Ehre, in welcher dieser wáli bei dir steht, o Allah! gewähro mir dae Vorlangtol Ris an weit ist Alles noch giomlich orthodox; es versteht sich aber, dass die Ungebildeten einen bedeutenden Schritt weiter gehen in der Menschenverehrung. Der gewöhnliche Mekkaner, welcher schon lange vergebens nach der Erfüllung eines theuren Wunsches gestrebt und darum gebeten hat, geht endlich Nachts, am liebsten in der Nacht des Freitags, auf den $\mathrm{Ma}$ qā; wenn alle Mittel versagen, so ist unsere Herrin Chadiğah (sittanā chadiğah) immer noch da. Er kauft zuerst etwa einige Brode, welche er entweder im haram (der Moschee) oder auf dem heiligen Grabe selbst im Namen der lieben Frau an die Armen vertheilt; gestatten es seine Mittel, so miethet er noch einen fáqīh und lässt diesen im Grabgebäude einige ğuz' (Qurānabtheilungen) ableiern; er verbrennt in der qubbah etwas bachūr (jebacchir lesittanā), indem er vor dem auf dem Grabe befindlichen, mit einem schweren, goldgestickten Seidentuche überdeckten Holzgestelle steht. Die Geländer, welche das Gestell umgeben, sind niedrig genug, damit einer darüber hinweg den oberen Theil der kisweh (Bekleidung) mit der Hand berühren kann. Dies thut nun auch der Betende auf allen Seiten, bleibt hie und da bei dem Umgange längere Zeit stehen und sagt längere Gebetsformeln her. Beim Formuliren seiner speciellen Wünsche fasst er das Kleid mit einer Heftigkeit, alsob er einen irdischen Gönner beim Saume seiner ğubbah festhielte; jā sittaná dachrlik beğ āh èl-musțafā! begāh sittanā 
ehadrğgh ja $\mathrm{rabb}^{1}$ )! Manchmal gelobt, man 'ihr noch Besseres, als sie jetzt bekommen hat, sobald dureh ihre Vermittelung die Sache, um die es sich handelt, erledigt sein wird. Der Mund der Mekkaner ist immer voll von monotheistischen Formeln; innerlich sind sie aber in mancher Beziehung noch Heiden. Abgesehen von der Form, in welcher der Islūm sich diese Dinge assimilirt hat, ist das tawassul namentlich der ungelehrten Muslime lauter Vielgötterei.

Die Wallfahrtskuppel des Sprichwortes denke man sich ähnlich eingeriehtet, wie wir eben die qubbèt sittan ā chadiğah besehrieben haben, und voll von verborgenen Segnungen (ba raki $t$ ), welehe den Besuchern zu Theil werden. $\$$ Ich bin, Gott sei Dank, »von meiner Krankheit wieder hergestellt", bebarakat sittana $=$ sdurch die Segnung unserer Herrin (Chadiğah)" sagt der Mekkaner. Es wäre also die grösste Enttäuschung, wenn man anstatt der barakāt in einer Kuppel, welche aussieht wie das Grab eines Heiligen, nur Steine tände. Steine stellen ja bildlich die Unbiegsamkeit, den Geiz, die Unfruchtbarkeit dar (vgl. $N^{0}$. 5 und $\left.\mathrm{N}^{0} .12\right)$; der Stein ist $\mathrm{j}$ äbis s${ }^{2}$ ).

Der Plural von حَبَّi ist derster Vocal fällt wegen des vorhergehenden $a$ weg wie in jā 'ḥmă $\mathrm{r}=» d u$ Esel!' Dieselbe Zusammenziehung könnte mit a ḥ̆gār stattfinden, aber diese

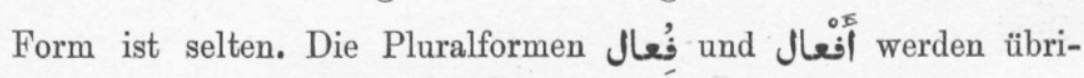
gens vielfach zusammengeworfen; so gebraucht man arjā ḥ neben rijāh, a mrār neben mirāa, ohne zu empfinden, dass die zwei verschieden sind.

Die Construction in unserem Sprichworte ist etwas frei: das Pronomen in wehrja vertritt: $\triangleright$ die qubbah, als welche du dir ihn gedacht hattest."

Die Warnung dient dazu, Einen, der grosse Erwartung von der Hülfe eines Freundes oder Gönners hegt, rechtzeitig vor Ent-

1) "O, unsere Herrin, (hier ist) dein Schützling bei der Ehre des Auserwählten "(Muhammed)! bei der Ehre unserer Herrin Chadǐ̆ah, o Herr!"

2) Dieses Wort bezeichnet sowohl die Härte als die Trockenheit; wenn ein vielgereister Mekkaner seinen zu Hause gebliebenen Freunden erzählen will von Ländern, wo es friert, so sagt er: min šiddet è l-bur a a çã r’t èl-moje h jă b’s e h = "durch die heftige Kälte war das Wasser hart geworden". Ein Stück Holz, das man nicht zerbrechen kann, ist jābi s bi l-marrah = "furchtbar hart"; ein Freund, der Einem nie etwas schenkt, ist $\mathrm{j} \overline{\mathrm{b}} \mathrm{b}$ is $=$ knauserig. Ueber bil-marrah vgl. $\mathrm{N}^{\circ} .47$, Anm. und $\mathrm{N}^{\circ}: 48$. 
täuschung zu bewahren. Du glaubst, N. N. sei reich, mild, ein treuer Freund in der Noth; gebe den Irrthum auf, es ist nichts mit ihm.

41.

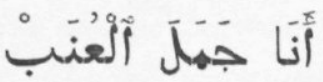

Ich bin (wie) das Kameel, welches die Trauben trägt.

Die herrlichen Früchte, welche die meistens den Scherifen zugehörenden Obstgärten in Țāif und in den Wādi’s zwischen Mekkah und Țāif im Sommer liefern, werden auf Kameelen nach der heiligen Stadt transportirt. Es wachsen in Țāif weisse und blaue Trauben. An geistreichen Ausrufen der Waarenverkäufer ist Mekkah nicht reich; gewöhnlich geht dem Namen der Waare ein durch $\mathrm{j} \overline{\mathrm{a}}$ von ihm getrenntes Wort voran, welches entweder die Qualität oder die Herkunft oder den Preis des zum Verkaufe Gebotenen oder aber eine andere, feinere Waare bezeichnet, mit welcher man die vorhandene ihrer Vorzüglichheit halber vergleicht, also ḥārr oder meqammar ${ }^{1}$ ) jā $\bar{a}^{c} \bar{e} \mathrm{~s}=»$ heiss" oder »ausgebacken, o Brot!"; sillami jā faḥ am = sillamitische ${ }^{2}$ ), »o Holzkohlen!"; casal jāruțab, šèlabi ${ }^{3}$ ) jā zēēēēn! = "Honig o Datteln (also Datteln so süss wie Honig), feinste Sorte, » Vorzügliches!"; sukkar jā chirbiz = „Zucker, o Melone!". Trauben preist man an, indem man dieselben mit Zucker oder mit.... fā lūdah (vgl. $N^{0}$. 35) vergleicht! sukkar ja cunab oder fālūdah iā cunab! ${ }^{4}$ ) schreien die Verkäufer. telātin jā tin = dreissig (Para's), o Feigen!" mesāma ḥ (aueh wohl $\mathrm{s} \overline{\mathrm{a}} \mathrm{m} \mathrm{ah}$ gesprochen) $\mathrm{j}$ ā lè bè̀̀̀̀ $\mathrm{n}=\gg \mathrm{um}$ ein Spottgeld, ${ }^{5}$ ) 0 Milch!"

1) Vergl. $N^{\circ} \cdot 35$.

2) D. h. aus der Ortschaft Sillam nicht weit von Ğiddah, welche wegen ihrer guten Holzkohlen berühmt ist.

3) Š è l a b I (türk. ججلبي) bedeutet in der Umgangssprache alles, was in seiner Art vorzüglich ist, nicht nü gute Natteln (vgl. Dozy, Supplément i.v.); es ist ungefähr gleichbedeutend mit dem viel gebrauchten (türk.) b i ri n ğ I = prima Qualität.

4) Der erste Vokal des Wortes 'u n a b wird vielfach ungefähr wie $\ddot{o}$ gesprochen. Eine Beere heisst ' $\mathrm{u} \mathrm{n}$ a b a h.

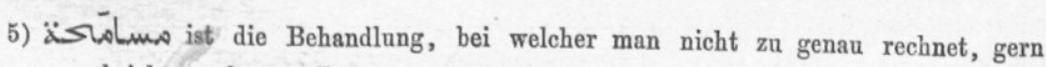
etwas nachsieht und verzeiht, so wie Gott die Menschen behandelt; ihr steht die 
Wenn man Einem alle Arbeit und Mühe für eine Sache aufgebürdet hat, ihn aber nicht mit davon geniessen lässt, so vergleicht er sich klagend mit dem »Kameele der Trauben", welches die herrlichsten Früchte trägt, ohne etwas davon zu bekommen.

\section{2.}

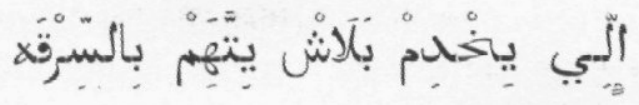

Wer umsonst Dienste leistet, kommt in Verdacht des Diebstahls.

Man spricht jittáhim und jittáham; der Verdächtige heisst mathūm. Das Sprichwort wird gebraucht von Einem, der umsonst oder gegen ganz geringe Belohnung sich für andere irgendwie bemüht hat, und dem man anstatt des Dankes Bemerkungen macht, weil er dies oder jenes vernachlässigt hat.

\section{3.}

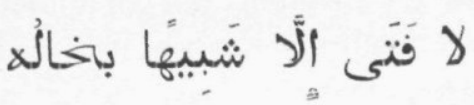

Es ist kein edler Jüngling, der nicht seinem chāl (dem Bruder seiner Mutter) gleicht.

فَنَّى gehört in Mekkah nicht mehr zur Umgangssprache; in Redensarten oder in gehobener Rede bezeichnet es, ebenso wie bei den alten Dichtern, den edlen, tüchtigen Jüngling (oder Mann). Von einem Medinenser hörte ich ein in seiner Heimath gebräuchliches mit dem unsrigen gleichbedeutendes Sprichwort; der Wortlaut desselben ist mir leider entgangen. Mehrere Stellen, aus welchen die Bedeutung des $\mathrm{ch} \overline{\mathrm{a}} \mathrm{l}$ in der altarabischen Gesellschaft erhellt, findet man bei G. A. Wilken, das Matriarchat bei den alten Arabern, (Leipzig, 1884) S. 44 ff., wo dieselben für die Ethnographie verwerthet sind. Trotz seiner litterarischen Form ist dieses Sprichwort unter allen Klassen der mekkanischen Gesellschaft verbreitet.

Statt فَتَّى wird auch فَتَى gesprochen.

مشناحِ gegenüber, welehe den Verkehr der Menschen mit einander beherrscht. M e$\mathrm{s} \overline{\mathrm{a}} \mathbf{m a h}$, vom Preise einer Waare gesagt, heisst also: so billig, als hätte man die Festsetzung dem Käufer selbst überlassen.

5e Volgr. I. 


\section{4.}

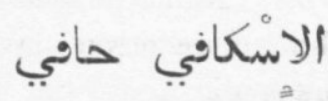

Der Schuster geht barfuss.

Dies ist eigentlich nur eine, freilich die bei Weitem gebräuchlichste, Hälfte eines Sprichwortes, dessen andere Hälfte mir entgangen ist; wenigstens wage ich es nicht ganz bestimmt zu sagen, ob diese letztere: wèl-chèjjāt t ${ }^{c} \mathrm{irj} \overline{\mathrm{a}} \mathrm{n}=$ »und der Schneider geht ungekleidet" lautet oder vielleicht anders. Der Meister ( $\left.\mathrm{me}^{\mathrm{c}} \mathrm{a} l \mathrm{ll} \mathrm{m}\right)$ in jedem Fache ist so sehr beschäftigt mit der Ausübung seines Gewerbes zum Nutzen anderer Leute, dass er kaum Zeit dazu erübrigen kann, seine eigenen Sachen heil zu erhalten. In diesem einfachen Sinne wird der Spruch vielfach gebraucht, aber auch wohl in etwas übertragener Bedeutung. Wenn Einer mit allen Kräften beschäftigt ist, z. B. Thee, Kaffee oder Speisen für Andere zu bereiten und an dieselben zu vertheilen, und schliesslich sich selbst vergessen hat, sodass für ihn nichts übrig bleibt, da sagt man: „Nein, das ist aber Unrecht; jetzt »hast du von dem Ertrage deiner Arbeit selbst nichts bekom»men"; èl-iskāfi hạ fĩ ? = »soll der Schuster selbst barfuss "gehen ?"

Ein anderer, etwas weniger gebräuchlicher Ausdruck desselben Gedankens ist folgender :

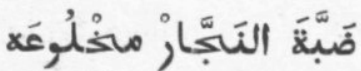

\section{Das Schloss des Zimmermanns ist zerbrochen.}

Eine mustergiltige Beschreibung der dhabbah, des hölzernen Schlosses der arabischen Haus- und Zimmerthüren, findet man bei Lane, Manners and Customs (5th edition), I : 23-24. Es ergibt sich daraus von selbst, dass die Anfertigung, resp. Ausbesserung dieser Schlösser das. Werk der Zimmerleute ist. Europäische Vorlegeschlösser werden in Mekkah immer mehr, namentlich zur Verschliessung von Schränken und Kisten gebraucht, weil die gewöhnlichen dhabbah's sehr leicht zerbrochen oder doch ohne Schlüssel geöffnet werden können.

Auch so sind aber diese Schränke zur Verwahrung von Geld und Kostbarkeiten nicht ohne Gefahr; die mekkanischen Zimmerleute sind keine Handwerker ersten Ranges, und das Holz, das sie 
meistens gebrauchen, krümmt sich entsetzlich unter dem Einflusse des heisstrocknen Klimas, sodass die meisten Thüren aussehen, als befänden sie sich nur zufällig zwischen den Thürpfosten und der Schwelle, welche sie umgeben. Nur die reichsten Kaufleute haben Feuerschränke; die Leute der mittleren Klassen verstecken ihr baares Geld und ihre Kostbarkeiten an Stellen, wo der Dieb dieselben nicht gleich suchen dürfte: in der Mauer hinter ein paar besonders dazu herausgebrochenen Steinen, unter einer Schwelle, unter einer von den aus Palmenblättern (خوص) geflochtenen Matten (خَصَف), welche den Fussboden bedecken u. s.w.

45.

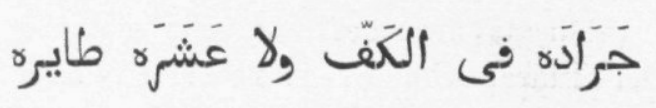

Eine Heusckrecke in der Hand ist besser als zehn, welche fiegen.

Dieses Sprichwort wird von den Mekkanern als beduinischer Herkunft betrachtet. kaff, Plur. kefūf, bedeutet sonst in Mekkah nur » Ohrfeige".

"Ein Sperling in der Hand ist besser als eine Taube auf dem Dache".

46.

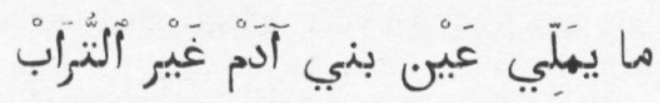

Nichts erfüllt das Auge des Menschen ausser dem Staube.

Dieser sehr alte Spruch gehört zu den nicht in die officielle Qurānredaction aufgenommenen Worten Allahs; vgl. die sehr von einander abweichenden Formen, in welchen das Orakel überliefert wird, bei Nöldeke, Geschichte des Qorāns, S. 175 ff. Die gewöhnlichste Lesart ist: ولا يهلَ جوف ابـ آنم الاّ التراب, aber in andern Ueberlieferungen kommen statt des Bauches auch der Mund, die Seele, die Augen und das Auge des Adamssohnes vor. Die Lesart von dem Auge ist wohl die sinnreichste, wenngleich sie vielleicht in der nicht-recipirten Qurānstelle nicht ursprünglich war. Sie hat auch späteren Schriftstellern am meisten zugesagt und wird z. B. in den Chroniken der Stadt Mekka, ed. Wüstenfeld, III : 102 angeführt. Heutzutage gilt die 
oben angegebene Form in Mekkah als ein Sprichwort, von dessen göttlichem Ursprunge Niemand gehört hat. ben I ādam ist an die Stelle des selten und nur von Gebildeten gebrauchten Singulars getreten; thatsächlich sind im Munde des Volkes Plural und Singular dieses Wortes identisch geworden, sodass bе п ז $\overline{\text { a }} \mathrm{da} \mathrm{m}$ bald einen Sing., bald einen Plural zum Prädicate bekommt. Einen Plural wie بِنْآنِِِيِ (Landberg, Proverbes et Dictons I, Glossaire i. v. بنى, vgl. die dort angeführten Stellen) gibt es in Mekkah nicht; auch kann ben $\bar{I} \overline{\mathrm{a}} \mathrm{dam}$ dort nur den Menschen in genere bezeichnen und sagt kein Mensch etwa wăhid beni ādam (Landberg I: 84). Es hat nahezu die gleiche Bedeutung wie èl insān, wird aber $1^{0}$ etwas häufiger gebraucht, $2^{0}$ als Sing. und Plur. behandelt, und $3^{0}$ dient es viel eher denn èl-insān als Subject eines Prädicats, welches eine sehr schlechte Eigenschaft bezeichnet. Der Plural von è]-insān: èn-nās vertritt die Stelle der beiden genannten Wörter nur in gewissen stehenden Redensarten (z. B. èn $-\mathrm{n} \overline{\mathrm{a}} \mathrm{s} \mathrm{k}$ ède $=$ »so sind nun einmal die Menschen"), steht aber häufiger für: »die Leute", z. B. èn-nās jeqū $l \bar{u} k$ ède $=>$ die Leute (etwa dieser Stadt, oder des Stadtviertels) sagen so". Ohne den Artikel heisst nās auch nur: "Leute", z. B. nās jeqūlū kède $=$ ses gibt Leute, welche so sagen". Eine bestimmte Anzahl (sei es Einzahl oder Mehrzahl) von Menschen kann keins von diesen Wörtern bezeichnen; dazu dient ādamı, Plural awādim ${ }^{1}$ ). Der Singular kommt ziemlich selten vor; statt wāḥid ädami pflegt man einfach wāḥid, zur Noth wāhid min èn-nās zu sagen. Den Plural gebraucht man auch in solehen Fällen, wo von einer zwar nicht bestimmten, aber doch bestimmbaren Anzahl die Rede ist, z. B. mā ša ' $l 1 \bar{a} h$ sūf hādi ' $l-g$ ğināzah; awādim ès-sūq miljān $=$ „Gott bewahre! sieh einmal dieses Begräbniss! (von) "Menschen, der Markt voll!" Fragt einer fíh awādim $\mathrm{fi}^{3} \mathrm{l}$ $\mathrm{be \overline {t }}=$ »sind Menschen in dem Hause ?" so geht daraus hervor, dass er nicht weiss, ob das Haus bewohnt wird; fīh $n \bar{a} s$ fi $^{3} l-$ bèt heisst dagegen gewöhnlich: »sind Leute (von den mir be»kannten Bewohnern) in dem Hause (oder: zu Hause)". wăḥid bābūr atcaw war ${ }^{2}$ ) fi ğiddah. $-k \bar{a} n \bar{u}$ frih fi bațnuh awā-

1) Die Bedeutung "honnête, poli” (Landberg, Glossaire, i. v.) ist in Mekkah völlig unbekannt.

2) heisst (Menschen oder Thieren) körperliche Beleidigungen zufügen, (Sachen) 


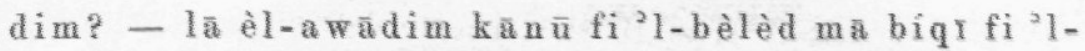
bābūr ghēr itnēn telātah min èl-bahrrjeh d. h. * Ein "Dampfer hat in Ğiddah bedeutenden Schaden erlitten". - Wa"ren Mensehen darin?" - Nein, die Menschen waren in der "Stadt, es waren nur 2-3 Matrosen auf dem Dampfer geblieben". Hier könnte anstatt des ersten awa $\mathrm{dim}$ auch nàs gesagt werden, weil man von den zum Dampfer gehörenden Leuten (gleichviel ob Reisenden oder Seeleuten) reden will; statt è l-a wa dim könnte man dagegen nicht èn-nās sagen. Der Sing. fem. èl àdamijeh wird (selten) gebraucht zur Bezeichnung einer bestimmten Frau, und es liegt dann eine gewisse Geringschätzung darin, z. B. ğatnā. - mIn? - èl-ādamrjeh d. h. s Sie ist (zu uns) gekommen". - "Wer?" - Die Weibsperson (nämlich: deren Besuch von uns erwartet wird, aber uns nichts weniger als angenehm ist)". Man merke sich noch den Ausdruck zèj $i$ èn-nās in zwei versehiedenen Bedeutungen: léś $m \bar{a}$ tiq ${ }^{c} u d$, teharriğni $\left.{ }^{1}\right)$, tilbas zèjj èn-nās $=$ »wesshalb »sitzest du nicht, redest du mich nicht an, kleidest du dich nicht, » wie es sich geziemt?" ca la fēn?-zèjj èn-nās =»wo (gehstdu) »hin?" - „Es passirt mir etwas Menschliches (= auf den Abtritt)".

Für »füllen" gebraucht man in Mekkah nur das Verbum IIten Stammes. Das "Füllen der Augen" bedeutet s behagen" (Dozy, Supplément i. v.) aber auch: »befriedigen" vgl. de Goeje's Glossar zum Ibn èl-Faqih i. v. L̊أ; auch Chron. der Stadt Mekkah, ed. Wüstenfeld III: 246 كان كرويّا نخيلا فى طايفة

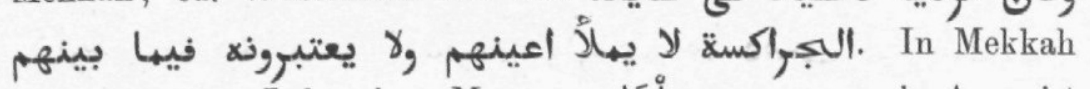

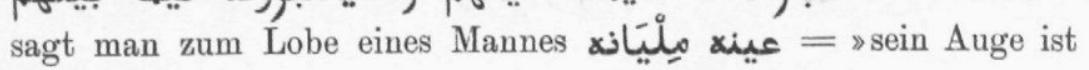
erfüllt", d. h. mâu țamma $\bar{a}^{c}=$ »er ist nicht begierig nach dem, was Andere besitzen"; es wird auch wohl speciell in Bezug auf

beschädigen, unbrauchbar machen; der Vte Stamm (أتسعسّر): solche Beleidigung oder Schaden erleiden (vgl. Dozy, Suppl. nach Boqtor: " عٌّ" mutiler"). 1ā tecaw wírn I $\mathrm{j} \overline{\mathrm{a}} \mathrm{s} \overline{\mathrm{e}} \mathrm{e} \mathrm{h}=$ "zerbrich mir die Glieder nicht, du!" sagt Einer, der geschlagen oder sonst gemisshandelt wird. la $\mathrm{a}$ e $\mathrm{e}^{\mathrm{c}} \mathrm{aw}$ wir è s-s $\overline{\mathrm{a}} \mathrm{a} \mathrm{h}$ h $\mathrm{a}$ q q a $\mathrm{t} \mathrm{I}=$ "verdirb mir meine Uhr nicht", gesagt zu einem Unkundigen der das Innere einer Uhr mit den Fingern berührt.

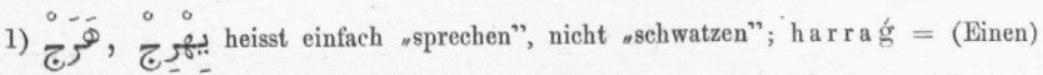
anreden, (mit Einem) sprechen; ihriğ oder ahriğ = sprich!"; harriğnI = "sprich (dentlich) zu mir!" harğ a h = Gerede; har ğ a h făr'ghah= "eitles Geschwätz". 
die Weiber gesagt ${ }^{1}$ ), z. B. von Einem, der mit seinen har am zufrieden ist, weder nach Vermehrung noch Veränderung strebt. Solchen Leuten gestattet man gern viel mehr Freiheit im Umgang mit fremden Frauen als unsittlichen oder auch keuschen Männern, welche immerfort Abwechslung in ihrem sexuellen Ungang wünschen. Das Auge ist ein Hauptsitz der Habsucht (ța mac) sowie des Neides (hasad); unzählige vulgärarabische Sprichwörter haben diese allgemein menschlichen Eigenschaften zum Gegenstande. Der Menschen Auge wird nicht gesättigt, d. h. sie begehren (jițma $\mathbf{a}^{\mathrm{u}}$ ), bis sie zu Grabe getragen werden; da füllt der Staub ihr Auge, und die Begierde hört auf.

Die Mekkaner sind fast alle auf die Ausbeutung ihrer jährlichen Gäste angewiesen, weil ihr Wohnort ihnen nichts bietet ausser seiner Heiligkeit. Dabei streben sie natürlich, einander zuvorzukommen; jeder warnt den Fremden vor seinen Mitbürgern, sodass der Vernünftige bald Keinem mehr Vertrauen schenkt. ahl makkah tammāin $a^{c} \bar{u} \bar{u}^{2}{ }^{2}$ billāh minnahum = „Die Mekkaner sind habgierige Leute, ich nehme meine Zuflucht "vor ihnen zu Allah", so spricht mancher Mekkaner; selbstverständlich nimmt er seine Wenigkeit von »den Mekkanern" aus. Leider ergibt sich meistens aus der näheren Bekanntschaft, dass diese Warner ziemlich Recht hatten, ausser mit der Ausnahme.

\section{7.}

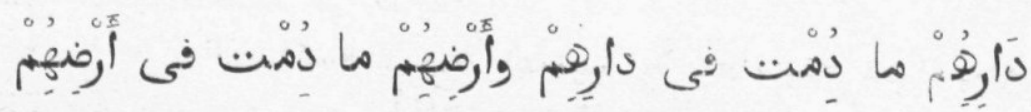

Verfahre vorsichtig mit ihnen, so lange du in ihrer Wohnung bist, und stelle zie zufrieden, so lange du in ihrem Lande weilst.

Die ouldar, welche auch in der heiligen Tradition anempfohlen wird, besteht darin, dass man ihnen mit Freundlichkeit entgegenkomme, ihre Eigenthümlichkeiten und Schwächen schone. Im alltäglichen Leben liegt der mudārāh weniger der Begriff der Liebenswürdigkeit als der einer gewissen unschuldigen Täu-

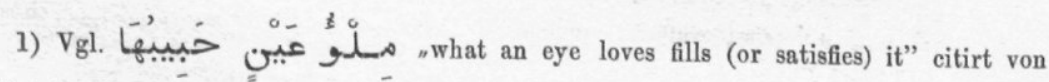
Wright, Grammar II, 275 .

2) Dieses d (j) wird von gebildeten Lenten richtig, von Andern wie $z$ (j) gesprochen. 
schung zu Grunde. Will man ohne Schaden für sich mit den Leuten verkehren, so muss man ja nicht zu aufrichtig sein; dieser Rath erlangt doppelte Bedeutung für solche, welche in fremden Ländern oder Städten weilen, also abhängiger von dem Wohlwollen ihrer Mitmenschen sind als sonst. Die höchste Bedeutung hat er, wenn man den Mekkanern Glauben schenken will, für Mekkah. Die älteren Pilgerhandbücher sind nicht nur unerschöpflich im Lobe der heiligen Stadt selbst, sondern auch ihrer Bewohner; diesen wird wegen ihrer Bewirthung der Gäste Allahs und wegen ihres stetigen Aufenthalts in der Nähe von Gottes Haus ein Recht auf die Verehrung aller Muslime zuerkannt. Die Traditionen, auf welche sich diese günstige Ansicht von den Mekkāwi's gründet, setzen bei den Hörern eine ziemlich grosse Naivetät voraus; man macht dieselben denn auch meistens nur ungebildeten Pilgern gegenüber geltend. Bei den Andern setzt man als bekannt voraus, dass solche Lobeserhebungen sich auf die längst vergangene Zeit beziehen, wo die Menschen überhaupt noch besser waren, und die Mekkaner den Gästen Allahs ihre Hülfe umsonst, liwa ğhi 'lláh boten.

Sobald der Mekkaner mit einem vernünftigen Fremden näher bekannt wird, schüttet er, in einem vertraulichen Gespräche mit ihm, das Herz über die ahl makkah aus. Nicht Habsucht ${ }^{1}$ ) allein, alle erdenklichen Laster legt er ihnen zur Last: is ma minnI, jā sidi, ahl makkah šajāṭı èd-dunjeh lā te-

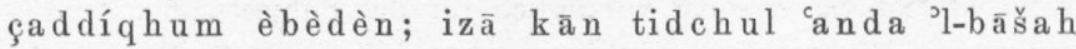
willā candak felūs jekarrimūk huma takrim zāid bil-ḥe $\mathrm{l}^{2}$ ), jeqūlú lak ahlán jā mōlánā, kuntū fēn? mā šufnāk, mā tisal cannanā! aqūl anā fi nafsi: dāe

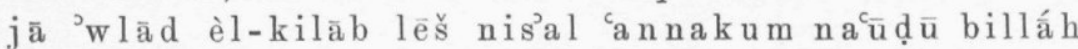
minnakum! lākin mā calehš challíhum jidchulū candak hatta tešũf ešs ghajèt murādahum, lā budd jibghū minnak hăğah; dārihum etc. $=$ »öre mich an, mein guter »Herr, die Mekkaner sind die schlimmsten Teufel der Welt, glaube

1 Vergl. $\mathrm{N}^{\circ} 46$.

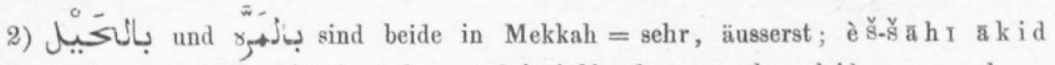

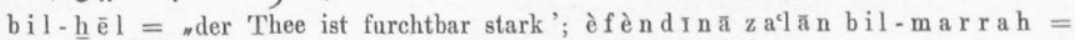
"der Wālī ist äusserst zornig.”. "tout-à-fait” (Landberg, Proverbes et Dictons, Glossaire i. v., ) heisst in M. bil.k ull $\mathrm{rjeh}$; "pas du tout" $=\mathrm{ma} \ldots$ marrah z. B. mā š ufuh marrah = "ich habe ihn gar nicht gesehen”. Vgl. No 40 , Anm. und No 48 . 
»ihnen niemals; wenn du Eintritt hast beim Pascha (d. h. èf èns dınā, dem Wālı des Ḥiğāz) oder wenn du Geld hast, so ehren » dich die Leute in ganz übertriebener Weise. Sie sagen dir: „Will» kommen, gnädiger Herr, wo warst du (in der letzten Zeit)? wir » shaben dich (seit lange) nicht gesehen, du fragst gar nicht nach »uns!" Ich sage aber zu mir selbst: »was soll denn das, ihr $\gg$ Hundesöhne? wesshalb sollen wir nach euch fragen ? Wir nehmen »»vor euch unsere Zuflucht zu Allah". Aber es macht nichts aus, >lass sie bei dir eintreten, damit du sehest, was ihr eigent»liches Verlangen ist. Kein Zweifel, dass sie etwas von dir wün»schen; verfahre u. s. w."

Die Wahrheit liegt, wie gewöhnlich, in der Mitte: die Mekkaner sind weder so schlecht, als jeder die Gesammtheit beschreibt, noch so gut, als man aus der Zusammenzählung der Selbstbeschreibungen vieler Individuen erschliessen könnte. Für die Fremden, welche längere Zeit in Mekkah verbleiben, hat es seinen Vortheil, dass die Einwohner sie mit dem angeführten Sprichworte vor sich selbst warnen.

Das Sprichwort ist der Form nach nicht so vulgär, wie manche der von uns aufgezählten; an Verbreitung steht es keinem andern nach. Wie man aus unserer Vocalisirung ersehen kann, gibt es eine mehr und eine weniger gebildete Aussprache. Der Vocal des

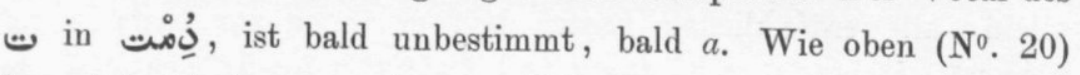
bemerkt, ist das a sonst vorzüglich für das Subjectssuffix der Iten Person im Gebrauche; hier kann aber schon wegen des vorhergehenden Imperativs keine Zweideutigkeit entstehen.

48.

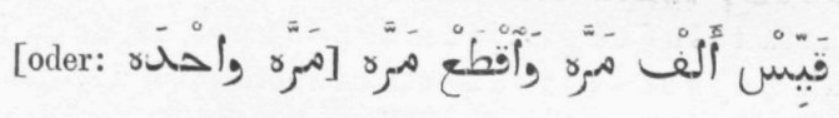

Miss tausendmal, dann aber schneide auf einmal durch.

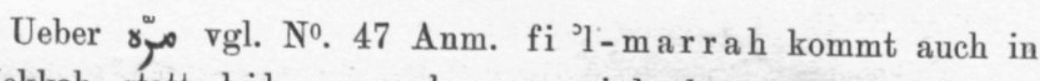
Mekkah statt bil-marrah vor, wird aber von eigentlichen Mekkanern kaum gesagt; wie oben bemerkt wurde, heisst es nie: "ganz und gar". chāliç kommt in dieser Bedeutung vor, aber fast nur zur näheren Bestimmung des Prädicats: an $\bar{a} t^{c}{ }^{c} b \bar{a} n$, arqān, wa ğ ${ }^{c} \bar{a} n \operatorname{cha} l i c ̧=$ sich bin ganz und gar erschöpft, 
DR. C. SNOUCK HURGRONJE, MEKKANISCHE SPRICHWÖRTER. 505

in Schweiss, krank"; huwa šè bah ${ }^{1}$ ) chāliç = »er ist ein ganz (alter) Greis". „Gar nicht" heisst bald mā... marrah, bald mā .... marrah $w \bar{a} h^{2} \mathrm{deh}$, oder auch, ohne irgendwelche Bezugnahme auf die Zeit: $m \bar{a} \ldots$ è bèdèn. $m \operatorname{arrah} w \bar{a} h^{2} \mathrm{~d} e \mathrm{~h}$ heisst nämlich nicht sein einziges Mal", sondern »auf einmal" und daher »gänzlich". $\mathrm{r} \overline{\mathrm{a}} \mathrm{h} \overline{\mathrm{u}} \mathrm{marrah} w \overline{\mathrm{a}} h^{2} \mathrm{deh}=$ auf einmal sind sie (alle) fortgegangen". māu bațțā marrah wāh ${ }^{3} \mathrm{deh}$ lākin $\mathrm{n} \overline{\mathrm{a}} \mathrm{qi}$ ç $=$ »es ist nicht ganz und gar schlecht, aber mangelhaft". mā lāqēt chudhrah fi 's - sūq èbèdèn = sich habe gar keine Gemüse auf dem Markte gefunden". Auch das a. a. O. erwähnte bil-kullījeh wird mit der Negation mà verbunden.

Das Sprichwort ist dem Schneidergeschäfte entnommen. Der vollständige Anzug des Mannes heisst bèdleh. Dazu gehören das $t \bar{o} b$, ein langes Hemd aus dünner weisser Leinwand (bèfteh), Kattun (šit) oder einem durchsichtigen tüll-artigen Zeuge (dara $\mathbf{a} b z \bar{u} n=$ Trapezunt), der $\operatorname{sirwāl~(Beinkleider)~mit~der~}$ dikkeh (tikkeh); über denselben tragen die mittleren und höheren Klassen den antarì (auch die šājah genannt), welches bier mit dem ägyptischen qufțan ${ }^{2}$ ) nahezu gleichbedeutend ist. Dieses Kleidungsstück wird aus ähnlichem gestreiftem Zeuge gemacht wie in Aegypten, aber in der heissen Jahreszeit ziehen die Meisten dünneres Zeug vor und kleiden sich in antarîs und Ueberkleider ( $\mathrm{g}$ ubbah's) aus der ganz durchsichtigen weissen dūria oder, wenn ihnen dies zu theuer ist, aus weisser Leinwand. Der 'antarı (š ājah) wird durch den Gürtel (hizām) ${ }^{3}$ ) zusammengehalten; dieser ist entweder ein zusammengefalteter

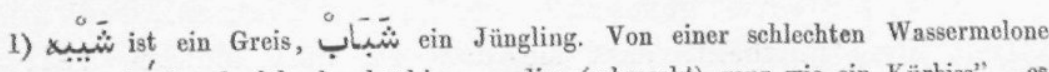
sagt man: hăda dubbah chāliç = "dies (schmeckt) ganz wie ein Kürbiss”, „es ist ein reiner Kürbiss".

2) Vgl. die Beschreibung und Abbildung Lane's, Manners and Customs (5th edit.) I, $36-37$.

3) Man nennt die dazu verwendeten Shawls auch g habā $\mathrm{nah}$, Plur. ghabān vorzüglich wenn man dieselben zur Herstellung einer ' $\mathrm{i} \mathrm{m} a \mathrm{~m}$ a h gebraucht. Die Syrer und Aegypter winden bekanntlich vielfach solche ghabān I um ihren Tarbusch herum; die Mekkaner gebrauchen dieselben in dieser Weise nur als Nothbehelf. Man pflegt zu Hause die 'i $\mathrm{m}$ a $\mathrm{m}$ a h abzulegen und den Kopf nur mit der a ra q i jeh (Schweissmütze) zu bedecken. Wenn man nun spätabends oder frühmorgens ausgehen muss und möglichst wenig Toilette machen will, so windet man einfach einen Shawl um die 'ara qijeh, gewöhnlich einen, der sonst als Gürtel dient. 'imām’tr fōq āchud ghabānah wekān = "mein Turban ist oben, ich will eine"ghabãnah nehmen, das genügt". 
Kashmirshawl (salım I) oder aus sogenanntem šām I oder istambūli-Zeuge (von hellgelber Farbe, mit dunkelfarbiger Seide durchwebt) gemachte Tücher. Ueber dem gestreiften 'antari trägt man inmer, über dem weissen aber bisweilen eine ğ ubbah von anderem Zeuge, sei es Tuch (جوخ) oder Seide; die Vornehmen haben dieselbe gewöhnlich aus Mohr, welches man qaramsūd

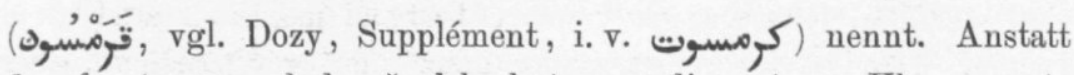
des antari und der ğ abbah tragen die unteren Klassen entweder gar nichts oder eine kleine gestreifte Weste (çidrrjeh) mit hübschen Randborden über den Taschen, oder (gleich über dem tōb oder über der Weste) ein bèdèn ohne Aermel.

Der beniš mit seinen weiten Aermeln ist fast gänzlich ausser Brauch gekommen; vor etwa 20 Jahren pflegten die vornehmeren Leute denselben noch an allen Feiertagen anzulegen; jetzt haben nur wenige altmodische Leute (nās qudum) diese Sitte beibehalten. Aus der Vergleichung dieser Notizen mit den Mittheilungen Burckhardts (Travels in Arabia, London 1829, I : 335 ff.) ersieht man, dass die launische Mode auch in Mekkah herrscht. Das Zusammensein von Leuten aus allen muslimischen Ländern reizt zur Nachahmung der Sitten und der Tracht. Uebrigens wirkt auch die Neigung der unteren Klassen, den Vornehmen nachzuäffen, dazu mit, dass Letztere dann und wann ihre Tracht ändern, um sich von dem profanum vulgus zu unterscheiden. Ueber die Weiber übt die Mode natürlich noch eine ganz andere Gewalt als über die Männer; da diesen die Sorge für die kisweh ihrer Frauen obliegt, gibt jede neue Mode zu bäuslichen Streitigkeiten Anlass. »Dieses Kleid ist noch wie nagelneu, du hast es kaum ein halbes Jahr, es hat soviel gekostet!" wendet der Mann ein, wenn seine Gattin ihm mittheilt, dass sie dasselbe dem Makler (dèllīil) übergeben will, um es auf dem Versteigerungsmarkte (s ūq èlḥarāğ) zu verkaufen. Da klingt ihm die kurze Antwort: bațțaluh = »man hat es abgeschafft" wie eine Schreckensnachricht in die Ohren; es hilft also nichts, es muss das gute Kleid dem fann ğedrd ${ }^{\mathbf{l}}$ ) Platz machen.

Das Wort bèdleh bezeichnet den vollständigen Anzug, wird aber auch für die ğ ubbah und den cantari gebraucht, vor-

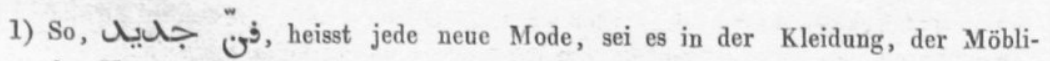
rung der Häuser oder in anderen Sachen. 
züglich wenn diese beiden Stücke aus demselben Zeuge gemacht werden. Man kauft sich z. B. eine țāqah (ein Päckchen) bèfteh oder dūria, nimmt dieselbe zum Schneider und sagt zu ihm: faççíl li min hádā bèdletēn $=$ »schneide mir aus diesem Zeuge zwei Anzüge"; in diesem Falle werden nur die ğubbah und der antari gemeint. Das tafȩil begreift das taqjis und das $q a t^{c}$ in sich; der Schneider jefaççil d. h. er nimmt einem das Maass, zeichnet dasselbe auf dem Zeuge ab und schneidet schliesslich mit der Scheere (maqaȩç) die einzelnen Stücke ab. Das Resultat der ganzen Handlung, der »Schnitt", heisst daher auch tafȩil: bèdletak há di lōnuh mā šá ’llāh ḥílu ${ }^{1}$ )

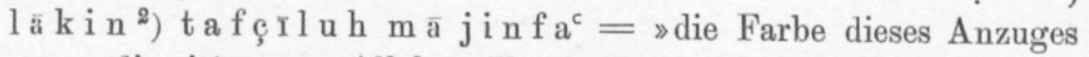
»von dir ist (was Allah will!) hübsch, aber der Schnitt taugt »nicht". Der Schneider, der etwas Gutes liefern will, muss also unserem Sprichworte zufolge mit der grössten Pünktlichkeit den ersten Theil der Handlung des $\mathrm{t}$ a f ȩ I l vornehmen; ist er einmal damit fertig, dann soll er auch ohne Zaudern schneiden.

Der Rath, welchen das nächstfolgende Sprichwort gibt, wird hier dahin ergänzt, dass man, nachdem der Entschluss gefasst ist, nicht länger auf beiden Seiten hinke.

\section{9.}

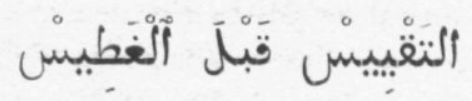

\section{Dass Messen muss dem Eintauchen vorangehen.}

Für »messen" und die davon abgeleitete Bedeutung »ermessen, vermuthen" gebraucht man immer den IIten Stamm قيَّس : تئس : Mes-

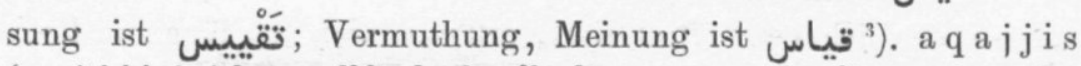

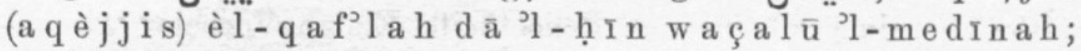
$\mathrm{m} \bar{a} \mathrm{u}$ qijāsak kède? = »ich denke mir, die Karavane ist

1) حلب bezeichnen verschiedene Nüancen des Schönen; ğam ml ist etwas vornehm und $\mathrm{kew}$ ajjis wird gar nicht gebraucht. $\mathrm{Vgl}$. $\mathrm{N}^{\circ} 30$

2) La kin und hatta setzt man in Mekkah oftmals dem Worte oder dem Satze, anf welche sie sich beziehen, nach, z. B. "Das Wasser ist bitter”. - bã rid l'ákin

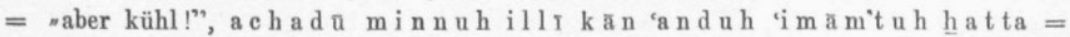
"sie haben ihm alles genommen, was er bei sich hatte, bis auf (sogar) seinen Turban".

3) Vergl, $\mathrm{N}^{\circ} 40$. 
sjetzt in Medinah angelangt; glaubst du nicht auch?" Ueber die Infinitive der Form فعيل vgl. No. 50, Anm.

Dem Handeln muss die Ueberlegung vorangehen. Derselbe Gedanke wird in etwas feinerer Form ausgedrückt in dem bekannten :

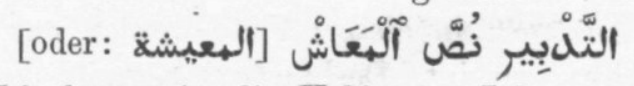

Die Ueberlegung ist die Hälfte des Lebensunterhalts.

Letzteres hört man in Mekkah nur von gebildeten Leuten sagen.

Es könnte Wunder nehmen, dass in dem wasserarmen Mekkah gerade das Bild des Eintauchens populär ist. Ǧiddah liegt aber so nahe, dass man von dorther leicht Ausdrücke herübernimmt, auch wenn der Sinn derselben ins mekkanische Leben nicht passt. Es gibt in Mekkah Tausende von Leuten, die keine Ahnung davon haben, wie ein Dampfer eigentlich aussieht; nur soviel haben sie gehört, dass es ein dampfendes, lärmendes, Feuer ausspeiendes Fahrzeug ist, welches sich mit unglaublicher Geschwindigkeit auf dem Wasser bewegt. Diese Vorstellung genügte aber im Ramadhān des Jahres d. H. 1302 dazu, einem Sohne Mekkahs mit allgemeiner Zustimmung den Zunamen $b \bar{a} b \bar{u} r^{1}$ ). zu geben. Nach dem 'is werden an den 'Ảbenden des Fastenmonats in der Moschee gleich die tarāwị (Gottesdienste von $20 \mathrm{rak}^{c} \mathbf{a}$ h's) abgehalten. Die zum Ýšā-Gottesdienste versammelte Gemeinde theilt sich dazu in Gruppen, deren jede etwa 10-100 Mann stark ist; jede Gruppe hat ihren, aus ihrer Mitte für den ganzen Monat gewählten, im ām. Einige von diesen Vorbetern richten die taraw i ha der Art ein, dass sie während der 30 Nächte ein oder mehrere Male den ganzen Qurān durchrecitiren; man kann sich aber auch für jede rakch mit der fātiḥah und einem sehr kurzen Kapittel begnügen. Da nur wenige anständige Mekkaner diese Gottesdienste vernachlässigen, aber viele während der Ramadhānnächte ausserordentlich beschäftigt sind, erfreuen sich die längeren Recitationen keiner allgemeinen Beliebtheit. Einige Vorbeter versammeln also die Gläubigen hinter sich, welche des Guten nicht zu viel haben möchten, und recitiren lauter kurze Suren. Einer von

1) Man sagt bāb ur und wābur, der Plural baw a $\mathbf{a} \mathbf{r}$ ist aber beliebter als wa $\bar{b} a \mathbf{r} \bar{t}$; für den Uebergang des $v$ in $b$ vgl. bintu (Louis d'or) aus venti; unser holländische Vice-consul in Giddah, Herr van der Chijs ist den Arabern nur als bekannt. Wie sehr man es liebt, auch von Fremdwörtern gebrochene Plurale zu machen, ersieht man aus der viel gebrauchten Pluralform $q$ a ba $\mathrm{d}$ In $\mathrm{nu}$ $q \bar{a} b$ u dān oder $q \mathbf{a} b d \bar{a} n=$ Kapitän. 
DR. C. SNOUCK HURGRONJE, MEKKANISCHE SPRICHWÖRTER. 509

denselben recitirte in jeder von den $20 \mathrm{rak}^{c} \mathbf{a}$ h's nur die fātihah und die 112te Sure; durch lange Uebung hatte er es in der Verbindung des unentbehrlichen ta ğ w Id mit der grössten Schnelligkeit so weit gebracht, dass die ganze Sache nur wenige Minuten in Anspruch nahm, woher die erstaunten Besucher des hạam ihn bald allgemein è $l-b \bar{a} b \bar{u} r$ nannten.

Das Eintauchen, resp. Waten, ist aber den Mekkanern nicht nur dem Namen nach bekannt. Die entsetzlichen Regenfluthen (sijūl), welche Westarabien dann und wann heimsuchen, machen aus einer Haupstrasse Mekkahs öfters auf 3-4 Tage einen förmlichen Giessbach. Auch sind mitunter ganze Strecken auf dem Wege von Mekkah nach Medinah dermassen überschwemmt, dass unser Sprichwort auch ohne bildliche Auffassung Anwendung findet.

50.

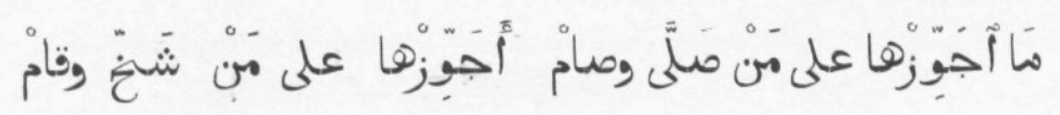

Ich gebe sie nicht dem zur Ehe, der betet und fastet, sondern dem, der harnt und aufsteht.

Der Vocal des Präfixes der Iten Person Imperf. der Verba IIten und IIIten Stammes ist gewöhnlich $a^{1}$ ), welcher mit vorhergehendem a leicht zusammenfliesst. Ueber den ausgedehnten Gebrauch der Präposition cala im Vulgärarabischen handelt Spitta, Grammatik, S. 370 ff. šachch ist das gewöhnliche Wort für بال, welch letzteres nur von Medizinern und vornehmen Leuten gebraucht wird, daher šuchchān = das Harnen ${ }^{2}$ ), der Urin, vgl. taflān oder tafalān $=$ Speichel, von tafal, taffal $=$ speien. Bekanntlich harnen die Muhammedaner immer sitzend (niedergehockt), und erheben sie sich erst nach weitläufiger Reinigung. Das Pro-

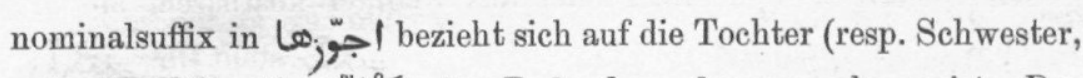
auf alle Fälle die مَوْليَّة) des Redenden, deren walī er ist. Der

1) Vergl. $N^{\circ} 12$, Anm.

2) Die Handlung heisst auch š a c h I ch ; überhaupt ist die Form فَّ für Infinitive nicht so selten, wie Spitta, Grammatik, $\$ 95$ meint; so $\mathrm{ghat}$ t I s = eintauchen, . charit = die Hant unter den Kopfhaaren reinigen (von Frauen). 
w alı gebraucht diese Redensart, wenn ein heirathslustiger Mann das Gespräch allmählich auf seine Mündel hinlenken zu wollen scheint, und gibt ihm dadurch höflich, aber spöttisch zu erkennen, dass er nur nicht weiter gehen soll, weil von der gewünschten Ehe nicht die Rede sein kann. Es ist kein besonderer Grund vorhanden, weshalb der unglückliche Candidat als »der, welcher fastet und betet" und der zukünftige Bräutigam als»der, welcher harnt und nachher aufsteht" bezeichnet werden, da beide Prädicate von jedem ordentlich erzogenen Muhammedaner gelten; auch liegt die Absicht ganz fern, den Ersten als besonders religiös zu bezeichnen, den Andern spöttisch anzudeuten. Für die heutigen Mekkaner besagen die Ausdrücke nichts mehr, als wenn man statt derselben etwa Hans und Friedrich setzte. Mehr Tiefsinn ist auch früher wohl kaum in dem Sprichworte versteckt gewesen.

51.

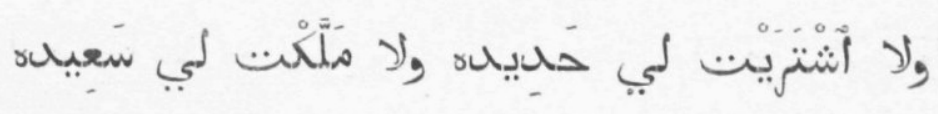

Du hast mir weder ein Fussband gekauft, noch mir eine Sklavin geschenkt.

Das - der zweiten Person sing. mase. wird hier in beiden Fällen entweder mit einem unbestimmten Vocal ( $t e)$ oder mit dem sonst nur bei der ersten Person ${ }^{1}$ ) üblichen $a$ (ta) gesprochen. Die erste und zweite Person sind einander, wenn kein Bindevocal gebraucht wird, bekanntlich immer gleich. Hier ist die sonst (wo ein Vocal erfordert wird) für die zweite Person übliche Pluralendung ( $\bar{u}$ für um) unnöthig, weil das nachfolgende لي im Zusammenhang jeden Zweifel wegnimmt. Die hadıdeh (eigentlich: Eisen) ist ein von Frauen und Kindern getragener Fussring; man macht denselben aus Silber oder aus weniger kostbarem Metall,

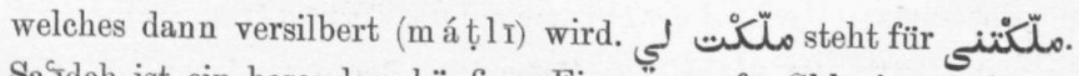
Sa Tdeh ist ein besonders hänfiger Eigenñame für Sklavinnen ebenso wie $\mathrm{Sa}^{\mathrm{c}}$ id für Sklaven, etwa wie Hans und Hannchen. Der Gatte ist bekanntlich nach dem muslimischen Gesetze verpflichtet, seiner Frau ihrem Stande gemässe Kleidung, Wohnung und Bedienung

1) Vergl $N^{\circ} 20$. 
zu verschaffen. In Bezug auf die Bedienung ist es der Frau natürlich bei Weitem am liebsten, wenn der Mann ihr eine Sklavin kauft, und in der Kleidung begnügt sie sich ungern mit dem gesetzlich bestimmten Minimum; ein einigermassen bemittelter Mann kann schwerlich umhin, seiner Gattin wenigstens einige Armbänder (sa ${ }^{c}$ eh, suwār, ii $\left.^{c} \mathrm{dhad}^{1}\right)$ ), Fussbänder (chulchāl, hạa $\mathrm{i}-$ deh), Ohrringe (halaq), einen Nasenring (chuzām) zu geben. Thut er es nicht, so bekommt er, wenn er ihr irgendwelche Vorwürfe macht, schon bald zur Antwort: »Hast du denn das »Recht, das alles von mir zu verlangen? Woher? du hast mir »weder ein Fussband gekauft, noch mir eine Sklavin geschenkt, »mir keinerlei Beweise besonderer Liebe gegeben".

52.

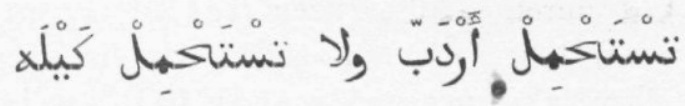

Ein è $r \grave{e} b b$ erträgst $d u$, und ein $k \bar{e} l e h$ erträgst du nicht?

Das èr $\mathrm{dè} \mathrm{b} \mathrm{b} \mathrm{(ein} \mathrm{Hohlmass)} \mathrm{hat} 40 \mathrm{ke}$ leh. Diese Redensart wird meistens als Schmeichelei von einer Frau zu ihrem Manne gebraucht, z. B. sie hat ein neues Kleid von ihm verlangt, er behauptet aber, kein Geld dafür verfügbar zu haben; nun versucht sie. ihn dadurch zu überreden, dass sie seiner Freigebigkeit das höchste Lob spendet. »Sonst bist du in grossen Sachen immer so »nachgiebig, und jetzt weigerst du dich, mir diesen kleinen Wunsch » zu erfüllen?"

53.

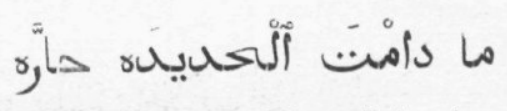

Während das Eisen heiss ist.

Dieser elliptische Satz dient dazu, sich selbst oder Andere zu schnellem Handeln zu ermuntern, weil die Umstände günstig sind. »Man muss das Eisen schmieden, so lang es glüht". هلهيل (für die Bedeutung »Fussband" vgl. No. 51) heisst ein Stück Eisen, eine Eisenstange.

1) Der $\mathrm{mi}^{\mathrm{c}} \mathrm{dh}$ a d ist ein einziges. Armband, welches am rechten Oberarme getragen wird; die beiden andern Arten trägt man an den Pulsen der beiden Hände. 
512 DR. C. SNOUCK HURGRONJE, MEKKANISCHE SPRICHWÖRTER.

54.

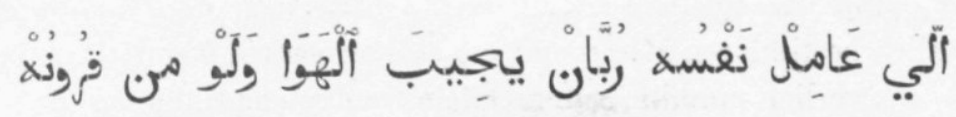

Wer sich für einen Lootsen ausgibt, der muss den Wind zur Noth aus seinem Kopfe hervorbringen.

illı wird häufig mit einem Particip construiert: illı šā rid me ha $\mathrm{m} \mathrm{m}$ è $\mathrm{d}=$ ع es ist Muhammed, der ausgerissen ist." heisst: »sich ausgeben für...."; diesen Ausdruck und andere, welche damit verwandt sind, erklärt mit zahlreichen Belegen Dozy, Supplément, i. v. lēš ti ‘ mal nafsak kebireh=»wesshalb führst du dich so hochmüthig auf ?" Hier, wie in sehr vielen Fällen, kann man سمّ ersetzen (lēš tesáw durch etc.); nicmal (nesawwi) lak šăhì?= =sollen wir dir Thee machen?" camalt ē jā 'ḥmār? hast du da gemacht, du Esel?" - »ich habe es nicht mit Vorsatz gethan." - ca malijeh ist die Methode, eine Sache anzufertigen, bei welcher es gewisse Kunstregeln zu beobachten gibt: èddūjān ${ }^{2}$ ) 'candi lākin mā araft èl- 'amalrjeh $=$ ¿ich habe die Medicamente, aber ich verstehe die Zubereitung nicht”. rub$\mathrm{b} \overline{\mathrm{a}} \mathrm{n}$ heisst eigentlich der Lootse oder der Steuermann; die Städter nennen aber jeden Seemann so, welcher augenscheinlich höher steht als die Matrosen (baḥrijeh), ohne Schiffskapitän zu sein. wela ${ }^{3}$ ) kommt in der mekkanischen Umgangssprache oft ganz für sich, als elliptischer Satz vor: $m \bar{a}$ 'rūh lahum dā'l-ḥin bèlki candahum nās. - welau! = »ich will jetzt nicht zu ihnen gehen, vielleicht sind Leute bei ihnen." - »und wenn (dem auch so wäre, was würde es dir machen)?" - قرونه kann »seine Haartressen" bedeuten (vgl. Dozy, Supplémenti. v.; Burckhardt, Bedouins and Wahabys, I: 49) ${ }^{4}$ ), heisst aber auch »die

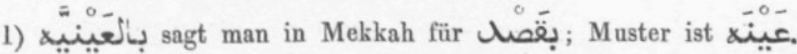

2) Plural von dáw a (sl, $)$, vgl. g hátā (Deckel) g h utjān u. a. m.

3) Vorzuglich in dieser Combination, sei es als elliptischer Satz oder (wie im Sprichworte) in der Bedentung "wenngleich", ist diese Conjunction in Mekkah überaus häufig. Vgl. Spitta, Grammatik, S, 184.

4) Prof. Nöldeke gibt mir die nachfolgenden Belege aus der älteren Litteratur an: Buchāri I, 318, Z. 4, 7 vgl. ibid. unten; Ibn Hišām 809, Diwān Hudail 68, 1; Imru'ul-Qais 19, 32 (Ahlwardt), Hamãsah 757, 14. 
Stirnbeinhügel" und steht hier zur Bezeichnung des ganzen Kopfes.

Wer behauptet, eine Sache zu verstehen, nun aber, wenn die Gelegenheit sich darbietet, Proben seiner Fertigkeit zu geben, nichts zu Stande bringt und dann vorgibt, es seien allein die ungünstigen Verhältnisse, das schlechte Material u. s. w. an dem Misslingen Schuld, den hat man in Verdacht der Unfähigkeit; der tüchtige Handwerker bewährt sich unter allen Umständen. Solche Aufschneiderei tadelt man, indem man sie mit dem Verfahren des guten Lootsen vergleicht. Das Volk wendet aber das Sprichwort auch auf Fälle ganz anderer Art an; es drückt darin sein Misstrauen gegen die Aufrichtigkeit von Leuten aus, welche betheuern, dass sie sich für eine Sache aufs fleissigste bemühen, , obgleich das Resultat immerfort ausbleibt. Manche Männer z. B. geben ihrer Frau dasselbe Haus zur Wohnung, in welches sie solche Verwandte untergebracht haben, welche sie auf ihre Kosten beherbergen müssen. Dies kann allerdings nur dann stattfinden, wenn die Frau es sich gefallen lässt, deun das Gesetz erkennt ihr das Recht auf eine separate, ihrem Stande gemässe Wohnung zu. Nicht selten führt ein solches Zusammenwohnen auf die Dauer Misshelligkeiten zwischen den Verwandten des Mannes und seiner Gattin herbei. Ist die Geduld der letzteren erschöpft, so sagt sie zu ihrem

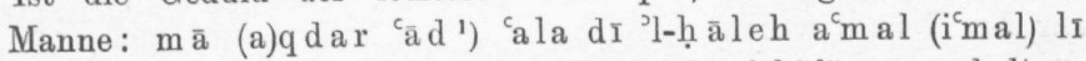
bēt šari $=$ »ich kann in diesem Zustande nicht länger aushalten, »bereite mir eine den Vorschriften des Gesetzes entsprechende „Wohnung."

Der imperative Theil dieses Satzes ist der technische Ausdrück für solche Fälle. Der Mann kann dagegen nichts Wesentliches einwenden; er entschliesst sich aber nicht ohne Widerstreben zu dieser Vermehrung seiner jährlichen Ausgaben. Zunächst vergisst er die Sache täglich, verspricht jeden Abend, dass er sich den nächsten Tag nach den verfügbaren Wohnungen erkundigen wird. Sodann gibt er vor, er sei zu wiederholten Malen vom Ma' $\bar{a}$ bis zur Mèsfalah durch Mekkah gegangen, habe sich alle Wohnungen angesehen, aber keine dem Zwecke entsprechende gefunden; er werde aber nicht nachlassen, denn es sei ihm voller Ernst mit der Sache. Die Frau kann jetzt aber die Aeusserung ihres Zweifels nicht länger unterdrücken: ' $a$ ğa $\bar{i} b$ jā sid $\bar{i}^{2}$ ),

1) Vgl. Landberg, Proverbes et Dictons I, Glossaire i. v. عـو . In Mekkah habe ich niemals eine andere Form als $m \bar{a} \ldots . . \bar{a} d$ gehört.

2) Die Frau pflegt ihren Mann entweder mit der kunjah oder mit jā sı $\mathrm{d} I$ 5e Voigr. I. 
billáhi atfarrağt cala 'l-maḥall kullahā wemā lāqēt wálā ${ }^{1}$ ) hạăgeh menās'bah? mā jidchul fi 'l-caql hádā; illı ${ }^{c}$ āmil nafsuh etc. = »Sonderbar, mein Herr! bei Allah, »hast du dir alle Wohnungen angesehen und gar nichts Passen»des gefunden? dies geht wirklich nicht in den Verstand (kein »vernünftiger Mensch kann es glauben); »wer sich für einen » Lootsen ausgibt u. s. w." ",

55.

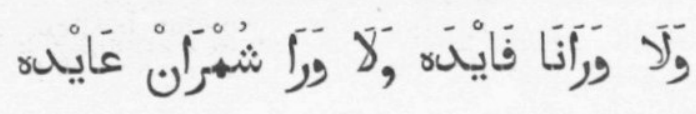

Hinter uns steckt kein Vortheil, ebenso wenig als es hinter Schumrān eine Abgabe gibt.

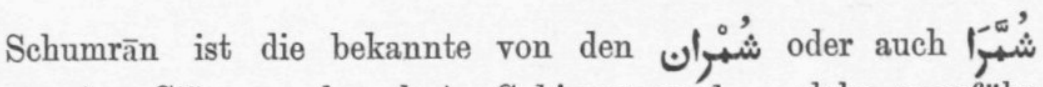
genannten Stämmen bewohnte Gebirgsgegend, welchẹ ungefähr die südliche Grenze des Gebietes darstellt, wo zu gewöhnlichen Zeiten immer die Autorität der Scherife von Mekkah anerkannt wurde. عايْله (der Singular steht nur des Reimes wegen), bezeichnet allerlei Sachen und auch Vorgänge, welche sich nach einer zur Regel oder gar zum Gesetze gewordenen Gewohnheit wiederholen: jährliche Geschenke, Abga-

anzureden. Mit jă s I $\mathrm{I}$ redet man auch seinen Grossvater und dessen Brüder, öfters auch dessen Vettern an; vorzüglich diesen Brüdern und Vettern legt man das s I d I

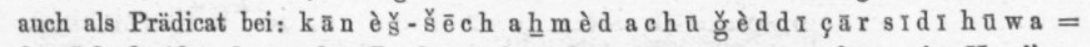
der Schēch Ahmed war der Bruder meines Grossvaters, er war also mein Herr" çār $\mathbf{r}$ (ص) wird in Mekkah ganz ebenso gebraucht, wie b a q a (Spitta, Grammatik, S. 177) in Aegypten. Dieses بقى heisst auch sonst im ägypt. Arabischen "werden", und diese Bedeutung, nicht " sein" (so Spitta), liegt dem adverbialen Gebrauche zu

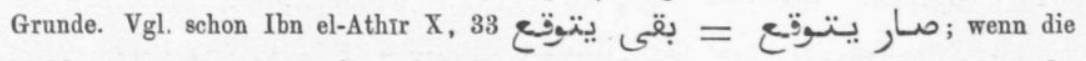
Mekkaner sagen: çar māje rahh lahum 'a d = "(also) pflegt (pflegte) er nicht mehr zu ihnen zu gehen", so kann dabei die Person selbst, welche den Verkehr abbricht, als Subject za çã r gedacht werden, ebenso wie in dem aus Ibn el-Athir citirten Beispiele. Da man nun aber für die IIte und IIIte Person Sing. und Plur. ebenfalls nu r

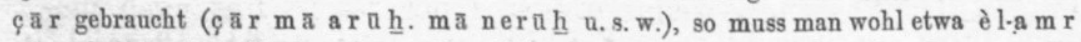
oder ähnlich als Subject ergänzen. Der Uebergang von diesem Gebrauche des unveränderlichen $c^{\bar{a}} \mathbf{r}$ zum rein adverbialen Gebrauche ist leicht verständlich: $c^{a} \mathbf{r}$ è $\mathbf{n} \mathrm{e}$ mènte rādhI = "also du willst nichtp" çār hawa min ahl èl-y̆g a wah $=$

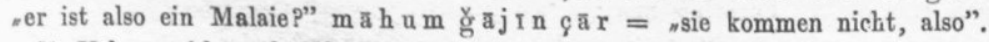

1) Ueber wála agl. Nº 18. 
DR." c. SNOUCK HURGRONJE, MEKKANISCHE SPRICHWÖRTER. 515

ben, Festlichkeiten u. s. w. (vgl. auch Dozy, Supplément, i. v.); als Singular gebraucht man auch sole. So erhalten auch die regierenden Scherife von den ihnen untergebenen Stämmen gewisse durch altes Herkommen geregelte Abgaben, 'cawāi d. Bei jedem zu leistenden Dienst, jeder zu unternehmenden Arbeit, formulirt der Durchschnittsaraber laut oder leise die Frage: ēš èl-fājdah = »was für Gewinn oder Vortheil wird sich daraus für mich ergeben ?" Die Bedeutung, welche dem ersten 1,g in diesem Sprichworte beigelegt wird, habe ich nicht mit völliger Sicherheit feststellen können; sie ist den Leuten, welche die Redensart gebrauchen, selbst nicht recht klar, weil sie ausserhalb des sonstigen Sprachgebrauches liegt. Wenn statt waránā: ḥawālèna oder hawālēnanā stünde, so wäre der Sinn: »es gibt von uns keinen Vortheil zu ziehen, ebenso wenig u. s. w." So wird im Ḥiğāz folgendes ägyptisches Sprichwort gebraucht: $m a \bar{a}$ ḥ $a w a \bar{l}$ ēn èçÇa $a^{c} \bar{a} j d a h$ fājdah illā kelēmah zājdah= $=$ von den Leu»ten Oberägyptens gibt es keinen Gewinn zu erlangen, ausser etwa »einem überflüssigen Wörtchen"; mit diesen Worten bezeichnen zwar auch die Mekkaner den geizigen Charakter der Leute vom Ça ${ }^{c} \mathbf{I} d$, aber sie wenden dieselben häufig auch auf Geizhälse irgendwelcher Herkunft an. Hier wird ha wā lēn von jedem Mekkaner verstanden, obgleich das Wort in dieser Bedeutung in Mekkah selten ist und man dort eher geneigt wäre, 'can da zu sagen. Es ist möglich, dass wárā hier $=$ hạ a àlēn = canda genommen werden muss, denn das Sprichwort wird zu Einem gesagt, der Andere jeden Augenblick um Dienstleistungen und Hülfe angeht, ohne seinerseits ihre Bemühungen je zu belohnen, und die unzweifelhafte Absicht ist, einem Solchen zu sagen, von jetzt an sei es mit diesem ungleichen Verhältnisse aus. Also: belästige uns nur nicht mehr mit deinen Bitten, denn es gibt (jetzt) bei uns nichts (mehr) auszubeuten, ebenso wenig u. s. w. Da aber wárā in diesem Sinne sonst unbekannt und wohl überhaupt nur wegen des folgendem wárā gewählt ist, wäre vielleicht noch eine andere Erklärung

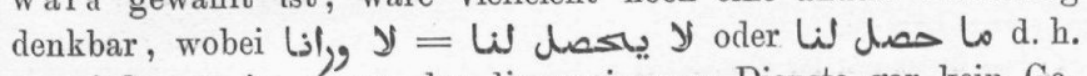
es wird uns ja wegen der dir erwiesenen Dienste gar kein Gewinn zu Theil, ebenso wenig u.s.w. (oder: es ist uns noch niemals.... zu Theil geworden). 
56.

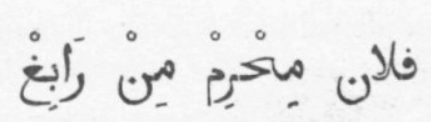

N.N. hat von Räbigh an den Thruäm angelegt.

Rābigh ist die bekannte, 3-4 Tagereisen nördlich von Mekkah, eine Stunde östlich vom Meere gelegene Ortschaft, wo die vom Maghrib, Aegypten und Syrien kommenden Mekkahpilger den Ihrām anzulegen haben ${ }^{1}$ ). Eigentlich sollten diese, falls sie den Weg über Medinah nehmen, den Iḥrām schon viel früher, nicht weit von Medinah anlegen; sie schieben es aber fast alle bis Rābigh auf. Wer zur See reist, unterzieht sich dieser Vorschrift, sobald das Schiff gegenüber von Rābigh gelangt ist. miḥrim ist die Vulgärform für muhrim.

Diese Redensart gehört zum speciellen Sprachgebrauche der geselligen Partien (q ēlah's) in Mekkah. q ēlah ist bekannt genug in der Bedeutung der "Sieste" oder des Anfenthaltes am Mittage; zur mekkanischen Bedeutung des Wortes stimmt in den Wörterbüchern nur Dozy's »passer la journée" (Supplément, i. v. قيّل, nach Cherbonneau). Jede Partie, jedes gesellige Zusammensein von Männern oder Frauen, welches ohne vorhergehende Einladung zu Stande kommt, heisst q ēlah, und die versammelten Freunde sind meqèjjilın; jede Mahlzeit oder Festlichkeit, zu der man Bekannte einlädt, heisst ebenso wie die Einladung selbst cazi$\mathrm{mah}$ und die eingeladenen Gäste sind $\mathrm{ma}^{\mathrm{c}} \mathrm{z} \overline{\mathrm{u}} \mathrm{m} \mathrm{In}$. Die ${ }^{\mathrm{c}} \mathrm{azimah}$ hat in den meisten Fällen einen besonderen Grund ${ }^{2}$ ), welcher aber nicht allen Gästen bekannt zu sein braucht. Gewöhnlich hat die Zusammenkunft vor dem Essen einen religiösen Charakter, indem ein oder mehrere fúqahā einige Theile des Qurāns und ein mōlid (Geschichte des Propheten oder Lobgedicht auf denselben) recitiren und den Gästen vorgehen im allgemeinen

1) Das Gesetz gibt für diese Pilger a l-Ǵ $\mathrm{uhfah}$ an; da dieser Ort aber nicht mehr bekannt ist, hat man denselben durch den Marktflecken $\mathrm{R} \overline{\mathrm{a}} \mathrm{bigh}$ ersetzt. Der Thrām ist nicht, wie die europäischen Handbücher es lehren, mit der lḥrām-kleidung-identisch; jede Uebertretung der Vorschriften, welche sich auf die Kleidung beziehen, kann durch Opfer oder Fasten ersetzt werden. Das Wesentliche im Ihräm ist nur die nijjah, das Aussprechen oder innerlich Formuliren der Absicht, die Pilgerfahrt zu machen.

2) Rückkehr eines Mitgliedes der Familie von einer Reise, Beschneidung, Rasirung des Hauptes neugeborener Kinder und dgl. 
dikr ${ }^{1}$. Nach dem Essen waschen alle sich die Hände, welche sodann gewöhnlich mit Rosenwasser begossen und berüuchert werden; und darauf kehren sie heim, den Gastherrn oder seine bei der Thüre stehenden Verwandten mit Segensprüchen überhäufend. Letztere erwidern daranf mit dem Danke für die Mähe, welche sich die Gäste um ihretwillen gegeben haben: $\mathrm{sakar}^{\mathrm{k}}$ Allah sajakum heisst es gewöhnlich.

Ganz anders die qêlah; hier ist nichts Förmliches, weder förmliche Einladung noch ordnungsmässige Qurānrecitirung oder dikr, fast alles ist den Umständen und dem Belieben der meqèjjilın überlassen. Findet die qēlah im Hause eines Mekkaners statt, so ist sie gewöhnlich durch irgend eine zufallige Begegnung veranlasst worden. A. geht z. B. zu B. in der Absicht, ihn ganz flüchtig zu besuchen; B. hat zufillig gerade den beiderseitigen Freund (mehibb èl-ğamr $)$ C. bei sich, ist gut aufgelegt und lässt seine Besucher nicht gehen. Wer von den Bekannten noch zufallig hereintritt, wird mit festgehalten; der Hausherr sendet noch etwa zu drei oder vier Freunden oder Nachbarn, deren Anwesenheit allen erwünseht ist. Jeqūl lak sIdr atfaddhal anduh fi 'l-bēt dā 'l-ḥineh $=$ mein Herr lässt »dir sagen: sei so freundlich zu ihm (zu kommon) in Haus jetzt „im Augenblick", sagt der abgesendete Sklave. ë̌̆ ca ndahum = »was gibt's denn bei ihnen?" bemerkt der Aufgeforderte. meq èjjilın humma = sie halten qēlah", antwortet der Sklave lachend, »sidi felān wesidi felān" u.s. w. = »mein »Herr A. und mein Herr C. u. s. w. sind alle da". Ebenso geht es unter Damen; Freundinnen und Nachbarinnen kommen zufällig zusammen oder werden theilweise zusammengeholt; man macht Kaffee und Thee, die šišeh's (شِيَشْ) werden unaufhörlich gestopft und mit frischem Wasser versehen, man kocht und brät. Ein guter Bekannter betritt die Vorballe (dihliz) ${ }^{2}$ ) des Hauses, hört den Lärm oben und fragt den Hausherrn: ē̌s $h \bar{a} d \bar{a}^{\prime} t-t a b c h$ wèn-nafch $h=$ »was ist das für ein Kochen »und Geräusch (Blasen)?" candahum qēlah ist die Antwort, d. h. »Sie (harimi, gewöhnlicher ğamáatis ${ }^{c}$ ) oder ahl èl-

1) Gewöhnlich dikr oder dikir gesprochen.

2) Ǧiddah heisst vielfach dihlız èl-ha ram $=$ die Vorhalle des heiligen Gebietes.

3) Ǧa máat I heisst: meine Frau, meine Weiber und Sklavinnen oder die weiblilichen [Mitglieder meiner Familie; è l-ğ a $\mathrm{m}$ ăa h bezeichnet auch eine dem Redenden 
$\bowtie b \bar{e}$ ) haben qēlah". Eine andere, sehr beliebte Form der $q \bar{e} \mathrm{l} l a h$ ist das Picknick. Einige Leute (oft ganz verschiedenen Alters) schiessen dazu etwas Geld zusammen, oder jeder übernimmt die Besorgung eines Theiles des Nöthigen, z. B. Einer bringt tumbāk und šršeh's, einige Andere bringen Reis, ein Anderer die Gewürze (ab̄̄zīr) und Kochgeräthe, alles nach vorher gemachter Verabredung. Ein paar von den jüngeren Leuten der Gesellschaft verstehen wohl meistens genug von der Kochkunst, um auch in dieser Beziehung als Aufwärter (mebāširin) zu fungiren; sonst nimmt man dazu Sklàven oder einen kundigen Koch (țabbāch) mit. Ist es vorzüglich auf die Schmauserei abgesehen, so wählt man als Ort der Zusammenkunft ein paar luftige Zimmer in der Stadt; es verfügt wohl immer Einer von den Schmausern über ein halb oder gänzlich unbewohntes Haus, namentlich wenn noch keine Pilger angekommen sind. Bringt dieser und jener von den m e q èjjil In einen Freund als Gast

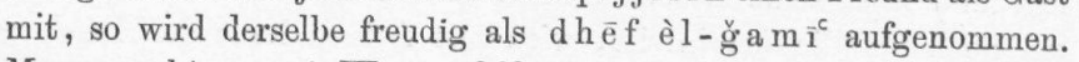
Man raucht zuerst Wasserpfeifen, isst, trinkt Kaffee und Thee, raucht, schläft und geht wieder nach Hause. Gemüthlicher als diese Partien sind die, zu welchen man sich an einem Orte ausserhalb der Stadt versammelt. Es gibt in der nächsten Umgebung Mekkahs viele Sommerfrischen, welche die Eigenthümer gern ihren Freunden zur Verfügung stellen; auch die unbewohnten Landhäuser der Scherife mit den dazu gehörenden Palmen- und Obstgärten kann man meistens gegen ein bachšıš an die Thorhüter zum Zwecke einer q ēlah benutzen. Eine nach vorn offene Vorhalle ( $\mathrm{d} \overline{\mathrm{i}} \mathrm{w} \overline{\mathrm{a}} \mathrm{n})$, deren Bodenfläche mit erhärteter cementartiger Masse belegt (mețabtab $\left.{ }^{1}\right)$ ) ist, wird dann gewöhnlich mit den nöthigen Matratzen (țurrāhāt) und Kissen (mesānid und mechaddāt) bequem zum Sitzen eingerichtet. Vor dem Eingange derselben findet sich vielfach eine birkah d. h. ein mit

und dem Angeredeten bekannte Person, welche man wegen der Anwesenheit anderer Leute nicht näher bezeichnen will

1) Die Fussböden der Zimmer, Hallen und des bēt èl-mã (vergl. unten $N^{\circ} 65$ ) sind in den besseren Wohnhäusern immer mit $t \circ b \mathrm{t} a \mathrm{~b}$ (einer Art Cement) belegt; desgleichen auch die Treppen (darağa h, Plural: darağ und durğ a n). In den älteren und weniger vornehmen Häusern hat man auf allen Stockwerken einen Sandboden, welcher mit aus Palmenblättern geflochtenen Matten ( $\mathrm{ch}$ a ç a f) bedeckt ist, über

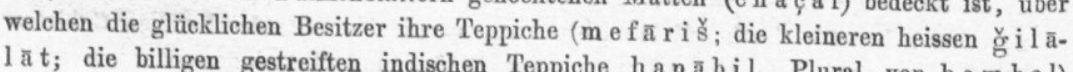
$\mathrm{l} a \mathrm{t}$; die billigen gestreiften indischen Teppiche $\underline{\mathrm{h}}$ anābil, Plural von $\underline{\mathrm{h}} \mathrm{am} \mathrm{mal}$ )
ausbreiten. 
einigen hundert qirbah's Wasser gefültes Bassin, welches die nächste Umgebung ein wenig abkühlt; darin tauchen die jüngern Leute wohl zur Erfrischung des Körpers unter. Mancher wird zum Scherze von seinen Genossen hineingeworfen oder von den darin Befindlichen im Vorbeigehen hereingezogen. Um die birkah herum dehnt sich der Garten aus, in welchem dichtbelaubte Bäume den darunter Liegenden Schatten gewähren. Jeder amüsirt sich in seiner Weise; während die Jünglinge scherzen und spielen, sitzt manchmal im dīwān ein Alter einem Kreise von Zuhörern Abschnitte aus einem interessanten Buche vorlesend ${ }^{1}$ ) und schlummern Andere draussen im Garten. Nur zu den Zeiten des Gottesdienstes versammlen sich Alle, um sich die Vorzüge der gemeinschaftlichen çalāt nicht eutgehen zu lassen; diejenigen, welche in einen Zustand der Unreinheit gerathen sind, hockern an der birkah nieder, um ihre religiösen Waschungen zu vollziehen; die sèğğg dah's werden ausgebreitet, der Aelteste oder der Gelehrteste aus der Gesellschaft steht voran, lässt den a d̦a n und die iqāmah ertönen und betet vor. Nach dem çala t betet jeder für sich in sitzender Haltung ein kürzeres oder längeres Gebet $\left(d u^{c} \bar{a}\right)$ oder summt doch einige religiöse Formeln (dikr) vor sich her. Dann erheben sich Alle und beschliessen die Andacht, indem Einer zum Anderen sagt: taqabbal Alláh $=\triangleright$ Allah »nehme (deine fromme Uebung gnädig als vollgültig) an!" worauf dieser mit einem: taqabbal mínnanā wemínnakum $=$ „Er nehme an von uns und von euch!" antwortet. Auch zur Mahlzeit versammeln sich die meqèjjilı̃n in dem dīwān und gruppiren sich je 5-6 um eine sufrah herum. So oder ähnlich geht es bei den qēlah's zu; dieselben gebören zu den Hauptvergnügungen der Mekkaner aller Stände, und eine q $\bar{e} l a h$ nimmt öfters zwei Drittel eines Tages in Anspruch.

Kommt nun Einer mit leeren oder nahezu leeren Händen zu einer solchen Picknick-qēlah, wo jeder Theilnehmer seinen Antheil in natura zu liefern hat, da sagen die Genossen spöttisch zu einander: "Der hat von Rābigh an den Iḥ̂a $\mathrm{m}$ angelegt." Ueber den Ursprung dieses Ausdruckes wusste mir Niemand genaue Auskunft zu ertheilen; über die Bedeutung dagegen ist kein Mensch zweifelhaft. Für Mekkah und seine Bewohner hängt bekannt-

1) Ich war einmal bei einer $q \bar{e} \mathrm{l} a \mathrm{~h}$ zugegen, wo aus dem $\mathrm{H}$ è z z è $\mathrm{l}-q \mathrm{u} h \mathrm{u} f \mathrm{u}$. $\mathrm{a}$. eine hübsche Auseinandersetzung über den Begriff der $\mathrm{q} e \overline{\mathrm{l}} \mathrm{l}$ a h vorgelesen wurde; leider kann ich im Augenblick die Stelle nicht auffinden. 
lich die Bedeutung und der Werth jedes Landes der Welt aufs Engste mit der Anzahl und dem Wohlstande der Pilger zusammen, welche es jährlich liefert. Waren vielleicht die Pilger, wolche den Weg über Rābigh zu nehmen pflegten, zur Zsit der Entstehung unserer Redensart ihrer Armuth und ihres Geizgs halbər in Mekkah verrufen ?

In Bezug auf die grosse Mehrzahl der pilgernden Magharibinor und Aegypter läge diese Deutung nahe, dagegen nicht für die von Syrien kommenden ha a ğğ I's. Die Ersteren nehmen meistens wenig Geld mit und lassen sich die immer zu bezahlende Hülfe der Ğiddāwr's und Mekkāwì's nicht gefallen, weil sie sich selbst zu helfen wissen. Namentlich die Maghribiner stehen im Rufe, immer und überall voranstehen und das Bэste geniessen, abər alles umsonst haben zu wollen. Oder ist der Vergleich vielmehr dem von Medinah nach Mekkah Pilgernden entnommen, weil dieser schon von $\mathrm{D} \overline{\mathrm{u}}^{2}-1-\mathrm{h} u \mathrm{u}$ aifah den Iḥrām anlegen sollte, somit, wenn er dies bis zur Abreise von Rābigh aufschiebt, zu erkennen gibt, dass er sich die Sache möglichst leicht und billig machen will? المله اعلم

57.

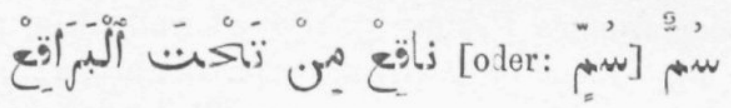

Tödtliches Gift (schaut) unter den burqu ${ }^{\mathrm{c}}{ }^{\prime} s$ (heraus).

Das burqu ${ }^{c}$ wird genau bəschrieben von Line, Manners and Customs, I : 57 (5 $5^{\text {th }}$ edition); es wird mit der melājah von den Frauen angezogen, wenn sie ausgehen. Die melājah beschreibt im Allgemeinen richtig Dozy, Supplément i. v.; nur dass der Gebrauch dieses Kleides im Hị unteren Klassen beschränkt ist. Jede Mekkanerin trägt einen solchen Ueberwurf, gewöhnlich blau gestreift (die türkischen und auch andere fremde Weiber tragen weisse melajah's), je nach ihren finanziellen Verhältnissẹn zum grösseren Theile aus Seide oder aus Baumwolle gemacht; die melājah ğāwi (von Singapura) ist die geschätzteste Sorte. Nur zum gelegentlichen Nothbehelf oder aus Armuth hüllt sich die Mekkanerin in ein (vielfach weisses) šèršèf (šèršèfeh) d. h. ein einfaches Tuch, welches nicht wie die melājah mit einem weiten Saume und schönen, mit Gold- 
draht gestickten Quasten versehen ist. Verweilt eine Frau einen Augenblick bei einer Bekannten, so schlägt sie die melājeh auf und wirft das burqu über den Kopf herauf; bleibt sie längere Zeit, so legt sie beide erhitzende Kleidungsstücke ab (t efassi ̣ oppos. tilbas; fassi ḥ haw āj $j^{3}$ gak = lege deine [Ober-] kleider ab). Ueber dem nackten Körper tragen die mekkanischen Weiber zunächst ein sirwāl (Beinkleider), meistens aus gestreif tem Seidenzeug ${ }^{1}$ ), eng schliessend; dis sirwāl wird mittels einer aus leichtem Stoffe gemachten und mit aus Golddraht und Seide gestickten Blumen versehenen dikkeh (weniger häufig : tikkeh) ${ }^{2}$ ) oberhalb der Hüften zusammengezogen. Die Hosen wohlhabender Weiber sind von unten mit einer Randborte versehen, welche sich auf der Aussenseite längs der Naht ein paar Decimeter weit fortsetzt. Sie besteht aus mehreren (vielfach 3) Streifen von aus Gold- und Silberdraht (resp. von schmalen dünnen Streifen Gold- und Silberblech) ${ }^{3}$ ) gewirktem Bande. Die ganze Borte heisst tarkỉb (tarkíbeh) oder tarqideh ${ }^{4}$ ). Viele Weiber tragen unter diesen Beinkleidern noch dünne, weisse. Unterhosen und zu Hause ziehen sie öfters nur letztere an, alles um das unausbleibliche Schmutzigwerden der Beinkleider durch den Schweiss möglichst lange zu verhüten. Der obere Körper ist nur theilweise durch eine kleine, von oben bis auf die Mitte der Brust ausgeschnittene Weste (çidrijeh) mit 3 bis 4 Knöpfen bedeckt. สำ Meistens ist die Weste aus demselben Stoffe wie die Beinkleider gemacht. Das Kopfhaar wird vielfach, dem muslimischen Gesetze gemäss, in ein Tuch (mèḥ ramah oder mi ḥramah) ${ }^{5}$ ) gehüllt; viele Weiber ziehen es aber vor, mehr oder weniger von diesem natürlichen Schmuck herausgucken zu lassen, welchen sie mittels hineingeflochtener Gold- und Silbermünzen und ähnlicher Schmuckgegenstände noch zu erhöhen verstehen. Das Kopftuch ist einfach

1) Die gebräuchlichsten Sorten sind unter den Namen hi n d I und š a m I bekannt.

2) Jā mèfk aket èd-dikkeh = ,o du, deren dikkeh geöffnet ist (wird)" gehört zu den gemeinsten Ausdrücken, mit denen man eine mekkanische Fran beschimpft.

3) Die schmalen Streifen Gold- und Silberblech heissen t èlí; Gold- und Silberdraht $=q$ a çab.

4) Einem mekkanischen Etymologen zufolge heisst diese Borte so la'innehum je $\mathrm{raqqid}$ ah a fi a tra $\mathrm{r}$ ès-sirwāl d. h. weil man dieselbe gleichsam niederlegt auf die Enden der Beinkleider.

5) Ein Taschentuch oder ein von Männern auf der Schulter getragenes Tuch, welches dessen Stelle vertritt, heisst $\mathrm{m}$ è $\mathrm{n}$ d I 1 ; ist dasselbe aus feinem Stoffe gemacht und mit einer gestickten Borte versehen, so nennt man es š $\sigma \mathrm{rah}$ oder ša a u rah. 
und meistens roth gefärbt. Ueber dasselbe wird aber, sobald die Fraa sich nicht mehr mit häuslicher Arbeit zu beschäftigen hat, ein anderes, grosses Tuch von feinem tüll-artigen Stoff geworfen, welches auf den Seiten mit zierlich aufgenähter Goldspitze (ס̄jeh, wie mir Dr. Houtsma mittheilt= türk. اويا) versehen ist. Dieses obere Tuch heisst medawwarah ${ }^{1}$ ) und wird von jeder Frau nach eigenem Geschmack und Phantasie um das eingehüllte Haar herumgewunden. Gewöhnlich bleibt ein langer Zipfel der medawwarah oben am Haupte oder am Halse frei herabhängen, welcher dann und wann dazu verwendet wird, den unteren Theil des Gesichtes zu verhüllen, wenn die Frau ihren Kopf aus einer Thüre heraussteckt, um sich mit einem draussen stehenden Manne zu unterhalten. Ueber der Weste und den Beinkleidern wird mitunter noch ein dünnes, durchsichtiges Hemd $(\mathrm{t} \bar{o} b)^{2}$ ) getragen. Wenn dies herabhängt, umgibt es den ganzen Körper vom Halse bis auf die Zehen; gewöhnlich wird es aber auf beiden Seiten aufgenommen und in die Beinkleider hereingesteckt. Anstatt dessen tragen die weniger vornehmen Weiber und solche, welche viel im Hause arbeiten, und in der kälteren Jahreszeit auch wohl die vornehmeren, eine kurteh oder ğèllābījeh, welche sich von dem Morgenkleide einer europäischen Dame kaum unterscheidet.

Das burqu $u^{c}$ stellt unter gewissen Umständen in Arabien symbolisch die ganze Frau dar. Vor wenigen Jahren, unter der Regierung des Grosscherifs Abd el-Muțtálib, entstanden in der Nähe von è s-Sēl (eine Tagereise von Țāíf entfernt) Misshelligkeiten zwischen den auf der Reise nach Ṭä̈f befindlichen Leuten des Scherifs und einigen Huḍel-Beduinen. Letztere zogen im Anfang den Kürzeren; infolge dessen wurden die Männer der Truppe von den Dienern des Scherifs festgenommen, von den Weibern dagegen nur die burqu's abverlangt. Sie konnten somit zu Hause ihren Männern zeigen, dass sie gleichsam zur Beute geworden waren; man wagte es aber nicht, dieselben wirklich festzuhalten.

Das tanin (سمّ سمّ (سمّ oder) wird, ebenso wie andere sonst

1) Es ist viereckig, hat aber seinen Namen daher, dass es um das eingebundene Haar herumgewunden wird.

2) Von Männerkleidung gebraucht, bedeutet $t \bar{\sigma} b$ in Mekkah nur das den nackten Körper bedeckende Hemd. 
aufgegebene Endungen, in der Vulgärsprache beibehalten $1^{\circ}$ in stehenden Formeln und adverbialen Ausdrücken; $2^{\circ}$ wo der Reim oder das Versmass es verlangt und $3^{\circ}$ in feierlicher, affectirter oder sentenziöser Rede, wie in Sprichwörtern und Redensarten; vgl. $\mathrm{N}^{\circ}$. 58. Dass die ungebildeten Leute dabei von der eigentlichen Bedeutung dieses ićā b keine Ahnung haben, versteht sich von selbst. Was Landberg, Proverbes et Dictons, I, 174 von der Verwech-

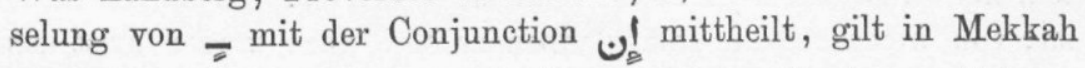
gleichfalls. Mitunter bringen die ${ }^{c} \mathrm{a} w \overline{\mathrm{a}} \mathrm{m} m$ den i $^{c} \mathrm{r} \overline{\mathrm{a}} \mathrm{b}$ zum Seherze in ihrer Rede an, wenn sie dem Kanzlei- oder Fetwastil nachahmen wollen. Ein zum Mekkāwi gewordener Ḥadhrami, der vielen Javanen Geld auf Zinsen geliehen hatte und in dieser schlechten Zeit wenig davon zurückbezahlt erhielt, kam öfters zu mir, sich Raths zu erholen, wie er mit diesem oder jenem Schuldner handeln solle. Gewöhnlich deutete er in solchen Fällen den Zweck seines Besuches dadurch an, dass er scherzhaft mit den üblichen Anfangsworten einer Anfrage um ein Fetwa anhub; er sagte dann: mā qōlakum, dāmu fadhlikum fi rağulan ${ }^{1}$ ) achadu felūsin wemā jirdhājeruddahā? Aehnlich machen es die Leute immer wenn sie, sei es auch im Ernste, den todten i i $\mathrm{r} a \bar{b} b$ wieder ins Leben rufen wollen.

Das Gift, von welchem unser Sprichwort redet, ist die Wirkung schöner Frauenaugen. Es wird z. B. gesagt, wenn Mädchen von bekannter Schönheit auf der Strasse an einer Gesellschaft von Männern vorbeigegangen sind.

58.

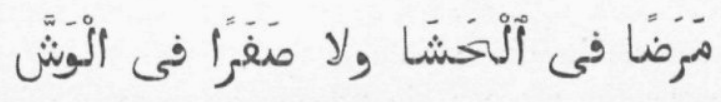

Lieber Krankheit in den Eingeweiden als Erblassen (Gelbwerden) im Gesichte.

Ueber das tanwin in Sprichwörtern und auch sonst in gehobener Rede vergl. $\mathrm{N}^{\circ}$. 57. Das Wort wè̀g h wird in Mekkah

1) Die Frage um ein Fetwa hebt bekanntlich meistens ungefähr in dieser Weise an:

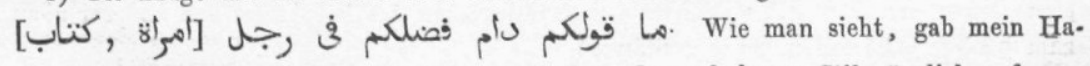
dhrami nach der Erwähnung der theuren fel ns den gehobenen Stil gänzlich auf. 
von gebildeten Leuten, namentlich wenn ein Suffix angehängt ist, rein gesprochen; die unteren Klassen sagen vielfach wišš und wašš (vgl. $\mathrm{N}^{\circ}$. 32); das ش wird hier des Reimes wegen vocalisirt. Mit dem Gelbwerden ist das Erblassen des Gesichtes in Folge von Schande (عار); nicht die Scham = حياء) gemeint. Wie oben $\left(N^{\circ} .10\right)$ bemerkt, betrachten wohlerzogene Leute das Betteln als $\mathrm{tadhj}_{\mathrm{I}}^{\mathrm{c}}$ èn-n $\overline{\mathrm{a}} \mathrm{m} \overline{\mathrm{u}} \mathrm{s}$; man zieht sich dadurch eine Schande zu, von welcher dem Volksglauben zufolge nach kurzer Frist das Gesicht durch die Veränderung der Züge und der Hautfarbe Zeugniss ablegt. Der Hunger ist besser als die Schande, sagt man desshalb, und ich habe in Mekkah viele Leute gekannt, welche diesen Grundsatz thatsächlich anwendeten; dies will etwas sagen in einer Stadt, wo die Hälfte der Bewohner sich auf eine Art ša hạ tah, (die Ausbeutung der Pilger) gewerbmässig verlegt. Es wirkt dies wie eine ansteckende Krankheit; die meisten Knaben der mittleren Klassen machen eine Periode durch, wo ihnen der Beruf des mețawwif oder delrl als das höchste Glück erscheint. Ein junger Scherif sagte mir einmal: a h l Makkah dōl walláhi jerabbū awlādahum tarbíjeh ćăgibeh, awwal mājekūn jewadd úhum èl-fáqih ilēen

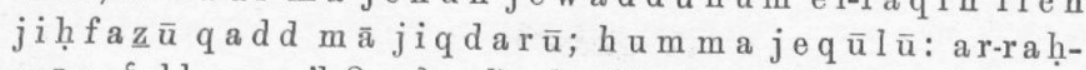

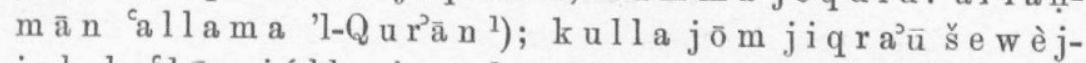

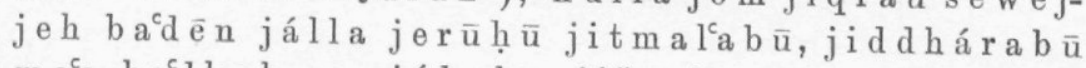

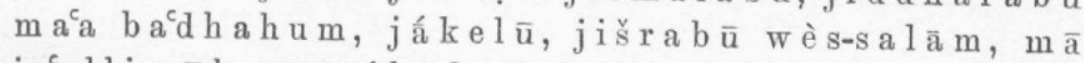

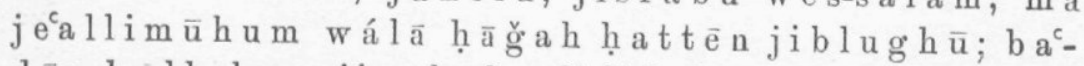

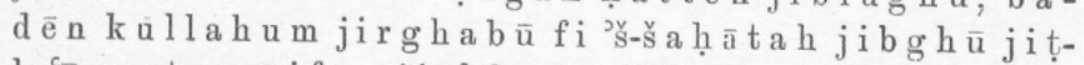
lacu mețawwifin jinal abū šs-šaḥ hạtah dōl. d. h. „Diese Mekkaner erziehen ihre Kinder, bei Allah! in seltsamer »Weise; vor allen Dingen bringen sie dieselben zum $f a ́$ $q^{i} h^{2}$ ) »(bei welchem sie in die Schule gehen), bis sie möglichst viel (vom »Qurān) auswendig wissen; sie pflegen zu sagen: »der Barmher» zige hat den Qurān gelehrt" '). Jeden Tag recitiren sie (die Kin»der) also ein bisschen, und nachher vorwärts! gehen sie und spie-

1) Qurān LV, 1.

1) Der fáqìh (selten: fíq Ih) ist in Mekkah derjenige, welcher den Kindern im Qurānrecitiren Schul- oder Privatunterricht ertheilt, sie auch wohl einmal in die Anfangsgründe des Gesetzesstudiums einführt, bei häushichen Festen den Qurān und das molid recitirt; viele von ihnen sind zu gleicher Zeit Gehülfen der Metawwifs und auf eigne Faust $\mathrm{meza}$ w wirs (Führer bei den Besuchen des Friedhofes und anderer nicht zum $\underline{\mathrm{h}}$ a ğ ğ gehörenden heiligen Stätten).

2) Qurān LV, 1. 
>len, schlagen sich mit einander, essen, trinken, und"damitaus. »Man lehrt sie nicht das Geringste, bis sie erwachsen sind. Sodann »bekommen sie alle Lust zur Bettelei und wünschen Mețawwifs »u werden. - Verfluche (Allah) den Vater dieser Bettler,zunft!"

Die beiden Formen ilēen und hattēn, welche in der oben angeführten Rede vorkommen, liessen sich in diesem Zusammenhange

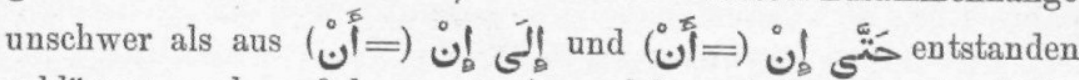
erklären; auch auf lammān ${ }^{1}$ ), welches vielfach an die Stelle des einfachen la mm $\bar{a}$ tritt, liesse sich diese Erklärung anwenden. Die Sache wird aber dadurch erschwert, dass ilēn sehr häufig als Präposition fungirt: ruḥnà ilēn èl-bēt, țilicnāilēn fōq èl-ğ̀̀ bèl. Man könnte nun hier wohl an eine Ellipse denken und in den angeführten Beispielen hinter ilēn etwa ğ In ā (جنمنا) oder waçalnā ergänzen; um so eher, da wirklich die reine Conjunction lammān in ganz gleicher Weise vorkommt. Nun kommt aber hinzu, dass neben mète? in gleicher Bedeutung mètén? gesagt wird. Letztere Form wird mit Vorliebe gebraucht, wenn kein Verbum nachkommt, z. B. »ich habe N.N. dort gesehen." - mètén ? ${ }^{2}$ ) = »wann war es?" Sie kommt aber auch vor dem Verbum, z. B. mètēn ğ $\bar{a}=$ »wann ist er gekommen ?". Hier hilft, wie ich glaube, weder إن إن noch das andere Dictons I: 173-4, eine äusserst lehrreiche Ausführung gibt. Ich weiss alle diese räthselhafte - ēn nicht zu erklären und möchte auch gar nicht behaupten, dass es für alle eine Erklärung gibt. Wer uns über diese Dinge aufklären will, muss auch $\mathrm{ba}^{\mathrm{c}} \mathrm{d} \overline{\mathrm{e}} \mathbf{n}$ mit in Betracht ziehen, denn die Ansicht Spitta's (Grammatik, S. 173), es wäre »durch Dehnung aus b a den = بَ entstanden", ist unhaltbar.

Erstlich stünde diese eigenthümliehe »Dehnung" ganz vereinzelt da und darf somit nicht zur Erklärung schwieriger Erscheinungen dienen. Zweitens ist - $\overline{\mathrm{e}} \mathrm{n}$ augenscheinlich demonstrativ, nicht nur wegen der Betonung, sondern weil das Adverb in erster

1) Auch in Mekkah hat L W sehr oft die Bedeutung wenn; vgl. oben $N^{\circ} .24$ und Landberg, Proverbes et Dictons I, 296. Für $\underline{h}$ a $t$ t ēn hört man auch $\underline{h}$ a $t$ tã $n$, dagegen niemals ilā $\mathrm{n}$.

2) Diese Form ist niemals Conjunction, also auf keinen Fall dem é m t a n Landbergs gleichzusetzen. 
Linie die Bedeutung: darauf und nur secundär die Bedeutung des unbestimmten: nachher hat. Man könnte versucht sein, die Präpositionen ilēn und hattēn aus حتى أَيسن erklären; denn die Mekkaner lieben es ausserordentlich ihre Rede mit Fragepartikeln zu unterbrechen, z. B. ba c dēn ištarèt è qure 'e $\left.\overline{s ̌ s}^{1}\right)=$ »darauf habe ich gekauft was? ein Brödchen". tilic ${ }^{c} n \bar{a} f i{ }^{~} l-\bar{e}$ èl-bābūr wešufnà èl-è èl-qābudān qāl lanā sallimū èl-ēš èl-uğrah = »wir gingen auf den was? »den Dampfer, dort sahen wir den was? den Kapitän; der sagte »uns: zahlt den was? den Fahrpreis". In ähnlicher Weise liesse

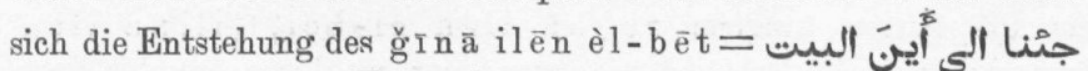
verstehen; in vielen Fällen könnte es mit hatta gerade so sein und die anderen Fälle sowie der Gebrauch des lammān als Conjunction könnten durch falsche Analogie veranlasst sein. Die als Conjunctionen gebräuchlichen Zusammensetzungen könnten je aus einer Conjunction und إن bestehen, und die Aehnlichkeit der verschiedenartigen Composita hätte den Unterschied verwischt. Eine Spur der ursprünglichen Frageform lässt sich aber nicht mehr beobachten; es wäre denn, dass man die öfter sehr gedehnte Aussprache des ilēēēen als solche ansehen dürfte. Auf diesen Einfall lege ich aber einstweilen besonders desshalb nur geringen Werth, weil $\mathrm{ba}^{\mathrm{c}} \mathrm{d} \overrightarrow{\mathrm{en}}$ und mètēn dabei leer ausgehen.

awwal ma jekūn ist ein sehr gebräuchlicher adverbialer Ausdruck: »zu allererst", »vor allen Dingen". »Zuerst" heisst: awwal oder awwalijeh; letztere Form ist beliebter. Statt

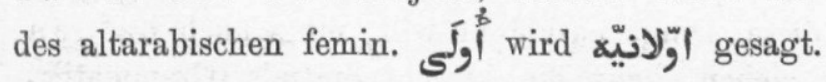

\section{9.}

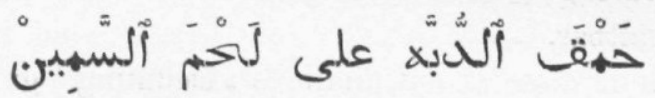

Den Zorn des Kürbisses (legen wir) ${ }^{2}$ ) auf das fette Fleisch.

Ueber die idhāfah: laḥm ès-semin siehe Spitta, Grammatik, S. 259 ff., vgl. Landberg, Proverbes et Dictons, I: 5.

1) Auch vielnals qu rça 'ē ğ gesprochen, ebenso wie ku lla sèn eh. Die Anwendung des $\mathrm{N}^{\circ} 20$, Anm. angegebenen Grundsatzes findet nämlich auch in solchen Füllen statt, wo der besonders häufige Gebrauch der i d ha $\mathrm{f}$ a h zwei Wörter sehr eng mit einander verbunden hat.

2) Prof. Nöldeke ist geneigt, حمق abhängig zu betrachten; also: "(es ist) der Zorn des Kürbisses auf das fette Fleisch." Es wäre damit Zorn ans Neid ge- 
ḩ a mq bezeichnet nur den Zorn (vgl. No. 21), vorzüglich den unbegründeten Zorn; a hạ aq = jähzornig. Die dubbah (alt-

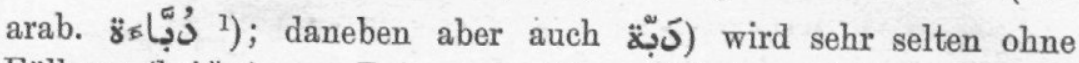
Füllung (ḥ̂́šu) von Reis, gehacktem Fleische und dgl, gegessen. Für sich ist dieser Kürbiss nämlich ganz unschmackhaft; man vergleicht daher andere Früchte, welche nicht reif oder nicht süss genug sind, mit der dubbah: hādr 'l-ḥábhabah dubbah $\mathrm{ch} \overline{\mathrm{a}} \mathrm{liç}=$ »diese Wassermelone ist eine reine dubbah"; ebenso alles Alberne und Abgeschmackte.

In dem Sprichworte steht der Kürbiss für eine gänzlich unbedeutende Person, welche von ihrem aus nichtigen Gründen entstandenen Zorn viel Aufhebens macht. Vorzüglich wenn Kinder in Wuth gerathen, sagen andere Kinder oder ältere Leute zu ihnen: »meinst du etwa, wir kümmerten uns um deinen Zorn? $\gg$ Ach nein, den Zorn des Kürbisses" u. s. w. Aehnlich im Holländischen :

»Ben je boos,

¿luk een roos,
»Zet die op je hoed, „Dan wordt je weer goed".

60.

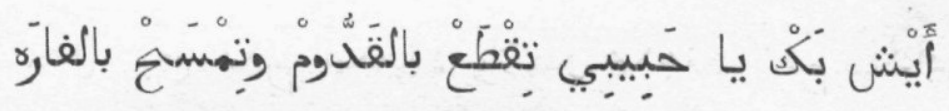

Was ist dir, mein guter Freund? du schneidest mit dem Hohlmeissel und glättest wieder mit dem Hobel?

q add $\bar{u} m$ heisst der gewöhnliche Hammer, aber auch ein Tischlerinstrument, welches zugleich als Hammer und als Hohlmeissel dient; vgl. Dozy, Supplément, i. v.

Diese Worte sagt man höhnend zu Einem, der in heftigem Zorne gegen einen abwesenden Feind die furchtbarsten Drohungen ausspricht, nachher aber, wenn die Zeit des Handelns gekommen wäre, es kaum wagt, ihm gegenüber den Mund zu öffnen.

Ueber ha abib vgl. No. 21.

meint: „die fade Speise zürnt der fetten, kräftigen.” Dass diese Auffassung sinnreicher und wohl auch älter ist, als die von mir gegebene, leuchtet ein. Letztere wurde mir aber von vielen Mekkanern, erstere von keinem gegeben; relat a refero. Vgl. übrigens die zwei verschiedenen Auffassungen von $\mathrm{N}^{\circ}$. 11 .

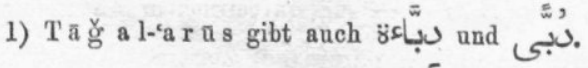




\section{1.}

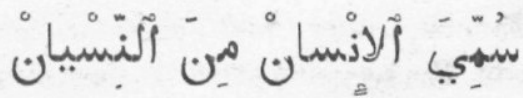

Der Mensch (insān) hat seinen Namen vom Vergessen (n isjān).

Diese aus der ältesten Zeit des Islāms stammende etymologische Spielerei kennt jeder Mekkaner und er entschuldigt sich damit, so oft er einen Auftrag oder eine Verabredung vergessen hat. Man sagt ebenso häufig: èl-insān merakkab ${ }^{1}$ ) $\mathrm{m}$ in èn-nisjān= »Der (Name) Mensch ist zusammengesetzt aus (dem Worte) Vergessen". Sogar Leute, welche des Lesens und Schreibens unkundig sind, verstehen den Witz; die höher Gebildeten citiren statt dessen den Vers:

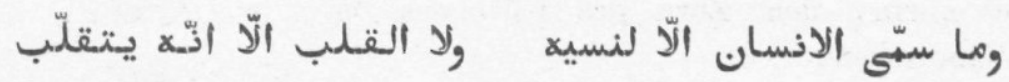

»Der Mensch hat seinen Namen daher, dass er vergesslich ist, »Und das Herz den seinigen daher, dass es unbeständig ist".

62.

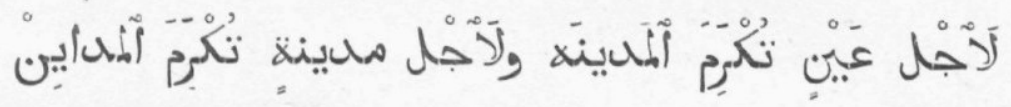

Wegen einer (trefflichen) Person ehrt man die (ganze) Stadt und wegen der (einen) Stadt ehrt man die Städte.

Das zweimalige tanwin und der Gebrauch von medinah als Appellativum geben diesem Sprichworte eine etwas gelehrte Färbung (vgl. $\mathrm{N}^{\circ}$. 57 und $\mathrm{N}^{\circ} .58$ ); es wird jedoch vorzüglich von

1) Es sei hier nebenbei bemerkt, dass رَّب in Mekkah auch in der Bedentung: "zubereiten (von Speisen)" vorkommt; daher heisst mer a k k a b ein Gemach, gewöhnlich in der Mitte zwischen zwei Stockwerken, aber jedenfalls nicht (wie gewöhnlich die eigentliche Küche $=\mathrm{matbach}$ ) oben auf einer Terrasse, wo man zum Nothbehelf etwas kochen kann. $\mathrm{tarkib}$ ist mitunter gleichbedentend mit $\mathrm{tab} \mathbf{c} \mathrm{ch}=$ das Kochen, die Kochkunst, die (nach den Nationalitäten verschiedene) Küche. Gewöhnlich bezieht sich aber $t a r k I b$ auf eine bestimmte Speise, $t a b i c h$ auf die Methode, allerlei Speisen zu bereiten; z. B. ja bint èn $\mathrm{t} I$ 'araftít $\mathrm{tabich}$ è l-hun ud? araftuh qalilqalıljăsidi. - tajjib èl-jóm rakkibi lenā 'rruzz t a rk I b èl-hindr, d.h. "Du, Mädchen! verstehst du dich auf die Küche der Inder?" - "Ich verstehe ganz wenig davon, mein Herr". - "Schön! koche uns heute den "Reis auf indisch". 
wenig gebildeten Leuten gebraucht. تكرم wird meistens tukrim (auch tikrim) gesprochen, aber immer als IIIte Person (mit Stadt, resp. Städte zum Subject) aufgefasst. Diese Form des Verbums hat natürlich für das Bewusstsein der Ungebildeten nichts Passives; die passive Bedeutung im Sprichworte wird dagegen ganz lebhaft empfunden. lağl wird von feinen Leuten le-ağl gesprochen.

Dies ist eine schmeichelnde Redensart, mit welcher man sich die Fürsprache eines Bekannten erbettelt oder z. B. um die Erlaubniss ersucht, mit ihm zusammen einer angesehenen Person einen Besuch abzustatten. Die vornehmen Mekkaner lieben es, sich bei förmlichen Besuchen von verschiedenen Freunden und Clienten begleiten zu lassen; ihr grosses Gefolge zeugt von ihrem nefūs (vergl. $\mathrm{N}^{\circ}$. 10). Wird eine Mahlzeit von einem Mekkaner zu Ehren eines Freundes veranstaltet, so lädt er ein: ȩāhíbnā felān weman jelūz (يلوز) buh ${ }^{1}$ ) = punseren Freund N. N. sammt seinem Anbange"; und es wird für höflich angesehen, dass der Eingeladene diese Hinzufügung im umfangreichsten Sinne anwendet. Auf der andern Seite legen die »Anhänger" grossen Werth darauf, allen Leuten zu zeigen, wie vornehmer Schutzherren sie sich erfreuen, und durch deren Vermittelung mit andern Notabilitäten bekannt zu werden.

Das Sprichwort dient bisweilen auch einfach dazu, einem Freunde zu betheuern, wie hoch man seine Freundschaft schätzt.

63.

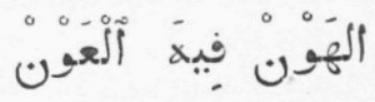

In der Ruhe (Gemächlichkeit) ist Hülfe (Gottes).

Dieses in Mekkah und Ğiddah sehr viel gebrauchte Sprichwor soll von den Beduinen herübergenommen sein. Die Städter nehme dagegen das folgende, gleichbedeutende gänzlich für sich i Anspruch:

1) Vgl. Chroniken der Stadt Mekka, ed. Wüstenfeld, III, 1.0: وكانت

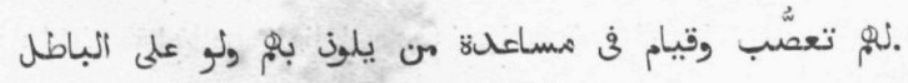
5e Vo!gr. I. 


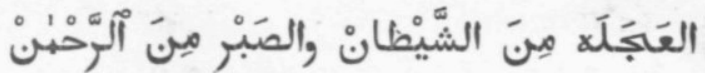

Die Eile ist vom Teufel, die Geduld dagegen ist von dem Barmherzigen (Gott).

Die beiden Hälften des Letzteren werden auch einzeln gebraucht. Anstatt çabr spricht man vielfach çabur (vergl. $\mathrm{N}^{\circ}$. 64).

Nichts ist dem Orientalen unverständlicher als die Neigung des Europäers zur Vollendung einer Arbeit innerhalb einer voraus bestimmten Zeit und zur pünktlichen Erfüllung von Versprechen und Verabredungen überhaupt. Jeder, der den Orient nur flüchtig gesehen hat, erinnert sich des ewigen bukrah in šá $\left.{ }^{2} 11 \bar{a} h^{1}\right)$, womit seine Geduld oft hart erprobt wurde. Viele Muhammedaner betrachten das Antreiben zur Eile und das Dringen auf die genaue Bestimmung einer Frist sogar als frevelhaft; das fieberhafte Jagen der Europäer ist ihnen ein neues Zeugniss von deren Gottlosigkeit; bejèdd beni ā dam hūwa? huwa behawák ? = »steht es in der Menschen Hand?" » hängt es von deinem Belieben ab?" Aehnliche Ausdrücke halten sie ärgerlich demjenigen entgegen, der sie wegen ihrer Gleichgültigkeit tadelt. Man thut Unrecht, wenn man diese auffallende Erscheinung hauptsächlich vom muslimischen Prädestinationsglauben herleitet; dieser lässt an und für sich der menschlichen Thätigkeit so viel Raum, als sie braucht. Auch für die Anhänger der Lehre des liberum arbitrium ist ja der Lauf der weltlichen Dinge im grossen Ganzen unabhängig vom menschlichen Willen; im schlimmsten Falle könnte die absolute Prädestinationslehre nur das sittliche Gefühl, nicht aber die Thatkraft der Gläubigen ersticken. Nur soviel ist richtig, dass, wo einmal der Prädestinationsglaube herrscht und zu gleicher Zeit die Neigung zur Faulheit ziemlich allgemein ist, diese sich gern zu ihrer Entschuldigung auf jenen beruft. Sollte einmal die Energie der Muslime aufwachen, so fände sie in der religiösen Litteratur wenigstens ebenso viele Lobsprüche auf sich vor, wie jetzt die geliebte Ruhe. Sogar in den Sprüchen volksthümlicher Weisheit fehlen diese nicht. Dann und wann begegnet man in der arabischen Gesellschaft energischen Männern, welche leider von ihrer Umgebung allerseits zurückgehalten werden; wenn man diesen das bequeme: èl-hōn fíh èl- $-^{\complement} \bar{o} n$ entgegenführt,

1) Die frommen Mekkaner fügen dieser Formel meistens noch die Worte b e ha uli’llá h we quw w a $\mathrm{u}$ h hinzu. 
DR. C. SNOUCK HURGRONJE, MEKKANISCHE SPRICHWÖRTER. 531

so erwidern sie mit den Worten:

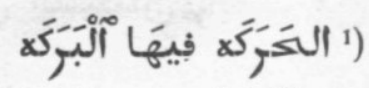

Im Bewegen ist Segen.

Von der populären Weltanschauung gilt ebenso wie von der officiellen Lehre der prophetische Ausspruch: ichtilāfu ummati rahmatun $=$ die Meinungsverschiedenheit in meiner »Gemeinde ist ein Beweis von Gottes Gnaden."

64.

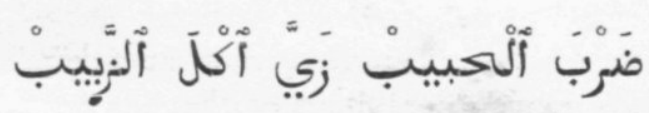

Die Schläge des Geliebten (schmecken) wie das Essen von Rosinen.

hạib wird hier im ganz allgemeinen Sinne genommen (vergl. $N^{\circ}$. 21). Wenn das $l$ von akl nicht durch ein vocalisch anlautendes nachfolgendes Wort oder Suffix vocalisiert wird, so sagt man akil. Ueberhaupt wird in solchen Fällen die Aussprache der fal-fil-f u'l-Formen durch Hineinfügung eines Vocals erleichtert, vgl. siḥir $\left(\mathrm{N}^{\circ}\right.$. 27), filis $\left(\mathrm{N}^{\circ}\right.$. 32), miliḥ, sèmin, rațil, caçur (N॰.35), çabur (N॰.63), ferner çubuh, dhuhur, bakur (so wird immer der Eigenname بَ gesprochen) ba hạ u. s. w.

Wenn z. B. ein Freund den andern schwer beleidigt oder ihm empfindlichen Schaden verursacht hat und ihn nun deswegen zu wiederholten Malen um Verzeihung bittet, so antwortet dieser wohl mit unserem Sprichworte. Im eigentlichen Sinne wird es auch vielfach von Sklavinnen (Concubinen) gebraucht, wenn ihr Herr sie in zorniger Uebereilung durchgeprügelt hat und nachher sagt, es sei nicht so schlimm gemeint gewesen; mit ha bi b meinen sie aber in diesem Falle keineswegs den Gegenstand sexueller Liebe, sonst könnten sie zu ihrem Herrn gar nicht so reden.

1) Ausser "Bewegung” im Algemeinen, bezeichnet ha ra k a h in Mekkah besonders das Bemühen der mit einer Neuerung in der Verwaltung (z. B. in Bezug auf Steuererhebung, auf die Vertheilung der ägyptischen Korn-ça daqah u. A.) unzufriedenen Leute, dieselbe zu hintertreiben, den Versuch einer Partei, einen ihr verhassten Beamten zu stürzen, das gemeinschaftliche Einreichen einer Bittschrift zu irgend einem Zwecke. nesáw i harakah = wir wollen zusammen Massregeln (dagegen) ergreifen”. Vgl. N 19. Bewegung, Lärm (von einem oder von mehreren hervorgebracht) heisst g hála bah; Aufregung, Verwirrung, Krawall = kárkabab. 
65.

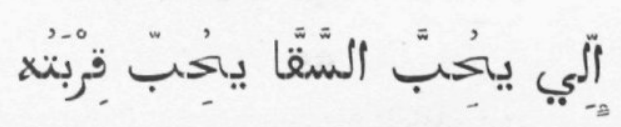

Wer den Wasserträger liebt, soll auch dessen Wasserschlauch lieben.

Das Wasser zum häuslichen Gebrauche ist in Mekkah seit der letzten Wiederherstellung der Wasserleitung (عَيْين iَبْيْن nennt die Bevölkerung dieselbe noch immer; sie heisst aber sonst auch umsonst zu haben; jeder hat das Recht, zu jeder Zeit aus den Reservoirs zu schöpfen. Da letztere in allen Hauptstrassen der Stadt vorhanden sind, braucht man hier für den Wassertransport nicht wie in Ǧiddah Kameele ${ }^{1}$ ), sondern bringen die saqqa's'in für eine kleine Belohnung ihre grossen Schläuche gefüllt ins Haus, wo sie dieselben in den im bêt èl-m $\bar{a}^{2}$ ) befindlichen $\mathrm{z} \mathrm{Ir}^{3}$ ) ausleeren. Die saqqa ${ }^{3}$ In gehören zur ärmsten Volksklasse; die meisten sind freigelassene Negersklaven. Die qirbah heisst in der Schriftsprache der Mekkaner auch اورية) (vgl. Chroniken der Stadt Mekka, ed. Wüstenfeld, II: $\mathbb{I}_{4}$ u. a. S.); dieselbe ist immer aus Leder gemacht.

Wer eine Person liebt, muss mit deren Eigenthümlichkeiten, auch wenn diese ihm nicht alle angenehm sind, Nachsicht üben;

1) In Ǧiddah kauft man das Wasser von den Eigenthümern der Cisternen (çahă rı ğ) und der Gruben (hufar Plur. von hufrah), welche dasselbe in kleinen q i rab ins Haus bringen lassen. Ein Kameel trägt 8 qirab auf jeder Seite. Eine ganze Kameel-

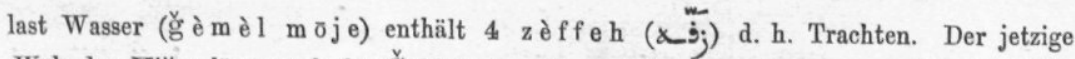
Wālı des Hiō̄āz lässt auch für Ğiddah eine Wasserleitung construieren, welche der Vollendung schon nahe ist. Die Sklaven oder Diener, welche in Ǧiddah die Wasserkameele begleiten und das Wasser ins Haus tragen, heissen ebenfalls s a q q à'rn.

2) Dieses "Wasserhaus", welches in keinem Hause und sogar in keinem "von einer Familie bewohnten Stockwerke" (mehill) fehlt, dient zu gleicher Zeit als Abtritt und als Badestube und Waschhaus. Daher heisst "Abtritt" in Mekkah gewöhnlıch einfach

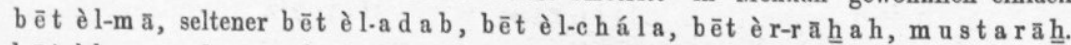
$\mathrm{b}$ ēt è $\mathrm{l}-\mathrm{m} \mathrm{a}$ und $\mathrm{m}$ a w èr $\mathrm{d}$ sind die einzigen Wörter, wo o seine klassische Form behalten hat; das Volk denkt dabei gar nicht mehr an "Wasser" und accentuiert sogar häufig bēt è l-m ã.

3) Ein grosses irdenes Gefäss, welches alles Wasser für den Hausbedarf enthält; man giesst darans das Trinkwasser in kleinere poröse irdene Krüge ( $r \mathrm{n}$ b ${ }^{c} \mathrm{~T}$, Plural $\mathrm{rab} \bar{a}^{c} \mathrm{~T}$; šèrbeh, Plural šèrbāt; qullah, Plural qulal; diese drei Gefässe sind von einander der Form nach ganz und gar verschieden; gegen Landberg, Proverbes et Dictons, I, 94). 
DR. C. SNOUCK HURGRONJE, MEKKANISCHE SPRICHWÖRTER. 533

wer eine Sache wünscht, der soll auch die damit verknüpften Mühseligkeiten und Unannehmlichkeiten ertragen.

66.

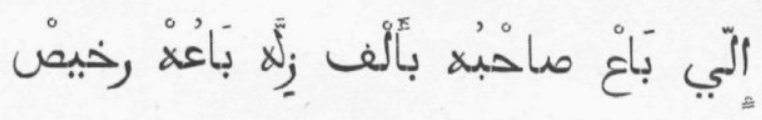

Wer seinen Freund um tausend (gegen ihn begangene). Fehler verkauft, der verkauft ihn billig.

Dies ist die Antwort, welche ein gebildeter Mekkaner seinem Freunde gibt, wenn dieser sich entschuldigt, weil er ihn so lange nicht besucht, ihm zu einem Feste nicht gratulirt hat oder ähnliche Nachlässigkeitsfehler gegen ihn begangen hat. »Unter so guten Freunden als wir sind, macht das nichts aus".

\section{7.}

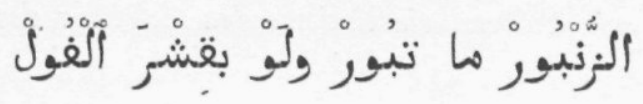

Den $x \tau \varepsilon$ ís hat man nicht umsonst, wäre es auch nur für eine Bohnenschale.

Die Sachen, um welche es sich hier handelt, würde man in dieser Form in den feineren Gesellschaften Mekkahs kaum besprechen, ohne um Erlaubniss zu bitten. 'azzak Állāh (كزّ) =

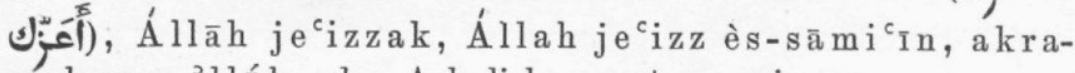
makumu 'lláh oder Aehnliches sagt man immer, wenn man von Eseln (hamır oder anständiger: bahāim) ${ }^{1}$ ), Fussbekleidung, Hunden oder ..... Weibern spricht; alle diese Ausdrücke heissen dasselbe wie: bela $\mathrm{muw} \overline{\mathrm{a}} \mathrm{chazah}$, geben dies aber in der Form eines sles.

زنبور, heisst eigentlich clitoris, wird aber als gleichbedeutend

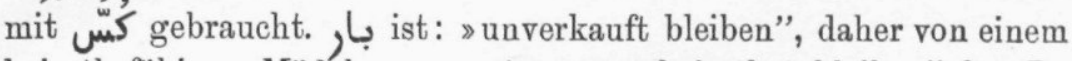
heirathsfähigen Mädchen gesagt: »unverheirathet bleiben" 2). Da

1) Vergl. $\mathrm{N}^{\circ} 4$.

2) Vergl. Landberg, Proverbes et Dictons I, 133-4. Man könnte an und für sich unser Sprichwort auch in dem Sinne des Verses auffassen: 
534 DR. C. SNOUCK HURGRONJE, MEKKANISCHE SPRICHWÖRTER.

aber die schon lange unverkauft liegende Waare immer billiger zu haben ist, wird بار geradezu: »umsonst zu haben sein", und diese Bedeutung hat es hier. Also: gänzlich umsonst bekommt man keine Frau, der Preis mag so gering sein wie er will.

قِشْ heissen auch in Mekkah die Hülsen der Kaffeebohnen,

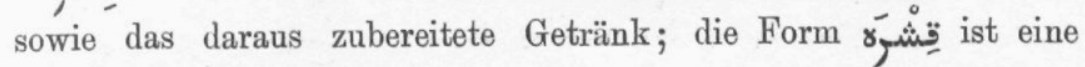
weniger edle Nebenform (vergl. oben $\mathrm{N}^{0}$. 11). Fischschuppen sind تِشْتَ السهك ; die Söhne eines Mannes, der in Giddah die auf dem Markte gekauften Fische für eine kleine Belohnung abschuppte, hatten den Geschlechtsnamen qišr ès-s èm è k.

68.

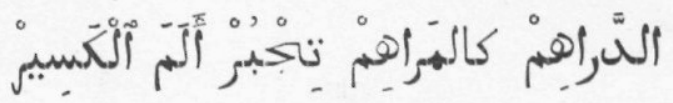

Dirhems sind wie Salben, sie lindern den Schmerz des zerbrochenen Gliedes.

Der Plural von dirhè $\mathrm{m}$ wird ebenso häufig in der Bedeutung: „Geld" (felūs) gebraucht wie der Plural von dīwān (dawāw In $\left.{ }^{1}\right)$ ), obgleich bekanntlich nach dirhèms nicht einmal mehr gerechnet wird und diwānI's nicht mehr. vorkommen. fēn ${ }^{2}$ )

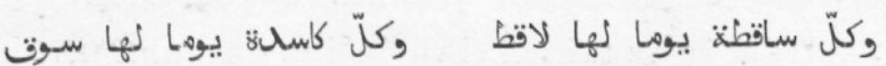

Dabei würde بار die Bedeutung: „unverheirathet bleiben” behalten. Ich will nicht behaupten, dass man dasselbe in Mekkah niemals in dieser Bedeutung gebraucht; ich habe es aber nicht gehört.

1) Eine ähnliche Pluralbildung (salātin, Plur. von sultānrjeh) erwähnt Spitta, Grammatik, S. 146. Für den Gebrauch des Singulars von d I wã n I (der d Iwã $\mathrm{n} \mathrm{I}$ in genere) in der Bedeutung: "Geld", vgl. oben $\mathrm{N}^{\circ} 5$.

2) Ich benutze diese Gelegenheit, zu bemerken, dass die Erklärung von fēn aus fi ēn (Spitta, Grammat., S. 172, Minhầil Șabbāğg, ed. H. Thorbecke, Strassburg 1886,

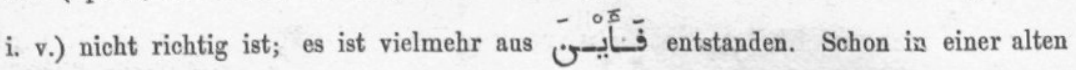
Tradition (Buchārr, Kitāb al-Ǵihād, bāb 18) heisst es : فعـال رسول الله مَّ فئين قأل هينـ

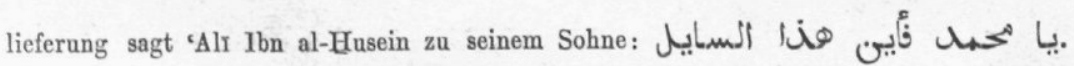
In späteren Quellen gibt es natürlich mehrere Beispiele dieses Gebrauches von "wo 
èd - d a wāwin? sagt der Kaufmann zu dem Diener, welcher die gekaufte Waare abholt.

qaddēš candak darāhim? = »wie viel Geld hast du in der Tasche?" - Wieder einer von den vielen Sprüchen, in welchen der Araber die Allmacht des Geldes betont.

69.

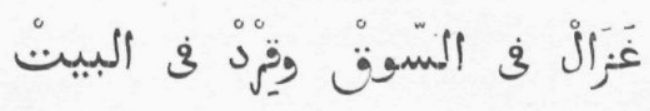

Draussen (auf dem Markte) eine Gazelle, zu Hause ein Affe.

Die Gazelle vertritt in den Sprichwörtern alles Schöne; der Affe ist in dieser Beziehung ihr Gegensatz. Diese Redensart dient gewöhnlich als Antwort auf die Frage eines Heirathslustigen, ob ein gewisses Mädchen (welches er nie gesehen hat) ebenso schön sei wie ihr Bruder, den er kennt. Die Antwort wird von einer Mittelperson (sei es Mann oder Frau) gegeben, und sie ist nichts weniger als eine Empfehlung: so schön wie der Bruder ist, so hässlich ist die Schwester. Oftmals werden aber von diesen uneigennützigen Kupplern Gazellen beschrieben, welche sich in der lēlet èd-duchleh als Affen entpuppen. Die Weise, wie der junge Mekkaner sich vor solchen Täuschungen in Acht nimmt, habe ich an einem andern Orte $^{1}$ ) beschrieben.

\section{0.}

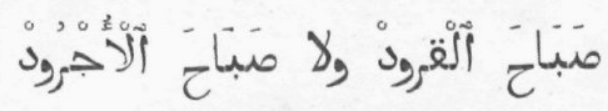

Besser der Morgengruss der Affen als der Morgengruss des Bartlosen.

Mit dem »Morgengruss" ist die Begegnung überhaupt gemeint; bekanntlich (vgl. oben $\mathrm{N}^{\circ} .28$ ) legt der Volksglaube allen Begeben-

denn?" statt: "wo?"; dialectisch tritt bekanntlich w $\overline{\mathrm{e}} \mathrm{n}={ }_{\text {"und }}$ wo?" an dessen Stelle;

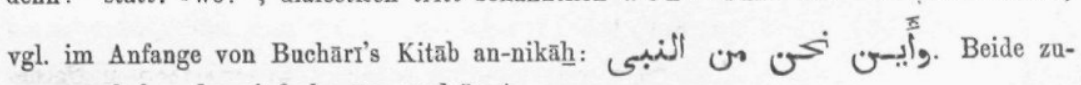
sammen haben das einfache ē $\mathbf{n}$ verdrängt.

1) Bijdragen tot de Taal-, Land- en Volkenkunde van Nederlandsch Indië, uitgegeven door het Koninklijk Institunt enz., Deel XXXV (1886), blz. 371. 
536 DR. C. SNOUCK HURGRONJE, MEKKANISCHE SPRICHWÖRTER.

heiten, welche sich am Morgen ereignen, ganz besondere Bedeutung bei.

a ğr $\mathbf{u} d$ und uğrīd sind Vulgärformen ${ }^{1}$ ) für a ğrad; sie bezeichnen den erwachsenen Mann, welcher anstatt des Bartes höchstens einige spärliche Haare im Gesichte aufzuweisen hat. Der uğrūd und der aqra ${ }^{c}$ sind in der arabischen Gesellschaft wenig beliebte Erscheinungen. a q ra ${ }^{c}$ ist der Kahlkopf, welcher seinen Haarwuchs, meistens bei einer Krankheit, eingebüsst hat (denn kahle, rasirte Köpfe haben die Städter nahezu alle); nicht selten zeigt die Haut seines Kopfes davon die hässlichen Spuren. Man erzählt sich viel von dem Neide und der Listigkeit dieser Kahlköpfe und fürchtet Unheil von ihrem Besuche. Natürlich finden diese und ähnliche Ergebnisse der volksthümlichen Weisheit nur in solchen Fällen Anwendung, wo die Wirklichkeit damit übereinstimmt, d. h. man beurtheilt den Charakter einer Person, welche man nicht kennt, weder nach ihren Kopf-, noch nach ihren Barthaaren. Den uğrūd hält man für schlau und verschmitzt; er versteht es, die Leute auszubeuten oder irgendwie anzuführen. Im Gespräche oder in Verhandlungen mit ihm muss man auf seiner Hut sein, damit man nicht hereinfalle. So sagt der Verfasser des Hèzz è l-quhūf, des Commentars zur q a ç Idah des A bu u Š̀a

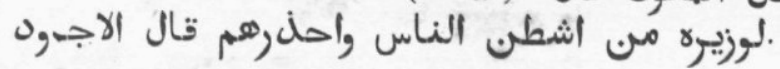

71.

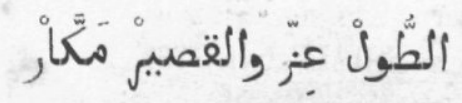

Körperlänge ist Würde, der Untersetzte dagegen ist ein verschmitzter Kerl.

Das Wort عَّ, bezeichnet das Imponirende, Würdevolle der ganzen Person, wovon die imponirende Gestalt der populären Anschauung nach Zeugniss ablegt. عز heisst u. A.: selten und

1) Vgl. schon Chroniken der Stadt Mekka, ed. Wüstenfeld, III, Mr., wo es von وكان طويلا خغيف اللحيبة بكيث :

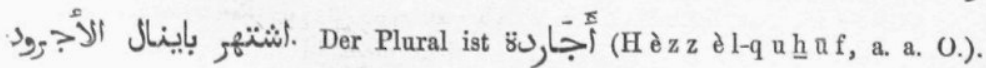


daher theuer, werthvoll sein. Nach langer Dürre heisst es: èlmōje çārat 'azizeh oder 'cazzet èl-mōje. Ein Mekkaner sagte mir, seine Verhältnisse könnten ihn schon veranlassen, für sich und seine Familie um einen Antheil an dem jährlich aus Aegypten nach der heiligen Stadt gesandten Korn (ç a daq at èlhabb) zu bitten, lākinn èn-nafs ${ }^{c} a z i z e h=» a b e r$ meine spersönliche Würde hält mich davon zurück."

Man gebraucht dieses Sprichwort, wenn ein untersetzter Mensch Einem eben einen gemeinen Streich gespielt hat; es wird aber auch öfters nur zum Scherze zu einer gar nicht hinterlistigen kleinen Person gesagt.

\section{2.}

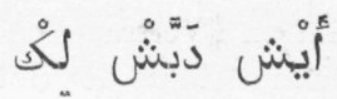

Was hat er dir zur Aussteuer mitgegeben?

Die Möblirung des Hauses wird in der Regel gänzlich oder grösstentheils von Seiten der Frau besorgt. Der Heirathspreis (mahr oder çadāq), welchen der Mann ihr zu bezahlen hat, wird darauf verwendet; gestatten es die Verhältnisse des Vaters einer Braut, so fügt er demselben gern etwas hinzu. Ueberhaupt besorgt der walı des Mädchens, gleichviel ob ihr Vater oder ein anderer von ihren. Agnaten, die zur Aussteuer (כَ) nöthigen Einkäufe, da das Mäddchen selbst nicht die nöthige Erfahrung besitzt; in den untern Klassen gibt es Väter genug, welche bei jedem Einkaufe auch selbst etwas für ihre Bemühung nehmen. Dies alles gilt nur, wo eine Jungfrau (bint èl-bēt) verheirathet wird. Ist die Braut schon früher verheirathet gewesen ('a z a b e h) '), so hat sie auch die ganze Möblirung aus dem Hause ihres letzten Mannes mitgenommen, denn von Gütergemeinschaft zwischen Mann und Frau ist im Islām keine Rede. Für weitere Ehen bedarf die Aussteuer also höchstens einiger Ergänzung, und diese besorgt die geschiedene oder verwittwete Frau öfters, schon bevor noch ein neuer Candilat sich gemeldet hat. Daher wird auch in den mittleren Klassen der Heirathspreis gleich bei der zweiten Ehe bedeutend niedriger ${ }^{2}$ ); die Hausgeräthe sind schon da, und

1) Das entsprechende männliche Wort ist ' $\mathrm{azab}$, seltener ' $\overline{\mathrm{a}} \mathrm{z} \mathrm{i} b$, Plur. immer ' $\mathrm{u} z \mathrm{z} \overline{\mathrm{a}} \mathrm{b}$.

2) Der Grund dieser Herabsetzung des Preises liegt nicht in dem Verluste der Jung- 
man hat nicht die kostspieligen Festlichkeiten, welche bei der Ehe einer Jungfrau als unentbehrlich betrachtet werden. Zu diesen Festlichkeiten, welche ich an einem andern Orte zu beschreiben denke, gehört die der feierlichen Ueberbringung der Hausgeräthe aus dem Hause der Braut in das Haus des Bräutigams (عريس). Dieser Aufzug heisst ebenso wie die Aussteuer selbst: d abaš; der walı der Braut miethet dazu eine grosse Anzahl (manchmal 100-200) Packträger (ha mmalin), welche er einige Tage vorher beim šèch èl-ḥammālah ${ }^{1}$ ) bestellt. Gewöhnlich würde ein Zehntel von diesen Leuten vollständig für die Transportirung des dabaš genügen, aber man macht möglichst viel Aufsehens mit der Sache; ein hammāl trägt etwa ein paar Töpfe oder einen kleinen Teppich. Die Aufsicht über die ganze Sache wird von Seiten der Braut einigen »Vertrauensmännern" (أمَنَـان tragen: nach der Ankunft im Hause des Bräutigams werden diese ebenso wie die Packträger von dessen Verwandten bewirthet.

Obgleich nun das dabaš der jungfräulichen Braut zum Theile, und öfters gänzlich, auf ihre Kosten zu Stande kommt, so hat doch der Vater (resp. der Bruder oder wer sonst als wali fungirt) thatsächlich einen so grossen Antheil an der Besorgung, dass der junge Ehemann mehr Grund hat, seinen Dank oder seine Unzufriedenheit ihm zuzuwenden als seiner Gattin. Auf der andern Seite wird die Achtung, welche die Braut von ihren Verwandten geniesst, vielfach nach dem Werthe ihres $\mathrm{dabaš} \mathrm{beur-}$ theilt. dabbašu lahā ášjā muctábarah = Man hat ihr

frauschaft, denn auf letztere an und für sich legen die Araber viel weniger Werth, als man oft behauptet. Bei den allerärmsten Klassen, wo von einer Aussteuer kaum die Rede ist, und bei den sehr reichen, wo die Geldfrage für nebensächlich gilt, ist denn auch kein so bedeutender Unterschied zwischen dem $\mathrm{mahr}$ der $\mathrm{b}$ int è l-bēt und dem der ' $\mathrm{a}$ z a b e h.

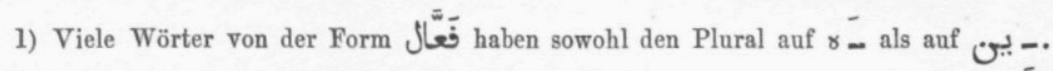
Erstere Pluralform bezeichnet dann die Gesammtheit der Leute, welche das genannte Gewerbe ausüben, die Zunft (è l-ğ a mmālah, è l-hammālah, è š-ś $a \underline{h} \underline{h} \underline{h}-$ $\bar{a} \mathbf{a} \mathrm{h}=$ die Kameeltreiber-, die Packträger-, die Bettlerzunft) oder eine Gesellschaft, welche einige Zunftgenossen zum Zwecke einer bestimmten Arbsit bilden (z. B. è lğammalah = alle Kameeltreiber, welche zu unserer Karavane gehören; in solchen Fällen kann man auch den Plural auf -I n gebrauchen); diese wird nur in Vcrbindung mit dem Artikel gebraucht. Die andere Form bezeichnet einfach eine (bestimmte oder unbestimmte) Zahl von den Leuten. So dürfte auch der Plural auf $\mathrm{Ij}$ a h von Relativen, welehe eine Zanft, Sskte |u. s. w. bezeichnen, einen anderen Grund haben als die Erleichterung der Aussprache (Spitta, Grammatik, S. 135). 
eine glänzende Aussteuer mitgegeben". So wird die Möblirung der ehelichen Wohnung dem Ehemanne gleichsam zur sichtbaren Erinnerung an die Achtung, welche er seiner Frau schuldet. Ist das da ba š werthvoll, so kann die Frau jedesmal, wenn ihr Gatte ihr Unrecht thut, darauf hinweisen in der festen Ueberzeugung, dass Verwandte, welche ihr so kostbare Sachen mitgegeben haben, auch nie verfehlen werden, sie, wo nöthig, zu beschützen. Beschwert sich dagegen eine Frau, welche nicht viel ins Haus mitgebracht hat, über schlechte Behandlung von ihrem Manne, verlangt sie von diesem mehr als er zu geben gewillt ist, so lautet die Antwort eines egoïstischen Gatten vielfach: „Was hat er >(dein wali) dir denn zur Aussteuer mitgegeben (dass du es » wagst so hohe Anforderungen zu stellen)?"

73.

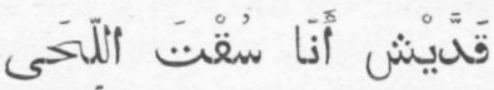

Wie sehr habe ich die Bärte angetrieben!

قَّ werden durch einander gebraucht; in der id hāfah und in der Verbindung mit Suffixen hört man aber fast nur قuّ : ğ $\bar{a}$ qa'ddr $=$ »das (Kleid) passt mir”; māu qadda dā = »es ist nicht so schlimm". Für Bart sagt man meistens daqn, auch wenn der ganze Bart gemeint ist; der Schnurrbart heisst š èn è b. Die Bärte bezeichnen hier Männer. Die Redensart dient zur Antwort auf einen Verweis wegen der Vernachlässigung einer Arbeit oder einer Bemühung, welche man nicht allein zu Stande bringen kann. Der Getadelte wirft die Schuld auf Andere, welche ihm ihre unentbehrliche Hülfe vorenthielten! Es wird vorzüglich gesagt, wo von der Beilegung einer Streitigkeit (çulḥ, taçlı̣̆) die Rede ist.

74.

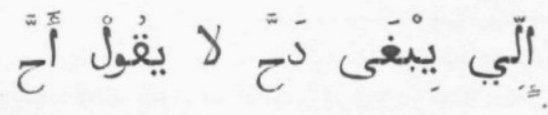

Wer daḥ̆a haben will, muss nicht ach! sagen.

$\tau^{\varpi} \mathcal{J}$ ist ein Wort aus der Kindersprache, mit welchem man 
alles bezeichnet, was die Aufmerksamkeit des Kindes fesselt, wonach es hascht ${ }^{1}$ ). tibghā daḥha? = =willst du das schöne Ding (welches ich dir vorhalte)?" jibgha a ${ }^{2}$ ) (man gebraucht nur das Imperfectum) ist in Mekkah das gewöhnliche Wort für »wünschen, wollen". Wo der Syrer sagt: šu bitrid? der Aegypter: bitrid ē? sagt der Mekkaner: ēš tibghā, der Jemāni: ēš tištèhı? rād = »wollen" wird seltener gebraucht, nur murād kommt häufig vor: ēš murādak $=$ »was verlangst du eigentlich?" oder » was meinst du (mit den eben gesprochenen Worten)?" Das ägyptische cāwiz ist gänzlich unbekannt. má "bgha $=$ »ich will nicht" hört man jeden Augenblick aus dem Munde verzogener Kinder. Der Gebrauch von بغى im Sinne eines Futurums, welchen Landberg, Proverbes et Dietons, I: 35 von Mesopotamien und den syrischen Beduinen erwähnt, ist in Mekkah überaus häufig: jibghā jemūt $=$ »er ist nahe daran, zu sterben". báa ā 'l-bēt jibghā jețị̣ ${ }^{3}$ ) $=$ »dieses Haus will einfallen." Ferner ist jibghā das gewöhnliche Wort, mit welchem man Einem mittheilt, dass ein hoher Regierungsbeamter, oder, wenn der Angeredete selbst Beamter ist, dass sein Vorgesetzter mit ihm zu sprechen wünscht. èfèndínā ${ }^{4}$ jibghák $=$ »er Wālr wünscht mit dir zu sprechen" (also: komme zu ihm). Desselben Ausdruckes bedient man sich im Hause bei ähnlichen Aufforderungen vom Vater an seine Söhne, von dem Herrn an seinen Diener usw.; gewöhnlich sagt man aber in solchen Fällen: jā felān! kallim abūk, sidak, oder, wenn

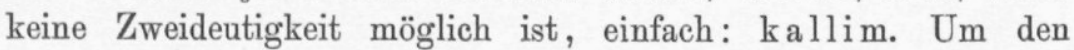

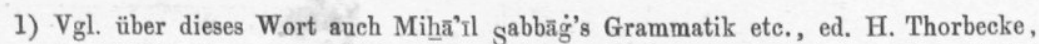
Strassburg 1886, i. v. Von einem Unterschiede zwischen $\mathrm{d} a \underline{h}$ a und $\mathrm{d} a \underline{h}$, wie ihn Spitta, Grammatik, S. 71 angibt, habe ich niemals gehört. dìs a (vgl. dis s bei Spitta a. a. O.) heisst in Mekkah ein Stück Geld.

2) J a bg h I kommt nicht vor.

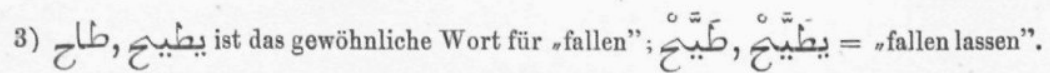

4) Dies ist der Titel des Wālı’s des Hiğāz; die Mekkaner sagen unter einander öfters scherzhaft: è fèn $\mathrm{d}$ án $\mathrm{a}$. $\mathrm{ji} \mathrm{i} \mathrm{g} \mathrm{h} \overline{\mathrm{a}}$ mit der Präposition $\mathcal{J}$ nd einem directen Objecte bezeichnet Letzteres als zu der durch die Präposition regierten Sache gehörend, dazu erfordert: $\mathrm{ji} \mathrm{i} g \mathrm{~h} \frac{\prime}{\mathrm{a}} \mathrm{l} \mathrm{u} h$ š e w è j jè $\mathrm{t} l \mathrm{è} \mathrm{b}$ è $\mathrm{n}=$ "dazu müsste man etwas Sauermilch haben"; hãdā 'l-fānas jibghă luh taçli ha, jibghá luh wudneh ğedIdeh $\Rightarrow$ "diese Laterne müsste einmal reparirt, werden, müsste einen neuen (blechernen) Ring (zum Anfassen) bekommen"; jibgh a a lu h 'alqah m a't abarah „er müsste einmal tüchtige Prügel haben". 
Hausherrn aus der Gesellschaft herauszurufen, damit er mit seinen harim rede, sagt der Diener: kallim oder kallímhum fōq. abghák = »ich wünsche mit dir zu reden" klingt nicht höflich, wird jedoch wohl gesagt. Ich hörte es einmal den še êh è s-s a deh (das Oberhaupt der Abkömmlinge Muhammeds durch Ḥusein) zu einem Besucher sagen, der schon unzählige Male mit nista'dínkum ${ }^{1}$ ) um Erlaubniss gebeten hatte, sich zu empfehlen. Zuerst schüttelte der šêch ès-sādeh jedesmal den Kopf; endlich rief er ungeduldig: $m \bar{a}$ qulta lak: abghāk? = »habe »ich dir nicht gesagt (nämlich بالاشار): ich wünsche mit dir zu sprechen?" Der Mann stand aber im Rufe, sehr mitkabbir zu sein. Als Antwort auf die Frage tíbghā min ist dagegen die Antwort $a b g h \bar{a} k$ èn te nicht unhöflich. Wird man gerufen von Einem, den man als seinen Oberen behandeln, oder gegen welchen man höflich sein will $^{2}$ ), so sagt man wenigstens: marhabā! aber $n a^{c} a m$ ! und lèb bēk! gelten als viel feiner. Wenn der Angeredete in den beiden letztern Fällen die Höflichkeit erwidern will, so sagt er auf $\mathrm{na}^{\mathrm{c} a m}$ !: $\mathrm{na}^{\mathrm{cc} a m a k}[\mathrm{all} \overline{\mathrm{a} h}]^{3}$ ) bilğènneh! oder $[a l l \bar{a} h]^{3}$ ) jen a $a^{c c i m a k}$ bil-ğènne $\left.\mathrm{h} !{ }^{4}\right)=$ Allah schenke dir die Wonne des Paradieses!"; und auf lè bbēk!: fi carafah in šā cllāh! = (mögest du lèbbēk sagen) in 'Arafah, wenn Gott will!" d. h. mögest du die Wallfahrt machen! Auf alle solche Redensarten lässt sich passend mit einem : ğ a m Ican (جَيْيُعا) antworten, d. h. »es sei (was du da nennst) uns allen gegeben!", und dies wird vielfach, um jeden Exclusivismus zu vermeiden, folgenderweise formulirt: ēwállāh, we-u mmèt mehammèd ğamían oder ēwállah wekull èl-muslimin, a $\mathrm{mIn}=\gg \mathrm{Ja}$, bei Allah, und die ganze Gemeinde Muhammeds" oder $\gg \mathrm{Ja}$, bei Allah, und alle Muslime, amen!" Es gäbe kein Ende, wollten wir die gebräuchlichsten Höflichkeitsformeln aufzählen; manche sind übrigens aus der Litteratur bekannt. Wer einen Knaben, einen Diener oder einen Sklaven um einem Becher

1) Vergl, oben $N^{\circ} 22$.

2) Sind keine Höflichkeitsformen zu beobachten, so sagt man einfach: tajjib.

3) A 11 a h kann nach Belieben gesagt oder verschwiegen werden.

4) Wenn der mezèjji n (Barbier) Einem die Toilette gemacht hat, so beschliesst er seine Arbeit immer mit der Formel: na'im an (نَعينًا) = "(es sei) dir zum Glück!" Auch darauf antwortet man mit einer von den oben angegebenen Formeln. 
542 DR. C. SNOUCK HURGRONJE, MEKKANISCHE SPRICHWÖRTER.

Wasser bittet, sagt einfach asqini oder asqini mōje, bisweilen mit vorgesetztem bíllāh. Seinesgleichen oder älteren Leuten gegenüber bedürfen diese Worte noch einer Einleitung wie: rábbanā lājehinak oder belā muwāehazah ${ }^{1}$ ) $=$ sllah erniedrige dich nicht!" oder »nimm es mir nicht übel". Hat der Durstige den Becher in die Hand genommen, so dankt er mit: Allāh jisqīk fi l-ğènneh oder bil-kauthar $\Rightarrow$ Allah gebe dir (einmal) zu trinken im Paradiese" oder saus dem Kauthar (einem Flusse im Paradiese)!" Die Formeln, welche das Trinken selbst begleiten, findet man bei Burton, Pilgrimage, $3^{\mathrm{d}}$ edition, S. 4-5. Begleitet der Hausherr einen Besucher von dem ersten Stockwerke seines Hauses bis unten an die Thüre, oder ist er ihm etwa beim Anziehen seiner ğ ub bah behülflich, so dankt dieser ihm mit: casāk tislam (عساك تسلم) = ses werde dir Heil zu Theil" oder Aehnlichem. Leuchtet er ihm mit einer Laterne (فانوس تسمس)

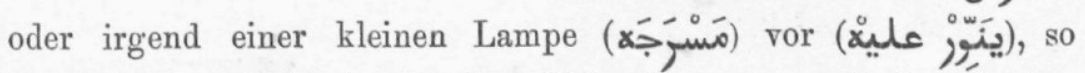
wünscht der Fortgehende ihm Erleuchtung von Gott mit den Worten: allāh jenawwir calēk, u.s.w.

Unser Sprichwort erinnert das Kind, dass es nicht schreien, nicht ach! rufen soll, wenn es die von ihm gewünschte schöne Sache haben will. Man gebraucht es aber in der Bedeutung: wer ein Ziel erreichen will, muss sich auch die Mühe und Arbeit gefallen lassen, welche dahin führen. Mein ägyptischer Freund 'Abd er-Raḥim Efendi Aḥmed erzählte mir, َّ bedeute in seinem Lande ein Knabenspiel, welches hauptsächlich darin besteht, dass die Spielenden sich in zwei Gruppen theilen, von welchen eine über ein mit einem Knoten versehenes Tuch (طُمَّ) verfügt, indem die Knaben der andern Gruppe je in eine Hand ein Stückchen Holz, ein Steinchen oder dgl. ${ }^{2}$ ) nehmen, und dann die beiden geschlossene Hände der andern Gruppe entgegenhaltèn. Einer von den Knaben dieser Gruppe räth (ياكتبار) nun, in welcher Hand seines Gegners sich das Ding befindet. Räth er richtig, so nimmt er ihm das, was sich in seiner Hand befindet, ab; geht er dagegen fehl, so hat sein Gegner das Recht, ihn mit der turrah auf die Hand zu schlagen. Danach hiesse das Sprich-

1) Hier wird das $j$ immer wie ; gesprochen; sonst meistens a chad, ja chud, a c h i d.

2) Diese in der Hand zu verbergende Sache heisst, gleichviel was es ist, ğ e d Id. 
wort: wer das da ḥ̣ a-Spiel spielen will, muss nicht ach! rufen, wenn er die als Strafe für das Fehlgehen bestimmten Schläge bekommt. In Mekkah kennt man aber, so viel ich weiss, weder diese Bedeutung, noch das Spiel, dem sie entnommen ist.

\section{5.}

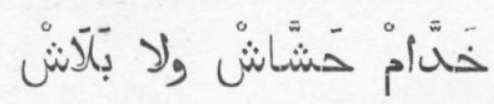

Ein Diener, der Haschisch raucht, ist besser als keiner.

chaddām In heissen ebensowohl die freien Lohndiener (ȩáb I plur. çubjān, weibl. chaddāmah, āt) als die Sklaven ('abd plur. ' $a b_{\bar{i}} d^{1}$ ) weibl. ğ $\bar{a} \mathbf{r i j a h ^ { 2 }}$ ) plur. ğawār). Letztere heissen collectiv èr-raqiq, welches in der mekkanischen Sprache nie den

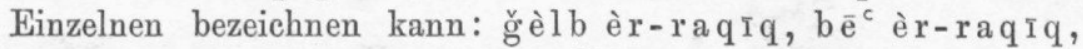
èr-raqiq māhum sáwā (»die Sklaven sind nicht alle gleichen Werthes"). Der Unfreie heisst auch mamlūk (fem. - ah), der Freigelassene $\mathrm{ma}^{\mathrm{c}} \mathrm{t} \overline{\mathrm{u}} \mathrm{q}(-\mathrm{ah})$. Im Gegensatz zum Sklaven heisst der Freie walad èn-nās (= altarab. ḩurr, welches jetzt sehr vornehm klingt), fem. bint èn-nās, resp. »Sohn" und »Tochter der Leute". Der Sklave wird auch wohl walad èl-baḥr (baḥar) = »Sohn des Meeres", häufiger aber die Sklavin bint èl-baḥ ${ }^{3}$ ) = »Tochter des Meeres" genannt, namentlich wenn man ihre gesellschaftlichen Verhältnisse mitleidig bespricht. Im Allgemeinen zieht der Mekkaner den mamlūk als Diener dem »Sohne der Leute" vor.

Viele behaupten, der Werth der Sklaven sei besonders hoch zu veranschlagen, wenn man dieselben ganz jung, oder doch ungelehrt (ghašim, fem. $-\mathrm{a} h$, plur. $\mathrm{ghu}$ š $\left.{ }^{4}\right)$ ), kauft, sodass man

1) Dieser Plural bezeichnet nur Sklaven (von Menschen); der Plural 'i b a d dagegen ausschliesslich Diener (Allahs).

2) Man spricht auch ğ $\overline{\mathrm{rj}} \mathrm{eh}$. Dass dieses im Altarabischen das "Mädchen" bezeichnende Wort schon in sehr alter Zeit ohne weiteres für "Sklavin” gebraucht wurde, erhellt aus unzähligen Stellen. Vgl. in der Tradition z. B. das 67ste Bāb von Buchārı's Kitāb an-nikāh ; dass in der classischen Sprache der Araber auch wohl seine Fran nennt, theilt mir Prof. de Goeje mit. Nach dem neueren Sprachgebrauch wäre dies eine schwere Beleidigung.

3) Bint è l-háwa = "Tochter der Luft” ist eine unsittliche Weibsperson, gleichviel ob sie verheirathet sei oder nicht.

4) Mit diesem Adjectiv bezeichnet man gleichfalls die fremden Pilger oder m e ğ ã- 
¿sie gänzlich nach eignem Geschmacke erziehen kann. Andere, welche mit dieser eignen Erziehung schlimme Erfahrungen gemacht haben, ziehen es vor, gleich einen unterrichteten ( $\mathrm{me}^{\mathrm{c}}$ alla $\mathrm{m}$ ) Sklaven zu kaufen; erziehe lieber einen Hund als einen Sklaven, sagen diese. Auf alle Fälle vermeiden auch sie es, einen in Mekkah aus Sklaveneltern geborenen Sklaven (mewallad) zu kaufen. šajāṭin èd-dunjeh humma= lautet das einstimmige Urtheil.

Die Sklaven haben auf die Dauer mehr Interesse daran, sich die Gunst ihrer Herren durch ihre Tüchtigkeit zu erwerben, als gemiethete Diener; auch gibt es wirksame Mittel, jene zu bestrafen, weil das hakm über sie ungetheilt in Händen ihrer Herren ist, während der çábi neben seinem Meister ( ${ }^{c}$ a m m) oftmals seinen Vater, Vormund oder seine Mutter als Zuflucht hat und

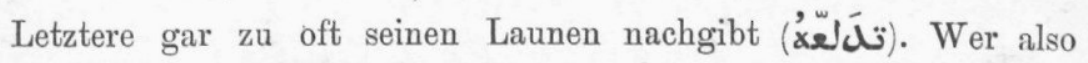
die Mittel dazu auftreiben kann, geht auf den Sklavenmarkt (dèkkeh) ${ }^{1}$ ) in dem Bāb Derëbeh (einem der Thore und dazu gehörigen Vorhallen der Moschee), besieht die dort ausgestellte menschliche Waare, befragt die dèllālin (Makler), ob es ihres Wissens in den "Häusern der Leute" (bijūt èn-nās) noch bessere Sklaven zu verkaufen gibt, und kauft sich von Jenem (mit dem Eigenthümer hat er dabei nichts zu thun) was ihm am besten gefällt. Findet er sich nachher in seinen guten Erwartungen vom gekauften Sklaven getäuscht, so bringt er denselben wieder auf den Narkt (jenazziluh èd-dèkkeh), wo er vielleicht einen andern Herrn findet, dessen Charakter besser mit dem seinigen übereinstimmt. Aus dem mekkanischen Sprachgebrauch will ich hier noch ein paar Sachen anführen, welche sich auf die Sklavenwelt beziehen. Sklaven, welche längere Zeit mit einander denselben Herrn (oder in einem Hause) gedient haben, sprechen von einander immerfort als sandūl (fem. sandūlah, Plur. sanādill); sie reden einander mit »Bruder" und "Schwester" an, aber einer von ihnen beschreibt sein Verhält-

wir In, welche mit der Sprache und den Sitten der Mekkaner noch nicht genügend bekannt sind, und deswegen auf dem Markte und sonst die Hülfe anderer Leute brauchen.

1) Der ganze Markt wird so genannt nach den dèkkeh's ( $\alpha \overline{\bar{S}} \bar{j}$, man spricht auch wohl einmal dikkeh), auf welchen die zum Verkaufe gebotenen Sklaven und Sklavinnen sitzen. An einem andern Orte gedenke ich nächstens die Verhältnisse der Skla ven in Mekkah etwas ausführlicher zu besprečhen. 
niss zum andern einem dritten, indem er sagt: sandūli hu $\bar{u}$ a $=$ »er ist mein sandūl". Es liegt allerdings nahe, darin mit

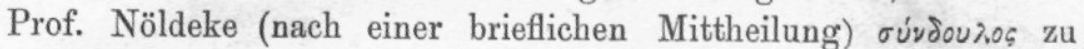
sehen; nur scheint es seltsam, dass gerade ein griechisches Wort in die Sprache der mekkanischen Sklaven (meistens Nubier und Abyssinier) gedrungen wäre. Ueberhaupt reden Sklaven ungefähr gleichen Alters einander mit a chūje, u chti (Bruder, Schwester) an; die jüngeren sagen zu den älteren je nach der Innigkeit des zwischen ihnen bestehenden Verhältnisses: 'ammi ('ammatr) oder $\left.a b \bar{u} j e\left(u m m I^{1}\right)\right)$ - die älteren nennen die jüngeren einfach beim Namen, oder setzen waladi, binti hinzu. Jeder mamlūk redet, wenn er höflich sein will, jeden irgendwie anständigen Freien mit: sId (resp.: sitti) an, vorzüglich aber alle Verwandte, Freunde und Bekannte seines Herrn, gleichviel ob sie jung oder alt sind. Der Freie nennt den Sklaven entweder beim Namen oder, wenn ihm dieser z. B. unbekannt ist, $j \bar{a}$ walad = »o Junge!" Sagt der Herr zu seinem eignen Sklaven; jā walad, mit oder ohne den Namen des Betreffenden, so liegt darin etwas Gebietendes oder Zorniges. Auch sagt man zu einem Sklaven, den man freundlich anreden will: $\mathrm{j} \overline{\mathrm{a}} \mathrm{a} \mathrm{ch} \overline{\mathrm{u}} \mathrm{je}=\gg$ mein Bruder", wenn dieser gleich doppelt oder auch nur halb so alt wäre als der Anredende. Anders nennen aber Kinder die Sklaven und Sklavinnen, von welchen sie gleichsam grossgezogen worden sind; zu diesen können sie abūje (resp. u mmI) sagen; technisch ist aber $d \bar{a} d \bar{I}($ resp. $d \bar{a} t \bar{I})$. Sagt ein Mekkaner von einem Sklaven: »dieser ist mein $d \bar{a} d "$, von einer Sklavin: »diese ist meine dāt", so können diese Prädicate nur solche bezeichnen, welche irgendwelchen Antheil an seiner Erziehung gehabt haben; dieses Verhältniss ist ein dauerndes und wird auch fortwährend durch dieselben Worte ausgedrückt. In der directen Anrede gebraucht man die Worte aber aus Höflichkeit auch sonst gegen anständige Sklaven, welche man ihres Alters wegen ehren will. Die Bedeutungen, welche Dozy, Supplément i. v. داد ol und ชذادّ angibt, gehen wohl alle auf die Begriffe »Vater" und » Mutter" zurück. Es scheint wohl, dass $d \bar{a} d$ oder $d \bar{a} d \bar{a}$ ursprünglich zu den Wörtern der Kindersprache ${ }^{2}$ ) gehört, wie mir dies Prof.

1) Diesen Worten wird häufig der Name des Angeredeten hinzugefügt.

2) Vergl. auch Hèzz è l-quḥuf, S. 109-10, wo unter den Wörtern der jetzigen Kindersprache Aegyptens: $b \bar{a} b \bar{a}, m_{\bar{a}} \mathrm{~m} \bar{a}$, wa $\bar{w} \bar{a}$ für Vater, Mutter und Bruder vorkommen.

ie Vo gr. I. 
Nöldeke durch die Mittheilung einer Reihe von ähnlichen Beispielen aus verschiedenen Sprachen bestätigt. Einmal in die Reihe der Begriffswörter übergetreten, nahm dād dann auch die weibliche Endung an, mit welcher es im mekkanischen Dialecte zu d a t zusammengezogen "wurde.

Dass Sklaven überhaupt die besten Diener sind, drücken die Mekkaner oft in dieser Weise aus: a ḥsan min felūsak mā fIš = ses gibt nichts Besseres als dein eignes Geld" d. h. das »von dir Gekaufte".

Viele Mekkaner und meğāwirin gebrauchen jedoch die gemietheten Dienste der "Söhne der Leute", sei es aus Geldmangel, oder weil sie nicht allzu lange Zeit in der heiligen Stadt zu verbleiben gedenken. Javaneu, Malaien und Inder haben meistens çubjān von ihren Landsleuten, und junge Leute von diesen Nationalitäten findet man auch gar nicht selten als Hausdiener bei den ahl makkah. Die meisten freien Diener sind aber ḤadhramI's, welche wegen ihres Fleisses, ibrer Genügsamkeit, ihrer Ehrlichkeit und Gewandtheit (شطار) bei den Kaufleuten besonders beliebt sind. Im Anfang verwendet man sie zu kleineren

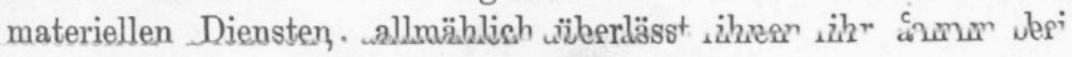
seiner Abwesenheit das ganze Geschäft, oder wenn derselbe mehrere Buden besitzt, überlässt er einem ȩábi die ganze Führung einer Bude. Die Sparsamkeit der Ḥadhā ramah setzt die meisten nach wenigen Jahren in den Stand, auf eigne Rechnung Geschäfte zu unternehmen. Arme Slēmānr's, Maghār ${ }^{2} b a h$ und Ḥiğāzi-beduinen ${ }^{1}$ ) vermiethen sich in Mekkah vorzüglich als Portiers (bawwābin); die Higiḡāzı's geniessen in Bezug auf ihre Ehrlichkeit einen ebenso guten Ruf wie die H̦adhā $\mathrm{r}^{3} \mathrm{mah}$, taugen aber wegen ihres Mangels an šațārah nicht für Handelsgeschäfte.

Ein dem verbotenen Genusse des Haschisch ergebener Diener wäre in fast jeder Stellung unbrauchbar; solche chaddāmin gehören aber in Mekkah zu den Ausnahmen. Ḥaššăšin in des Wortes eigentlicher Bedeutung findet man hauptsächlich unter den Müssiggängern, den türkischen Soldaten und der schlechtesten Sorte der freigelassenen Negersklaven. Der Name bezeichnet

1) Mit Hiğaza ist hier das kleine Gebiet in der Nähe von Täif gemeint, welches von Alters her diesen Namen getragen hat und noch heute von der Bevölkerung ausschliesslich so genannt wird, nicht die grosse Provinz des türkischen Reiches, welche nur der Administration und den Schriftstellern, die ihrem Sprachgebrauche folgen, als Biğăz bekannt ist. 
aber alle Leute, welche sich immer unanständig betragen, zanken, gleich darauf losschlagen, schmutzig gekleidet herumgehen, kurz deren Dasein der Gesellschaft sehr wenig nützt. Ein chaddām ḥaššāš ist, was der Aegypter ein chaddām chára nennen würde. - balāš heisst »umsonst" und steht oft für: »es ist nicht mehr nöthig" (von einer zuerst verlangten Sache) z. B. zu einem Sklaven, den man gerufen hat, dessen Aufgabe aber inzwischen schon Andere erledigt haben: balāš $=$ »bleibe nur da, wir brauchen dich nicht mehr", zu Einem, der auf den Markt geht, Brod, Gemüse u. s. w. zu kaufen: èl-ḥabḥabah balā̌s $=$ die Wassermelone (von welcher zuerst die Rede war) brauchen wir nicht mehr". Im Sprichworte steht es für x'íc oder

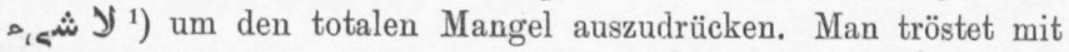
dem Sprichworte Einen, der sich über einen schlechten Diener beschwert, aber einstweilen keinen andern bekommen kann.

\section{6.}

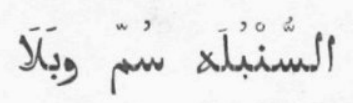

Die Sumbulah (die »Jungfrau" des Thierkreises) ist summ (Gift) und $b \grave{e} l \bar{a}$ (Elend).

Von den »vier Jahreszeiten" haben die Mekkaner nur aus den Büchern Kenntniss. Im gewöhnlichen Leben spricht man nur von dem Sommer $=$ çēf oder der Hitze $=$ ha $\operatorname{rrr}^{2}$ ), und von dem Winter = šíta, šíte oder der Kälte = burād. Diese » Kälte" ist allerdings eine verhältnissmässige; man braucht nicht mehr aus Furcht vor Erstickung auf den Dächern der Häuser zu schlafen, und man kann sich ohne Scheu ordentlich kleiden; nur selten wird es wirklich etwas kühl und die ganze kühle Jahreszeit dauert höchstens vier Monate. Da die „Ernte" der Mekkaner (d. b. das Pilgerfest) sich nach dem Mondjahre regelt, haben als weitere Zeitabschnitte die Monate des muslimischen Jahres für die heilige Stadt die höchste Bedeutung; man beachtet die Festtage, wєlche für Mekkah am wichtigsten sind, dann den Monat Rèğ èb,

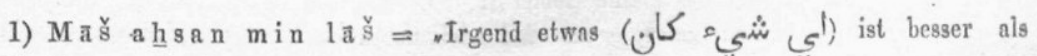
nichts" sagen die Aegypter.

2) Hararah heisst nur ein rother Aussatz, an dem die meisten Mekkaner in der heissen Jahreszeit leiden, vorzüglich wenn sie viele "heisse" Speisen geniessen, 


\section{DR. C. SNOUCK HURGRONJE, MEKKANISCHE SPRICHWÖRTER.}

wo die Waller nach Medinah pilgern, den Fastenmonat Ramadhān u.s.w. Zur Bezeichnung natürlicher Jahreszeiten haben die ungebildeten Mekkaner nur noch einen Anhaltspunkt in der Zeit der Reife der am meisten geschätzten Früchte (Datteln, Feigen u. s. w.); diese reifen aber alle kurz nacheinander im Laufe des Juli. Die Gebildeten kennen ausserdem die Sterngruppen des Thierkreises oder doch einige davon, mit welchen sie auffallende Erscheinungen des Klimas in Beziehung bringen. Diese ihre meteorologische Weisheit haben sie in Redensarten niedergelegt, welche ebenso regelmässig wiederkehren, als die Sonne durch den Thierkreis geht. Einige von denselben werden so oft wiederholt, dass sie schliesslich auch von den unteren Klassen gebraucht werden.

Die meisten Mekkaner kennen das hier angeführte Wortspiel, und wenn sie auch von dem Thierkreise sonst nicht die geringste Ahnung haben, sagen sie doch manchmal, wenn die Hitze des „Sommers" ihnen unerträglich wird: a qèjjis niḥnā dā 'l-ḥineh fi 's-sumbelah ${ }^{1}$ ) = sich vermuthe, wir sind wohl jetzt in der sumbulah".

In den Monaten Juli, August, September und Oktober erreicht die Hitze in Mekkah ihren höchsten Grad. Nicht einmal der Wind, von dem man übrigens in diesem abgeschlossenen Thale oft lange Zeit nichts bemerkt, gewährt die 'erwünschte Erholung. Kommt er von Norden, Nordosten oder Osten her, so heisst er sam $\mathrm{m} \mathrm{m}$ und macht denen, die sich auf die Strasse begeben, den Eindruck, als befänden sie sich vor einem entsetzlichen Feuer, dessen Hitze ihnen mittels eines riesigen Blasebalges zugeführt würde; ištadd 'alēnā 'l-ḥ̄o m ${ }^{2}$ ) $=$ »die trockene Hitze ist uns schwer geworden" sagt man in solchen Tagen. Weht ein südlicher oder südwestlicher Wind (a zjab), so bringt dieser soviel heissen Wasserdampf mit sich, dass die Luft äusserst schwer auf dem menschlichen Körper lastet. Diese feuchtschwere Hitze nennt man wamd (vgl. altarab. wamad); der Wind, welcher dieselbe erzeugt, gewährt doch auf der Strasse noch eine Art Abkühlung, welche man im Hause vergeblich sucht; die Mekkaner ziehen jedoch den sam $\mathrm{u} m$ mit seinem hạm dem azjab und seinem

1) Der zweite Vocal dieses Wortes wird vielfach unbestimmt in der Aussprache; dirs erleichtert das Wortspiel in unserem Sprichworte.

2) $\stackrel{0}{\circ}$ ist der terminus technicus für die aus dem s a m a m entstehende Hitze. 
wa md vor. Der trockne Nordostwind mag so heiss sein, wie er will, er kühlt doch das in den porösen thönernen Gefässen $(r a b a \bar{T}$, šèrbāt, qulal) befindliche Wasser ein wenig $a b$; unter der Herrschaft des a zjab gibtes nur moje da fjeh $=$ lauwarmes Wasser, und das ist in Mekkah etwas Sehreckliches. Die 7eit, wo die Sonne in die sJungfrau" ") tritt, ist nun in Mekkah besonders verrufen, weil darin nach der geltenden Ansicht h̆om und wamd, samūm und azjab unaufhörlich abwechseln. Die sumbulah ist den Mekkanern gewissermaassen das, was. für uns die Hundstage sind; nur der Grad ist etwas verschieden!

Im benachbarten Ğiddah sind die klimatischen Verhältnisse durchweg von den mekkanischen verschieden. Die Hitze erreicht nicht den hohen Grad wie in Mekkah, ist aber durch die entsetzliche Feuchtigkeit der Atmosphäre viel schwerer zu ertragen. Die Eingebornen fürchten sich aber in Ğiddah mehr vor der kalten als vor der heissen Jahreszeit. Theilweise hat diese Furcht vielleicht ihren Grund darin, dass die kalte Jahreszeit oft mit einem Regenschauer anfängt, dem gewöhnlich das Ausbrechen von Krankheiten aller Art folgt ${ }^{2}$ ). Jedenfalls scheint den ǦiddāwI's im »Winter", vorzüglich im Anfange desselben, alles doppelt gefährlich. Gegen eine Kühle, welche uas als wohlthätig erscheinen dürfte, schützen sie sich nicht nur durch dicke Kleidung, sondern sie hüllen den Kopf in Tücher, welche nur einen Theil des Gesichtes entblösst lassen. Dagegen schliessen sie in derselben Jahreszeit jeden Sonnenstrahl ängstlich aus dem Zimmer aus, weil auch die Sonne im ersten Theile des Winters schlimmer (1َ) sei als je; allerhand Krankheiten schreiben sie ihrer bösen Einwirkung zu. Mit dem Nahen des Sommers nimmt diese ängstliche Fürsorge $a b$; den letzten Theil der kalten Jahreszeit betrachtet man sogar als der Gesundheit zuträglich; Kühle und Sonne schaden Einem nicht mehr, man darf sich ohne Scheu ausserhalb der Stadt begeben. Diese empirische oder pseudo-empirische Weisheit äussert sich in dem Spruche:

1) Sumbulah heisst eigentlich "Aehre"; die Sterngruppe, in welche die Sonne im August eintritt, heisst auch im Arabischen wohl "Jungfrau" ('a d $\mathbf{r} \bar{a}^{\prime}$ ), wird aber meistens nach einem von den Sternen, aus welchen sie zusammengesetzt ist, "Aehre" (vgl. das lat. spica) geheissen.

2) Europäische Aerzte in Ğiddah behaupten aber, dass der Regen nicht so schlimme Folgen für die Ǧiddāwr's haben würde, sobald die Faecalienabfuhr auf bessere Weise als bisher eingerichtet'wäre. 


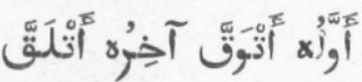

Hüte dich vor seinem ersten (Theile), gehe seinem

letzten (Theile freudig) entgegen.

Die beiden Imperative gehören zu den Vten Stämmen von لقي und وقى; die beiden Suffixe beziehen sich auf èš-šít e $=$ den Winter.

\section{7.}

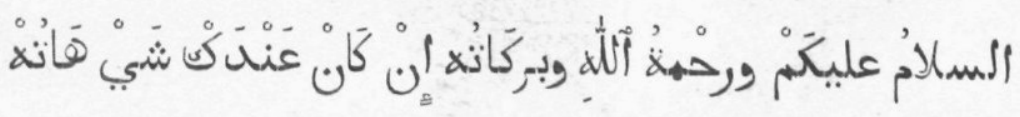

Der Friede sei über euch und Allahs Gnade und seine Segnungen! wenn du etwas bei dir hast, her damit!

Der erste Theil dieser Redensart enthält die Grussformel, welche der Prophet seinen Gläubigen als die beste und vollständigste anempfohlen haben soll. Abgesehen von den Gelehrten, gebrauchen die Gläubigen meistens als erste Begrüssung nur die Worte: ès-salāmu calēkum, und zur Erwiderung derselben: wéalè$\mathrm{kum}$ ès-salām, welch letzterem aber die Mekkaner fast immer war-raḥmah, weraḥmatu 'lláh oder wal-ikrām hinzufügen. Der Gebrauch der dreigliedrigen Formel ist verhältnissmässig selten, vorzüglich für den, der zuerst grüsst. Durch den Gegeusatz der weitläufigen Segenssprüche und der unmittelbar darauffolgenden Aeusserung grosser Habsucht verspottet man die Leute, welche einen überschwänglichen Gebrauch von Höflichkeitsformeln machen. Die Mekkaner gebrauchen aber die Redensart oft zum Scherze und ohne irgendwelche Absicht, wenn sie zu einem guten Bekannten eintreten.

Nachtrag In der Anmerkung zu S. 448 (16) habe ich der mir früher als wahrscheinlich erschienenen Erklärung des Wortes بواريلهي als entanden, keine Erwähnung gethan, weil dieselbe mir "wegen der ausnahmslosen Vocallosigkeit des, unhaltbar zu sein schien. Inzwischen erfahre ich von einem Syrer, dass man die Polizisten in seiner Heimath vielfach بَوَارِيديّيَ = „Flintenträger" nenat; obgleich nun die Flinte in West-arabien

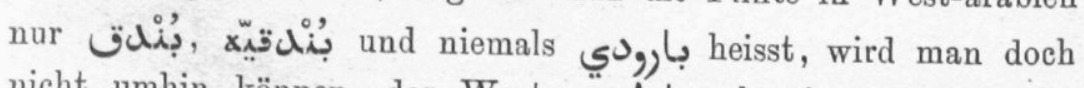
بواريلهي als eine aus باروارني als 
DR. C. SNOUCK HURGRONJE, MEKKANISCHE SPRICHWÖRTER, 551

\section{N DE X.}

$1-\lceil$ als Vocal des Praefixes der Isten Pers. Imperf. der Verba IIten und IIIten Stammes 456 (24) Anm. ; 492 (60), 507 (75). Dieser Vocal sowie auch das $a$ der ersten Pers. Imperf. der concaven Verba Isten Stammes, fällt nach $a$ aus; vgl. auch 512 (80), 509 (77).

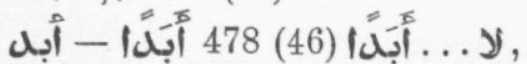

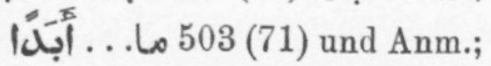
505 (73).

(36); 468 ماحب =ابو - ابو ابو

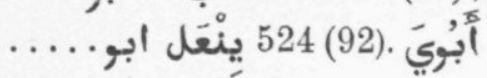
545 (113) ff.

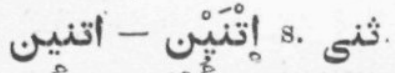

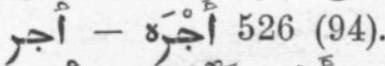

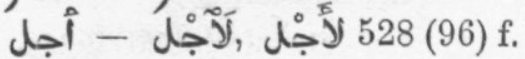

u. s. w.

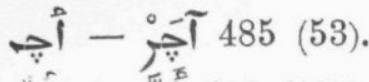

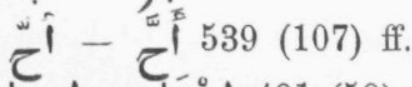

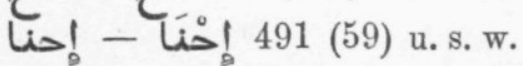
vgl. نسكن.
أخل - s. أخل

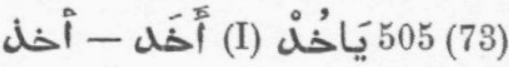

Anm.507 (75) Anm.; 542(110)

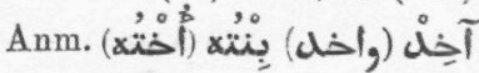

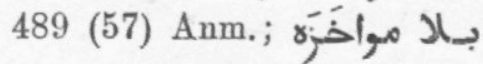
533 (101), 542 (110).

آخْرَاني - آخر - 484 (52) Anm.; آخِرَ (118).

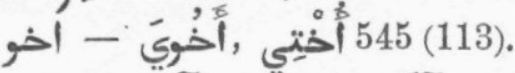

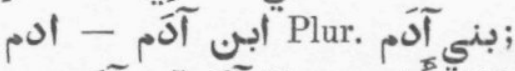

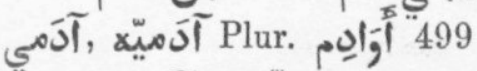

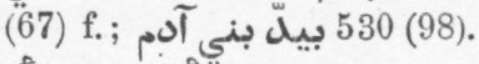

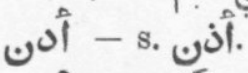

أن - أنى (II) 456 (24); Impf.

(92).

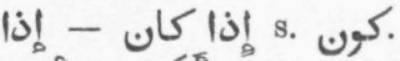

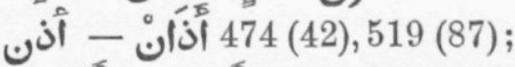
أَّأَ 435 (3) Anm. ; أستأدن أدن (X) 466 (34), 541(109);

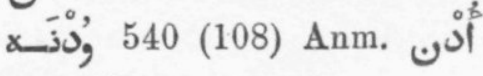
491 (59).

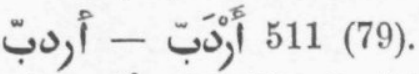
j) - ऑ 485 (53) ff. ; 528 (96)

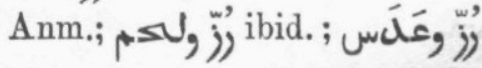




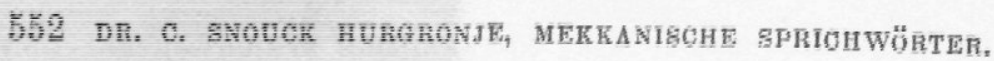

$\left.480(54) ;(5)^{3}=3\right)^{4}=480(54)$.

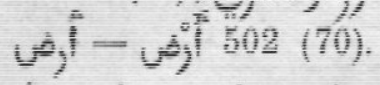

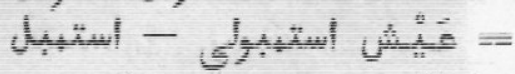

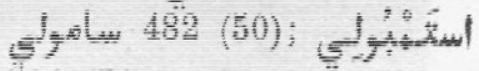
506 (74).

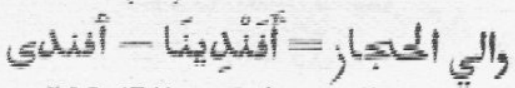

503 (71) und Anm; 540 (108)

und Anm, 1. ร. W.

या - या 508 (71) Anm.

لكآل Imperf.

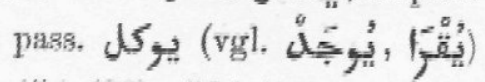

454 (22); 524 (92) u. ร. w.;

ฝึ่ 531 (99).

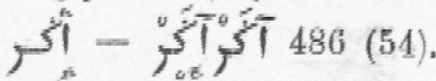

ألी - 504 (72), 533 (101).

गी

أل 514 (82), 542 (110);

aلl, passim.

إلـي - 524 (92) ff.

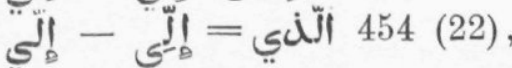

457 (25), 507 (75) Anm.u.s.w.

إلّي 468 (3) إلّي عنله رإِّي mit Participp. verbunden 512 (80).

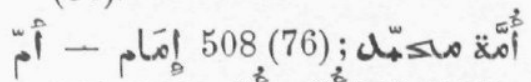

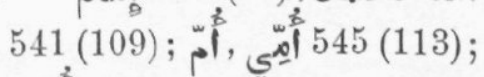

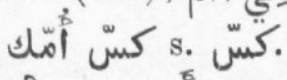

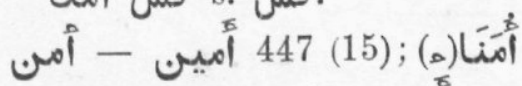

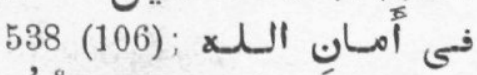
كَفْظْ 466 (34).

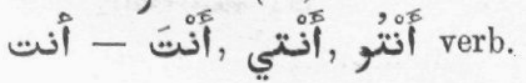

mit der Negation Lo 491 (59);

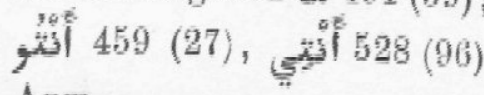
Anm.

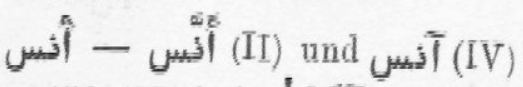

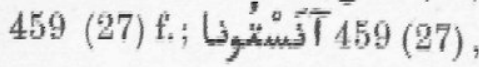

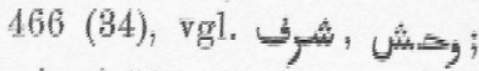

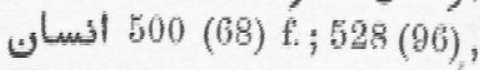
Plur, yLu, 500 (68); Beden-

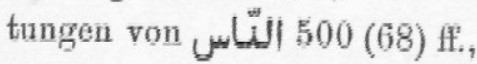

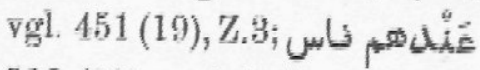

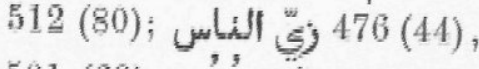

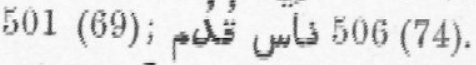
548 (111); 544 (112). لoا - 443 (11); ull البال 149 (17); 502 (70), 503 (71), 524 (92);

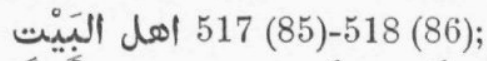

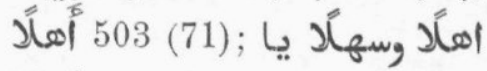
(34).

أوفة 480 (48) ff.

لأ أََّّ (Adverb) 445 (13),

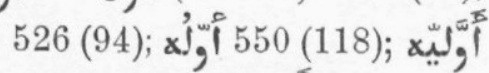
526 (94); 484 (52)

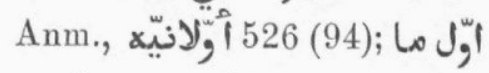
كون. S.

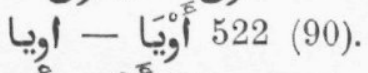

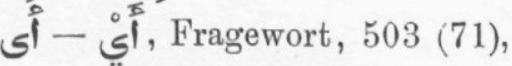
512 (80); als Flickwort gebraucht 526 (94).

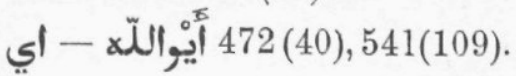


DR. C. SNOUCK HURGRONJE, MEKKANISCHE SPRICHWÖRTER. 553

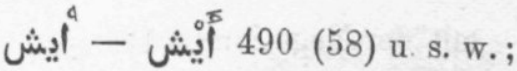

als Flickwort gebraucht 526

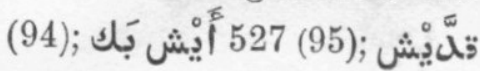
s. $\mathrm{d}$.

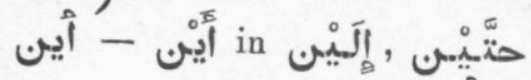

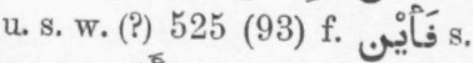

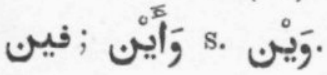

— die Präposition صِ vor dem Imperfectum 435 (3) Anm.

ب - in hadhramitischen Geschlechtsnamen $=\pi 448$ (16) Anm.

545 (113).

500 بَوَابِير Plur بَابُور - ب بابور (68) f.; 508 (76) und Anm.; 526 (94).

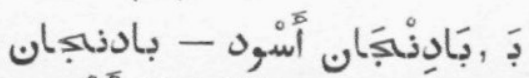
أَّأْ (54).

(24).

فَضَّه = ديواني = بِاره - باره 445 (13).

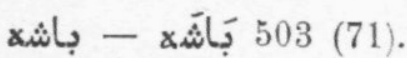

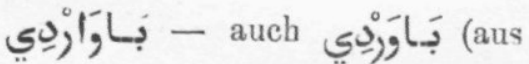

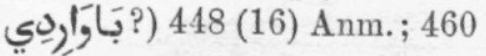
(28)Anm., vgl.Nachtr.550(118). 450 (18) ff.

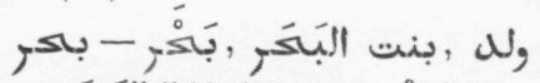

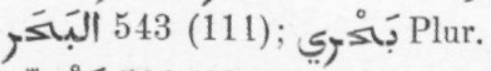
. 501 (69), 512 (80). بكات - 485 (53) Anm.

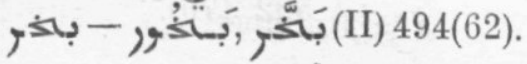

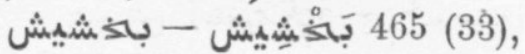
518 (86).

لَّ 503 (71).

بَ بَنْل 505 (73).

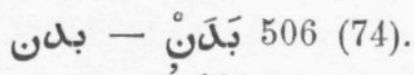

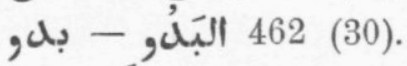

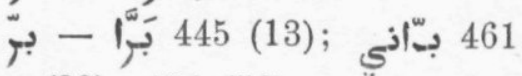
(29), 484 (52).

483 (51) Anm.; 486 (54); - بَرَّ Anm. ; 495 (63) An 547 (115), بَرَّان 465 (33). (30). م20 (88) ff. (12), Z. 74 ; بَّكَّ (63); 4931 (99).

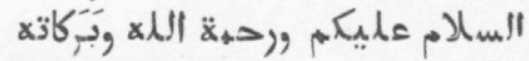
510 (118); $x$ x 518 (86) f. 496 (64). 518 (86).

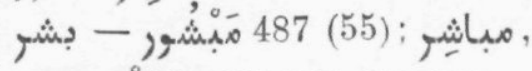
. 465 (33), 518 (86). بطّل 505 (73), بطّال - (II) 506 (74).

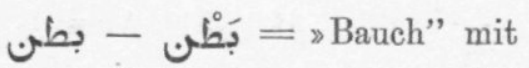
den Verben مشك , مشى 455

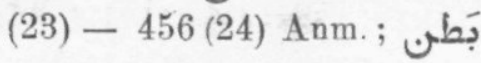
$=$ (28) f.; 500 (68). 445 (13), 524 (92) ff. 
554 DR. C. SNOUCK HURGRONJE, MEKKANISCHE SPRICHWÖRTER.

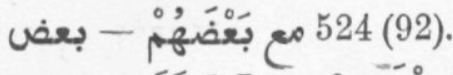

503

(71), 524 (92), 539 (107) ff.

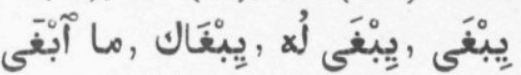

$$
540 \text { (108) f. }
$$

(73), 507 (75).

= بـى 501 (69) بـقِى -

صار 514 (82) Anm.

530 بُكْرَه ان شاء ألله, - بـكس

(98); بَكُ 531 (99).

(25).

485 (53) Anm.

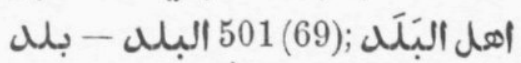

449 (17); 482 (50).

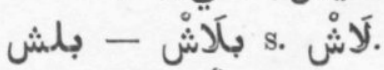

(30).

بَلَغ - بلغ (I) 524 (92).

512 بَآِْي - (80).

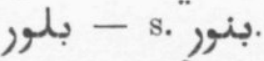

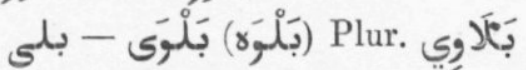

461 (29); als Apposition, ibid.

Anm.; گَ̣ 547 (115).

بنتو

Ann.

(74).

483 (51) Anm.

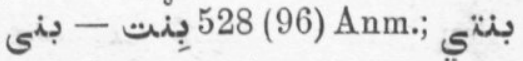

545 (113); بنت 451 (19); بنات بنت الكللب ,المكافر - :عمّم . عمّ بنت الجمبل ; s. بنت البكر, بنت الناس ;نهل

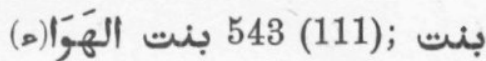
481 بَنَّا(ه) ; (105) 537 البَبْتِ (49).

444 (12), 533 (101).

يا الله على ; فتحي .s باب - بوب .

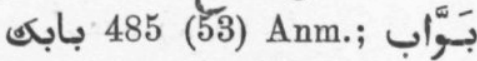
546 (114).

533 (101). f.

بول - 444 (12), Z. 6.

535 (103) u. s. w.,

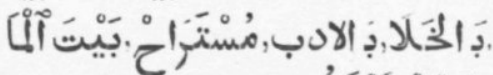

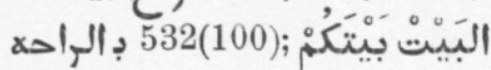

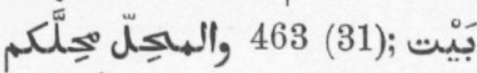

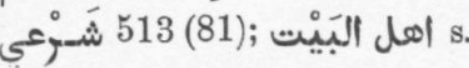
537 (105); 544 (112).

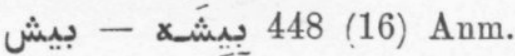
468 (36).

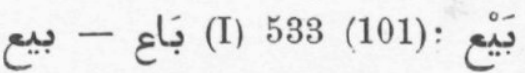

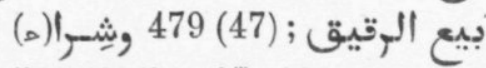
543 (111); 469 (37).

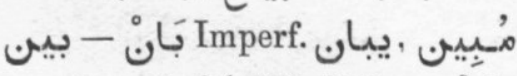

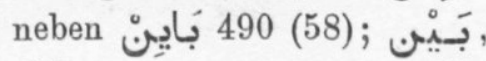

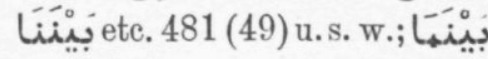
458 (26).

(๘)

$$
\text { تَت } 459 \text { (27). }
$$

(88).

504 (72). 
DR. C. SNOUCK HURGRONJE, MEKKANISCHE SPRICHWÖRTER, 555

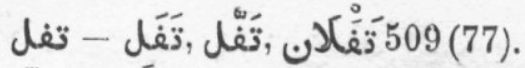
تَّك (73), 505 (89), vgl. كَّك

460

(28) Anm.

- s. ثلت - s.

521 (89) Anm:

518 (86).

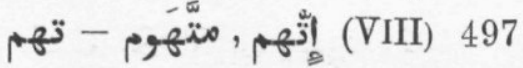

(65).

(15).

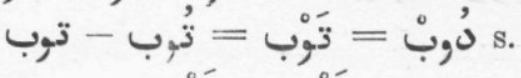

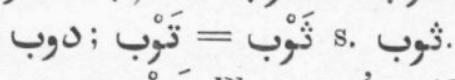

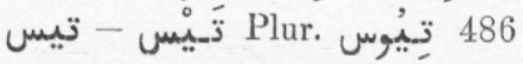

(54) Anm.

486.(54), 496 (64).

$\dot{ث}$

451(19); 501 (69);

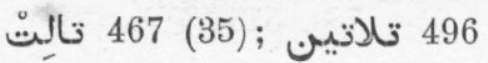

(64).

501 (69).

505 (73), 506 (74),

522 (90) und Anm.

\section{ج}

جاء Imp. 444 (12), Z. 6 und Anm., 446 (14) Z. 6

v. u. 451 (19) Aum. ; 461 (29), 501 (69), 514 (82) Anm.u.s. w. جـاوات , جـاري ,جَاوره - جـاوره
451 (19) Anm. ; 514 (82), 522 (90); 520 (88).

468 (36), 494 (62), 505 (73) f., 542 (110).

534 (102).

(Subst.) 542 (110)

Anm.; فَلَّ جله 506 (74); جلّ 514 (82).

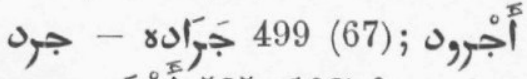

= 535 (103) f.

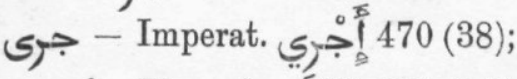

جاريx Plur. جواري 451 (19), 543

(111) und Anm.

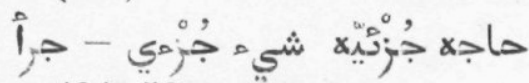
484 (52).

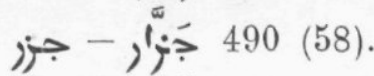

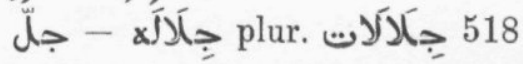

(86) Anm.

543 (111); جَلْب الرقيقى - جلبَ جاربية

كَلَّابيّه 522 (90).

جلس - 465 (33).

جماعة - 459 (27), 517 (85)

Anm.; 517 (85);

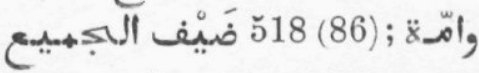

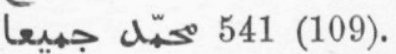

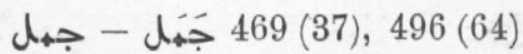

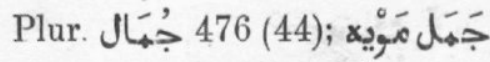

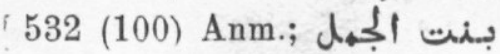

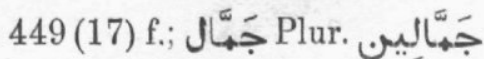
und جَهَّاله 538 (106) Anm.; 476 (44), 507 (75) Anm. 
556 DR. C. SNOUCK HÜRGRONJE, MEKKANISCHE SPRICHWÖRTER.

etc. 541 (109) f.

جَنْب - جنب (Subst.) 458 (26);

Präp. 480 (48).

جن 500 (68).

484

(52) Anm.

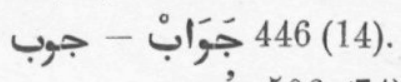

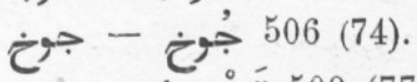

509 (77).

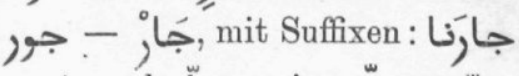

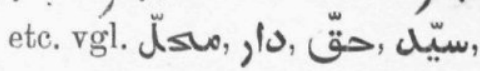

بــيست, u. s. w. 463 (31); مباورين 543 (11) Anm. ff. جـ - 468 (36) Anm. ;

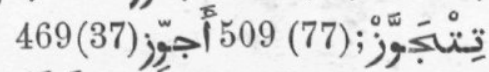

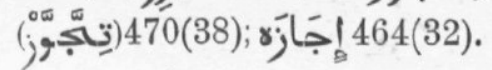

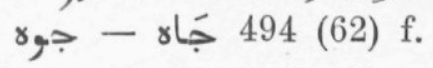

جاب - Impf.

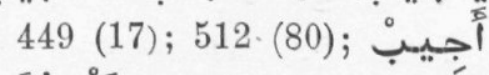
هُ هَكَّ (60).

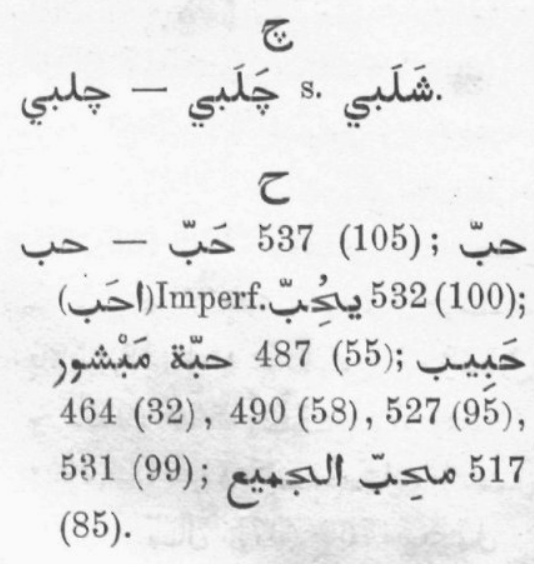

حَبْنَكَبَه ,حَبَكَبْ - حبريب 468 (36) f.; 527 (95).

حَبَّس - (II) 453 (21) Anm.

حبل - Perfect. 464 (32); Imperat. 449 (17); حُبَّ 450 (18). حتى - 456 (حتَّى (24), Z. 17; 503 (71) u. s. w.; nachgesetztes

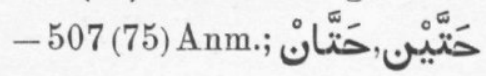
524 (92) ff.

حمّ ج حسبَ 445 (13), 455 (23); Plur. أحْبَار 476 (44), الكَكَبَّْ ; 493 (61) ff. 481 (49).

حِيَّ 546 (114) Anm.;

(114) Anm.

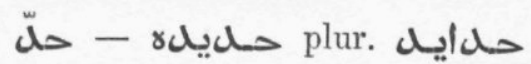
510 (78), 511 (79).

; - 547 حَرَاره , حَرّ Anm.; ; 483 (51) Anm.; 485 (53) Anm. ; 496 (64), 511 (79); 543 (111).

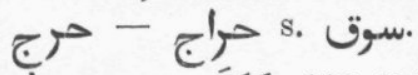

\ـ - (99) und Anm.

م - 494 (62), 509 (77), 517 (85); مَ 455 (23);

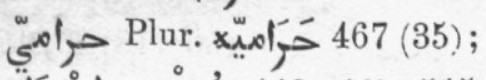

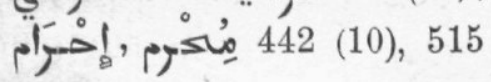


DR. C. SNOUCK HURGRONJE, MEKKANISCHE SPRICHWÖRTER. 557

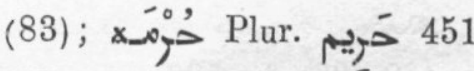

(19) und Anm., 517 (85), 541

(109); Plur. مَئ 517 (85);

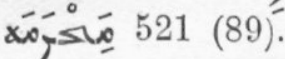

- -

حَسَبَ (1) 493 (61);

(51).

هسل - 502 (70)

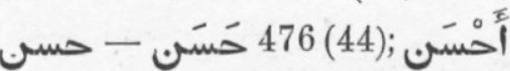

478 (46), 546 (114), 547 (115)

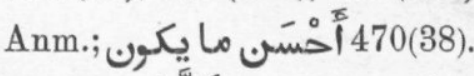
543 حسشـيش ,حَشَّاشن - حشّن

(111) $\mathrm{ff}$.

حشم - 453 (21) Anm.

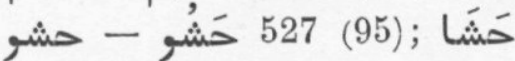

523 (91).

هصل (I) 515 (83).

(37).

حضر (I) 459 (27).

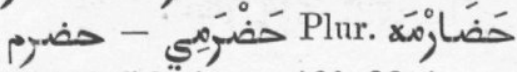

448 (16) Anm.; 460 (28)Anm.;

546 (114).

532

(100) Anm.

حفظ - s. حفض.

في أمسان الله ورَفْظه - - هفظ

466 (34); حَفَّ (I) 524 (92).

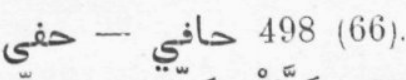

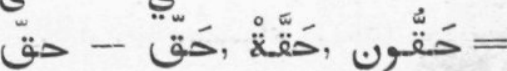

(18) ff., 454 ('2), 468 (36) f.; 501 (69); u. s. w. 450 (18);

حقَّ رَّا : mit Suftixen etc., vgl. جوق 463 (31).

464 (32).

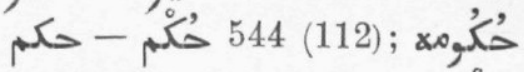
450 (18), 453 (21) Anm.; هِكْ (1)

Plur.

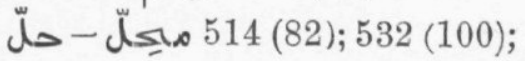

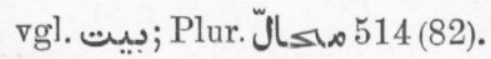
483 (51); . 486 (54).

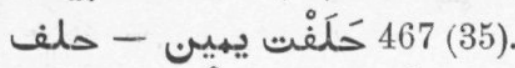
511

(79).

هلو 456 (24), 460 (28),

476 (44), 507 (75) und Anm.

Anm.

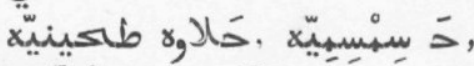
(53).

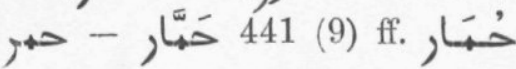
444 (12); Plur. حبي ibid., 533 (101); ) 495 (63), 512 (80).

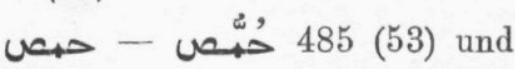
Anm.

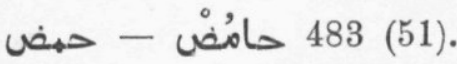

حهط - 486 (54)

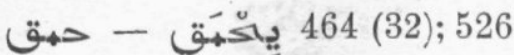

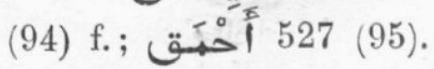

إستحهل (X) 511 (79);

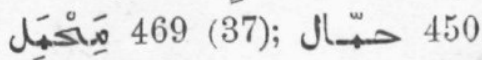


558 DR. C. SNOUCK HURGRONJE, MEKKANISCHE SPRICHWÖRTER.

(18) Anm.; Plur. حبّالين und 481 (49); 538 (106) und Anm.

ى -

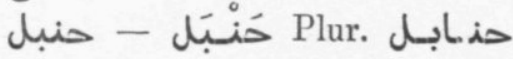

518 (86) Anm.

471 (39), 484 (52), 503 (71), 514 (82),

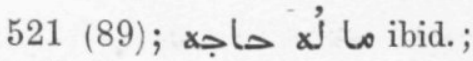

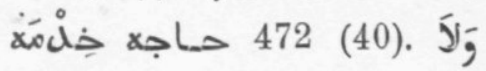
كَاجَهَ (92).

هول

456 (24); حاله 513 (81);

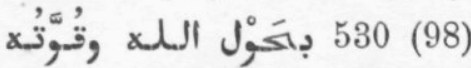

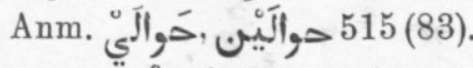

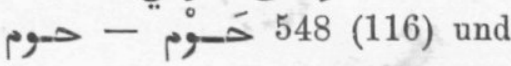

Anm. ff.

حيا(ه);(17) 449 استحكى - حي" 524 (92).

هير احتار, - (VIII) 478 (46). ديل 503 (71) Anm. - بالكينل

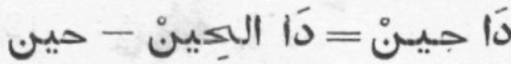
447 (15), 462 (30) Anm.; 489 (57) f.; 507 (75), $512(80)$;

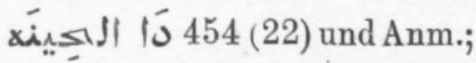
517 (85); 548 (116).

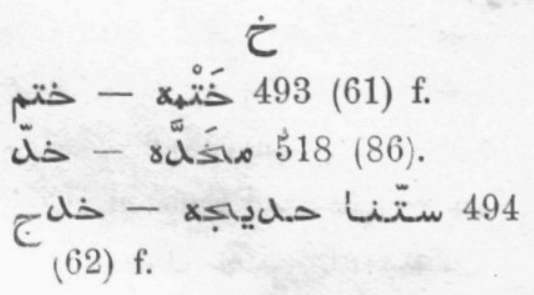

448 خِِلِ (16), 472 (40), 497 (65); خَلَّام 543 (111) ff.

547 (115). (64) u. s.w.

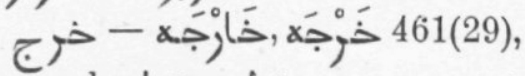

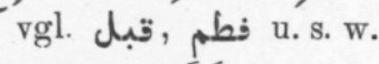

خََّّ - خص - خـر (II) 491 (59); ibid. 509 (77) Anm. 511 (79).

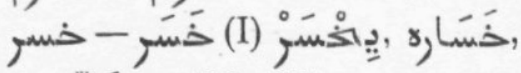
(58).

451 (19).

499 (67), 518

(86) Anm.

خضخ 505 (73).

خ - 454 (22).

484 (52).

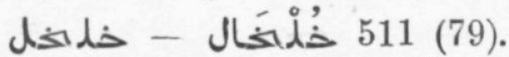

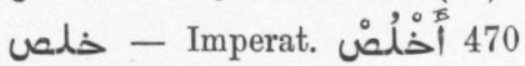

(38); خ خَالص 504 (72)-505

(73), 527 (95).

خلع - (66).

خلّّى - خلى - خلى (II) 459 (27); 478

(46): 503 (71); خَلِّي نَفْسَكْكَ 470 (38).

441 (9).

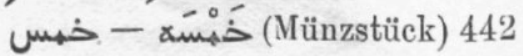
(10), 460 (28) Anm.; 482 (50);

(die Hand) 455 (23). 
DR. C. SNOUCK HURGRONJE, MEKKANISCHE SPRICHWÖRTER. 559

خون - 499 (67).

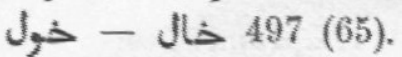

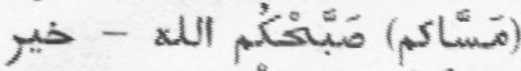

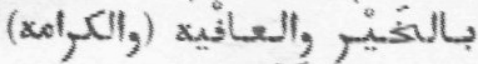

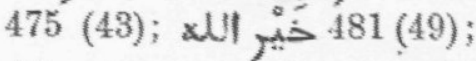

484 (52); اخينار

542 (110).

498 (66).

o

$10-$ s. 13.

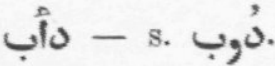

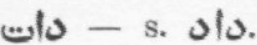

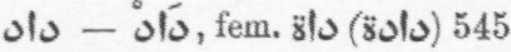

(113) f.

ذاك - s.

468

(36), 486 (54), 505 (73) Anm.;

526 (94).

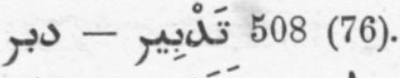

دَبَّش ل ل. . . دَبَش - ندِير (II)

537 (105) ff.

حَ - حَّ 539 (107) ff.

503 (71);

514 (82);

494 نخيل ; (32) 464 ن دخول

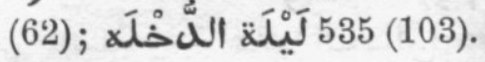

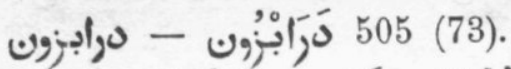

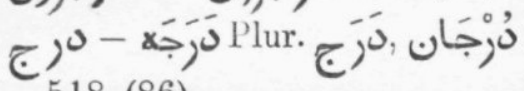
518 (86).

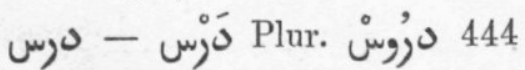
(12).

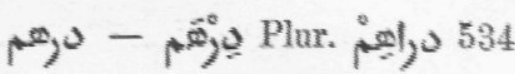
(102).

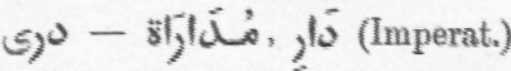
$502(70) \mathrm{ff}$.

نّ - دَّ 540 (108) Anm.

كئز 450 (18).

ئس 549 (117).

.

פ, als Apposition, 461 (29)

Anm.; xتُ 475 (43); 481 (49).

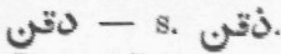

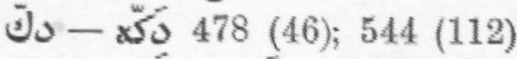

und Anm. $x \stackrel{5}{\leq} 0$ vgl. $x \underbrace{2}_{3}$;

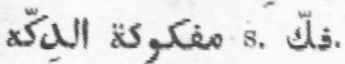

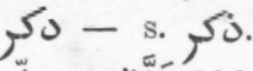

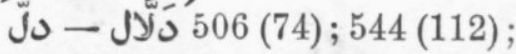

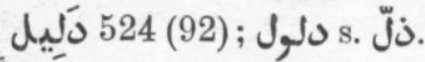

(َلَّلع (II) 544 (112).

503 (71),

544 (112).

479 (47); 517

(85).

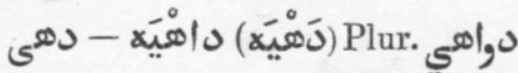
als Apposition, 461 (29) Ânm.;

(58).

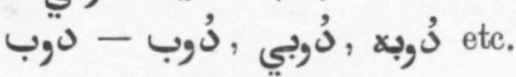

445 (13) ff.

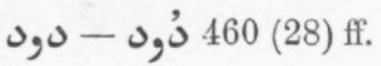

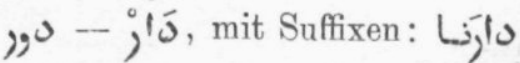

etc., vgl. جـ 463 (31); 
560 DR. C. SNOUCK HURGRONJE, MEKKANISCHE SPRICHWÖRTER.

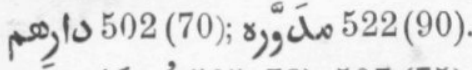

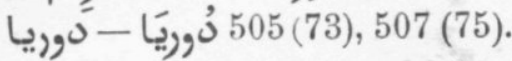

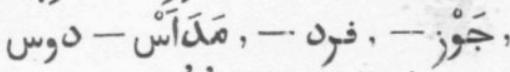

Plur. 468 (36) Anm. (33) Anm. دَولْ : دlur.

Pron. s. 13.

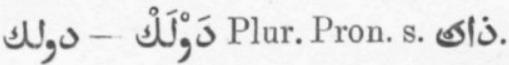

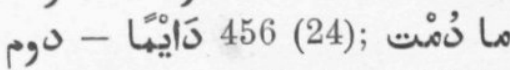

502 (70); ما دامَامت 511 (79);

523 (91).

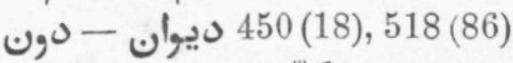

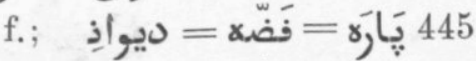

(13); Plur. دَوَاَوِيَ 534 (102) Anm.

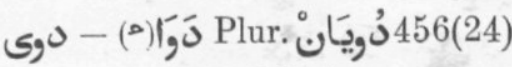

Anm.; 512 (80) Anm.

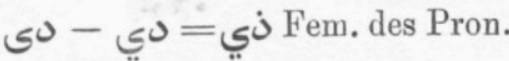

j w.m.n.

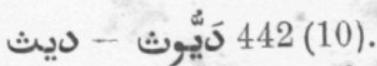

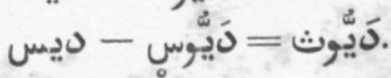

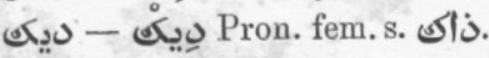

j

13 - 15 demonstr. Pron., fem.

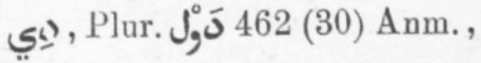
vgl. 444 (12) Anm., 451 (19) Z. 2 ; 456 (24) Z, 1; 503 (71) Z. 28 , u. s.w.

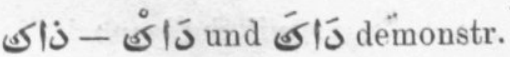

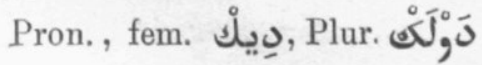

462 (30) Anm.; vgl. 444 (12), Z 3, 4 und Anm.

(107).

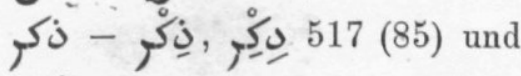
Anm.

(31)

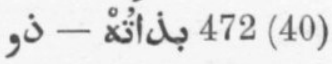

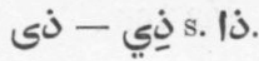

راس ; رُكَّى s. راس سُكَّى - رأس (52).

وأى - vgl.

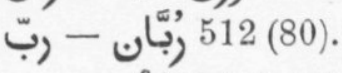

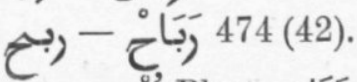

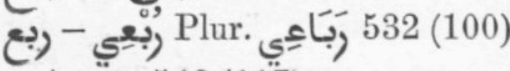
Anm.; 549 (117).

رابغ - 516 (84) ff.

تَرْبِيه (57) 489 (II) 524 (92).

486 (54).

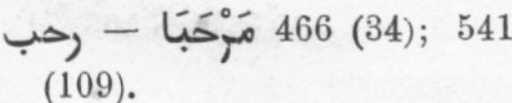

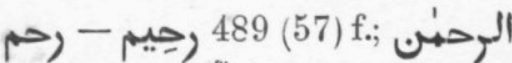

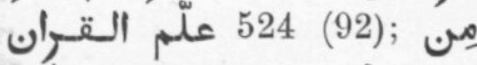
492 (60); السلام عليكم ورحهة ; الله - الترحيم ; (118) (27) 550 وبركاته 474 (قبل , في , بعل 532 (42).

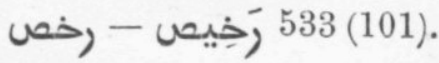


DR. C. SNOUCK HURGRONJE, MEKKANISCHE SPRICHWÖRTER. 561

492 (60).

خر 469 (37) -

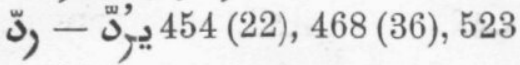
(91).

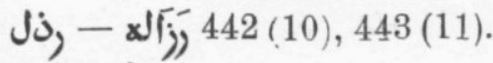

أز

J) - s.

(و) - (I) 479 (47).

صر - مصَّاص 445 (13).

ضمى - 444 (12), Z. 6 :

523(91); اضي (82) Anm.; أ Imperat. IV) 502 (70).

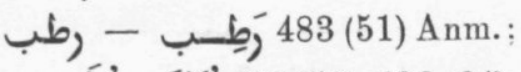

(طَبَ), 482 (50), 496 (64). (ط) - 482 (50) ff., 531 (99).

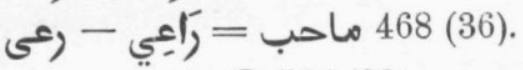
رغبت - رغب رغب (I) 524 (92).

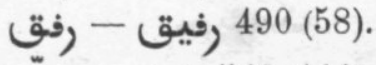

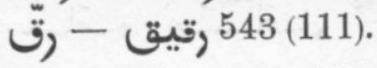

رقّل ; 458 (26) f.: 477 (ت)

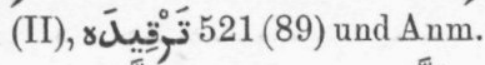

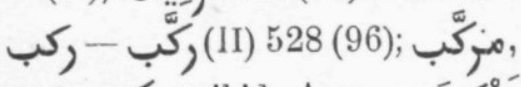

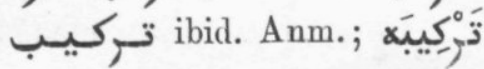
521 (89).

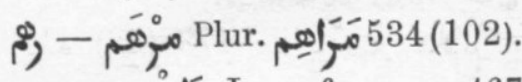
467 (35), 468 (36), 505 (73), 524 (92) u. s. w.; construiert mit der Präp. J 512 (80), 514 (82);

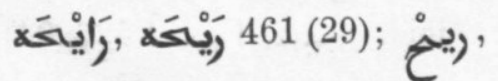

Plur. 495 (63); 508 (76).

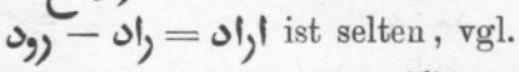

464 إركاد ه 539 (107) ff.

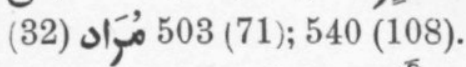

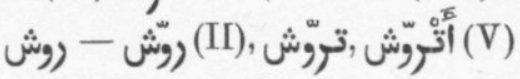

479 (47) - 480 (48).

448 ريش - ريش (16).

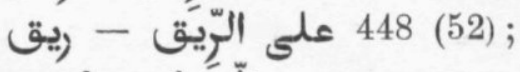

vgl. auch فكلى

;

531 (99).

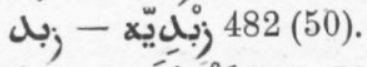

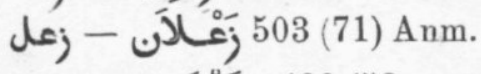

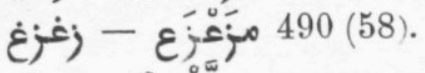

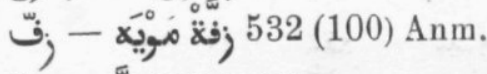

J; - 533 (101).

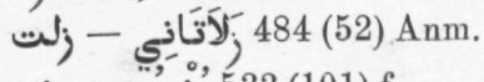

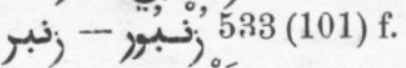

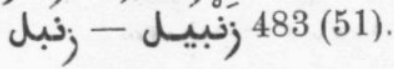

جوز - انبين.

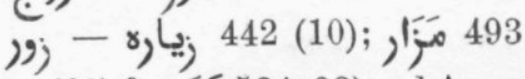

(61) f.; 524 (92) und Anm.

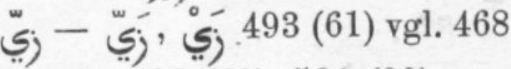
(36), 492 (60), 531 (99) u. s.

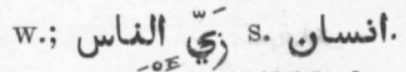

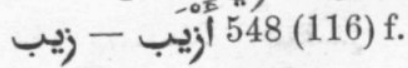

زيل زايل - 503 (71), 515 (83).

زير (47) Anm.; 532 (100) und Anm.

5e Volgr. I. 
562 DR. C. SNOUCK HURGRONJE, MEKKANISCHE SPRICHWÖRTER.

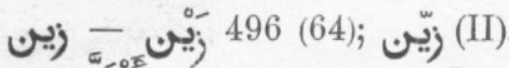

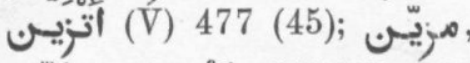

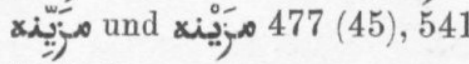
(109) Anm.

\section{w}

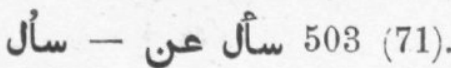

(25).

(Münzstück) 456

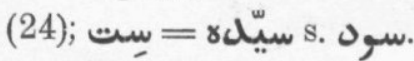

(23),

519 (87).

. اكسال

(37).

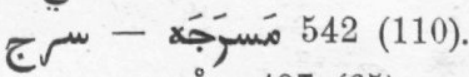

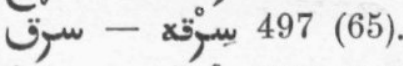

ن 505 (73) f.; 521

(89) und Anm.

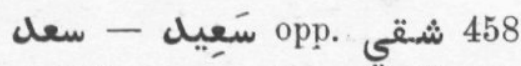

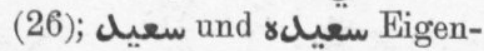
namen von Sklaven 510 (78).

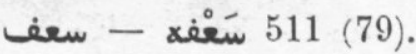

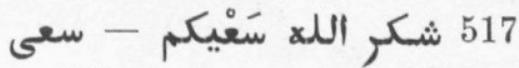

(85).

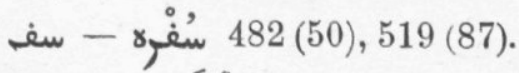

(81) 513 مَسْفَله -

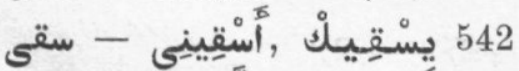

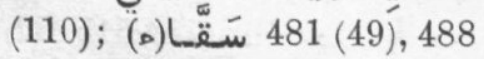

(56), 532 (100).

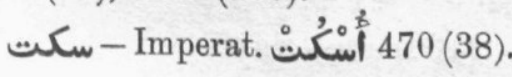

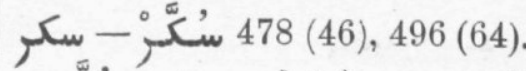

سُ هنلاي , سُ مَصْري ,راس سُكَّر

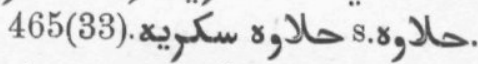
إسنكافي - 498 (66). سلاتاني ; 484 سَآّات - سلت 484 (52) Anm.

سلاطيب .Plur سلطانيّه - سلط 534 (102) Anm.

سلَّْ - (I) 542 (110); (II)

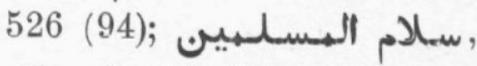
(22), 475 (43); السلام عليكمب ورحمة الـله 524 , 524 (السلام 550 (118) وبركاته (92); سِلَّبَّي , 496 (64); أ. 506 (74).

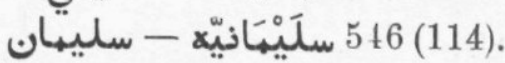

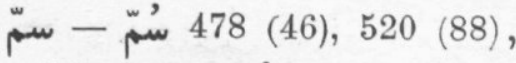
547 (115); سَّوبر 548 (116)f. 485 (5ْْْبوسَكَ - (53).

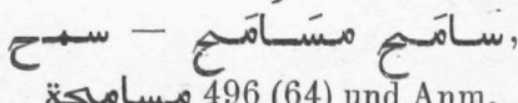

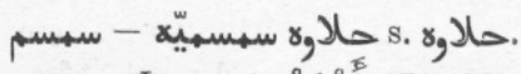
سنع (38); Imperat.

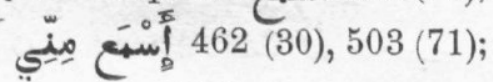
الرلة 453 (21) Anm.

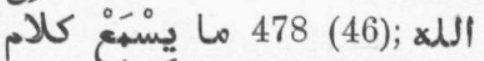
533 (101).

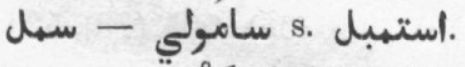

سهن - سَنْنْنِ - 481 (49) ff.; 531

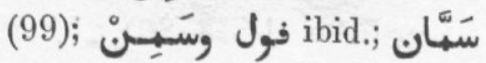

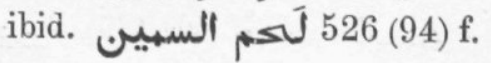


DR. C. SNOUCK HURGRONJE, MEKKANISCHE. SPRICHWÖRTER. 563

سمَاَرْْ - سهور (samovar) 465(33). 444

(12), Z. 4 und Anm.; 528 (96).

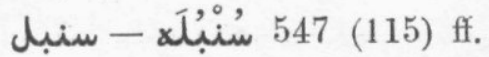

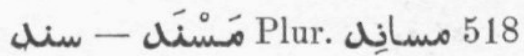
(86).

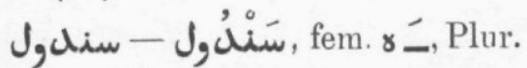

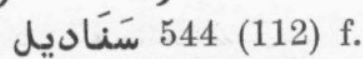

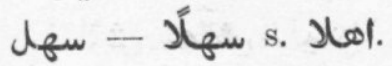

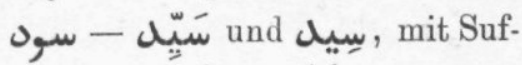

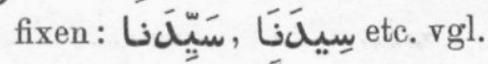
463 (31); جرور 494 (62) f.:

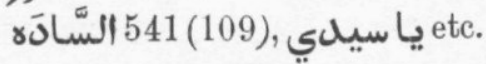
513 (81) Anm. ff.

(79).

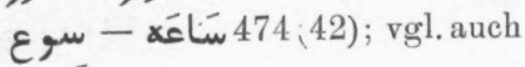
لمَسَّا.

539 (107):

أسمل 500 (68); 505 (73); 535

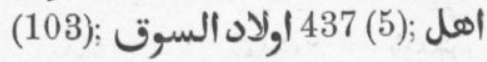
(10), 443 (11); .

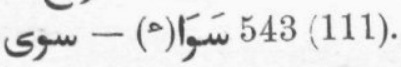
سوّى (II), 1ste Pers. des Imperf. أَسَوَي (27); 4769 (44); 479 (47) Anm.; 512 (80), 531 (99) Anm.

سَيَّب - سيب (II) 470 (38), 478 (46).

509 سِيُول.Plur); سَيْل - سيل
السَّـنْـل

$$
\text { ش }
$$

473 (َاشْ - شاشن ش

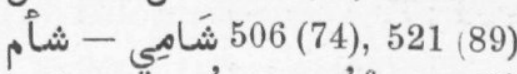

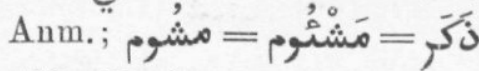
458 (26) f.

465 (33) ff;

512 (80); ماكي 503 (71)

Anm.; عَتْتَري = 503 (73) ff.

505 شُبَّان Plur شَبَاب - شب

(73) und Anm.

454 (22)

486 (54) u. Anm.

شَبِيه - 497 (65)

(115).

. 460 (28) ff.

. 497 مشاحِّه - شحَّ

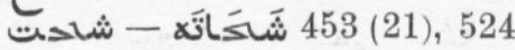

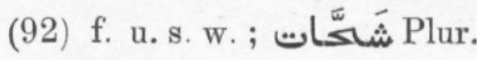

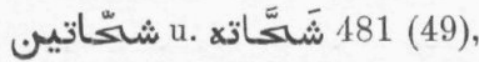
524 (92) f., 538 (106) Anm.

شكا. As. شكت

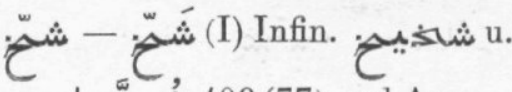
شُشَكَّان 409 (77) und Anm. 495 شِلَّة ; 447 (15) يشَّروا - شَّل

(63); إَْْتَلَّا (VIII) 548 (116). شَرْبَ ; شِرب - شرب (I) 524 (92) 532 (100) Anm. ; 549 (117). 
564 DR. C. SNOUCK HURGRONJE, MEKKANISCHE SPRICHWÖRTER.

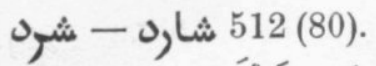

.

513 (81).

(29) 461 الاشراف , الشّيفِ - شرفي

f. ; Titel des Scherifs 463 (31),

472 (40); شرف (II) 459 (27),

466 (34), vgl. وحش , أنس شرف :

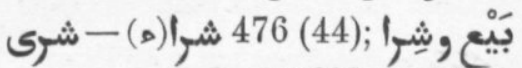

s. اشترى ; بيع (VIII) 490 (58), 510 (78).

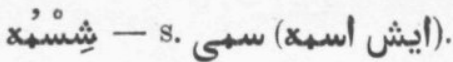

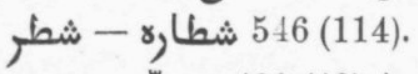

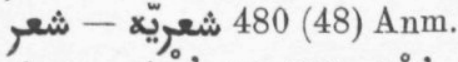

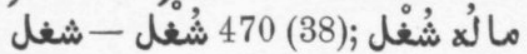

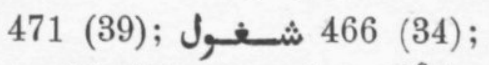

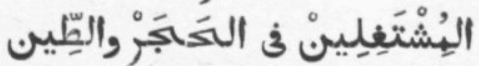
481 (49).

شَقَاِِفْ مُ شُقْفُف - Alur. شقلف 469 (37) f. ; 489 (57) f.

484 مشَقْلَبَاني - (52).

(25) 457 سعبِيلى - opp.

- 458 (26).

517 (85) شكر الله سَعيكم - شكر

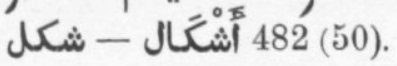

الشتكى - شكى (VIII) 457 (25).

(64), vgl.

هلبمي

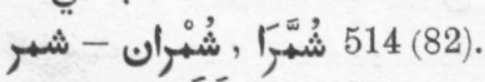

539 (107).

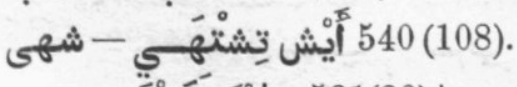

521(89)Anm.

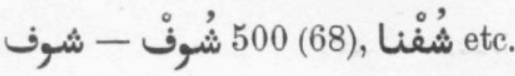

503 (71) und Anm. ; 526 (94).

455 شَوْكَ مَوْكَ , شَوْكَ - شوك

(23).

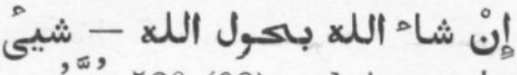
ما مان ماء الله (68), 507 (75);

471 (39) - 472 (40), 491

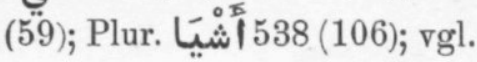
إن ; لاش , ماش ,ليش , إيش

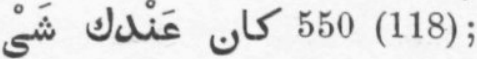
شوَيَّي 524 (92), 540 (108) Anm.

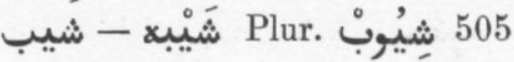

(73) und Anm.

. 505 (73).

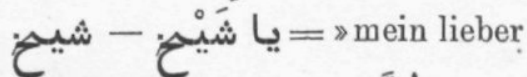

Freund إكتَّاله

538 (106); 541 (109).

483 (51). شَيَكَه - شيره

459 شَيَش . Plur شِيشَ - شيش

(27), 465 (33), 517 (85).

530 مي الشيطان - شيطن

503 (71), 544 شياطير النّنِيا

(112).

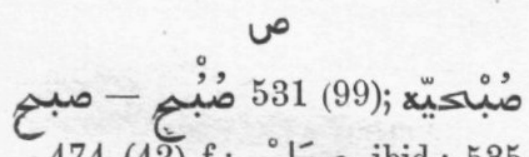

474 (42) f.; صبَّاح ibid.; 535

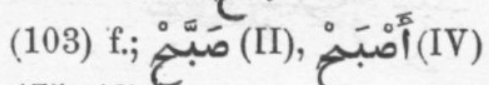

475 (43). 
DR. C. SNOUCK HURGRONJE, MEKKANISCHE SPRIOHWÖRTER, 565

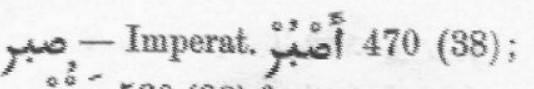
صبع 530 (98) f.

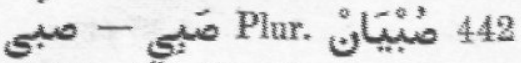
(10), 481 (49), $543(111)$.

ماصب - ماكب 467 (35) ff.;

490 (58); 533 (101).

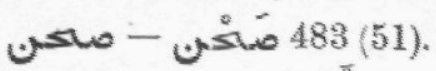

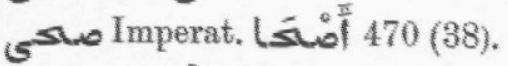

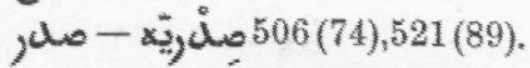
صلم - صلت (II) 503 (71);

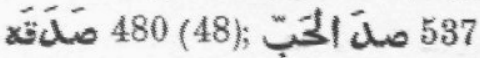
(105); صَّأَات 537 (105).

صعايْلَه Plur. صعيلي - صعل 515 (83).

صفُرًا - 523 (91).

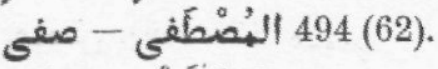

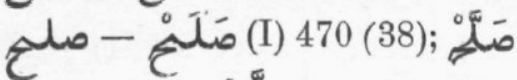

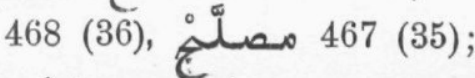
539 (107), 540 (108) Anm.

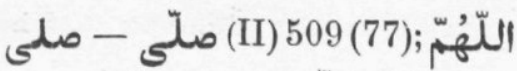
444 (12);

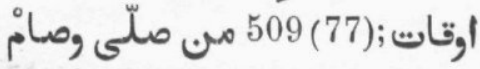
(42), 519 (87).

(41).

صنع - صَنْعَ - 467 (35).

صهاريجر.Plur صُْرِيج - صهرج 532 (100) Anm.

صَاٌْ ;(38) 470 يصيٌْ ,صَاْْ - صور

adverbial gebraucht 514 (82)

Anm.

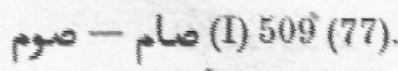

كئف 547 (15).

\section{p}

فأ. 485 (53) Anm.

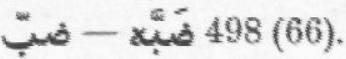

481 (49).

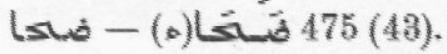

- 457 (25); 531 (99); Im-

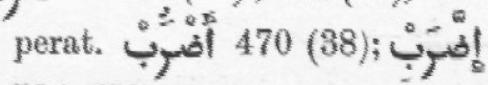
524 (92).

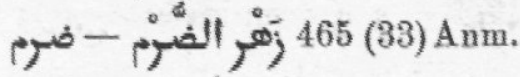
bo - s.

ضَيَّع - ضيع (II) 453 (21); 489

(57) f.; 524 (92).

518 (86). ضيف الحبهيع - ضيف ;

b

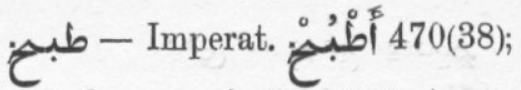

Infin. Aبيم (96) Anm.;

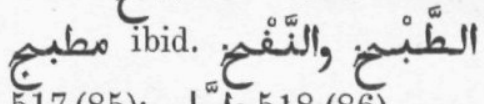

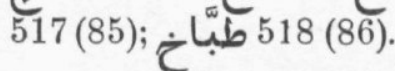

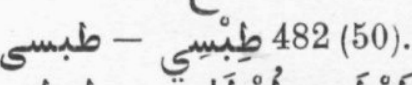

518 مطَبْطَب ,طُبْطَابِ - طبطب

(86) und Ann.

484 (52);

(52).

حلاور.s. حلاور طكينيه, - طنَّ. (110).

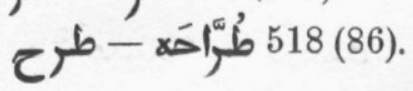


566 DR. C. SNOUCK HURGRONJE, MEKKANISCHE SPRICHWÖRTER.

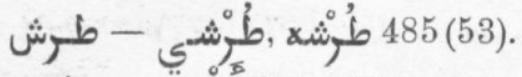

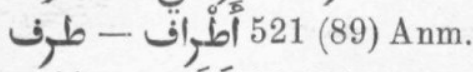

طَلَب - طلب (I) 481 (49).

طلع (I) 524 (92), 525 (93) $\mathrm{f}$.

485

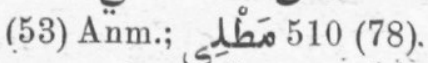

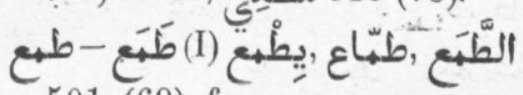
501 (69) f.

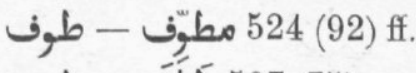

(75).

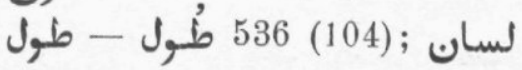

إيـله طويله طويـل 447 (15);

Plur. طُوَّال 476 (44).

528 (96) Anm.;

541 (109) Anm.

طَيَّح , يطِيح , (I) طلح - طيح

(II) يَّيَّيَّيَّ (108) und Anm.

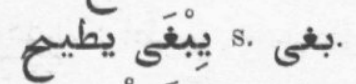

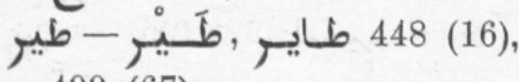

499 (67).

481(49). الحكبر والطيب -طيب.

b

(38) f.;

485 (53); - قبل , فى , بعل

474 (42) ; طُ 531 (99);

(42).

\section{$\varepsilon$}

Plur. عبل - عبل عبل und
543 (111) und Anm. مبر مُعتبَبَ - (21) Anm.; 456 (24), Z 12; 538 (106); 540 (108) Anm.

543 (111).

524 (92);

(81). 513 عبsايب عايب

ل 530 (98).

ع عَاسلَ 486 (54).

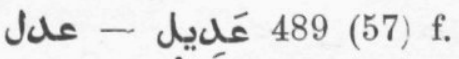

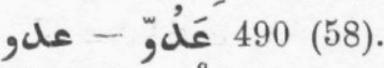

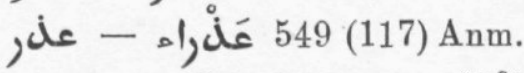

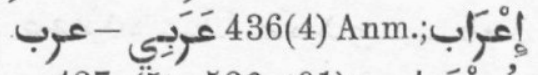

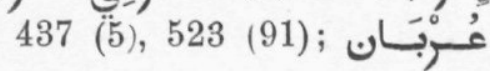

448 (16).

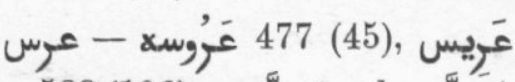

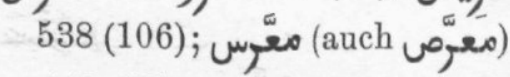
442 (10).

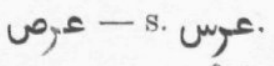

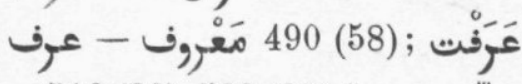

512 (80), 528 (96) Anm.; عرّف

(II) 472 (40).

(109).

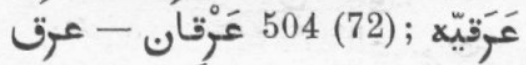

505 (73) Anm.

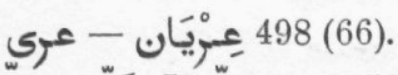

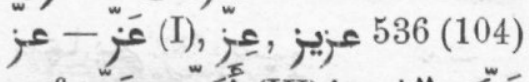
f.; عَبَّكَ الله etc. 533 (101).

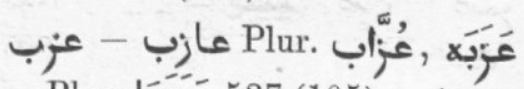
Pl. 537 (105) u. Anm. 
DR. O, SNOUOK HURGRONJE, MEKKANISOHE SPRIOHWÖRTER. 567

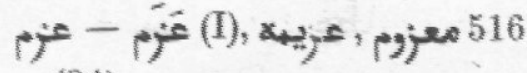

(84).

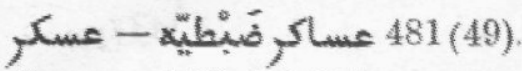

(6) 496 (64).

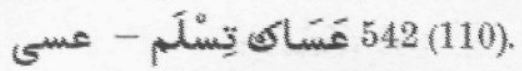

عاشر - III, Imperf. u. Im-

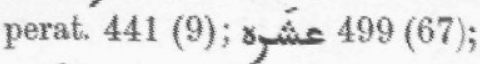

عَشَ Geldstück $482(50)$.

عأش 474 (42), 508

(76).

- die Hauptmahl-

zeit 485 (53) ff.; أتعََّّى 456

(24).

مصَّن 485 (53), 531 (99).

عض - 511 (79) u. Anm. صطى - Imperf. 460 (28) Anm.

صَبْكْكُم الله بالخَيْتر - عفى 475 (العافْيه

514 ما يلهخل في العقل - عقل

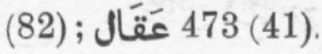

عَلْفَّ - 489 (57); 540 (108)

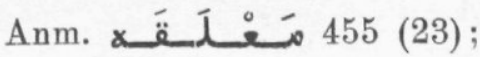

(27).

= مَعْلوم

»natürlich" 470 (38), 473 (41)

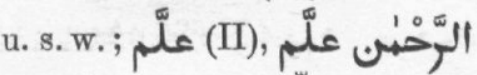

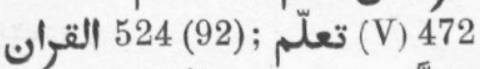

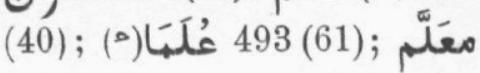
544 (112).

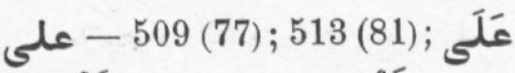
(ما) علَيْهُ ; 501 فَيْيَ ;
$491(59) ; 503(71)$; كleo 494 $(62), 513(81)$.

(47) Anm.; 544 (112); $545(113) ;$; 488 (56) ff.; 545 (113); 449 (17);

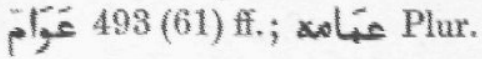
ع 473 (41), 505 (73) ff.; xide 507 (75) Anm.

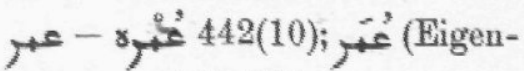
name) 443 (11).

عَّل (I) 472 (40); 513 (81);

512 (80).

عَّ 435 (3) Anm; 436 (4)

Anm.

عُنبه

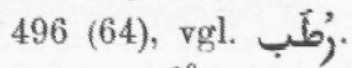

عنتى 505 (73) ff.

عن - 515 (83), 517 (85);

إن 535 (103); عَنْن

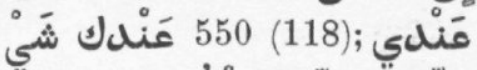

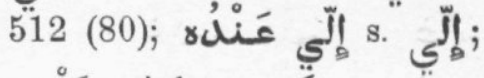
كَون كان عَنْله

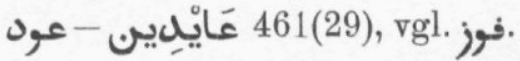
. L . . . . . 513 (81) und Anm. 514 عوايل Plur عاده ,عايله (82) $\mathrm{f}$.

أعوذ بالله - عون (56), 4802 (70), 503 (71).

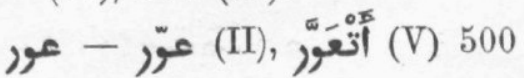

(68) und Anm.

عَاوز - (ägypt.) 540 (108). 
568 DR. C. SNOUCK HURGRONJE, MEKKANISCHE SPRICHWÖRTER.

529 (97) f.

453 (21) und Anm.;

524 (92).

481 (49) u. s. w. ; عَسامولي;

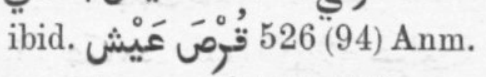

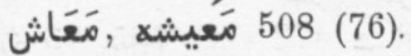

(67) f, vgl.

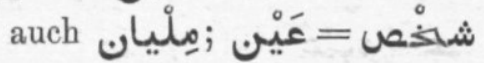

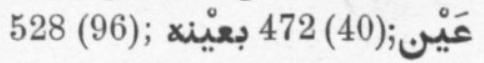

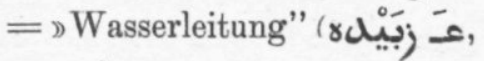

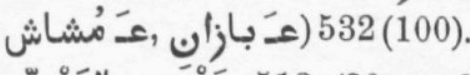

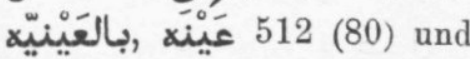
Anm.

$\dot{\varepsilon}$

488 الغَبْره = الـــــابْرَهَ - غبر

(56) ff.

505 غَبَاني Plur. غَبَانَه - غببر

(73) Anm.

484 (52)f.

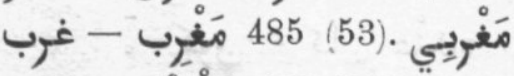

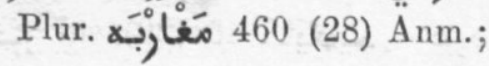
546 (114).

(103).

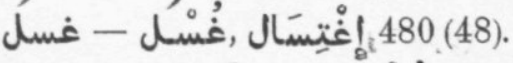

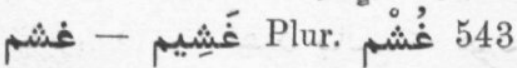

(111) ff.

. 448 عَصْبَ عنّي - (16) - غصبب

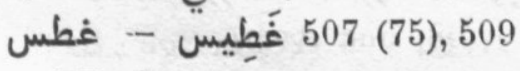

(77) Anm.
512 غُطْيَاِ Plur. غَطَا - غُطَى (80) Anm.

فَلَبَّه (47) 479 مغلوب - غلب

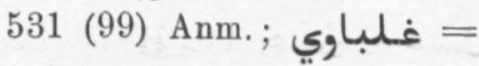

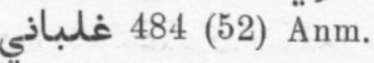

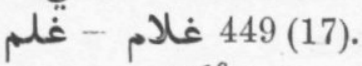

484 (52) Anm.

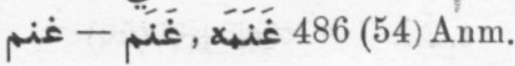

(71).

459 (27).

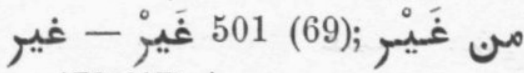

479 (47) Anm.

\section{ف}

486 (5َ), 496 (64).

375 (43);

f 508 الفاتحكي (76) f.

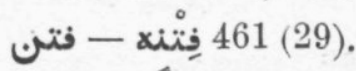

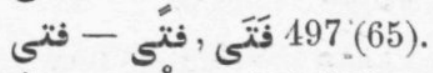

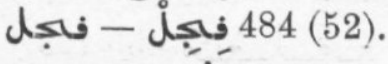

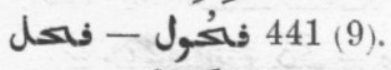

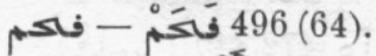

(82).

468 (36).Anm.; 469

(37).

518 مفارش Plur. مَفْرَشَ - فِشش

(86) Anm.

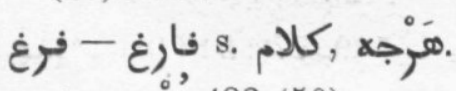

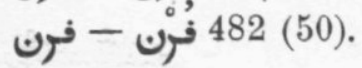


DR. C. SNOUCK HURGRONJE, MEKKANISCHE SPRICHWÖRTER. 569

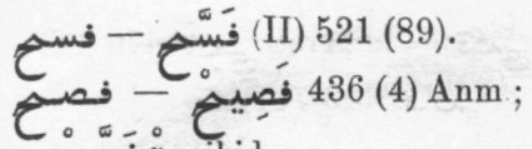

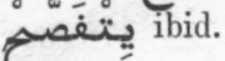

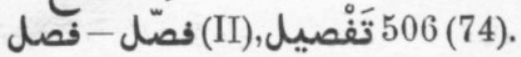

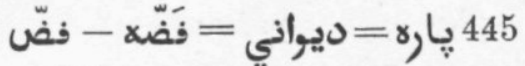

(13).

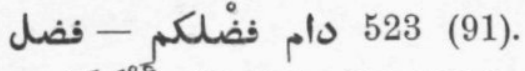

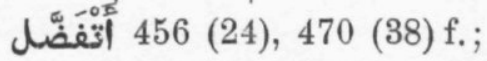
517 (85).

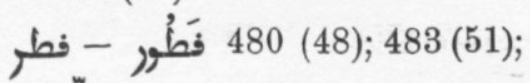
فطّ (II) 484 (52).

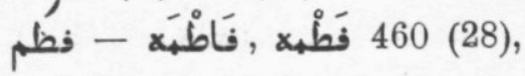

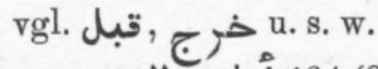

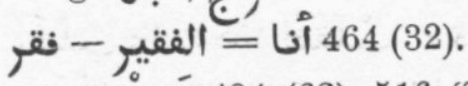

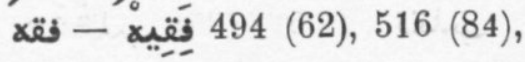

524 (92) und Anm.

حَّنس

(21) Anm.; فكوك ,فكّ الريق (51); 484 (52);

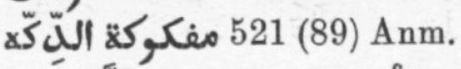
- فَكَّ (II) 463 (31); als Apposition 461 (29) Anm. (20) (13), 452 (20) f., 454 (22), $493(61), 503(71)$, $522(90), 534$ (102), 546 (114); فِ, als Apposition 478 (46), 531 (99).

فرّ 506 (74).

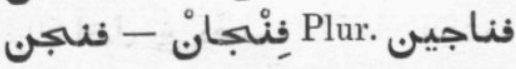
und فناجيـل 465 (33), 471 (39), 483 (51).
468 (36), 540

(108) Anm., 542 (110).

فهم 444 (12).

527 (95).

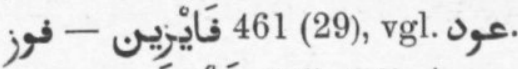
505 (73) Anm.;

541 (109).

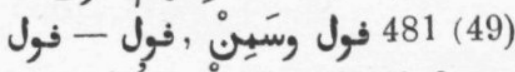

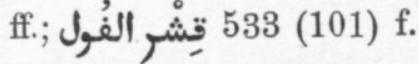

ف - Präp. 440 (8) Anm.; 500 فين ; 491 (ما) فيش في (8) (68) $\mathrm{f}$.

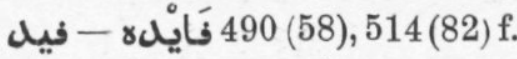

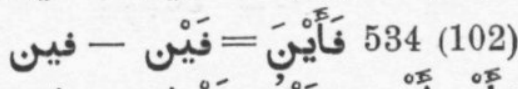

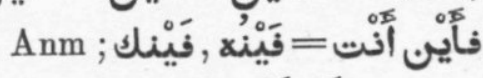

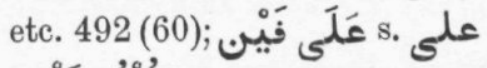
503 كُنْتو فَيْرِ

\section{ษ}

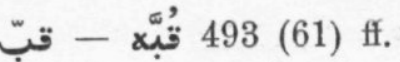

Plur. (76) Anm.; 526 (94).

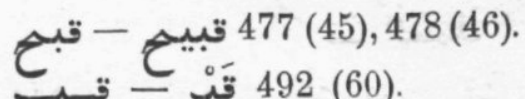
حَبْف

(24) Anm. 507 (75) u. s. w.

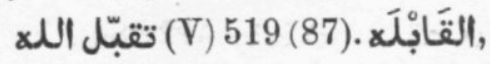
فطم . 460 (28) f., vgl القَبْلَه u. s. w. 
570 DR. C. SNOUCK HURGRONJE, MEKKANISCHE SPRICHWÖRTER.

تــ Imperf. und Imperat. 478 (46).

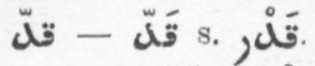
(I) 513 (81),

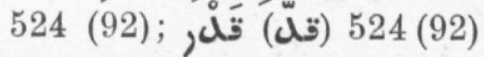

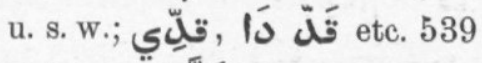
(107); تَلََِّيْيَي (103), 539

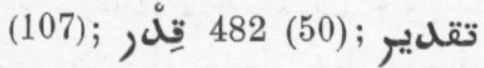
444 (12).

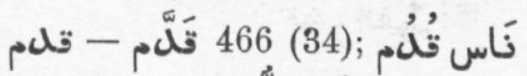
506 (74); قَلَم 527 (95). ك 484 تُلَّاماني " 524 (92); Imperf. pass.

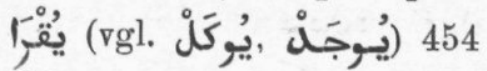
(22).

قِتربْ - 488 (56); 532 (100) und Anm.

535 (103) f.

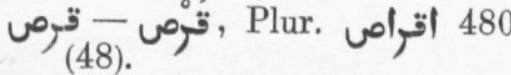
(104). (74). (53) Anm. (80).

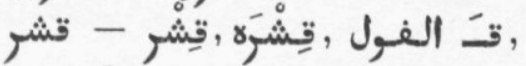

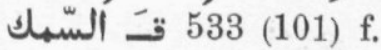
مقَصّ ; 456 مَقْصوص - قصَّ (24) 507 (75).

521 (89) Anm. 512 (80). (15); 536 (104). Plur. قُصَار 476 (44).
أقضْضي - Imperat. 470 (38); 443 (11) f. - تُطّ - Imperat. 470 (38).

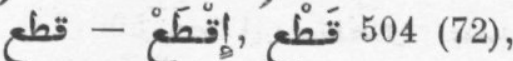
507 (75), 527 (95).

تعل - Imperf. 458 (26) f.; 501

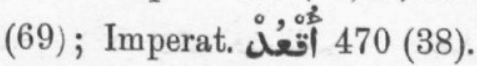
(73). 461 (29), 507 (75).

قليل قليل ; (24) 456 تليل - تلّ 528 (96) Anm. ; قلَّلَ 532 (100) Anm.; 549 (117).

قَلْبَ 458 (26)

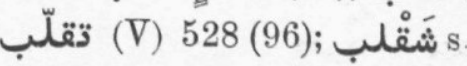
مقبنب

444 يـقلع (إقْلَعْ) عَيْنه - تِلع (12) Anm.

487 (55). (25).

485 (53).

482 (50), 496 (64). 465 (33) ff.

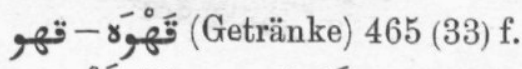
تَهْوره Plur. 442 (10), 443 (11).

4.تَوَّاد - تون (10), 443 (11). تال - تول - (I) 490 (58); 517 (85);

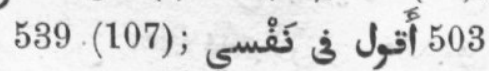

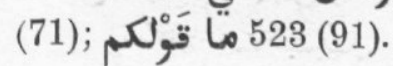
458 (26) f., 
DR. C. SNOUCK HURGRONJE, MEKKANISCHE SPRICHWÖRTER. 571

477 (45), 509 (77); ..... قام معام 450 (18); 462 (30); (8) 519 (8) 519 إقامة

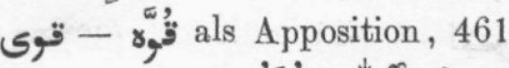

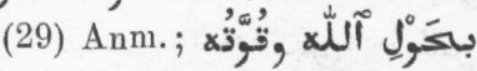
530 (98) Anm.

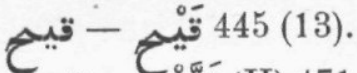

قَيَّنَ - قيسيس (II) 471 (39), 493

(61), 504 (72), 507 (75) f., 548

(116); مياس 507 (75).

قَيْله

ibid.

477 (45), مقَيْنَهَ, مقَيَّنَه - تين 478 (46).

\section{6}

كُبَارِّيّ ; 541 مِتْكَبِّ - كبر

437 (5).

كتب 457 (25).

كثر. - s. - كتر

ما هو كتير ; (9) 441 كُتْره - كثر - كثر

(49). 481 عليكه كترك

كنب .s - كلب كلبك.

كَ 500 (68), 507 (75)

u. s. w.

كـن - Imperat. 470 (38); كابك 467 (35).

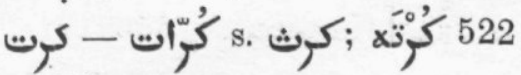
(90).

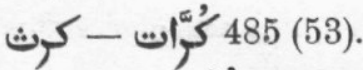

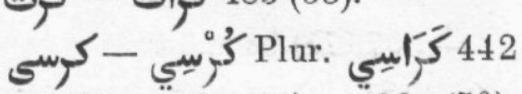
(10), 443 (11), 482 (50).
(92) Anm.

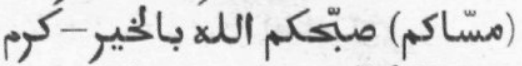

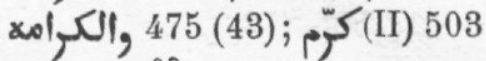

(71); أكْ (IV) 528 (96) f.;

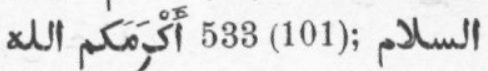
.

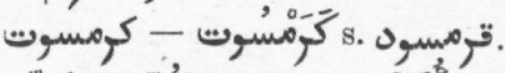

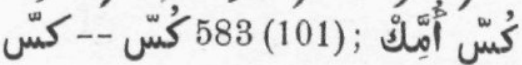
443 (11).

كَسيبر ; كَسَّر - كسر (II) 453 (21) 534 (102).

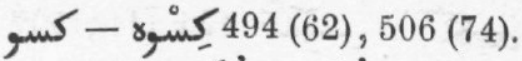

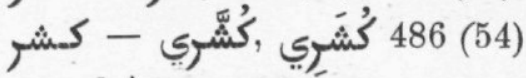

und Anm.

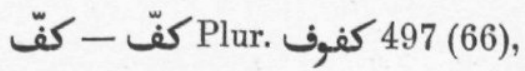

489 (57) ; كوف . كونيّيّة

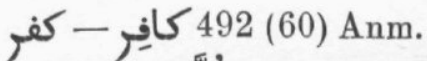

524 (92), vgl. 477

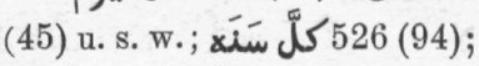

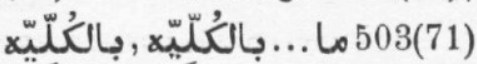

Anm. ; 505 (73).

453 كلامه مسبوع - كام كلم : (21),

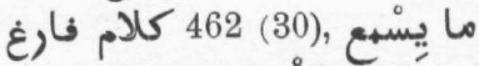

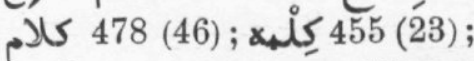
540 (108) f.

كنف كُنَافَه - كنَ - 480 (48) ff.

كنى كنْيْهِ - 513 (81) Anm.

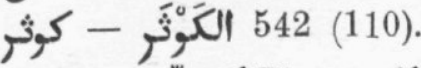

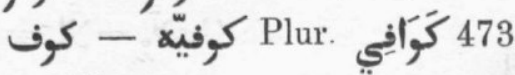

(41). 
572 DR. C. SNOUCK HURGRONJE, MEKKANISCHE SPRICHWÖRTER.

كَانْ 470 (38); 470 كَانْ (38), vgl. 440 (8), 456 (24) Z. 12; 505 (73) Anm.

إذإنا

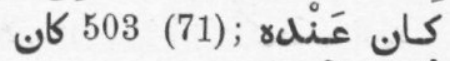

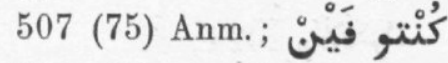
503 (71); احسن ما يكون 470 (38); 524 أُوّل ما يكون ما يكون (92), 526 (94); بكون ماكون 444 (12), Z. 6 , vgl. 440 (8) Anm.

476 (44), 507 (75) Anm.

(79).

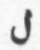

J- لي statt des Objectsuffixes 510 (78), vgl.dagegen 491(59). ע- wird verkürzt und mit der folgenden Silbe zusammengezogen, wenn ihm ein Imperf. 1sten Stammes eines concaven Verbums oder ein Imperf. IIten oder IIIten Stammes folgt 460 (28) f. Anm.

ע, mit Acc. auf der ersten Silbe 460 (28); 514 (82), 524 (92); y, -y, ibid.; 510 (78)u. s. w.; 514 (82);

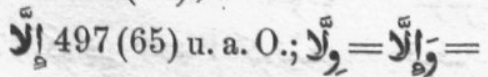
, 470 (38), 503 (71) u.s. w.
بَلاَث ; 547 (115) Anm 54 لآشْ -لاش 497 (65), 543 (111), 547 (115).

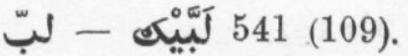
501 (69), 521 (89).

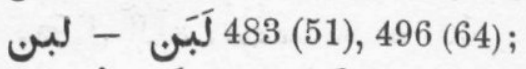

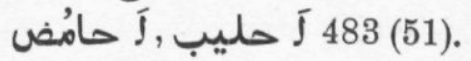
454 (22), Anm., 490 (58); 485 (53) f. لكمب مقلْقَل 487 (55);

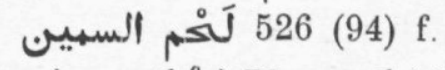
539 (107).

لّ - 485 (53) Anm. 471 (39).

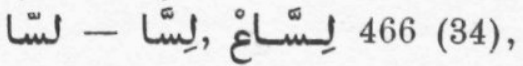
468 (36).

(57).

524 (92).

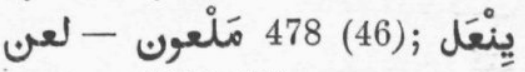

…. 524 (92).

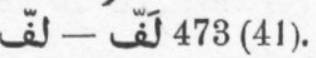

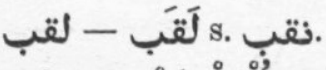

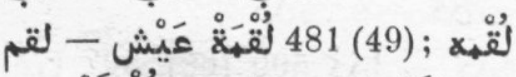

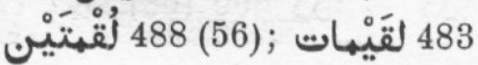
(51).

(73), 514 (82); 505 لاقي - لأقَى (I8).

أتْْلَقَّ (Imperat. V) 550 (18).

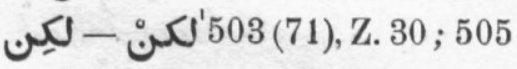

(73), Z. 8 u. s. w.; nachgesetztes

-507 (75) Anm.

لهَ له لهis" 470 (38); die 
DR. C. SNOUCK HURGRONJE, MEKKANISCHE SPRICHWÖRTER. 573

letzte Silbe wird verkürzt u.s w. vgl. لا لََّّان: 525 (93) Anm. 525 (93) ff.

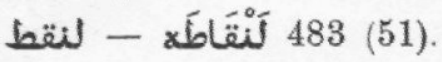

- s. لنقط - لنطط ل

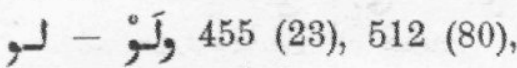

533 (101). צَّ 444 (12), 477

(45).

ومَنْ يـلـوز (يلون) بُسـه - لـون

529 (97).

(33) Anm. ;

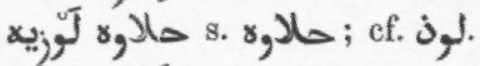

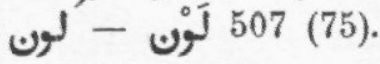

441 (9).

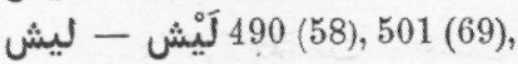

503 (71), 512 (80) u. s. w.

474 (42);

(103).

Lo - Die Conjunct. Lo wird verkürzt u. s. w. vgl. ע.

しَ, seine Verbindung mit den persönl. Pronomina; مَوْْ =

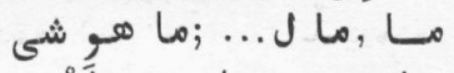

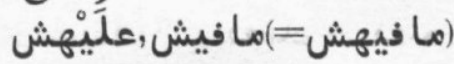
491 (59); 514 (82) Anm.

ماش - مَاشْ - 547 (115) Anm. ماما ماثل

بتع مامع - s.

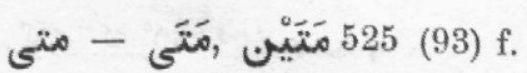
(9).

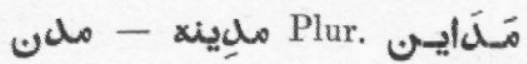
528 (96); ماله 507 (75).

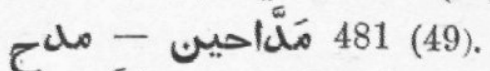

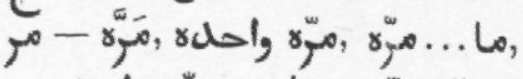

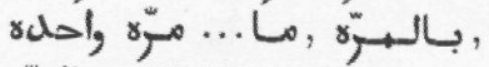
(63) Anm.;503(71) Anm.; 504 (72) - 505 (73);

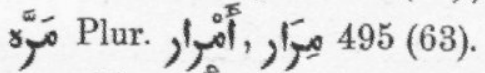
مرؤ 451 (19), Z. 8

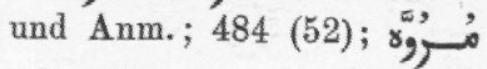
442 (10).

مَرَضَ - 523 (91).

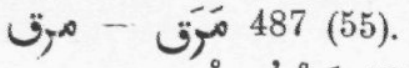

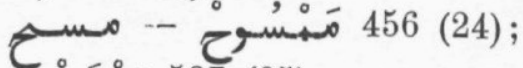

527 (95).

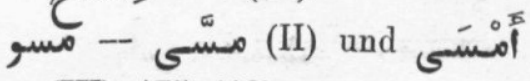
(IV) 475 (43).

مشَّى - مشىى (I und II) Bedeutungen 455 (23)-456 (24),

vgl. بـطـ , بــال; Imperat. (38).

(47).

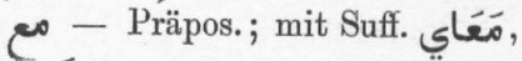

مَ 456 (24) und Anm.

502 (70), 503

(71), 524 (92), 546 (114).

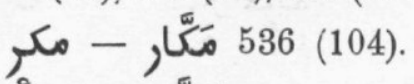

مَلَّْى - مَكلى (II) 499 (67) ff.; (61); 500 (68); 
574 DR. C. SNOUCK HURGRONJE, MEKKANISCHE SPRICHWÖRTER.

مآَيَx f. 501 (69) عينه مِلْيان 520 (88) ff.

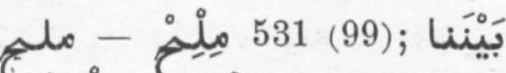
481 (49) und

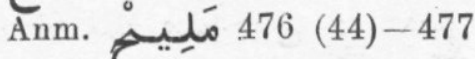
(45). Plur. $ح$ إن ibid.; vgl. 507 (75) Anm.

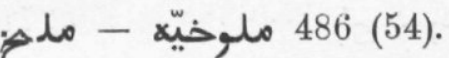

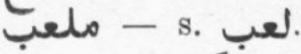

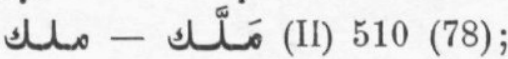

(111) ff.

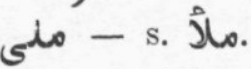

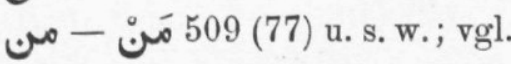

Präpos., vor Suffixen

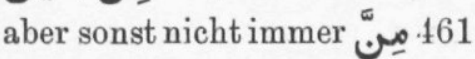

(29) Anm., vgl. 449 (17) u. s. w.

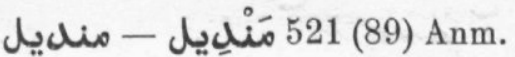

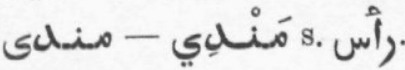
مهري 537 (105).

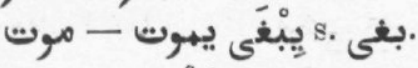

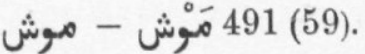

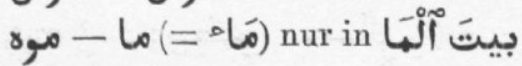

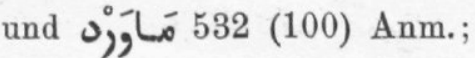
vgl. 479 (47) Anm. ; 518 (86) Anm.; ; 456 (24) — 457 (25); 479 (47); 495 (63) Anm.; 537 (105); 542 (110);

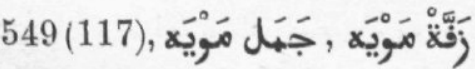
532 (100) Anm.

501 (6َن = مِيننْ - ميبن (109), u. s. w.
ن

نَبَّوت ; f. 475 نَبَاتْ - نبت 482 (50).

485 بَاكْتني على النبى - نبى Anm.

(66).

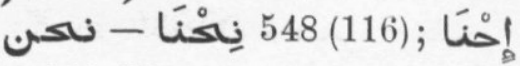
491 (59).

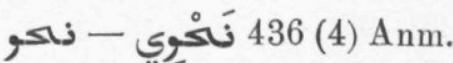

نَلََّر ; يِنْلْرْ Imperf (II) 445 (13).

- نَزَّل - نَل 544 (112).

(82). 514 مناسِب - نسب

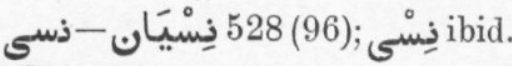
نصف - s. نصّا.

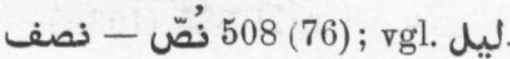

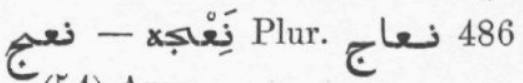
(54) Anm.

468 جَوْز - , فرن - - نَعَالْ - نعل

(36) Anm., vgl. ملاس فعاس ; - vgl. لeع.

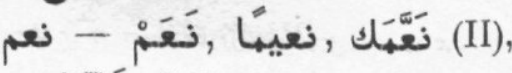
541 (109) und Anm.; تَنِْْعِيمِ (Eigenname) 442 (10).

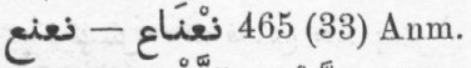

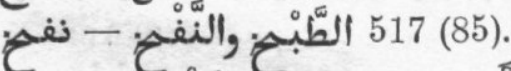

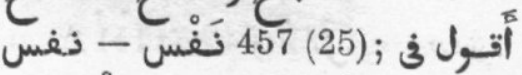

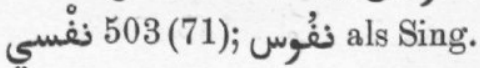
450 (18), 452 (20) ff.; 493 (61); 
DR. C. SNOUCK HURGRONJE, MEKKANISCHE SPRICHẄÖRTER. 575

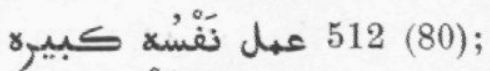

(105).

ن 507 (75).

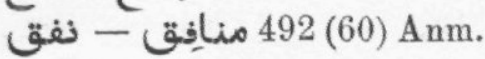

(51).

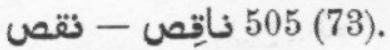

520 (88).

"ناموس - نهس نافع (20) ff.; 524 نامع

(92).

etc. 474 (42) f.

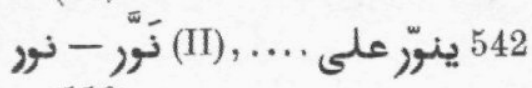

(110).

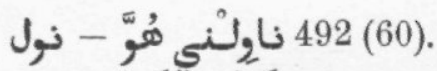

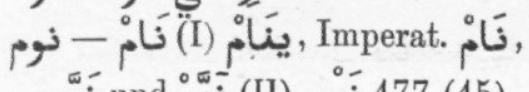

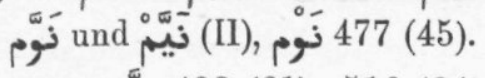

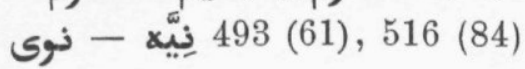

Anm.

442 نايك أَبُوك , أُهَّْْ - نيك

8

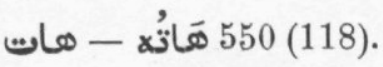

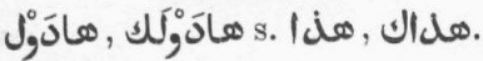

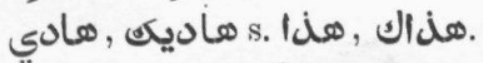

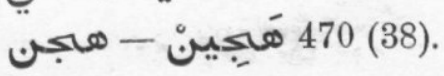

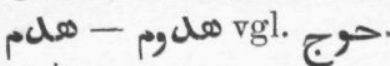

ه demonstr. Pron.,

fem. كـادئ 462 (30) Anm.; vgl. 443 (11) - 444 (12), 451

(19) Annı. u. s. w. Plur. هادَ 451 (19), Z. 15. هoادَاكَ هذاكاك demonstr. Pron.,

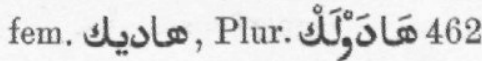
(30) Anm ; vgl, 455 (23) u. s.w.

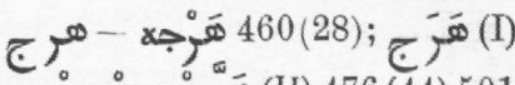

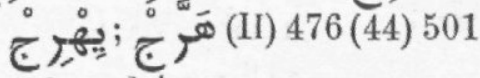
(69) und Anm.

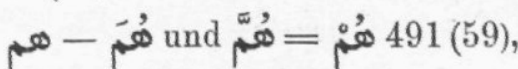
503 (71), 517 (85) u. a. 0. . 448 (هنيَّك) هنيئك - هناً (16)

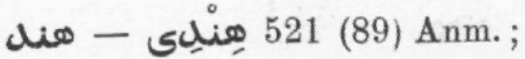
تركيب الهنلي , طبيح الهنود 528 (96) Anm.

471 (مَنْحَسْ - منله 4 (39).

451

(19) Anm.; 456 (24), 462 (30), 490 (58), 491 (59), 493 (61); 530 (98) u. s. w.; gebraucht anstatt der Suffixe 492 (60).

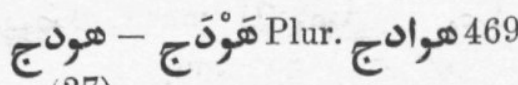
(37).

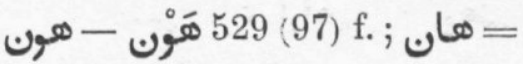
الهان (IV), Imperf. يهئ Imperat. 452 (20), 542 (110).

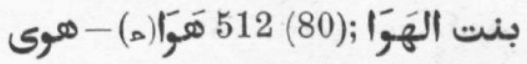

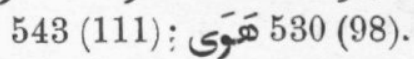

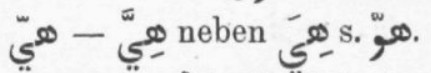
453 مَيْبَ - هيب هيب

بابور. - - وابور.

. 
576 DR. C. SNOUCK HURGRONJE, MEKKANISCHE SPRICHWÖRTER.

وتوتْ - 465 (33).

(vgl 454 (22).

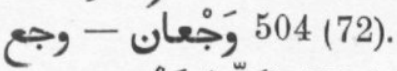

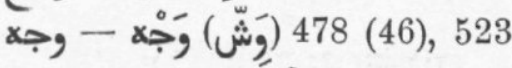

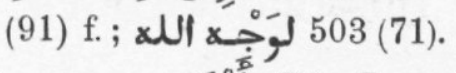

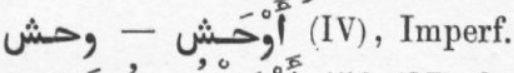
(27) f.,

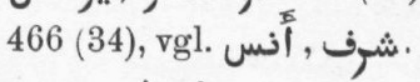

اخل - s. اخل

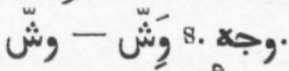

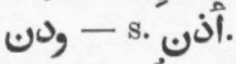

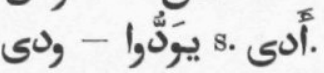

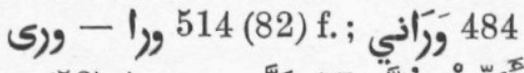

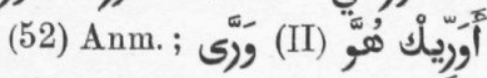
492 (60).

وسط - وسُطناذي (52) Anm. 484 (52)

(63).

يُوصَل - وصَل - Imperf. (I) Im 507 (75), 525 (93).

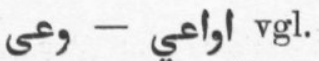
474 (42).

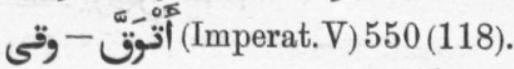

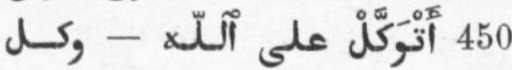

(18) und Anm.

y, - s. s. y.

وله البَكَّ, ; 478 (4َ)
543(111);543(111). أَّْلاد العلاب ; 543 يا ورََل 503 (71); - أولاد السّّــوق 437 (5); مُ 524 (92) ;

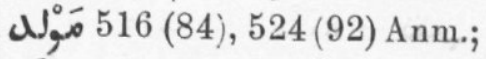
(112).

493 (61) ff. ; 509 (77) f., 5337 (105) ff.; مَّلاَنَ 503 (71); مَكْلِيَّ 509 (77); 537(105)f. do, - ل ل 534 (102) Anm.

\section{s}

يَ يَا - in den Ausrufen der Waarenverkäufer 496 (64). 483 (51) Anm. ; 495 (63) und Anm.

447 (15), 454 (22), 457 (25), 530 (98)

458 (26).

كِّ 524 (92).

467 (35); vgl. يسسر.

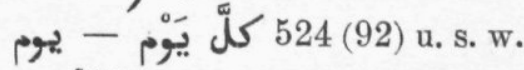
(96) Anm. u. s. w. 492 (60). 